\title{
Sustainable energy development under uncertainty
}

Citation for published version (APA):

Fuss, S. (2008). Sustainable energy development under uncertainty. [Doctoral Thesis, Maastricht University]. Universitaire Pers Maastricht. https://doi.org/10.26481/dis.20080424sf

Document status and date:

Published: 01/01/2008

DOI:

$10.26481 /$ dis.20080424sf

Document Version:

Publisher's PDF, also known as Version of record

\section{Please check the document version of this publication:}

- A submitted manuscript is the version of the article upon submission and before peer-review. There can be important differences between the submitted version and the official published version of record.

People interested in the research are advised to contact the author for the final version of the publication, or visit the DOI to the publisher's website.

- The final author version and the galley proof are versions of the publication after peer review.

- The final published version features the final layout of the paper including the volume, issue and page numbers.

Link to publication

\footnotetext{
General rights rights.

- You may freely distribute the URL identifying the publication in the public portal. please follow below link for the End User Agreement:

www.umlib.nl/taverne-license

Take down policy

If you believe that this document breaches copyright please contact us at:

repository@maastrichtuniversity.nl

providing details and we will investigate your claim.
}

Copyright and moral rights for the publications made accessible in the public portal are retained by the authors and/or other copyright owners and it is a condition of accessing publications that users recognise and abide by the legal requirements associated with these

- Users may download and print one copy of any publication from the public portal for the purpose of private study or research.

- You may not further distribute the material or use it for any profit-making activity or commercial gain

If the publication is distributed under the terms of Article $25 \mathrm{fa}$ of the Dutch Copyright Act, indicated by the "Taverne" license above, 
Sustainable Energy Development under Uncertainty 
(c) 2008 Sabine Fuss

All rights reserved.

Source of photo used for cover: (c) M. Beßler/PIXELIO

Prepared with LATEX

Published by Universitaire Pers Maastricht

ISBN 9789052787077

Printed in the Netherlands by Datawyse Maastricht 


\title{
Sustainable Energy Development under Uncertainty
}

\author{
Proefschrift \\ ter verkrijging van de graad van doctor aan de Universiteit Maastricht, \\ op gezag van de Rector Magnificus, Prof. Mr. G.P.M.F. Mols, \\ volgens het besluit van het College van Decanen, \\ in het openbaar te verdedigen op \\ donderdag 24 april 2008 om 14.00 uur \\ door
}

Sabine Fuss

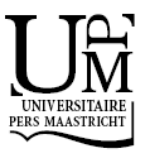




\section{Promotor:}

Prof. Dr. J. Muysken

\section{Co-promotor:}

Dr. A.H. van Zon

Beoordelingscommissie:

Prof. Dr. R. Cowan, voorzitter

Prof. Dr. C. Böhringer, Carl von Ossietzky Universität Oldenburg

Prof. Dr. P.C. Schotman 


\section{Acknowledgements}

As an old Dutch proverb says "a handful of patience is worth more than a bushel of brains". When I started the PhD study with my bushel of brains, patience was definitely not my major strength and the people that suffered the most from that are the same that have given me the largest support: my promotor Joan Muysken and my co-promotor Adriaan van Zon whom I want to thank for all the patience they had with me, especially in times when I myself was deeply mired in self-doubt. Still, I do not regret that I have spent the last years on the $\mathrm{PhD}$ and I am grateful to the Maastricht Research School of Economics of Technology and Organizations (METEOR) for financing my research.

When I started the PhD in 2003 I shared an office with Bas Straathof at MERIT and I consider this as a stroke of luck, since Bas was always helpful and kind and taught me a lot of useful things. In exchange I tried not be as much of a nuisance as I surely often was, even though he would be too polite to say so. In the meantime I had two more officemates (Tobias Kronenberg and Boris Lokshin) whom I want to thank here for their company and assistance.

A problem shared is a problem halved. Without the company of the other $\mathrm{PhD}$ students at MERIT (later UNU-MERIT), Maastricht University and NAKE the last years would have been much less fun and I want to thank especially Hannah Kiiver, who has accompanied me for years already before the $\mathrm{PhD}$. Even when she moved away to start her PhD in Utrecht, she never ceased to be a source of advice, moral support and friendship. The same applies to Tina Saebi, who joined UNU-MERIT only in my third year, but has been a true friend ever since. I could name lots of other students like Ekin Keskin and Semih Akcomak and many more that joined in later years, but the chance that I would forget someone would be too big, so I refrain from listing everyone and just say "thanks" to all of them.

A decisive turning point during my $\mathrm{PhD}$ was the summer of 2006 that I spent at IIASA. I can hardly tell how much I have learned there and a considerable part of my thesis is actually due to the work I was able to do there. In particular, I want to thank Michael Obersteiner, who was supervising me during that time, and Jana Szolgayova, who was and is my main collaborator and a dear friend by now. I have not regretted a single day that I have returned to IIASA last year and I want to thank all of my new colleagues for making it fun to come to work.

The climax of distress was reached in my last year when my computer died just before Christmas. Without the help of Hugo Hollanders, Mourik Jan Heupink and Herman Pijpers I would surely not have been able to continue my work and finish my thesis on time after this incident. I am deeply grateful for their assistance and apologize for wrecking their nerves just before the holidays. Similarly, life would have been hard without the help and kindness of Wilma Coenegrachts, Silvana De Sanctis, Sylivia Beenen, Fleur Keune, Eveline in de Braek, Monique Raedts and last but not least Ad Notten, who never let me down on organizing material that I had already ticked off as unavailable.

Furthermore, I am grateful to all the people that have shared their knowledge 
with me and spared the time to comment on my work or help me in another way: Robin Cowan, Peter Schotman, Christoph Böhringer, Jerry Silverberg, Huub Meijers, Thomas Ziesemer, Eddy Szirmai, Pierre Mohnen, Geert Duysters, Alexey Smirnov, Mykola Gusti, Nikolay Khabarov, Daniel Johansson, Ines Fortin, Jarka Hlouskova and the many uncounted people, who gave me precious feedback at conferences, seminars and workshops.

In addition, the ups and downs of a $\mathrm{PhD}$ are not all about research, but also about the friends and relatives that accompany you along the way and offer moral support and comfort when things are not going as smoothly as you wish. Even though my friends have been spread out all over Europe and some even farther by now, I have never had the feeling that any of them would not be there for me.

In the end I am very grateful to my parents, Gabriele and Karl Fuss, my sister Susanne Fuss and my brother Stefan Fuss for their continuous support and endurance during the last years, even though I had a hard time communicating what it actually was that I was doing. And finally, I want to thank Tim for his patience and for living through the $\mathrm{PhD}$ with me without complaining. 


\section{Contents}

1 Sustainable Energy Development under Uncertainty 1

1.1 Introduction . . . . . . . . . . . . . . . . . . . . 1

1.1.1 Economic Growth and the Environment . . . . . . . . . . . 1

1.1 .2 Methodology . . . . . . . . . . . . . . . 4

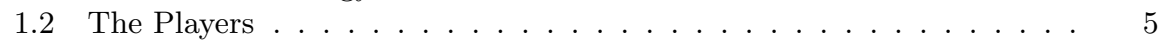

1.2.1 The Climate . . . . . . . . . . . . . . . . . 7

1.2 .2 The Electricity Sector . . . . . . . . . . . . . . . . 9 9

1.2 .3 The Government . . . . . . . . . . . . . . . . . . . . 14

1.3 Current Electricity Technologies \& Future Outlook . . . . . . . . . . . . 15

1.4 Contribution of this Thesis . . . . . . . . . . . . . . 17

1.5 Research Outline . . . . . . . . . . . . . . . . . . 19

2 Investment Theory under Uncertainty \& Irreversibility 23

2.1 Introduction . . . . . . . . . . . . . . . . . . . . . . . . 23

2.2 Orthodox Investment Theories _. . . . . . . . . . . . . . . . . . . . . . 24

2.2.1 The Jorgenson (1963) Model . . . . . . . . . . . . . . . . 25

2.2.2 Models with Irreversible Investment and Uncertainty . . . . . . 27

2.3 Real Options Theory . . . . . . . . . . . . . . . . . . . . . . 28

2.3.1 Methodology and Terminology . . . . . . . . . . . . 30

2.3.2 The Early Literature . . . . . . . . . . . . . . . . . . . . . . . . . 35

2.3.3 More Recent Frameworks . . . . . . . . . . . . . . . . 37

2.3.4 Remarks on the Investment-Uncertainty Relationship in Real

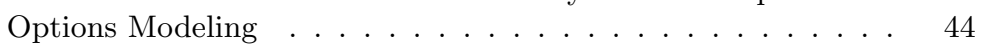

2.4 Portfolio Theory . . . . . . . . . . . . . . . . . . . . . 45

2.4.1 Theoretical Background . . . . . . . . . . . . . . . 45

2.4.2 Applications of Portfolio Theory to Real Assets . . . . . . . . . 49

2.4.3 Remarks on the Investment-Uncertainty Relationship in Portfolio Modeling . . . . . . . . . . . . . . . . 51

2.5 Vintage Models . . . . . . . . . . . . . . . . . . . . . . . 52

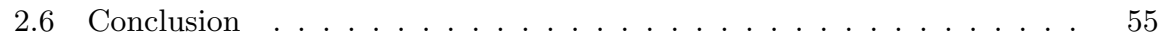

3 Energy Investments under Market \& Climate Policy Uncertainty 63

3.1 Introduction $^{\dagger} \ldots \ldots \ldots \ldots \ldots$. . . . . . . . . . . . . 63

3.2 Related Literature and Contribution . . . . . . . . . . . . . . 67

3.3 A Real Options Framework for the Electricity Sector . . . . . . . . . . 70

3.3 .1 The Model . . . . . . . . . . . . . . . . . . . . 71

3.3 .2 Solution Methods . . . . . . . . . . . . . . . . . . . . . . . . . . 74

3.4 Experiments and Results . . . . . . . . . . . . . . . . . . . . . 76

3.4.1 Data Description . . . . . . . . . . . . 76

${ }^{\dagger}$ This chapter is based on the article "Investment under Market and Climate Policy Uncertainty" by Fuss et al (2008). 
3.4.2 Effects of Different Types of Uncertainty . . . . . . . . . . . 78

3.5 Cap \& Trade System with Price Ceilings? . . . . . . . . . . . . . . . . . 85

3.5.1 Replacing Coal-Fired Capacity . . . . . . . . . . . . 88

3.5.2 Policy Experiments . . . . . . . . . . . . . . . . . . . . . . . . . . . . . 89

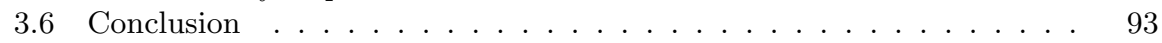

4 Fuel Price \& Technological Uncertainty in a Real Options Model for $\begin{array}{lr}\text { Electricity Planning } & \mathbf{9 7}\end{array}$

4.1 Introduction . . . . . . . . . . . . . . . . . . . . . . . . . . . 97

4.2 The Real Options Model . . . . . . . . . . . . . . . . . . . . . 104

4.2.1 Framework . . . . . . . . . . . . . . . . 105

4.2 .2 Coal and Wind Plant Data . . . . . . . . . . . . . . . . 108

4.3 The Results . . . . . . . . . . . . . . . . . . . . . . . 109

4.3.1 Technological Change and Uncertainty . . . . . . . . . . . . 109

4.3.2 Technological Change \& Fuel Price Uncertainty . . . . . . . . . 113

4.4 Conclusion . . . . . . . . . . . . . . . . . . . . 118

5 An Integrated Vintage-Portfolio Approach to Electricity Investment 125

5.1 Introduction . . . . . . . . . . . . . . . . . . . 125

5.2 A Mean-Variance Portfolio Approach to Investment in the Electricity

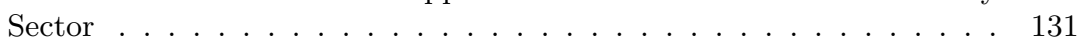

5.2 .1 The Framework . . . . . . . . . . . . . . . . . . . . . 132

5.2 .2 Results . . . . . . . . . . . . . . . . . . 134

5.3 The Vintage-Portfolio Approach . . . . . . . . . . . . . . 136

5.3 .1 The Setting . . . . . . . . . . . . . . . . . . . . 136

5.3 .2 The Vintage Model . . . . . . . . . . . . . . . . . . . . . . . 137

5.3.3 Expected Variance in Fixed \& Variable Cost Components . . . 138

5.3 .4 The Objective Function . . . . . . . . . . . . . . . . . . 139

5.3.5 Results and Interpretation . . . . . . . . . . . . . . . . 140

5.4 Evaluation and Comparison of the Two Approaches . . . . . . . . . . 144

5.5 Summary and Conclusion . . . . . . . . . . . . . . 146

6 Technological \& Price Uncertainty in the Vintage-Portfolio Model 151

6.1 Introduction* . . . . . . . . . . . . . . . . . . . . 151

6.2 The Vintage-Portfolio Model With Uncertain Investment \& Fuel Prices and Capital- \& Fuel-Saving Technical Change . . . . . . . . . . . . . . 152

6.3 Model Simulations . . . . . . . . . . . . . . . . . . . . . . 154

6.3.1 Experimental Setting . . . . . . . . . . . . . . . . 155

6.3.2 A Reduction in Fuel Price Variance . . . . . . . . . . . . . . . 155

6.3.3 A Reduction in Investment Price Variance . . . . . . . . . . . . 156

6.3.4 A Reduction in the Variance of Embodied Capital-Saving Technical Change . . . . . . . . . . . . . . . 157

6.3.5 A Reduction in the Variance of Embodied Fuel-Saving Technical Change . . . . . . . . . . . . . . . . . . . 158

6.3.6 An Asymmetric Case . . . . . . . . . . . . . . . . . . . 159

6.4 Summary and Conclusion . . . . . . . . . . . . . . . . . 163

${ }^{*}$ This chapter is based on the submitted working paper "Investing in Energy Conversion Technologies - An Optimum Vintage Portfolio Selection Approach" by van Zon and Fuss (2005). 
7 Extended Vintage-Portfolio Approach to Electricity Investment \& Climate Change Policy in the UK

7.1 Introduction ${ }^{\ddagger} \ldots \ldots \ldots \ldots \ldots$. . . . . . . . . . . . . . . . . . . . . . . . 167

7.2 The Vintage-Portfolio Model . . . . . . . . . . . . . . . . . . 170

7.2 .1 The Basic Framework . . . . . . . . . . . . . . . . 170

7.2 .2 Additional Features . . . . . . . . . . . . . . . . . . . 172

7.2 .3 Finalizing the Model . . . . . . . . . . . . . . . . . . . 173

7.3 Simulation Results . . . . . . . . . . . . . . . . . . . . . . 174

7.3.1 Technology Characterization . . . . . . . . . . . . . . 174

7.3 .2 Simulation Runs . . . . . . . . . . . . . . . . . . . . . 176

7.3 .3 Fuel Price Variance . . . . . . . . . . . . . . . . . . . . . . . . . 184

7.3.4 Increases in Technological Variance . . . . . . . . . . . . . . . 185

7.4 The Cost of the Renewables Obligation . . . . . . . . . . . . . . 187

7.5 Summary and Conclusion . . . . . . . . . . . . . . . . 188

8 Conclusion $\quad 193$

8.1 Introduction . . . . . . . . . . . . . . . . . . . . . . . 193

8.2 Different Types of Uncertainty . . . . . . . . . . . . . . . . . . . . . . . . 194

8.3 A New Theoretical Approach . . . . . . . . . . . . . . . . 195

8.4 The Role of Technical Change, Fuel Prices \& Uncertainty . . . . . . . 197

8.5 Further Research . . . . . . . . . . . . . . . . . . . . . . 198

${ }^{\ddagger}$ This chapter is an updated and extended version of the submitted working paper "Irreversible Investment under Uncertainty in Electricity Generation: A Clay-Clay-Vintage Portfolio Approach with an Application to Climate Change Policy in the UK" by van Zon and Fuss (2006). 


\section{List of Figures}

1.1 A Simplified Illustration of the Electricity Sector . . . . . . . . . . . . 10

2.1 Graphical Example of the Option Value . . . . . . . . . . . . . . 29

2.2 Option Value versus Standard NPV . . . . . . . . . . . . . 34

2.3 More Uncertainty Makes the $F(V(t))$-Schedule Rotate Upwards. . . . 34

2.4 Increasing Diversification Leads to a Fall in Unique Risk . . . . . . . . . . 46

2.5 Efficient Frontier . . . . . . . . . . . . . . . . . . . . . . . . 47

2.6 Risk and Cost of Generating Portfolios . . . . . . . . . . . . . . . . 50

2.7 Evolution of Output per Unit of Employed Capital for Successive Vintages 53

B.1 Argument for Smooth Pasting . . . . . . . . . . . . . . . 60

$3.1 \mathrm{CO}_{2}$ Permit Prices in $€ / E U A\left(1 \mathrm{EUA}=1\right.$ ton of $\left.\mathrm{CO}_{2}\right) \ldots \ldots 6$

3.2 Diagram of the Solution Method . . . . . . . . . . . . . . . 75

3.3 Profit and Investment Frequency Distribution for Stochastic Prices . . 79

3.4 Values of the Coal-fired Plant Only and of the Coal-fired Plant with CCS) 80

3.5 The Impact of Stochasticity on the Determination of the Optimum Tim-

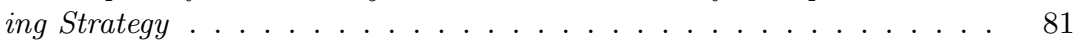

3.6 Learning about Government Commitment in Period 37 . . . . . . . . . 83

3.7 Option Value of the Plant with CCS exceeds the Difference between V1 and V2 after Year 29 until Year 37 . . . . . . . . . . . . . . . . 84

3.8 Timing of CCS Investment under Policy Uncertainty (sensitivity analysis with respect to commitment probability and commitment year) . 84

3.9 Average Profits in $€$ from Optimal Timing of Investments: The Deterministic Case . . . . . . . . . . . . . . . . . . 90

3.10 Average Profits in $€$ from Optimal Timing of Investments: The Stochastic Case . . . . . . . . . . . . . . . . . . . . 91

3.11 Average Profits in $€$ from Optimal Timing of Investments when the $\mathrm{CO}_{2}$ Price Grows More Slowly . . . . . . . . . . . . . . . . . . . . . . . . . 92

3.12 Simulation Results for Experiment with Lower $\mathrm{CO}_{2}$ Price Growth for the Coal-fired (left) and the Biomass-fired (right) Power Plant . . . . . 92

A.1 Electricity Price Data (Source: EEX spot market prices) . . . . . . . . 96

4.1 Daily spot prices for coal in EUR/t . . . . . . . . . . . . . . . . 98

4.2 Evolution of Overnight Investment Cost of Renewable Power Technologies 99

4.3 The Plant Value of the Wind Farm . . . . . . . . . . . . . . . . . 105

4.4 Option Values (circles) and Plant Values (triangles) for Low (Solid) Rate of Technical Change (TC) and High (transparent) Rate of Technical Change in $(€)$. . . . . . . . . . . . . . . . . 110

4.5 Option Values (circles) and Plant Values (steps) for High Uncertainty (transparent circles) and Low Uncertainty (solid circles) in (€) . . . . 111 
4.6 Option Value (circles) and Plant Value (triangles) for Very High Uncertainty in $(€)$. . . . . . . . . . . . . . . . . . . . . . . . 112

4.7 Plant Value (circles) and Option Values (lines) for Low (dashed line) and High (solid line) $\mathrm{CO}_{2}$ Prices in (€) . . . . . . . . . . . . . . . . . 114

4.8 Plant Value (circles) and Option Values (lines) for Slowly (dashed line) and Rapidly (solid line) Rising Fuel Prices in (€) . . . . . . . . . . . 115

4.9 Plant Value (circles) and Option Values (lines) for Slowly (dashed line) and Rapidly (solid line) Rising Fuel Prices in (€) . . . . . . . . . . . 116

4.10 Technological Uncertainty: Plant Values with Less Uncertainty (filled circles) and Higher Uncertainty (transparent circles) and Option Values (lines) for Lower (solid line) and Higher (dashed line) Uncertainty in

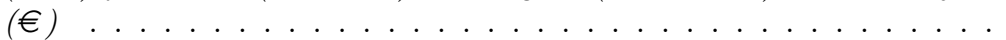

4.11 Investment and Profit Distributions for 1,000 Simulations. Profits are in $(€) \ldots \ldots \ldots \ldots \ldots \ldots$

5.1 Cost Distributions for Coal, Nuclear and Wind . . . . . . . . . . . 133

5.2 Efficient Frontiers for Investment at $t=0, t=5$ and $t=10$ (top to bottom) 135

5.3 Evolution of Capacities in the Base Run . . . . . . . . . . . . . . . 141

5.4 Net Investment in the Base Run . . . . . . . . . . . . . . . . . . . . . 141

5.5 Deviations from Base Run Net Investment for Less Coal Price Uncertainty ... . . . . . . . . . . . . . . . . . . 142

5.6 Deviations from Base Run Net Investment for Less Nuclear Technological Uncertainty . . . . . . . . . . . . . . . . . . . . . . 143

6.1 Deviations of Net Investment for Zero Fuel Price Growth Variance in TF1 . . . . . . . . . . . . . . . . . . 156

6.2 Deviations of Net Investment for Zero Investment Price Growth Variance in TF1 . . . . . . . . . . . . . . . . . . . . . 157

6.3 Deviations of Net Investment for Zero Variance in Capital-Saving Technical Change of TF1 . . . . . . . . . . . . . . . . 158

6.4 Deviations of Net Investment for Zero Variance in Fuel-Saving Technical Change of TF1 . . . . . . . . . . . . . . . . . . . . . 159

6.5 Base Run Investment With Zero Risk Aversion . . . . . . . . . . . . . 160

6.6 Base Run Investment With Moderate Risk Aversion . . . . . . . . . . . 161

6.7 Base Run Investment With High Risk Aversion . . . . . . . . . . . . . . . 162

7.12006 UK Electricity Generation Mix . . . . . . . . . . . . . . . . . . 168

7.2 Power Station Emissions of Carbon Dioxide . . . . . . . . . . . . . . . 169

7.3 Production Shares for the First (Low) Demand Scenario . . . . . . . . 177

7.4 Production Shares for the Second (High) Demand Scenario . . . . . . 177

7.5 Development of Capacity Shares . . . . . . . . . . . . . . . . . . 178

7.6 Composition of Capacity . . . . . . . . . . . . . . . . . . . . . . 179

7.7 Variance against Cost . . . . . . . . . . . . . . . . . . . . . . . . . . 180

7.8 Capacity Shares Coal . . . . . . . . . . . . . . . . . . . . . 181

7.9 Capacity Shares Gas . . . . . . . . . . . . . . . . . . . . . . 181

7.10 Capacity Shares Nuclear . . . . . . . . . . . . . . . . . . . . 182

7.11 Emissions . . . . . . . . . . . . . . . . . . . . . . . 182

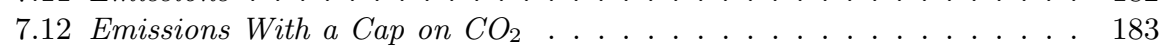

7.13 Differences Between Capacity Shares in R5 and R1 . . . . . . . . . . . 184

7.14 Effect of Larger Fuel Price Variance . . . . . . . . . . . . . . . . . . . 185

7.15 Effect of Larger Technological Variance . . . . . . . . . . . . . . . . . . 186 


\section{List of Tables}

1.1 Electricity Terminology . . . . . . . . . . . . . . . . . . 11

1.2 Power Plant Data . . . . . . . . . . . . . . . . . . . . . . . . . . . . . 12

1.3 Research Outline ...................... . 20

2.1 Organization of Literature Review . . . . . . . . . . . . . . . . . . . . 24

3.1 Real Options Literature on $\mathrm{CO}_{2}$ Price Uncertainty . . . . . . . . . . . 68

3.2 Power Plant Data . . . . . . . . . . . . . . . . . . . . . . . . . . 77

$3.3 \mathrm{CO}_{2}$ Price Experiments . . . . . . . . . . . . . . . . . 78

3.4 Market Uncertainty Experiments for $\mathrm{CO}_{2}$ Prices . . . . . . . . . . . . 80

3.5 Power Plant Data for Coal- and Biomass-Fired Plants and CCS . . . 88

4.1 Real Options Literature on Technological and Input Cost Uncertainty . 102

4.2 Experimental Settings in Sections 4.3.1 and 4.3.2 . . . . . . . . . . . . . 107

4.3 Power Plant Data for Coal and Wind . . . . . . . . . . . . . . . 109

5.1 Mean-Variance ( $M$-V) Portfolio Frameworks for Investment in the Electricity Sector . . . . . . . . . . . . . . . . . 126

6.1 Parameter Values. . . . . . . . . . . . . . . . . . . . 160

7.1 Characterization of Technology Families . . . . . . . . . . . . . . 175

B.1 Reorganizing Terms . . . . . . . . . . . . . . 191 


\section{Chapter 1}

\section{Sustainable Energy Development under Uncertainty}

\subsection{Introduction}

\subsubsection{Economic Growth and the Environment}

Economic growth has always entailed an increasing demand for energy, of which electricity constitutes a major part. As a matter of fact, since 1970, each increase of $1 \%$ in GDP has been accompanied by a $0.64 \%$ rise in energy consumption (IEA WEO, 2000). Even though United Nations forecasts estimate that the world population will stabilize around 2075 due to ongoing demographic transition, economic growth itself and the demand for rising living standards in developing and transition countries will still form a considerable force propelling the need for ever increasing energy sources. According to the IEA World Energy Outlook 2004, energy demand will be rising by $60 \%$ between 2002 and 2030. Especially developing countries such as China and India will need and demand energy as they further industrialize and begin to prosper. ${ }^{1}$

At the same time, most of the energy production worldwide still relies on fossil fuels and some developing and transition countries have large and cheaply accessible fossil fuel deposits, most notably in coal and oil. Furthermore, advanced nations like Canada also still benefit from technological advances that make e.g. the exploitation of tar sands economical and thereby expand available oil sources at the country-level. ${ }^{2}$

In fact, according to IEA projections, $85 \%$ of the aforementioned $60 \%$ increase in energy demand will have to be met by the conversion of fossil fuels. While economists

\footnotetext{
${ }^{1}$ About two thirds of the projected $60 \%$ increase will be attributed to developing nations.

${ }^{2}$ It is thus questionable whether the finiteness of resources would solve the problem of increasing emissions and the ensuing consequences.
} 
might have feared the finiteness of resources as a limit to economic growth in the past (cf. Malthus (1798), Hotelling, (1931), Meadows et al (1972), etc), scientific evidence brought forward these days shows that the externalities associated with the usage of these resources are much more hazardous by inflicting damages not only on nature and human health, but also to our economies, as Greenhouse Gas (GHG) emissions continue to be accumulated in our atmosphere (e.g. Graßl et al (2003), Stern (2006), etc).

The IEA notes that power generation has been the main source of $\mathrm{CO}_{2}$ emissions over the last decades and projects that the share of power production in total $\mathrm{CO}_{2}$ generation will increase further from $40 \%$ to $45 \%$ in 2050 (IEA, 2006). The underlying problem is that GHG emissions have been found to be the major reason for the increased rates of global warming (see Section 1.2.1 for details). Most climate models find that a doubling of pre-industrial levels of GHG emissions will most probably result in a rise of between $2-5^{\circ} \mathrm{C}$ in global mean temperatures between 2030 and 2060 (Stern Review, 2006). This will initially lead to slight benefits for some developed countries in higher latitudes in terms of rising attractiveness for tourists, increased yields from agriculture and lower heating needs, for example. However, as temperatures rise beyond the first $2-3^{\circ} \mathrm{C}$, the damages will start to exceed the initial benefits significantly. The economic costs of extreme weather (droughts, floods, storms, etc) alone are estimated to lie approximately between 0.5 and $1 \%$ of world GDP around 2050 with an increasing trend for higher temperatures (e.g. Stern Review, 2006).

There are thus two conflicting priorities at stake here. On the one hand, economic growth and the increasing demand for energy that accompanies this growth needs to be sustained and fulfilled. On the other hand, the supply of more energy always also implies a strain to the environment not only through the exhaustion of resources, ${ }^{3}$ but even more so in terms of increased emissions and accelerated global warming with - to some degree - uncertain, but ultimately adverse effects. The latter will then affect growth and welfare again in terms of the losses associated with the process of global warming. There is therefore a delicate balance between growth benefits and environmental costs that can translate back into economic disadvantages. The goal must thus be to maintain economic growth and ensure energy supply, while at the same time preserving the environment and stabilizing GHG emissions at a level associated with minimum damages. These ambitions have sometimes been referred to as sustainable energy development. The Brundtland Report (1987) defines sustainable development as the

[... development that meets the needs of the present without compromising the ability of future generations to meet their own needs. (World Commission on Environment and Development, 1987).

${ }^{3}$ The exhaustion of resources has lately often been associated with concerns of energy security, implying that countries, which transit away from fossil fuels, will also be less dependent on the supply of inputs from other countries. In this thesis such dependency hurts the investors through rising and fluctuating fossil fuel prices, but is not modeled through import shortages as in some general equilibrium models, since this would be beyond the scope of our analysis. 
Applied to the energy sector, this would mean to keep growing, while supplying more and more people with an increasing level of energy without compromising the future situation of the following generations. Munasinghe's (2004, page 789) definition claims that

[... sustainable energy development involves the harnessing of energy resources for human use in a manner that supports lasting development.

While this definition clearly includes issues of natural resource exhaustion, the focus of this thesis is on the external effects of using the resources for energy conversion, since it has become clear that resource depletion might not be the primary environmental problem that demands immediate action to preserve lasting development in the long run. On the contrary, the IPCC's Fourth Assessment Report (2007) urges policy makers to take on more stringent measures to restrict GHG emissions as fast as possible. Therefore, the accumulation of emissions represents a relevant problem that warrants thorough research for the creation of a more sustainable energy mix. ${ }^{4}$

In response to the increasing concerns about global warming and energy security, many policy makers in Europe have already been promoting the use of electricity from renewable sources over the last decades (e.g. through feed-in tariffs in Germany and Austria, or renewables quotas in the United Kingdom), while at the same time reducing the combustion of fossil fuels for power generation (e.g. by $\mathrm{CO}_{2}$ taxes or caps on emissions and permit trading like in the European Union). Simultaneously, international climate change negotiations for a post-1012 carbon policy aim at an agreement, which comprises the key players in the world economy, in order to ensure collective action against global warming. What policy can achieve in terms of changing the incentives of investors in the electricity sector depends on how investors react to changes and shocks in the key variables involved in their decisions. This also applies for the hopes that policy makers might put in the advance of technological progress and the volatility coming from fossil fuel prices. It is therefore necessary to develop a sound and thorough understanding of decision-making in the electricity sector, before any policy recommendations can be formulated.

In this thesis the focus will be on the generation of electricity because that is the process contributing the most to global $\mathrm{CO}_{2}$ emissions. The generation of electricity and how the composition of the sector's production technology mix will develop is contingent upon the decisions that investors have made and are making today. Since investments in the electricity sector are lumpy and associated with large sunk costs up front, electricity will be produced with whatever plants are installed now for the coming decades. If investors opt for fossil-fuel-based generation technologies, they will use them to serve the continuously rising demand and thereby constantly emit more $\mathrm{CO}_{2}$, which will then be accumulated in the atmosphere, further accelerating the process of global warming. This is the reason why it is important to analyze how investment decisions and the timing thereof are formed in the electricity sector in order to find the right incentives in time. Uncertainty can affect these decisions and their

\footnotetext{
${ }^{4}$ Moreover, the atmosphere can also be seen as an exhaustible resource - with the difference that property rights are not assigned.
} 
timing profoundly. This includes uncertainty not only about fuel prices and other cost items, but also uncertainty about the future stringency of policy and regulation and uncertainty about the rate of technological progress.

\subsubsection{Methodology}

Earlier studies on investment under uncertainty (e.g. Hartman (1972), Abel (1983), and Nickell (1978)) have found a positive effect of uncertainty on investment (see Chapter 2). In the electricity sector, this would imply that technologies exhibiting uncertainty would be adopted earlier. If we think about uncertainty in the evolution of fossil fuel prices, this is not a desirable outcome, since it would imply that fossilfuel-based technologies, which are also typically cheap in terms of capital, might be favored over "zero-fuel-price" technologies, which are environmentally more friendly. On the other hand, renewable energy carriers are an uncertain choice with respect to the speed of their technological improvement. Depending on which uncertainty represents the larger impact, either fossil-fuel-based or renewable technologies would be invested into earlier.

More recent modeling approaches include real options theory, which typically finds a postponement of investment as a response to uncertainty, and portfolio theory, which tries to minimize risk for a given level of expected return, thereby focussing more on the risk-return tradeoff and allowing the investor to determine optimal combinations of technologies at different degrees of risk aversion.

This thesis is concerned with the analysis of investment under uncertainty in the electricity sector with the goal of finding implications for the policy maker, who is concerned about sustainable energy development. The electricity sector is characterized by uncertainties, large, up-front sunk costs and therefore irreversible investment, and the freedom of investment to be brought forward or to be postponed (see Section 1.2.2 for more detailed information about the electricity sector). Therefore, it merits special treatment, since a standard Net Present Value (NPV) analysis regards investment opportunities as "once-and-for-all" choices and does not take into account the benefits from waiting and diversification entailed by uncertainty (see Chapter 2).

Real options theory is a tool, which is particularly suited to value the option of being able to time investments differently. It is used here to investigate, which types of uncertainty stimulate investment and what that implies for the policy maker. A contribution to the existing literature is the way how we distinguish between expected and actual values of the uncertain parameters that we analyze. This allows us to make a clear distinction between the effects emanating from different types of uncertainty.

Standard mean-variance portfolio theory as has previously been applied to investment into non-financial assets is myopic and looks at the risk-return trade-off at one point in time. However, we think that useful additional insights can be gained from allowing the investor to have different preferences over risk and thus the composition of his technology portfolio, since uncertainty will obviously create a demand for hedging. This diversification property of portfolio theory is something, which cannot be dealt with by using real options theory at a larger scale due to computational limi- 
tations. We therefore use elements from portfolio theory and integrate them into a vintage setting (see Chapter 2 for a description of vintage modeling) to overcome the disadvantage of standard mean-variance portfolio selection of being inherently static, while reaping the benefits of the portfolio framework to take into account gains from diversification. ${ }^{5}$

The aim of this thesis is therefore twofold: on the one hand, we want to understand decision-making under uncertainty in a sector having the peculiarities of the electricity sector. After all, other sectors are also characterized by large up-front sunk costs and sequential decision-making processes, which provides investors with a certain degree of flexibility. Examples include sectors, in which large research and development $(\mathrm{R} \& \mathrm{D})$ costs are required initially or where capital is expensive and task-specific. Oil drilling projects, for instance, demand an expensive exploration phase, but also costly machinery and equipment that cannot easily be resold. Coal mining and satellite launches are similarly capital-intensive and therefore suitable for analysis in a real options framework.

The insights gained from extending and refining the methodologies in this thesis can therefore have important implications for these sectors as well and for investment theory in general. On the other hand, these insights can and shall be used to analyze the impact of policies that are directed at preventing the effects of accumulated GHG emissions in the atmosphere (global warming, climate change and, further down in the causal chain, rising sea levels, water shortages, more extreme weather conditions, desertification, etc). If these policies will have the desired effect, when we account for irreversibility considerations, flexibility in sequential decision-making, different qualities and types of uncertainty and technological change, stands to question, especially when there is uncertainty about the direction of policy-making itself.

In the remaining chapter there will first be a description and analysis of the players or parties that are involved. Furthermore, an overview of existing electricity generation technologies and their contribution to the current energy mix will be given. Section 1.4 presents the contribution that this thesis attempts to make. Finally, there will be an outline of the research, providing not only a plan of the thesis, but also giving a short preview with respect to the results.

\subsection{The Players}

The electricity market and the players involved form a very complex, integrated system of supply, transmission, distribution, end consumption and regulation. Moreover, the electricity sector has undergone considerable changes in the past and continues to be liberalized in some countries and regions. In this thesis the focus is on three main categories of concerned parties: the production part of the electricity sector, the climate and the government. By choosing such a focus, we obviously make some important simplifications.

\footnotetext{
${ }^{5}$ Section 1.4 provides more details on the contributions of this thesis.
} 
First of all, we restrict our attention to the production rather than to the consumption side and ignore the latter for the larger part. This does not imply that we think that the consumption side does not make a difference for that matter. Quite on the contrary, the greening of consumer attitudes has contributed amongst other factors to increased political efforts for preservation and sustainable development in Western European countries. A concept called the Environmental Kuznets Curve (e.g. Selden, 1994, Copeland and Taylor, 2003, De Groot, 2000 and Smulders and Bretschger, 2000) relies on this argument to explain the phenomenon that pollution increases with rising levels of GDP, but often decreases after a certain threshold has been passed. The idea is that the values of the society change in favor of environmental quality, once people are provided with sufficient income to fulfill their basic needs in a satisfactory way. However, even though we do acknowledge that changes in policy and also in technology may be induced by voter interests and consumer demand respectively, we think that the most important changes in the electricity sector still emanate from the supply side and through government regulation, which is heavily influenced by climate change considerations lately. ${ }^{6}$

The reason for this choice is that electricity is still a commodity that is continuously consumed at a constant level - and almost subconsciously: while many people actively choose for relatively more expensive biologically cultivated food products and cars with more fuel-efficient engines, the share of people that choose for green energy by switching their provider or selecting a so-called "green mix" from their current provider is negligible, even though there are virtually no switching costs involved. In Germany, for example, only 500,000 consumers have so far decided to switch their electricity contracts to so-called "Ökostrom", which is an energy mix that is based on zero- or low-emission power generation technologies. ${ }^{7}$ This represents a tiny market share of only $1-2 \%$, which is also the case in other European countries. Only the Netherlands represent an exception, where the market share is almost $20 \%$. If this is the situation in "rich", industrialized countries, it is more than questionable whether the developing economies will accept environmentally friendly, but more expensive solutions for their provision with energy. Therefore, we conclude that the focus of policy makers should be on the supply side and more particularly on the investments that are taking place now and in the near future.

Another simplification that we make is that we concentrate on investment in power plants and generation equipment, although the electricity sector involves many more actors than the actual producer of electricity. The activities can be grouped into four components: generation, transmission, distribution and end consumption. ${ }^{8}$ One could argue that the government also has the possibility of regulating the latter three parts

\footnotetext{
${ }^{6}$ Through the latter, consumers do indirectly exert influence, of course, but this is not account for explicitly in the models developed here.

${ }^{7}$ See Wüstenhagen (2004) for more details on the concept of "Ökostrom" and an overview of the market situation in other European countries, the United States, Canada, Japan and Australia.

${ }^{8} \mathrm{~A}$ detailed overview of an electricity sector and all the individual tasks involved for the participants can be found in Botterud (2003).
} 
of the electricity sector, which it actually does in particular cases. ${ }^{9}$ However, we want to abstract from these complications, since e.g. a regulation that requires distribution companies to buy a certain percentage of renewable energy from the producers means that the demand for renewable energy increases, which leads to a rising price and therefore an incentive for the producers to invest in renewable energy carriers. While this is not the same as imposing the restriction directly on the producer, the results will ultimately go into the same direction. Nothing is lost in terms of analyzing the effects of regulations on the supply side, but much can be gained in terms reducing model complexity and increasing transparency.

\subsubsection{The Climate}

The primary concern of this thesis is not only to contribute to the literature and "toolbox" of (investment) decision-making under uncertainty, but also to tackle a problem that has continuously gained importance and ultimately presents a severe and urgent threat to human society. This problem is climate change and two questions that we have to answer before beginning the analysis are: (1) what exactly makes the climate change? And (2) why is climate change such a bad thing?

Concerning the first question, it is now established that the climate changes due to the warming of the atmosphere. The atmosphere warms up because of the socalled Greenhouse Effect. This effect in turn is due to increased accumulation of GHG in the atmosphere: normally, the sun sends radiation through the atmosphere and warms the surface of the Earth. The Earth itself releases infrared radiation into space, thereby cooling the temperature down again. This cycle is disturbed by the existence of GHG emissions in the atmosphere. As these accumulate, radiation sent off from the Earth cannot escape into outer space anymore, which ultimately leads to the abovementioned warming effect because the sun continues to warm the surface. While it has long been argued that the contribution of human beings to this process is only minor or not existent at all, recent evidence (e.g. the Fourth Assessment Report by the IPCC, 2007) leaves no doubt about this causality: the rate of natural warming is significantly increased by the additional GHG emissions generated by humans. This occurs mainly through the combustion of fossil fuels (up to 80\%) and politicians are more aware of the problem than ever before.

On January, $10^{\text {th }}$ 2007, José Manuel Barroso, President of the European Commission, proposed to strive for a $20 \%$ cut of $\mathrm{EU} \mathrm{CO}_{2}$ emissions by the year 2020, aiming at limiting global warming to $2^{\circ} \mathrm{C}$. The German government is debating a ban on less fuel-efficient cars; France and the UK call for a renaissance of (carbon-free) nuclear energy to replace coal- and gas-fired energy generation; the list is long.

So what has made those politicians so alert? The debate about the human contribution to climate change is not young at all. In fact, a Swedish scientists named Svante Arrhenius was the first to predict increased rates of global warming due to

\footnotetext{
${ }^{9}$ In Germany, for example, electricity producers are ensured by regulation to receive a premium from transmission and/or distribution companies on the price of electricity generated with specified renewables.
} 
the combustion of fossil fuels as early as 1896. Still, it took a long time until people started believing that climate change is real and that it is - at least partially anthropogenic. ${ }^{10}$ However, the recent IPCC report presents evidence that is difficult to ignore and more is accumulating (e.g. Schneider von Deimling et al, 2006). More importantly, however, the effects of global warming and climate change are already materializing: floods, more extreme weather conditions, large-scale wood fires, the melting of the arctic ice sheet, rising sea levels and an increase in the energy of heavy storms are only a few examples of the consequences of a warmer climate. Also here, evidence is solidifying about the connection between global warming and the phenomena that we increasingly observe: Rahmstorf (2006a and 2006b) does not only find a strong positive correlation between the energy of storms and the warming of the oceans, but he also warns that the increase in ocean temperature will eventually have an effect on the circulation of the underlying streams (and a breakdown of the thermohaline circulation would most probably have disastrous effects, which are not easy to estimate ex ante). Furthermore, the larger the difference between the air pressure levels at the two poles, the more intensive the storms will get progressively. More evidence about the rising storm intensity comes from Knutson and Tuleya (2004) and Emanuel (2005). Recent storms such as Katrina in New Orleans have shown how large the extent of (economic) damages can be in this case. ${ }^{11}$

While research about the exact relationships between climate change and the intensity of storms is still underway, there are more precise estimates in other areas, such as the rise of sea levels and what the economic losses for people living in coastal regions would be. As more and more of these causalities and the extent of the consequences become apparent, policy makers have realized that climate change will come at a considerable cost. This explains the recent urge with which politicians have been pressing for measures to decelerate the warming process by cutting emissions at higher than previously agreed rates.

The uncertainties involved in these processes concern two aspects of climate change in particular. First, climate change is irreversible. Warming is occurring and this process cannot be stopped or reversed in the short or medium run. ${ }^{12}$ Melted ice

\footnotetext{
${ }^{10}$ This attitude was enhanced by research often funded by the oil and coal industry trying to disprove the causal relationship between global warming and the combustion of fossil fuels or even the existence of the Greenhouse Effect as such.

${ }^{11}$ Even the storm 'Kyrill' passing through Europe in 2007, which was by no means comparable to Katrina, had devastating effects that outperform previous storms in this season. In Germany, at least eleven people were killed and hundreds were injured. Insurance companies estimate the damages to amount to 1 billion $€$ and this does not account for the losses due to power cuts, the breakdown of the train system and the destruction of 40 million trees, which is a disaster for the German forestry sector (see www.sueddeutsche.depanorama/artikel/877/98779, "Orkan 'Kyrill': Versicherer schätzen Schaden auf eine Milliarde Euro" 20-01-07 accessed 10-02-2007; and www.tagesschau.de/aktuell/meldungen, "Kyrill fällt mehr als 40 Millionen Bäume" 22-02-07 accessed 10-02-07). Europe-wide at least 39 people died due to Kyrill and the estimated damages are 5-6 billion $€$.

${ }^{12}$ Recently, this view has been challenged by proposing to use geoengineering to reverse global warming. Nobel Laureate Paul J. Crutzen, for example, suggests that injecting sulfur into the stratosphere could cool the planet to sustainable levels (Crutzen, 2006). However, geoengineering is fiercely debated for the risks that such drastic approaches bear and seems far from acceptance for now.
} 
sheets cannot be saved and risen sea levels cannot be forced back. However, there is still hope that global warming could be decelerated and eventually stopped at tolerable levels in the long run (see e.g. Rahmstorf, 2006a). The problem is that we are not yet sure what the exact environmental thresholds are, beyond which climate change will result in more fatal damages. Investors will not want to invest in mitigation assets and cleaner technologies, if in the end it turns out that the environmental thresholds are not that close. And even though all signs point into the direction that climate change is real, the majority still wants to invest into cheaper and more "dirty" technologies. Since investment in the electricity sector is mostly irreversible and the corresponding capacity will be used until the end of its economic lifetime, ongoing accumulation of emissions is the result. Therefore, the government will have to be the link between the climate and the electricity sector. On the other hand, the investor him-/herself is affected by different types of uncertainties in the face of which he will either bring forward investments into environmentally more friendly technologies or postpone them. In the latter case the risk of surpassing environmental thresholds increases, and the models presented in this thesis therefore provide important insights for policy makers, who want to give incentives to investors to develop a more sustainable energy mix.

\subsubsection{The Electricity Sector}

As already mentioned above, the electricity sector is a very complex, integrated system with many different actors, but we simplify this structure here for the sake of a clear and straightforward analysis and also because the details vary between countries and regions with different organization and legislation. In general, the process of producing and delivering electricity can be depicted as in Figure 1.1. The supply chain starts with the generation of electricity. Then the output is fed into the grid of transmission companies, who continue to channel it to the lower-voltage grids of the distributors. Finally, the distribution companies serve the end consumers. These can be industrial clients as well as households. Table 1.1 gives an overview of the terminology used to describe the electricity sector and its corresponding operations, which will serve as a glossary for the following chapters.

For reasons outlined in the introduction, we will abstract from impositions of regulations in the transmission and distribution part. In addition, the corresponding companies are often owned by the same companies anyway. It is a declared aim of the European Commission, for instance, to create a clearer separation of energy production from energy distribution in the near future. If we refer to the electricity sector on the following pages, we therefore mean the generation part of the supply chain.

When characterizing the electricity sector, a remarkable characteristic is its capitalintensity. Large investments have to be made before generation can take place, and once the plants have been installed, most of the installation cost is sunk. This might deter potential new entrants and protect incumbents leading to a situation that makes it difficult to maintain efficient competition. On the other hand, many deregulation and liberalization efforts have been made over the last decades in order to reduce the market power of individual utilities and enhance competition. In general, we 


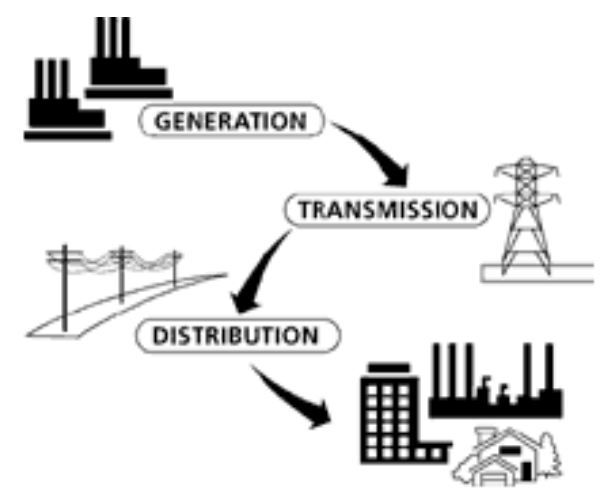

Source: adapted from Canadian Clean Power Coalition (2004).

Figure 1.1: A Simplified Illustration of the Electricity Sector

can say that investment in the electricity sector is subject to a substantial degree of irreversibility with respect to the capacity that needs to be installed up-front. ${ }^{13}$

Another feature of the electricity sector is connected to the nature of the commodity electricity itself. Because the capability of storing electricity are up to date more than limited, both generation and consumption occur virtually simultaneously. And since the use of electricity essentially pervades most of our activities in our daily lives (from switching on the lights in the morning, over using the computer during the day, to cooking in the evening), power generation and provision has to be a continuous process in order to cover a continuous demand that might itself evolve stochastically while rising with increasing population and rising demand for higher living standards (e.g. IEA, 2000). ${ }^{14}$

Most importantly, the electricity sector is influenced by a large number of uncertainties affecting each investment decision for the long term to a very high extent. As has already been mentioned above, increased liberalization has led to volatile output prices. At the same time, input prices are uncertain as well. A lot of fuel prices such as oil and gas prices fluctuate widely over longer periods of time, and economies lose large amounts of money from these fluctuations, since they depend on these fuels. Jones et al (2004), who base their results on Hamilton (2003), for example, investigate the effect of the oil price on economic activity between 1947 and 1998 and find that the GDP elasticity with respect to oil price changes is -0.116 . This implies that a $10 \%$ increase in the price of oil produces GDP losses of 127.6 billion $\$$ if we assume a GDP of 11,000 billion $\$$. An exhaustive overview of the empirical literature in this respect and additional links to energy security can be found in Awerbuch and Sauter (2006).

\footnotetext{
${ }^{13}$ See e.g. Table 1.2 for an example of the extent of capital costs in the electricity sector.

${ }^{14}$ Of course, the hourly load varies substantially over the day, typically peaking around noon and being low during the night. Even though the focus of this thesis is more on longterm electricity provision and the investment plans associated with this, we extend the model developed in Chapter 5 to take into account this aspect of the technological profile of generation techniques in Chapter 6 , since load characteristics will entice the investor to further diversify, so that there will never be shortages during peaks.
} 


\begin{tabular}{|c|c|}
\hline Term & Definition \\
\hline Base and peak loads & $\begin{array}{l}\text { Minimum and maximum loads respectively } \\
\text { experienced by an electric utility over a given } \\
\text { period of time. }\end{array}$ \\
\hline Capacity factor & $\begin{array}{l}\text { Ratio of the actual (electrical) output over a } \\
\text { period of time and its output if it had operated } \\
\text { at full capacity over that same period. }\end{array}$ \\
\hline CCS & $\begin{array}{l}\text { Carbon capture and storage techniques allow } \\
\text { utilities to filter out the } \mathrm{CO}_{2} \text { during the gener- } \\
\text { ation process, so that it does not get released } \\
\text { into the atmosphere. }\end{array}$ \\
\hline CHP & $\begin{array}{l}\text { Combined heat and power (CHP) plants are } \\
\text { plants, which produce both heat and electric- } \\
\text { ity. }\end{array}$ \\
\hline Combustible Renewables & $\begin{array}{l}\text { Examples include biomass, but also certain } \\
\text { waste products. }\end{array}$ \\
\hline Fossil Fuels & $\begin{array}{l}\text { Include (exhaustible reserves of) oil, coal and } \\
\text { gas, which all emit GHG gases during their } \\
\text { combustion. }\end{array}$ \\
\hline GHG & $\begin{array}{l}\text { Greenhouse gas emissions, which are a } \\
\text { byproduct of fossil fuel combustion (see also } \\
\text { previous section). }\end{array}$ \\
\hline Lead time & Time it takes to complete construction. \\
\hline Load & $\begin{array}{l}\text { Amount of electric power delivered or required } \\
\text { at any specified point or points on a system. } \\
\text { Load originates primarily at the power con- } \\
\text { suming equipment of the customer. }\end{array}$ \\
\hline Load duration curve & $\begin{array}{l}\text { Curve that displays load values on the hori- } \\
\text { zontal axis in descending order of magnitude } \\
\text { against percent of time (on the vertical axis) } \\
\text { the load values are exceeded. }\end{array}$ \\
\hline Load factor & $\begin{array}{l}\text { Ratio of the average load supplied over the } \\
\text { peak or maximum load during a designated } \\
\text { period. }\end{array}$ \\
\hline Merit order & $\begin{array}{l}\text { Set of available technologies ordered by as- } \\
\text { cending operating cost }\end{array}$ \\
\hline $\begin{array}{l}\text { Operating and mainte- } \\
\text { nance costs }(\mathrm{O} \& \mathrm{M})\end{array}$ & $\begin{array}{l}\text { Costs that relate to the normal operating, } \\
\text { maintenance and administrative activities of } \\
\text { the utility. }\end{array}$ \\
\hline Renewables & $\begin{array}{l}\text { Non-exhaustible resources for energy genera- } \\
\text { tion, such as solar power, hydropower, wind } \\
\text { power and geothermal power. }\end{array}$ \\
\hline
\end{tabular}

Table 1.1: Electricity Terminology

They claim that the losses from fuel price fluctuations could be reduced by including more renewables into the energy mix. Their results suggest that such "loss savings" 
amount to between 58 and 106 billion $\$$ for the US and EU combined. ${ }^{15}$

Other fuel prices (e.g. coal and biomass) are more stable and might be used to hedge against the risks emanating from such price shocks. The idea might emerge that renewable energy carriers are the solution to this problem, since their "fuel" comes at zero cost (e.g. the sun for photovoltaic energy or wind for wind power). That would simultaneously provide a remedy for the emissions problem. However, renewable energy still suffers from quite high capital cost and, in addition, their efficiencies and the times at which they are available represent a disadvantage (wind power, for instance, needs wind in the first place to generate some load at all). Table 1.2 shows the characteristics of some technologies in order to illustrate these differences in cost more thoroughly. Electric output is normalized to $3,285 \mathrm{TWh} /$ year to make the numbers more comparable.

\begin{tabular}{lrllll}
\hline Parameters & & Coal & Gas & Wind & Solar \\
\hline Electricity Output & {$[\mathrm{TWh} / \mathrm{yr}]$} & 3,285 & 3,285 & 3,285 & 3,285 \\
$\mathrm{CO}_{2}$ Emissions & {$[\mathrm{kt} \mathrm{CO} / \mathrm{yr}]$} & 2,155 & 1,094 & 0 & 0 \\
Fuel Consumption & {$[\mathrm{TJ} / \mathrm{yr}]$} & 23,188 & 19,710 & 0 & 0 \\
Fuel Cost & {$[€ / \mathrm{TJ}]$} & 1,970 & 3,790 & 0 & 0 \\
O\&M Fixed Cost & {$[1,000 € / \mathrm{yr}]$} & 40,250 & 15,250 & 19,667 & 45,938 \\
Installed Capacity & {$[\mathrm{MW}]$} & 500 & 500 & 1,389 & 1,563 \\
Capacity Factor & {$[\%]$} & 85 & 85 & 27 & 24 \\
Capital Cost & {$[1,000 €]$} & 686,500 & 251,500 & $1,043,735$ & $4,042,067$ \\
\hline
\end{tabular}

$k t$ stands for kilo tonnes; TJ for Terajoule; TWh for Terawatthour; MW for Megawatts. Source: "Projected Costs of Generating Electricity 2005 Update", OECD/IEA

Table 1.2: Power Plant Data

Evidently, capital costs are indeed considerably higher for renewables than for fossil fuel technologies. Especially solar techniques are at a significant disadvantage in this respect. It costs almost six times more to install enough solar cells to produce the same amount of electricity as a coal-fired power plant per year. The $\mathrm{CO}_{2}$ figures only matter in case the government enacts regulations or taxes because otherwise emissions are an externality, which does not affect the investment decision. In the case of $\mathrm{CO}_{2}$ taxes or permit trading, the zero emissions property is a clear advantage for the renewables. Please note however the low capacity factors of renewables: onshore wind turbines, for example, have a factor of only $27 \%$. As a consequence, 1,389 MW would be needed to generate the same amount of electricity as the coal-fired power plant, which is only $500 \mathrm{MW}$ big. For a typical unit size of $1.5 \mathrm{MW}$ per wind mill, this is a requirement of 926 wind mills! Obviously, there will therefore be maximum constraints on the usage of wind farms, for reasons of limited space in densely populated European countries.

On the one hand, proponents of renewable energy are optimistic that technological change might decrease their large capital costs and maybe improve their efficiency rather soon. On the other hand, technological change itself is an inherently uncertain

\footnotetext{
${ }^{15}$ These results hold for a modest $10 \%$ rise in the renewables share in the energy mix.
} 
process that moves more erratically than linearly and smoothly, which adds to the uncertainties inherent in investment decisions. Yet, there is some appeal in the thought that established technologies relying on fossil fuels are in a later stage of maturity than renewable technologies, which still have a lot of scope for improvement that might also occur relatively faster initially. Oxera Consulting Ltd present studies in a report to the Department of Trade and Industry (DTI) of the UK that indeed find evidence for this hypothesis. They look at so-called progress ratios (PR), a concept which describes the decrease in costs of generation technologies through the realization of economies of scale and technological improvements. More precisely, the PR is the percentage of initial unit costs that current costs will be resulting from a doubling of cumulative output. The result is that gas turbines - during their R\&D phase - had a PR of $80 \%$, i.e. costs fell by $20 \%$ each time cumulative production doubled. In their commercialization phase, the PR was only $90 \%$, i.e. costs fell only by $10 \%$ for each doubling of cumulative output. This suggests that technological progress decelerates, as technologies mature. Concerning renewables, the European Wind Energy Association (2004) projects a PR of $83 \%$ to $91 \%$ for the capital costs of onshore wind generation. While this indicates large potential (up to $17 \%$ capital cost reductions for each doubling of cumulative production, which is currently not at high levels), the wide range in the projections also points to the uncertainty associated with these promising rates of progress. ${ }^{16}$ Thus, fossil-fuel-based technologies might have more moderate prospects for technological advances, but these are at least occurring at a relatively certain rate, which can be an incentive for investors to opt for fossil fuels, even if renewable energy carriers promise high expected returns (exhibiting more volatility). A portfolio approach is obviously warranted to analyze the benefits of diversification in this context.

This thesis offers new insights into the importance and effects of technological uncertainty. By incorporating this into a vintage setting with elements from portfolio selection, we find that a decrease in technological uncertainty generally leads to a postponement of investment because investors want to maximize the benefits that they can reap from technological change that is now occurring with more certainty by waiting for these advances to materialize (see Chapters 5 and 6). Uncertainty about fuel prices has the opposite effect, which would represent an advantage for renewables. The same uncertainties, but then in a real options framework (see Chapter 4), lead to earlier investment in both cases.

Other sources of uncertainty are related to policy-making, which in turn is related to uncertainties about global warming and its effects and uncertainties emanating from international climate change negotiations. If electricity generators cannot be sure whether they will face a higher price for $\mathrm{CO}_{2}$ emissions (no matter if it comes in the form of taxes or emission permits) over the course of their planning period, they need to adapt their decisions in order to avoid considerable losses in any event.

It is important to note that there is a close relationship between the effects of irreversibility of investment and uncertainty that reinforces the need for special frame-

\footnotetext{
${ }^{16}$ See also Junginger et al (2004) for a detailed study on cost reduction projections for wind farms.
} 
works dealing with investment decision-making in the electricity sector. If the installation cost of a power plant were not sunk, decisions could be revised or at least updated by the time that uncertainties are resolved. However, irreversibility makes it impossible to build a gas-fired turbine at first and dismantle it in favor of a wind mill, the day that gas prices peak. Standard NPV optimization is therefore not an option because it treats an investment as a one-time opportunity and does not take into account the merits from postponing an investment rather than discarding it immediately. (see Chapter 2 for a more detailed analysis of this aspect). What is needed is also a framework that takes into account the dynamic nature of the problem of capacity planning (especially when e.g. technological change and increasing and stochastic fuel prices are involved). Once investments have been made, electricity generators are more or less "stuck" with their choices, so they need to account for uncertain developments of key variables ex ante in order to avoid unpleasant surprises ex post.

\subsubsection{The Government}

As has already become apparent in the characterization of the climate and the electricity sector, the government has a special role of "mediating" between these two "parties". The investor in the electricity sector has no incentive to install exclusively environmentally friendly technologies if the government does not entice him/her by imposing regulations or taxes on the use of fossil fuels or the generation of emissions or by making renewable energy carriers a more attractive option through granting subsidies or tax allowances. ${ }^{17}$ Without regulation, the pollution created during the electricity generation process is external to the firm's investment and production decisions.

The tools and instruments that the government has at its disposal to influence the investment incentives in the electricity sector can be grouped into two broad classes: instruments that punish the use of fossil fuels, such as $\mathrm{CO}_{2}$ taxes or permit trading, ${ }^{18}$ and instruments that support the adoption and diffusion of renewable energy such as subsidies and obligations. In the UK, for example, both types of policy tools are actually applied. The so-called Climate Change Levy is a tax imposed on the use of fossil fuels. Such a tax along with permit trading is regarded as an effective way of imposing a price on $\mathrm{CO}_{2}$ emissions. In addition, the government has implemented the Renewables Obligation, a regulation which requires a minimum percentage of produced electricity to be based on renewable energy carriers. This percentage had first been $10 \%$, but has subsequently been adapted and raised. In Chapter 7 we will present an analysis of the Renewables Obligation in the UK in an extended version of the vintage-portfolio model developed in Chapter 5. Other examples of policy measures are feed-in tariffs, which is a sort of legislated guarantee that a pre-specified amount of "green" electricity will be bought off producers for a fixed price that enables generators

\footnotetext{
${ }^{17}$ Thereby, the government is also an indirect way for consumers to influence the supply side of the electricity sector.

${ }^{18}$ The latter is often referred to as the "cap-and-trade regime", i.e. emissions are capped and the corresponding number of permits is computed on the basis of the allowed amount of emissions. The permits are then either allocated or auctioned off and subsequently traded at a $\mathrm{CO}_{2}$ permit exchange.
} 
to cover their expenses.

Gao et al (2005) and Madlener and Gao (2005) explore the differences in effects when using different policy instruments to support renewable energy and make a distinction between price and quantity controls. More specifically, they look at guaranteed feed-in tariffs (such as in Germany) and tradable permits and find that subsidies always outperform permits when technological innovation is possible.

In this thesis the primary interest is not in the difference in impact when different policy instruments are used, even though Chapter 3 analyzes the influence of stochasticity of $\mathrm{CO}_{2}$ prices and the implications of price caps as a "safety valve". ${ }^{19}$ Instead, the main focus is on the effect of changes in investment incentives in general and the impact of the uncertainties associated with the policy making process. For example, if international climate change negotiations are underway and investors do not know if they will be successful or not, they are effectively unsure about the direction that future policy will take. Similar uncertainties would arise in case of changes in existing regulations in response to changes in government and lobbying by industries, for example. Furthermore, a switch in measurement procedures and definitions also represents an uncertainty of the same type to the investor. These uncertainties can be classified as "policy uncertainty" therefore. Fluctuations in the $\mathrm{CO}_{2}$ price that arise e.g. during permit trading, on the other had, are referred to as "market uncertainty" and might in a Knightian sense (Knight, 1921, Keynes, 1921) be called risk or soft uncertainty because we can use historical time series to form expectations based on past trends and empirically motivated probability distributions. While people have generally been concerned that the risk associated with fluctuations in the $\mathrm{CO}_{2}$ price might lead investors to postpone their decision to invest in "green" technologies, we find that - for $\mathrm{CO}_{2}$ price processes that are volatile, but overall rising - the opposite is true: investors optimize under incomplete information and therefore tend to invest earlier. ${ }^{20}$

\subsection{Current Electricity Technologies \& Future Outlook}

The bulk of the electricity generated in the world today comes from coal-fired capacity accounting for some $40 \%$ of total generation. The fraction of oil-fired production had been decreasing sharply after the oil price shocks in the 1970s and the remaining capacity is mainly situated in developing countries. $19 \%$ are produced by gas-fired plants and only $16 \%$ is nuclear energy. Of the $18 \%$ renewable energy, the lion's share

\footnotetext{
${ }^{19}$ This analysis is mainly motivated by the policy debate whether a price cap on the $\mathrm{CO}_{2}$ permit price is warranted to protect $\mathrm{CO}_{2}$-emitters from the risks associated with $\mathrm{CO}_{2}$ price volatility.

${ }^{20}$ If expected prices are rising stochastically, the investment threshold is exceeded by upwards spikes and investment is thus triggered earlier than in the case of a smoothly rising price. Then, even if the price that the investor actually faces behaves non-stochastically, investment will always occur earlier than optimal, i.e. earlier than in the case where optimization occurs under non-stochastic prices.
} 
is due to hydropower, so only $2 \%$ are produced by wind farms, solar panels, geothermal plants, tide and wave installations etc.

Furthermore, $97 \%$ of all coal-fired electricity generation uses pulverized coal, most of which is subcritical. However, Integrated Gasification Combined Cycle (IGCC) plants are commercially used now as well, and these plants produce significantly less $\mathrm{CO}_{2}$. Such plants are more expensive to build than less modern coal-fired power plants, but are increasingly used in the developed countries. ${ }^{21}$ In addition, the possibility to retrofit existing capacity with Carbon Capture and Storage (CCS) facilities, or to install new plants with in-built CCS, offers even more scope for carbon emission reductions.

The cost of CCS is very much dependent on the type of plant. The most costeffective technologies will have capture costs between $\$ 20$ and $\$ 40$ per ton of $\mathrm{CO}_{2}$, but this does not include transport (about $\$ 10 /$ ton of $\mathrm{CO}_{2}$ ) and storage (between $\$ 1$ and $\$ 2$ per ton of $\mathrm{CO}_{2}$ ). The storage costs are dependent on the site where the $\mathrm{CO}_{2}$ is supposed to be stored, of course. In many cases there might actually be quite substantial benefits in terms of enhanced oil recovery. However, carbon capture has proven to be economically viable only for plants that operate at a relatively large scale with a relatively high efficiency so far. Since there are many different CCS technologies (e.g. pre- versus post-combustion capture) that are currently being developed and R\&D efforts to improve efficiency and costs are vast, this will most definitely not remain the case and CCS is generally seen as a promising way to reduce carbon emissions substantially in the near future.

Biomass-fired generation capacity combined with CCS can even lead to a net removal of $\mathrm{CO}_{2}$ from the atmosphere, since the growing of biomass sequesters more $\mathrm{CO}_{2}$ than is emitted in a plant with CCS. While this is a promising outlook, some countries might encounter natural limits to the production of biomass as a fuel on a large scale. The import of biomass as a solution to this problem is also debateable on the grounds of the emissions that transportation would cause.

The IEA provides technical and cost data for these technologies and also projects how they will develop in the future given current $R \& D$ efforts and scope for improvement (e.g. IEA (2006) or IEA (2005), where the latter is based on surveys of existing plants in various countries). These are used in the models of the first half of this thesis, as we think that they are the most up to date, most accurate and most consistent data that can possibly be obtained for this purpose.

In the second half of the thesis we are interested in a larger set of technologies and we adopt the view of a country, more precisely of the UK in Chapter $7{ }^{22}$ While coal still accounts for the largest portion of electricity generation there as well, the UK is considering a renaissance of nuclear energy to bridge the gap between an energy

\footnotetext{
${ }^{21}$ As a "rule of thumb", the IEA finds the largest fossil fuel users to be those with the most inefficient plants at the same time. If China, for example, would use more efficient coal-fired power plants, they would combust $20 \%$ less coal. Similar calculations apply to Russia's gas use (IEA, 2006).

${ }^{22}$ The cost data are specific to plants used in the UK and come from the same source (Anderson and Winne, 2004), but these had to be complemented by data from the DTI for our modeling purposes.
} 
system based on fossil-fuel-based electricity and one that relies on renewable energy (e.g. DTI, 2007a). This transition to a less carbon-intensive energy mix is difficult because the potential for hydropower is almost exhausted and also the acquisition of sufficient biomass is questionable. With other renewables still being rather expensive or unattractive because of low capacity factors, nuclear energy represents one alternative for relatively carbon-free energy generation. Furthermore, since fuel efficiency is rising and current uranium deposits are estimated to last for over 80 years at current consumption, nuclear energy would also serve the goal of enhanced energy security, which has high priority for the UK as well.

On the other hand, nuclear energy exposes the society to the risk of accidents with catastrophic consequences and other problematic issues such as the question of waste disposal. After the Three Mile Island incident in 1979 and the 1986 Chernobyl accident, many countries initiated the phase out of their own nuclear capacity. Since then it has been politically difficult to consider nuclear energy as an alternative in many countries, while others like France even produce a surplus and export this to other countries. Even though advanced light-water reactors feature enhanced safety already, it is clear that technological progress has to bring further improvements in that direction. ${ }^{23}$

Given the currently existing mix of generating capacity described above and the outlined potential of individual technologies in the future, it is important to note that the existing power plant stock in OECD countries is ageing and will need replacement over the next 10 to 20 years (IEA, 2006). This differs between countries, of course, and some of the existing plants might also be refurbished to extend plant life. However, growing energy demand (as indicated in the introduction) will add to the amount of capacity needed in the near future. Therefore, investment into new capacity will be decisive for the carbon-intensity of the future energy mix and it is important to develop an understanding of investment decision-making in this sector in order to avoid a lock-in to a carbon-intensive energy system for the coming decades.

\subsection{Contribution of this Thesis}

The discussion of methodologies above has outlined different investment theories and focussed on two methods in particular that take uncertainty into account. These two methods are real options theory and portfolio selection. Real options theory is a dynamic theory, where the control is the timing of investment. Uncertainty is represented by stochastic input or output prices or other parameters. Standard meanvariance portfolio selection as far as applied to non-financial assets, on the other hand, analyzes investment at one point in time and is therefore inherently myopic. The advantage from a technical point of view is that the analyst can consider many different technologies, of which the portfolio could be composed, and therefore accounts for the gains from diversification. These technologies may have different fuel price paths or

\footnotetext{
${ }^{23}$ This has to be kept in mind in the analysis presented in Chapter 7, where the focus is on the cost side and issues of safety risks are not accounted for.
} 
differently developing rates of technical change that can be correlated. In a real options framework, two (correlated) price processes make the model already relatively complex from a practical point of view. So, unless we are focussing at parameters that affect all technologies to the same extent (e.g. electricity prices or $\mathrm{CO}_{2}$ prices are the same (or zero) for all technologies, but fuel prices follow a different path for each technology), it becomes too complex to include many technologies. ${ }^{24}$ Still, the advantage that real options models can actively value the option of postponing investment is unique to this sort of approach. It is therefore an indispensable tool in decision-making under uncertainty, and especially in the electricity sector, where huge sunk costs are involved in investing in new plants and equipment.

In this thesis, real options theory is used to assess the impact of uncertain electricity and $\mathrm{CO}_{2}$ prices on investment behavior. There are not only contributions from a scientific point of view, but also in the area of policy making where much research is needed at relatively short notice because people are only realizing the need for change when the symptoms of the problem have already started to materialize. Methodologically, the contribution of the thesis in this respect is that uncertainty is not only analyzed in terms of stochastic processes and their variance, but also in terms of expected and realized processes, i.e. the processes, which are used in the optimization procedure, and the processes that the investor actually faces when picking the decisions according to his optimal strategy. ${ }^{25}$ This is very relevant when it comes to policy making, since - unlike electricity prices - the price of $\mathrm{CO}_{2}$ might not follow the same trend as it has done over the last one or two years. ${ }^{26}$ On the contrary, regulations might be adapted and procedures redefined. This may lead to a sudden change of slope or even direction of the $\mathrm{CO}_{2}$ price (as will be seen in Chapter 3) and it is important to understand, which effect this type of uncertainty exerts on investment plans. At the same time, the industry has expressed concerns that markets for emissions permits lead to a volatile $\mathrm{CO}_{2}$ price, which might provide disincentives for investors to acquire environmentally friendly technologies. This type of uncertainty is called "market uncertainty" in our framework and it turns out that it actually results in earlier investment for upward trending $\mathrm{CO}_{2}$ prices. "Policy uncertainty" on the other hand, leads to the postponement of investment into environmentally friendly technologies and thereby to prolonged periods of accumulating emissions at high levels because the option value more than outweighs the losses that are made by postponing investment in the face of rising $\mathrm{CO}_{2}$ prices. It is therefore the type of uncertainty that matters for the actual outcomes and thus also for the very effectiveness of policies.

Even though Markowitz mean-variance portfolio theory has a number of disadvantages when dynamics are important, the advantage over real options theory is that the return-risk tradeoff for multiple technologies can be determined in a very straight-

\footnotetext{
${ }^{24}$ However, including different technology investment options in one and the same framework implies that the options will be valued in the presence of each other. Fuss et al (2008) find that the option value of individual technologies therefore also become dependent on factors that drive other options' values.

${ }^{25}$ See Figure 3.2 in Chapter 3 for the precise setup of this framework.

${ }^{26}$ Empirical series for $\mathrm{CO}_{2}$ prices are typically short (less than two years of daily data) because permit markets only exist in very few countries since one or two years.
} 
forward way, even when different price processes apply to different technologies. In this thesis we use these elements of portfolio theory and combine them in a vintage setting (see Chapter 2 for an explanation of vintage modeling) in order to overcome this deficiency and benefit from the advantages of portfolio theory, while still being able to come up with dynamic portfolios. The idea is to not only find portfolios that maximize returns subject to a specified level of risk or vice versa in order to find the optimum composition of technologies at a point in time, but to determine the optimum path of development of such a portfolio over time, given changing input prices and ongoing technological progress and uncertainty about these processes. In other words, we find the optimum portfolio not only over technologies, but also across time and quality (represented by subsequent vintages). What we actually find is that this type of setting also generates an "implicit option value" of waiting: in the presence of ongoing (exogenous) technical advances, there is a value to waiting if these advances are more certain to occur. Therefore, one can say that - for the particular set-up of our model - we find a positive relationship between uncertainty and investment, which is not a typical result in real options theory, but which could have favorable implications for the adoption of renewable energy technologies, which typically suffer from technological uncertainty (see Chapter 4). An investigation of the difference between the traditional option value and the value of waiting arising in the portfolio-vintage setting provides interesting additional insights for modeling investment under uncertainty.

The combined approach of vintage modeling and portfolio selection is thus an improvement over existing approaches in the sense that it takes into account a lot of additional features of the electricity sector: dynamically evolving prices and rates of technical change, embodiment of technological progress and investment irreversibility.

Real options theory, on the other hand, is more explicit in considering these aspects and actively values the flexibility of timing an investment differently. Furthermore, while portfolio optimization is methodologically typically interesting for large investors, who diversify their investments over different technologies (or at the country level as in Chapter 7), real options are more helpful to analyze how the individual investor incorporates uncertainty into his/her decisions. Chapter 5 studies how the new vintage-portfolio approach compares to a "standard" Markowitz mean-variance portfolio framework with uncertain fuel prices and rates of technical change. This analysis demonstrates how the two different frameworks work in detail and emphasizes the contributions of the new approach.

\subsection{Research Outline}

The thesis is organized in two parts. Table 1.3 on the next page gives a rough overview of the research outline and summarizes the contents and/or modeling approach of each chapter. 
$\mathbf{1}$ - Sustainable Energy Develop-

Introduction: problem definition, description of contributions and research outline

Literature review: orthodox models, real options theory, portfolio selection and vintage approach; applications to electricity planning.

3 - Energy Investments under

Market \& Climate Policy Uncertainty

4 - Fuel Price \& Technological

Uncertainty in a Real Options Model for Electricity Planning

tainty are distinguished, namely market and policy uncertainty.

Technical change reduces the investment cost of a renewable energy technology, where innovations arrive according to a Poisson process. Uncertainty leads to later adoption. If existing capacity needs to be replaced by either the renewable or a fossil-fuel-based technology suffering from stochastic fuel prices, renewable energy turns out to be less profitable than fossil-fuel-based energy. $\mathrm{CO}_{2}$ prices can be used to make renewable energy attractive nonetheless.

5 - An Integrated VintagePortfolio Approach to Electricity Investment

Combination of a portfolio selection approach with a vintage setting, which allows not only to determine the optimal technology mix at a certain point in time, but also optimizes the adoption and scrapping of new and existing capacity. Detailed comparison with a standard Markowitz portfolio model with the same types of uncertainties and the same set of (stylized) technologies.

6 - Technological and Price Uncertainty in the VintagePortfolio Model - A Comparative Study show that fuel price uncertainty leads to later investment, while uncertainty about technical change triggers adoption in the concerned technology earlier.

Extended version of the modeling approach introduced in Chapter 6 with an application to

UK data with multiple technologies. Uses scenario analysis to include demand uncertainty, adds load profile (peak vs base), considers (cumulative) emissions and policy issues connected to this and includes maximum capacity constraints. Analyzes UK policies and implications of uncertainty about fuel prices and technological advance.

$8-$ Conclusion

I

I


The first part starts out by defining the problems addressed in this thesis, gives an overview of the contributions (Chapter 1) and reviews the relevant literature (Chapter 2 ). The remainder of part I is devoted to frameworks based on principles from real options theory and contains Chapters 3 and 4 . Chapter 3 presents a model, in which we deal with different types of uncertainty affecting the investor. In liberalized electricity markets, investors nowadays do not only face uncertainty from volatile electricity prices, but also from the possibility of stricter climate change policy. We investigate this in a real options framework with two types of power plants (both coal-fired, but one with a carbon capture and storage module, which therefore emits less $\mathrm{CO}_{2}$ ), where the prices of electricity and $\mathrm{CO}_{2}$ emissions are stochastic. In particular, we analyze the response of long-term investment to (higher) uncertainty about $\mathrm{CO}_{2}$ prices, which can come from two sources: price fluctuations around an average, rising price that might as well be market-driven, and uncertainty about the actions of the government, which can lead to sudden price jumps or drops. We find that producers facing market uncertainty optimize under incomplete information and invest into the carbon-saving technology earlier than they would have done if they had known what the prices indeed are, while policy uncertainty leads to postponement of investment, as the option value of waiting for the revelation of the policy outcome more than outweighs the losses associated with ongoing, continuously rising $\mathrm{CO}_{2}$ costs.

Chapter 4 is about a real options model, which considers both fuel price risk and technological uncertainty to determine the optimal investment strategy for an individual investor. The power plants under consideration are fossil-fuel-fired and based on renewables respectively, where the first one obviously suffers from fuel price risk, whereas the latter is subject to technical change and therefore also to technological uncertainty. While technical change itself is embodied and leads to a postponement of investment, uncertainty leads to further delays in the adoption of the concerned technology.

The second part of the thesis is occupied with applying portfolio selection to investment in the electricity sector. Chapter 5 presents an alternative to the real options modeling approach used in the first part of the thesis. By integrating ideas from financial portfolio theory into a vintage model of investment and production, interesting insights are gained into the pattern of decision-making of investors in the electricity sector.

The basic idea is that the methods by which fuels can be converted into electricity all belong to different "technology families": the "gas-fired-turbine-family", the "coalfired-turbine-family", etc. Each family consists of different generations of technologies, as in a vintage model. Within a family, the latest generation embodies the most recent level of knowledge, becoming outdated as new generations arrive. Producers face the problem of composing their portfolio of families to minimize risk-adjusted costs of investment and production under a given demand constraint. Risk emanates only from capital-saving technical change and volatile fuel prices, so this is a very simple model to illustrate principles first. The cumulative nature of embodied technical change provides some new insights that have so far been neglected in the literature. This 
becomes very clear when we set up a "standard" Markowitz framework with the same characteristics and the same type of technologies, which helps us to work out the differences between this and the new approach and to stress the advantages that the latter has over the former.

Chapter 6 then presents a vintage-portfolio model that takes into account not only capital-saving technical change and fuel price uncertainty, but also fuel-saving technical change and investment prices. While all these processes are surrounded by uncertainty, the investment response is quite different. This chapter therefore serves to further illustrate the workings of the new approach and to disentangle the causes of the effects that we observe. It becomes evident that it is necessary to make a distinction between the different types of cost and technical change when we want to apply the model reliably to a real world analysis in Chapter 7. Another important conclusion that we can derive from this version of the model is the importance of diversification opportunities that apply not only across technologies, but also over time and vintages, where later vintages represent a higher degree of quality with respect to productivity.

Chapter 7 is an extension of the model of Chapter 6 to capture more realistically all essential features of an electricity sector and to apply it to more precise data from the United Kingdom. Even though the data set is rather limited in some respects, this is a very useful illustration of the more theoretical principles obtained in Chapter 6 and provides a number of new insights. Moreover, its predictions compare favorably to those of larger macroeconomic models. In particular, we implement several features of present UK policy in order to illustrate the principles involved. We find that the reduction of risk goes together with an increase in total costs. We also find that for increasing values of risk-aversion, investors would be willing to adopt nuclear energy at earlier dates than otherwise would have been the case. ${ }^{27}$ In addition to this, we find that the embodiment of technical change, in combination with the expectation of a future switch towards another technology, may actually reduce current investment in that technology (while temporarily increasing current investment in competing technologies). The latter enables rational but risk averse investors to maximize productivity gains by waiting for ongoing embodied technical change to take place until the moment they plan to make the switch and then investing more heavily in the newest vintages associated with that technology at the time of the switch.

Chapter 8 first summarizes the results of the previous chapters, puts them into perspective with respect to climate change policy, and - most importantly - reviews and emphasizes the contributions and novel results. Being able to understand better how investors can respond to uncertainty, governments can better target their policies in order to obtain favorable results in terms of reduced $\mathrm{CO}_{2}$ emissions and maybe ultimately a stabilization of cumulative emissions arising from electricity generation. Furthermore, the chapter concludes and explains how the work of the thesis complements and extends existing work in the same field.

${ }^{27}$ This implies that nuclear energy is used as a "bridge" during the transition from a fossilfuel-dominated mix to a mix of renewable energy technologies - a role which would be impaired if other risks relating to nuclear energy generation (safety issues, waste disposal problems, etc) were explicitly accounted for. 


\section{Chapter 2}

\section{Investment Theory under Uncertainty \& Irreversibility}

\subsection{Introduction}

This chapter is devoted to a literature review of investment theory with particular focus on irreversibility and issues connected to uncertainty. It starts out with orthodox investment modeling approaches and then explains the theories used in this thesis in more detail in the following sections. In particular, real options theory is presented as a framework that allows to consider both uncertainty and investment irreversibility by timing the exertion of the investment option optimally. Second, portfolio approaches value the benefits from diversifying across technologies, so that a risk averse planner can determine the optimal (in the sense of maximizing return at a specified level of risk or minimizing risk for a particular return) mix of technologies at the corresponding degree of risk aversion. Third, a portfolio approach can be complemented by elements from vintage modeling, so that investors are not only able to diversify across technologies, but also across time and degrees of quality where later vintages are of higher quality with respect to productivity.

Moreover, applications to investment in the electricity sector are presented and reviewed along with the theory, which helps to put the contributions of this thesis further into perspective. Appendix A describes some tools that are used in largescale energy planning to integrate uncertainty into otherwise deterministic models. In Chapter 7 we use scenarios, for example, to account for demand uncertainty, while fuel price risk and technological uncertainty is captured by the stochastic variables underlying the portfolio optimization procedure. Table 2.1 summarizes the outline of this chapter. 


\begin{tabular}{|c|c|c|}
\hline Section & Subsection & Content \\
\hline 1 & - & Introduction \\
\hline \multirow[t]{2}{*}{2} & 1 & $\begin{array}{l}\text { The Jorgenson (1963) model (does not incor- } \\
\text { porate uncertainty and irreversibility) }\end{array}$ \\
\hline & 2 & $\begin{array}{l}\text { Hartman (1972), Nickell (1978), Abel (1983) } \\
\text { (extended investment models; also consider } \\
\text { uncertainty and irreversibility) }\end{array}$ \\
\hline \multirow[t]{4}{*}{3} & 1 & Demonstration of Methodology \\
\hline & 2 & $\begin{array}{l}\text { Early Literature (how real options theory } \\
\text { evolved; seminal studies) }\end{array}$ \\
\hline & 3 & $\begin{array}{l}\text { More recent frameworks focussing on (1) } \\
\text { technological uncertainty, (2) environmental } \\
\text { uncertainty, (3) policy uncertainty and (4) } \\
\text { electricity-specific applications. }\end{array}$ \\
\hline & 4 & Uncertainty-investment relationship \\
\hline \multirow[t]{3}{*}{4} & 1 & $\begin{array}{l}\text { Theoretical background of portfolio theory } \\
\text { (with detailed explanation of the Markowitz } \\
(1952,1959) \text { framework) }\end{array}$ \\
\hline & 2 & $\begin{array}{l}\text { Applications of portfolio theory to real assets } \\
\text { (focus on investment in the electricity sector) }\end{array}$ \\
\hline & 3 & Uncertainty-investment relationship \\
\hline 5 & - & $\begin{array}{l}\text { Vintage models (basic structure, embodied } \\
\text { technical change, scrapping rules and how we } \\
\text { can borrow elements to combine them with } \\
\text { portfolio theory) }\end{array}$ \\
\hline 6 & - & $\begin{array}{l}\text { Conclusion (emphasizing the contributions of } \\
\text { the thesis to the reviewed literature again, see } \\
\text { also Chapter } 1 \text { ) }\end{array}$ \\
\hline Appendix A & - & $\begin{array}{l}\text { Large-scale frameworks used in electricity } \\
\text { planning (description of tools used in large- } \\
\text { scale models to account for uncertainty such } \\
\text { as scenario analysis) }\end{array}$ \\
\hline Appendix B & - & $\begin{array}{l}\text { Technical illustration of the value-matching } \\
\text { and smooth-pasting conditions as shown in } \\
\text { Dixit and Pindyck (1994) }\end{array}$ \\
\hline
\end{tabular}

Table 2.1: Organization of Literature Review

\subsection{Orthodox Investment Theories}

Traditional economics literature about investment started with Jorgenson (1963). In a nutshell, his approach, which is based on the neoclassical theory of optimal capital 
accumulation, ${ }^{1}$ compares the value of the marginal product of capital in each period of time with the user cost of that capital. Equating those terms then delivers the optimal capital stock, from which we can derive the rate of investment. Tobin (1969) follows an essentially similar approach, founding the so-called $q$-theory of investment. He calculates the capital value of marginal investment and divides it by its replacement cost. The result is the so-called "q-ratio". If $q>1$, then investment is warranted, if $q<$ 1 the existing capital stock should be reduced. Both approaches, the Jorgenson (1963) model and the q-theory, do not take into account adjustment costs, however. This is a substantial drawback when considering that investment is often lumpy and usually irreversible in sectors like the electricity sector. Also, it ignores the fact that most industries exhibit specific dynamics, which cannot be taken into account in frameworks that are inherently static. Furthermore, these models do not consider the effects of uncertainty on the investment decision. Work that has followed from these seminal studies (e.g. by Sandmo, 1971, and Leland, 1972) have incorporated uncertainty and analyzed the effects on output and prices. These studies too suffer from the lack of dynamics and the failure to consider irreversibility in their models, however.

In the $70 \mathrm{~s}$ and $80 \mathrm{~s}$, the theory was extended by a number of seminal studies that finally acknowledged the importance of adjustment costs to give a realistic account of investment behavior. Most notably, Hartman (1972), Nickel (1978) and Abel (1983) have all developed investment models, which are suitable to analyzing the effects of uncertainty on investment in frameworks where adjustment costs are non-zero. Their shortcoming lies in the assumption that the investment decision is a "once-and-for-all" opportunity. Lensink et al (2001) point out that this is the reason why these models have generally performed rather poorly when applied econometrically. The flexibility to time investments differently implies that foregoing the opportunity to invest at a later point in time by investing now should be valued accordingly. This has been ignored in these studies.

This section is organized as follows: ${ }^{2}$ we will first give an outline of the neoclassical Jorgenson (1962) model, followed by a description of how uncertainty has been incorporated in this framework by other authors. Then we will turn to the models including adjustment costs that have been mentioned above: Hartman (1972), Nickell (1978) and Abel (1983).

\subsubsection{The Jorgenson (1963) Model}

The neoclassical investment model focusses on a firm facing perfect competition and having two factors at its disposal. These factors are labor $L$ and capital $K$, and they can be substituted for each other. The production function has constant returns to

\footnotetext{
${ }^{1}$ Even though the neoclassical approach to optimal capital accumulation (i.e. that production and investment plans are based on the maximization of utility over time) was receiving more acceptance than before by that time, not much had been achieved in terms of formulating it consistently and the econometric literature fell short of this as well.

${ }^{2}$ These sections will draw on the expositions in Lensink et al (2001), and more particularly the chapter about uncertainty in investment decision processes.
} 
scale as e.g. in the Cobb-Douglas case. Also, the Inada conditions are satisfied. ${ }^{3}$ Contrary to vintage theory (see Section 2.5), the stock of capital is homogenous and its productivity does not depend on its age. Moreover, it depreciates at a rate $\delta$. Cash flows are revenues less the cost:

$$
\pi=p \cdot Y(K, L)-w \cdot L-r \cdot I
$$

where $p$ is the output price, $r$ the purchasing price of capital ${ }^{4}$ and $w$ the wage rate. $I$ is investment, which can be broken up into replacement investment, $\delta \cdot K$, and net investment, $d K / d t$. The value function that the firm thus maximizes is

$$
V=\int_{0}^{\infty}\left\{p \cdot Y-w \cdot L-r \cdot\left(\frac{d K}{d t}+\delta \cdot K\right)\right\} \cdot e^{-\rho t} d t
$$

where $\rho$ is the discount rate. The problem is that net investment must be bounded for a solution to exist, so Jorgenson assumes that there are no spikes in net investment. The marginal productivity conditions that can be found when maximizing Equation (2.2.2) subject to the production function are well-known. The marginal products are equal to the ratio of factor and output prices, where in the case of capital discounting and depreciation have to be taken into account:

$$
\begin{aligned}
\frac{\partial Y}{\partial L} & =\frac{w}{p} \\
\frac{\partial Y}{\partial K} & =\frac{r(\rho+\delta)}{p}
\end{aligned}
$$

These conditions apply in each period $t$. However, as Lensink et al (2001) point out, the Jorgenson (1963) approach is not dynamic: since the optimality conditions (2.2.3) involve only current period variables, the neoclassical model is inherently static. In other words, the investor can make the optimal decision without considering the future, which hinges on the assumption that capital is rented. Also, as the neoclassical approach assumes perfect foresight, it precludes any treatment of the impact that uncertainty might have on the investment decision.

Leland (1972) and Sandmo (1971) extend the work by Jorgenson (1963) to incorporate uncertainty. Since the basic model can jump deliberately to a new optimum capital stock, the effects of uncertainty on investment decisions cannot be analyzed. What Leland (1972) and Sandmo (1971) therefore focus on is the effect of uncertainty on production plans. In particular, Leland (1972) looks at demand uncertainty. He finds that, facing uncertainty, it is very important to know which type of firm we are dealing with. For a competitive firm, which is able to set the quantity, that quantity has to be fixed before the firm knows how demand varies, whereas the price is determined ex post. His main conclusion is that a risk averse firm will produce less output if it faces uncertainty than in the case where demand is known with certainty. Sandmo (1971) has a similar framework with a price-setting firm, but the results are

\footnotetext{
${ }^{3}$ The Inada conditions are: $Y^{\prime}(0)=\infty, Y^{\prime}(\infty)=0$ and $Y(0)=0$

${ }^{4}$ The firm thus owns the capital stock rather than renting it.
} 
the same: uncertainty leads to a more cautious output plan, if the investor is averse to fluctuations in the price.

\subsubsection{Models with Irreversible Investment and Uncertainty}

In this section, three studies that have been very influential in the literature on investment theory including adjustment costs will be reviewed. The first is by Hartman (1972), who proposes a model with a perfectly competitive and risk neutral firm that faces uncertainty with respect to wages and the prices for output. Adjustment costs are steadily increasing over time, but even more so with the size of the (dis)investment. In case there is no (dis)investment, the adjustment cost will of course be zero as well. Again, gross investment is equal to the sum of net investment and replacement investment. The value function that the investor thus maximizes is the same as in Equation (2.2.2) in the Jorgenson (1963) model, but for the adjustment cost $C\left(I_{t}\right)^{5}$ and the fact that now the expected present value matters:

$$
V=\mathbb{E}\left[\int_{0}^{\infty}\left\{p_{t} \cdot Y_{t}-w_{t} \cdot L_{t}-r_{t} \cdot I_{t}-C\left(I_{t}\right)\right\} \cdot e^{-\rho t} d t\right]
$$

where $I_{t}=\frac{d K}{d t}+\delta \cdot K$, i.e. the same capital accumulation equation as before holds.

The first order condition that is derived under uncertainty is an equality between the expected present value of the net return on the marginal unit of capital and the marginal adjustment cost. In other words, the benefits that emanate from the purchase of one more unit of capital at time $t$ should be equal to the cost of adjusting the capital stock by one more unit.

$$
\frac{\partial C_{t}}{\partial K_{t}}=\int_{t}^{\infty} p_{t^{\prime}} \cdot \frac{\partial Y_{t}}{\partial K_{t}} \cdot e^{-(\delta+\rho)\left(t^{\prime}-t\right)} d t^{\prime}-r_{t}
$$

where $t^{\prime}>t$. While $\int_{t}^{\infty} p_{t^{\prime}} \cdot \frac{\partial Y_{t}}{\partial K_{t}} \cdot e^{-(\delta+\rho)\left(t^{\prime}-t\right)} d t^{\prime}$ represents the present value of the revenue from investing into one more unit of capital at time $t, r_{t}$ is the cost of doing so.

We now express all variables in per worker terms, so that output per head is $y=\frac{w}{p}+\frac{k \partial y}{\partial k}$. Following Lensink et al (2001), Equation (2.2.6) can then be rewritten in discrete time as follows:

$$
\frac{\partial c_{t}}{\partial k_{t}}=\sum_{t^{\prime}=t}^{\infty} \alpha_{t^{\prime}, t} \mathbb{E}\left\{p_{t^{\prime}} \cdot \frac{\partial y_{t}}{\partial k_{t}}\left(\frac{w_{t^{\prime}}}{p_{t^{\prime}}}\right)\right\}-r_{t}
$$

with $\alpha_{t^{\prime}, t}$ as the discount factor. By using Jenson's inequality, it can then be shown that an increase in the (mean-preserving) spread of wages and/or prices will lead to an increase in $E\left\{p_{t^{\prime}} \cdot \frac{\partial y_{t}}{\partial k_{t}}\left(\frac{w_{t^{\prime}}}{p_{t^{\prime}}}\right)\right\}$ as well. ${ }^{6}$ This implies that uncertainty is a stimulus to

${ }^{5}$ This function is increasing in the absolute size of investment, i.e. both investment and disinvestment are costly for the firm because the adjustment cost function is convex and has a minimum at zero for zero gross investment only.

${ }^{6}$ Jenson's inequality says that if $p_{t}$ is a random variable and $f\left(p_{t}\right)$ is a convex function, then $\mathbb{E}\left\{f\left(p_{t}\right)\right\}>f\left\{\mathbb{E}\left(p_{t}\right)\right\}$. For example, if $f\left(p_{t}\right)$ is the square of the price, and this price is distributed as $[1,3]$ at time $t$, but at time $t^{\prime}$ it has a larger spread such as $[-1,5]$, then 
investment, if the marginal revenue product of capital is convex in wages and prices.

While the Hartman (1972) model regards prices as random variables and therefore unknown at all times, Abel (1983) considers only future prices to be unknown; everything that has already occurred or is occurring is known with certainty. For the rest, Abel's (1983) assumptions coincide with those of Hartman (1972): the firm under consideration is competitive, risk neutral, maximizes profits under price uncertainty and produces under constant returns to scale. His results show that investment is a linear and increasing function of the marginal revenue product of capital, where the latter rises as the variance of the price process increases. In other words, investment is raised by higher price uncertainty, which is in line with the conclusion by Hartman (1972). Again, this only holds if the function to be maximized is convex in the stochastic variable(s). Caballero (1991) shows that the results derived by Hartman (1972) and Abel (1983) depend crucially on the assumptions of perfect competition and constant returns to scale.

The model by Nickell (1978) is similar to those by Hartman (1972) and Abel (1983). However, it also acknowledges that risk neutral behavior might not be the standard among firms and that risk aversion may possibly turn the effects of uncertainty on investment negative. Nickell (1978) incorporates risk averse behavior by maximizing a value function of profits rather than profits as such. In his model the value of the firm is equal to the present value of the expected value of profits less the variance and covariance of cash flows. In other words, uncertainty is actively valued in the objective function now. He uses his new objective function and applies it to the Hartman (1972) model to derive a comparable optimality condition. The results show that, for risk averse firms, the rate of investment is lower than for risk neutral firms. Therefore, under particular circumstances, the effect of uncertainty on investment might be negative instead of positive when assuming that investors are averse to risk.

The following section will describe in more detail, which tools have been developed so far and how they have been applied to the specific case of the electricity sector. While large-scale energy assessment models have typically relied on linearprogramming models (see Appendix A), smaller (partial equilibrium) models adopting tools from finance have proven very useful to analyze the effects of uncertainty, especially in combination with issues of irreversibility.

\subsection{Real Options Theory}

The special features of the electricity sector (uncertainty, irreversibility and the flexibility to postpone investments) make standard investment rules relying on the Net Present Value (NPV) inappropriate because they treat investment opportunities as "once-and-for-all" chances and therefore ignore the options involved in the sequence of decisions. As an example, Pindyck (1993) presents a case where an investment of $\$ 1$ is required at first, after which there is a probability of $50 \%$ that the project will be finished successfully. However, there is also a $50 \%$ chance that another investment of

$f\left(\mathbb{E}\left\{p_{t}\right\}\right)=4$ and $\mathbb{E}\left\{f\left(p_{t}\right)\right\}=10 / 2=5$. And $f\left(\mathbb{E}\left\{p_{t}^{\prime}\right\}\right)=4$ still, but $\mathbb{E}\left\{f\left(p_{t}^{\prime}\right)\right\}=26 / 2=13$. 
$\$ 4$ will be necessary to complete the project. The completed project will have a certain payoff of $\$ 2.8$, so with an expected cost of $\$ 3$ the NPV is negative and the traditional NPV rule would advise not to invest. More precisely though, the investor would take into account that he has the option to abandon the project after phase one and so the NPV adjusted for the option value is $50 \% \cdot(\$ 2.8)-\$ 1=\$ 0.4$, which is greater than zero, so at least the first phase should be undertaken. The option value can then be calculated as the difference between the traditional and the adjusted NPV. According to Pindyck (1993) this reasoning can be used to explain the fact that so many new nuclear power plants close to completion were canceled in the United States in late 1982, a time during which there was much uncertainty about construction costs, which had started to rise considerably after some projects had already been launched. ${ }^{7}$ It is important to note that the term "option" in this context should not be understood as a synonym for choice or alternative. An option as it is meant here is the right, but not an obligation, to realize an investment opportunity.

A very simple, graphical example illustrates this very clearly. In Figure 2.3 an investment option that can be exercised at time zero will deliver a profit of $\pi$ immediately. However, at time $t^{\prime}$ two different scenarios are possible and only at time $t^{\prime}$ the uncertainty will be resolved, which of the two will materialize. In one case the profits rise to $\pi^{\prime}$, in the other case there will be a loss of $\pi^{\prime \prime}$. Thus, by postponing investment, the investor might forgo the striped area of immediate profit flows, but can at the same time avoid the loss represented by the dotted area. As long as the latter exceeds the first, i.e. the gains from waiting exceed the opportunity costs of not investing, waiting will be optimal.

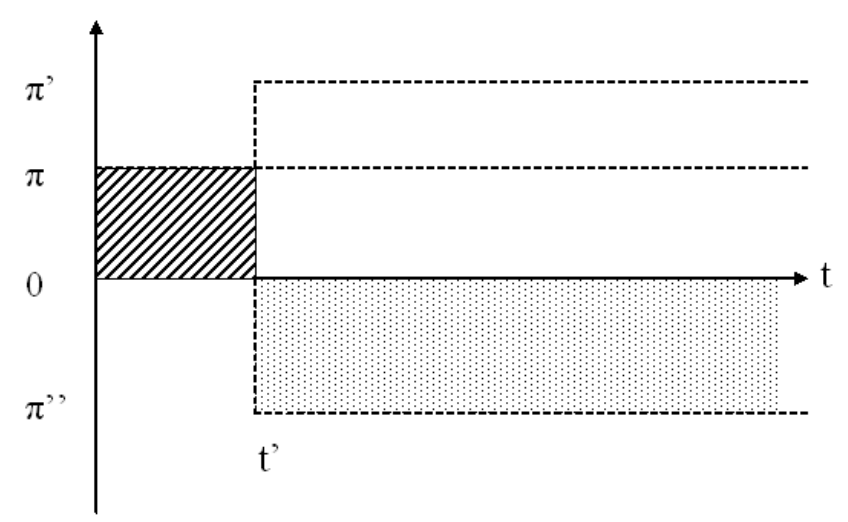

Source: adapted from Blyth (2007).

Figure 2.1: Graphical Example of the Option Value

\footnotetext{
${ }^{7}$ Of course, uncertainty pervades the decisions of most investors. However, the interaction with large sunk cost and the flexibility to time investments differently combined with the large extent of the uncertainties surrounding investment in power generating equipment, makes the electricity sector a particularly interesting area of application for real options models.
} 


\subsubsection{Methodology and Terminology}

The electricity sector exhibits a number of special features as explained in Chapter 1. These include the relative irreversibility of investments, the flexibility of timing investments $^{8}$ and the uncertainty surrounding the decisions to install power plant equipment. These characteristics make the standard NPV rule for investing inappropriate, as will be shown in this section. Real options theory provides a framework, in which investment under uncertainty can be investigated when irreversibility and flexibility with respect to the timing of sequential decisions are involved. This section describes the basic ideas and methodology, ${ }^{9}$ reviews some of the existing literature on real options theory and the applications to the electricity sector, and gives a preview on how we want to use these principles for our purposes.

Originally developed for valuing financial options in 1970s (e.g. Black and Scholes, 1973), economists soon realized that option pricing also provided considerable insight into decision-making concerning capital investment. Hence the term "real" options. Early frameworks were developed by McDonald and Siegel (1986), Pindyck (1988, 1991, 1993), and Dixit and Pindyck (1994). ${ }^{10}$

The basic idea is that standard investment theory relying on NPV calculations generally do not take into account the interaction between three important characteristics of numerous investment decisions: the irreversibility of most investments, which implies that a substantial portion of the total investment cost is sunk, the uncertainty surrounding the future cash flows from the investment, which can be affected by e.g. the volatility of output and input prices, and the opportunity of timing the investment flexibly. ${ }^{11}$ Regarding the opportunity to defer an investment as an option means that we can assign a value to waiting. In other words, investors gain more information about the uncertainty that surrounds economic decisions as time passes by, as in the example in Figure 2.3, where the investor learns about the level of profits only in period $t^{\prime}$. Therefore, staying flexible by postponing decisions has an option value if the degree of uncertainty faced is big enough. This value increases if the sunk cost that has to be incurred to launch the project is high, but also in times of larger uncertainty associated with future cost or revenues. In this case it pays off to wait and see how the conditions have changed, especially if they are expected to be rather stable afterwards.

In order to demonstrate the principles of the approach, first consider an investor, who can postpone the decision to invest. Furthermore, the value of the investment

\footnotetext{
${ }^{8}$ By flexibility we mean the possibility to postpone investment or to bring it forward in time.

${ }^{9}$ This part draws heavily on Dixit and Pindyck (1994), McDonald and Siegel (1986) and the survey by Carruth et al (2000).

${ }^{10}$ For a comprehensive treatment and overview of both financial and real options theory see Trigeorgis (1996). More advanced and with several applications is Schwartz and Trigeorgis (2001).

${ }^{11}$ It is the interaction between those characteristics that matters because only the combination of these factors creates an option value: if the investment was not irreversible, uncertainty would not represent such a big problem for the investor, since he could easily adjust the capital stock at low cost. Also, if there was no uncertainty, the ability to postpone investment would not be worth much. Vice versa, if the investor was not flexible, waiting would not be a way to overcome (some of this) uncertainty.
} 
is uncertain, and once committed, the cost of the investment cannot be recovered anymore. This implies that the investor can possibly gain by waiting until some of this uncertainty is resolved. In other words, there is a "wedge" between the standard NPV of a project - i.e. the value of the project considering the investment as a "onceand-for-all" opportunity - and the current value of the project to the investor taking into account the possibility of deferring the investment to a later point in time. If $V$ is the present value (PV) of the project to be undertaken and $C$ is the cost of the investment to be made, then the traditional NPV rule indicates that investment should only be conducted if $V \geq C$. However, if $V$ evolves stochastically, the true current value of the project will most likely be higher, since we also have to value the option to postpone the investment. Suppose $V$ follows a geometric Brownian motion, ${ }^{12}$ where $d V$ is the change in $V, \mu^{13}$ is a drift parameter, $\sigma$ is the volatility parameter and $d w$ the increment of a Wiener process. ${ }^{14}$

$$
d V=\mu V d t+\sigma V d w \quad d w=\epsilon_{t} \sqrt{d t}, \epsilon_{t} \sim N(0,1), E\left(\epsilon_{i} \epsilon_{j}\right)=0 \quad \forall i, j \quad i \neq j
$$

The expected $P V$ of the option to invest shall now be maximized. Following Pindyck (1991), we denote the option value by a function $F(V)$ :

$$
F(V)=\max _{t} E\left\{e^{r \cdot t} \cdot(V-C)\right\}
$$

where we omit to denote the dependence of $V$ on $t$ for simplicity. $t$ has to be chosen so as to maximize the expected value of the project. ${ }^{15} r$ is the discount rate. The expected return from postponing investment is $\frac{E\{d F(V)\}}{d t}$, which has to be equal to the opportunity cost (i.e. the interest that could be earned on $F(V)$, which is received upon investment, in the meantime) of postponing. This leads us to the following arbitrage equation. ${ }^{16}$

$$
\frac{E\{d F(V)\}}{d t}-r \cdot F(V)=0
$$

Intuitively, you could explain Equation (2.3.3) by the fact that it equates the marginal costs of waiting with the marginal benefits of doing so. In other words, the investor

\footnotetext{
${ }^{12}$ This process is simply the exponential of a Brownian motion with drift and was initially suggested by Black and Scholes (1973) and Merton (1973b) as a response to the weakness of the standard Brownian motion with drift to also assume negative values (since it is a Gaussian process after all), which is not a realistic property for modeling price behavior, which is what we intend to use this approach for.

${ }^{13}$ Pindyck (1991) splits $\mu$ up into the sum of the dividend rate and the expected capital gain. For our illustrative purposes, this more simplistic presentation is completely sufficient.

${ }^{14}$ See e.g. Mikosch (1999) for a comprehensible introduction into stochastic calculus and in particular the first three chapters for stochastic processes, the Itô Lemma and Itô stochastic differential equations, respectively. Another excellent treatment of stochastic differential equations is by Øksendahl (2003).

${ }^{15}$ Alternatively, the control could be a variable denoting e.g. a particular decision such as "invest the full amount of available funds", "do not invest at all", "invest first in R\&D and only in case of success into a new plant", etc.

${ }^{16}$ Dixit and Pindyck (1994) amongst others call this the Bellman equation because they use the so-called principle of optimality found by Bellman to derive it. In general, the Maximum Principle can also be used instead of dynamic programming. However, the Maximum Principle approach is much more suited for problems in continuous time and without uncertainty and less so for the situations that we want to explore in this chapter (Dixit, 1990).
} 
can earn $F(V)$ upon immediate investment and earn interest on that amount, but if investment is postponed these gains are foregone. These opportunity costs therefore have to be equal to the gains from waiting, which accrue from changes in $F(V)-$ a sort of "appreciation" of the underlying asset. Since we need to differentiate $F(V)$ to find the solution, we make use of Itô's Lemma (see Mikosch (1999), page 115).

$$
d F(V)=F^{\prime}(V) d V+\frac{1}{2} \cdot F^{\prime \prime}(V)(d V)^{2}
$$

Now we substitute the expression for $d V$ from Equation (2.3.1) into Equation (2.3.4) and take expectations. It is important to note that $E(d z)=0$ by definition of the process (see above), so the terms related to $d z$ drop out. This delivers

$$
E\{d F(V)\}=\mu \cdot V \cdot F^{\prime}(V) d t+\frac{1}{2} \cdot \sigma^{2} \cdot V^{2} \cdot F^{\prime \prime}(V) d t
$$

Substituting (2.3.5) into Equation (2.3.3) gives

$$
\left[\mu \cdot V \cdot F^{\prime}(V)+\frac{1}{2} \cdot \sigma^{2} \cdot V^{2} \cdot F^{\prime \prime}(V)\right]-r \cdot F(V)=0
$$

The corresponding boundary conditions can be found in Equation (2.3.7), where a tilde denotes the value of a variable at the optimum. The first condition conveys that the option value will be zero, if the project has a value of $V=0$. The second one requires $F(V)$ to be smooth and continuous around the optimum point, which only applies if the increase in $F$ at $\tilde{V}$ is equal to the increase in $V$ at its optimum, i.e. if the slopes are equal. Since the derivative of $V$ with respect to $\tilde{V}$ is 1 at this point, $F^{\prime}(\tilde{V})$ has to be equal to 1 as well. This condition is also widely known as the "smooth-pasting" condition (Dixit and Pindyck, 1994). Appendix B explains how Dixit and Pindyck (1994) show that the value-matching and smooth-pasting conditions indeed need to hold at the optimum point. Finally, at this optimum point, the payoff, $V$, net of the cost, $C$, will be equal to the option value, $F(V)$. This is best illustrated graphically, as in Figure 2.2.

$$
\begin{aligned}
F(0) & =0 \\
F(\tilde{V}) & =\tilde{V}-C \\
F^{\prime}(\tilde{V}) & =1
\end{aligned}
$$

For this problem, we are able to solve Equation (2.3.6) subject to the constraints in 2.3.7. ${ }^{17}$ We do so by following Pindyck (1991), who guesses a functional form and determines by substitution ex post. In this case, bringing $r \cdot F(V)$ to the right and dividing by $r$, we see that the solution to Equation (2.3.6), which satisfies the first

\footnotetext{
${ }^{17}$ To solve more complicated versions of the Bellman equation, such as typically the sum of the expected value of immediate profits and the continuation value of a project, sophisticated computing methods are needed. The approach via partial differential equations may not always be the most efficient or even possible way to deal with this. Therefore, dynamic programming is often combined with Monte Carlo simulation techniques or multinomial decision trees in order to find the most efficient and flexible solution algorithm.
} 
boundary condition, can be expressed as $V$ with an unknown exponent and multiplied by a constant factor:

$$
F(V)=a \cdot V^{\beta}
$$

where $a$ can be derived by substituting Equation (2.3.8) into boundary condition number 2 in (2.3.7). $a$ is therefore equal to $\frac{\tilde{V}-C}{\tilde{V}^{\beta}}$. Similarly, $\tilde{V}$ is the result of plugging the first derivative of $F(V)$ in Equation (2.3.8) into the smooth pasting condition. ${ }^{18}$

$$
\tilde{V}=\frac{\beta}{\beta-1} \cdot C .
$$

$\beta$ is composed of the parameters as follows. ${ }^{19}$ Note that it will always be larger than 1 because $0 \leq \mu \leq 1$ and $0 \leq \sigma \leq 1$.

$$
\beta=\frac{1}{2}-\frac{\mu}{\sigma^{2}}+\sqrt{\left(\frac{\mu}{\sigma^{2}}-\frac{1}{2}\right)^{2}+2 \cdot \frac{r}{\sigma^{2}}}
$$

In order to illustrate the difference between the standard NPV rule and the real options rule again, remember that we realized that there is a wedge driven between the NPV and the "true" current value of the project by the existence of uncertainty and the flexibility of timing the investment differently. Looking back at the boundary conditions in Equation (2.3.7) we have derived Equation (2.3.9). If we were following the standard NPV rule, then this equation would be $\tilde{V}=C,{ }^{20}$ so the wedge we were referring to earlier is exactly defined as $\frac{\beta}{\beta-1}$, which will always be greater than 1 . Therefore, we can conclude that under uncertainty the value of the project at the exercise date must exceed the mere cost of the investment. Furthermore, an increase in uncertainty, proxied by an increase in $\sigma$ will actually raise the wedge and, other things equal, lead to a postponement of investment because there is more to gain by waiting longer.

To illustrate the principles presented graphically, consider Figure 2.2, where the value of the project increases with time (maybe due to rising output prices). The option value, denoted by $F(V(t))$, starts out at zero because it can never be negative, as the investor can always choose not to exercise the option, i.e. $F(V(t))=0$. In contrast, the standard NPV can very well be negative, as long as the cost of exercising the option, $C$, exceeds the current value of the project, $V(t)$. Investment under the standard NPV rule therefore occurs where $(V(t)-C)$ crosses the x-axis, i.e. where $V(t)=C$. The option value $F(V(t))$, however, is higher than the simple NPV, since the wedge $\frac{\beta}{\beta-1}$ exceeds 1 as explained above, i.e. $\tilde{V}>C$ (see Equation (2.3.9)). The optimal exercise time therefore is at the point where the $F(V(t))$-curve crosses the $(V(t)-C)$-schedule, which is much later than the optimal point in time when

$18 \frac{\tilde{V}-C}{\tilde{V}^{\beta}} \cdot \tilde{V}^{\beta-1}=\frac{1}{\beta} \Leftrightarrow \frac{\tilde{V}-C}{\tilde{V}}=\frac{1}{\beta}$.

${ }^{19}$ It is derived by plugging Equation (2.3.8) into Equation (2.3.6). After canceling out, the quadratic equation $\frac{\sigma^{2}}{2} \cdot \beta \cdot(\beta-1)+\beta \cdot \mu-r=0$ remains. This actually delivers two solutions: $\beta=\frac{1}{2}-\frac{\mu}{\sigma^{2}}+\sqrt{\left(\frac{\mu}{\sigma^{2}}-\frac{1}{2}\right)^{2}+2 \cdot \frac{r}{\sigma^{2}}}$ and $\beta=\frac{1}{2}-\frac{\mu}{\sigma^{2}}-\sqrt{\left(\frac{\mu}{\sigma^{2}}-\frac{1}{2}\right)^{2}+2 \cdot \frac{r}{\sigma^{2}}}$. However, due to our conditions, the second solution can be excluded, since it would imply that $\beta<0$.

${ }^{20}$ This is the point at which it becomes profitable to invest; any $\tilde{V} \geq C$ also qualifies for investment, of course. 
the NPV rule is applied. More precisely, what can be gained from waiting can be measured as the vertical difference between $F(V(t))$ and $(V(t)-C)$ : at the point where $(V(t)-C)$ crosses the x-axis, $F(V(t))>(V(t)-C)$, so the benefits of waiting are larger than zero. As $(V(t)-C)$ continues to rise, however, these benefits diminish and it is optimal to invest when $F(V(t))=(V(t)-C)$.

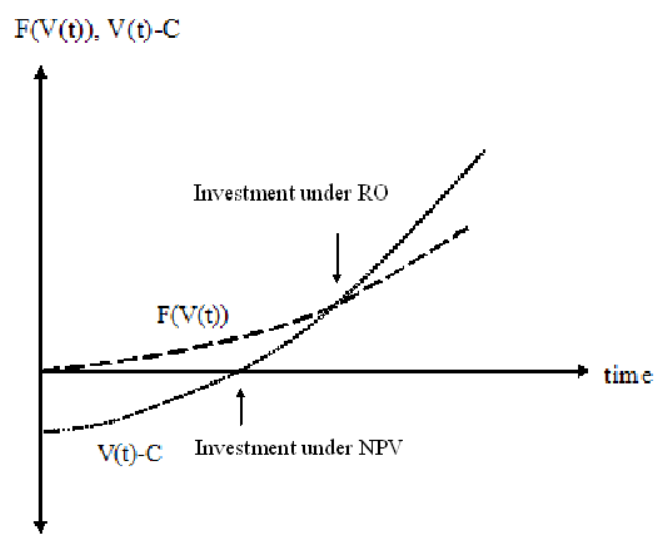

The optimal exercise time occurs later with an option value rule than with a standard NPV criterion.

Figure 2.2: Option Value versus Standard NPV

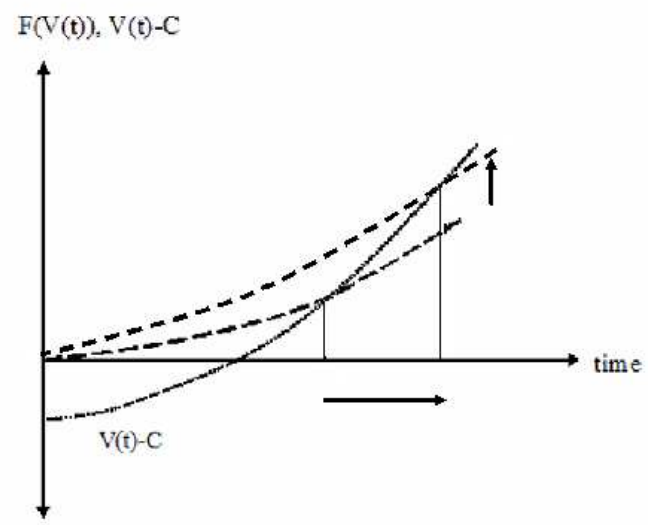

Figure 2.3: More Uncertainty Makes the $F(V(t))$-Schedule Rotate Upwards.

An increase in uncertainty rotates the $F(V(t))$-curve upwards, since the option to wait gets more valuable by Equation (2.3.9), where $\frac{\beta}{\beta-1}$ will increase in response to 
a higher $\sigma$ (see Equation (2.3.10)). As a consequence, the investment date is shifted farther into the future as indicated by the arrow in Figure 2.3.

Real options theory has been applied in a vast number of fields, such as the valuation of exploration projects of natural resources like e.g. oil (Diaz, 2004), the weighing of irreversibilities in natural damages versus the irreversibilities involved in committing resources to mitigation efforts (Kolstad, 1996a, 1996b, Ulph and Ulph, 1997), and the planning of infrastructure (Garvin and Cheah, 2004). In this thesis, however, we are primarily concerned with the use of real options methods for electricity planning.

\subsubsection{The Early Literature}

Options pricing had originally been developed to value financial options in the 1970s (Black and Scholes, 1973, and Merton, 1973). Already at that time, economists realized that the irreversibility involved in many economic decisions concerning investment also creates an option value for non-financial assets. Arrow and Fisher (1974) incorporate irreversibility and uncertainty into a model where decisions about environmental preservation need to be made (the irreversibility is then associated with pollution that cannot be cleaned up ex post, with the loss of a form of life or the destruction of a unique geomorphological phenomenon). They conclude that

[...] the expected benefits of an irreversible decision should be adjusted to reflect the loss of options it entails (Arrow and Fisher, 1974).

Likewise, Henry (1974) investigates what he calls the "irreversibility effect", by which he means that decisions that previously appeared to be economical become unattractive when irreversibility is taken into account. Furthermore, he finds that the irreversibility effect is enhanced by an increase in uncertainty.

Later models in which financial option pricing was deliberately adapted to the valuation of "real" assets can be found in Pindyck (1980), Brennan and Schwartz (1985), McDonald and Siegel (1986), Majd and Pindyck (1987) and many others. McDonald and Siegel (1986) propose a model in which the investor has to commit resources for a project with value $V$. The investment decision is irreversible, so the cost of the project $I$ is sunk. Both the value of the project and the investment costs are stochastic variables growing in time. When the ratio of the two variables reaches a critical level $(\tilde{V / I})$, the opportunity cost of committing resources has shrunk to zero and it is optimal to exercise the option, i.e. to invest. In a similar vein, Majd and Pindyck (1987) develop a model in which sequential investments can be analyzed. The option to abandon the project midstream can be considered in the same way as the example by Pindyck (1993) described above. Again, the value of the project after completion follows a stochastic process. More specifically, it is the cost that makes this value stochastic.

Brennan and Schwartz (1985) investigate whether and when it is optimal to take a copper mine into operation when the price of copper follows a stochastic process. Similarly, Pindyck (1980) uses real options to compute the optimal exploitation strategy for an exhaustible resource, but in this case it is not only the future cash flow, but 
also the level of the resource reserve that can vary stochastically. The applications to resource extraction projects have been vast in real options theory. Many authors have focussed on the oil business, where considerable investment outlays for exploration and the building of platforms have to be made. The earliest reference that can be found in this specific area goes back as far as 1979, when a PhD student by the name Tourinho wrote his dissertation "The Valuation of Reserves of Natural Resources: An Option Pricing Approach" (see e.g. Slade, 2001 or Armstrong et al, 2004). Even though the extractive sector had long known that standard NPV analysis systematically undervalues mineral properties, it was only from then on that a multitude of real options valuations for specific projects in natural resource extraction started to arise. One of the many examples that have been analyzed is the valuation of the option to temporarily close down a mine if output prices plunge into an unexpected trough or to abandon a mine altogether (as e.g. Brennan and Schwartz (1985), see above). Most applications have been made in the oil sector, of course. Paddock et al (1988), for example, focus on undeveloped oil reserves and find that, empirically, the real options valuation performs better than the traditional discounted cash flow (DCF) method.

Other important contributions are by Pindyck (1988) and Pindyck (1991), where the latter also gives a very good overview of the literature on irreversible investment at that time. The former adds to the literature mentioned above (e.g. Majd and Pindyck, 1987, Brennan and Schwartz, 1985, etc) by not only considering a discrete project that can be invested into or not, but also the possibility to invest into smaller factories and expand later on. In other words, Pindyck (1988) focusses on the incremental investment decision rather than on a complete investment plan. The value of the marginal unit of a unit of capacity includes the value of the option to leave that unit idle. The full value of the marginal unit must be equal to its full cost. The full cost is composed of all costs related to purchase and installation and the option to invest, i.e. the opportunity cost of exercising the investment option. An important finding is that (demand) uncertainty has two effects: on the one hand, it increases the value of a unit of capacity. On the other hand, it increases the value of the firm's investment options, since irreversible investment becomes more costly in terms of the opportunity cost of exercising that option. The latter effect is much larger than the former, which is why the firm's optimal capacity is reduced in the face of uncertainty. The option to expand existing capacity later on are called "growth options" by Pindyck (1988). With the help of some numerical simulations, he finds that these growth options are very valuable assets for the firm and that it is therefore important to account for them adequately. However, considering only one source of uncertainty (about demand) and making the strong assumption that all investment is incremental (while it is actually lumpy in many sectors) makes this study more of an illustrative than an applicable character for our purposes, although useful theoretical insights can be gained from the analysis. 


\subsubsection{More Recent Frameworks}

\section{Revenue and Technological Uncertainty}

While much of the work from the 1980s focussed on uncertainty about the value of a project or a firm, where the timing of sunk costs of known magnitude was optimized, the 1990s brought more elaborate frameworks, where the investment cost itself could be uncertain and where distinctions between different types of uncertainty became possible.

The paper by Pindyck (1993) already mentioned above, for example, acknowledges the fact that for large projects or projects that require initial R\&D phases, investment cost uncertainty might play a larger role than the value upon completion. Also, for projects that take time to complete, there are considerable uncertainties connected to the actual cost and construction time. ${ }^{21}$ He therefore makes a distinction between technical uncertainty, which applies when investment takes place, and input cost uncertainty, which matters even if there is no new investment, and allows for the opportunity to abandon the project midstream. Input costs comprise the cost of materials and labor, which can fluctuate regardless of the investment rate. The investment rule that he derives tells the investor to invest only if the expected total cost falls below a critical value. He then determines then how this critical value is influenced by the different types of uncertainty. He finds that technical uncertainty has a positive effect on the critical cost level, i.e. it becomes profitable to invest already at a relatively high cost level. Technical uncertainty and investment are therefore positively related. Numerical results ${ }^{22}$ show, however, that this effect is moderate and that a substantial increase in uncertainty would be needed to significantly raise the critical cost level. For input cost uncertainty, no analytical solution can be found at all. The numerical results reveal that even for low values of input cost uncertainty, the critical cost is reduced enormously, i.e. costs need to be very low in order for investment to be triggered. ${ }^{23}$ Input cost uncertainty and investment are therefore negatively related.

The intuition behind these results is that technical uncertainty always conveys the possibility that the actual cost to completion might become low enough to make the investment profitable. ${ }^{24}$ Furthermore, the truth about these costs will only be revealed if investment takes place. This, combined with the option to abandon the project when the cost turns out to evolve unfavorably leads to a higher critical cost and therefore earlier investment, i.e. investment is triggered already at a relatively high cost level. Input cost uncertainty will hit the investor regardless if the investment is carried on and therefore has a much more profound effect. In this thesis, we find similar results for the effects of input cost uncertainty, but the concern with technical

\footnotetext{
${ }^{21}$ An example could be an unforeseen circumstance that requires additional expenses for exploration or R\&D midstream.

${ }^{22}$ An analytical solution can only be found in the special case where the interest rate is zero.

${ }^{23}$ If the correlation with the market is taken into account, this effect is even enhanced, i.e. investment is further depressed.

${ }^{24}$ Even though not modeled here in this way, the cost might become so low as a result of technical change. This is the topic of Chapter 4 .
} 
uncertainty is different from Pindyck's (1993). What we want to focus on is not so much the (adverse) developments that might occur during construction and how they can affect total completion cost, but more the uncertainty that emanates from the process of technical change. Since the electricity sector is marked by an overwhelming influence of fossil-fuel-based electricity generating equipment, of which a major part has already reached technological maturity, it is interesting to explore if the promising, but uncertain progress of new technologies based on renewable energy carriers can make a difference for total future electricity provision.

Another study that includes uncertainty about technology into a real options model is by Farzin et al (1998). They extend the basic model presented in Dixit and Pindyck (1994) to include technical change. More specifically, producers generate a homogenous good, for which there is a technology parameter that follows a jump process. That implies that technological progress itself is uncertain, but also the size of the jump will be unknown. In other words, the speed of improvement and also the degree to which the new technology outperforms the old one are both uncertain. In a numerical example they compare their new investment criterion (the critical value of the technology parameter) with the NPV criterion. The result is that the former leads to slower technology adoption than the latter. Contrary to Pindyck (1993), they therefore find a negative relationship between investment and uncertainty and argue that this result is due to the fact that the option value of waiting increases with uncertainty. When Farzin et al (1998) extend this result for multiple switches between technologies, they find that this does not hold anymore: the standard NPV rule suddenly coincides with the one adjusted for the option value. However, this finding is only due to a mistake in their calculations as has also been pointed out by Doraszelski (2004) in detail.

Farzin et al (1998) provide a simple and therefore straightforward treatment of technical change in a real options setting that comes closer to our endeavors than Pindyck (1993) and even though we are not so much interested in the effect of the different components (rate of progress versus magnitude of changes) of technical progress, the model delivers useful theoretical insights for economic decision-making and provides a benchmark real options model that we can compare the results obtained with our new framework in Chapter 6 to. In particular, the real options model cannot take into account that less uncertainty may also depress investment by making waiting for more certain technical improvements more profitable - a feature which we are able to integrate in the new model developed in Chapter 6.

Other studies that focus exclusively on technological uncertainty are by Balcer and Lippman (1984), an older paper which is similar to Farzin et al (1998), and Grenadier and Weiss (1997). The latter do not only consider stochastic innovations, but investors that adopt new technologies in their model also become able to benefit more from future innovations, which can be regarded as a learning effect. Their results show that an increase in volatility has the effect of delaying investment, which is in line with the findings of Farzin et al (1998) and also Balcer and Lippman (1984) (and also our conclusions in Chapter 4).

Approaching the issue of technological change a bit differently, Kumbaroğlu et al 
(2004) include learning curves for renewable energy into their real options framework. They find that for Turkey the diffusion of renewable energy technologies will only occur if policies are directed to that cause because these technologies still suffer from high capital cost. On the other hand, active promotion of green technologies will accelerate learning and result in a higher extent of adoption of these technologies than initially because the decrease in costs will occur faster. By acknowledging the fact that the flexibility to delay investments can significantly influence the diffusion of renewable technologies and at the same time incorporating price uncertainty, they provide a very rich model. However, their treatment of uncertainty is confined to uncertainty about fuel and electricity prices only. The inclusion of the learning curves as a proxy for future rates of technological improvements remains deterministic.

Madlener et al (2005) develop a model, where uncertainty pertains to fluctuations in demand, peak load capacity, generation costs and the price of electricity. In particular, they model the expected value of these items as discrete stochastic processes and use a dynamic programming approach. Their results are based on data for the Turkish electricity sector, where a significant amount of gas-fired capacity has been installed lately, which the authors find to be a suboptimal choice because coal prices are much less volatile than gas prices in Turkey.

A recent paper by Murto (2007) wants to bridge the gap between what he calls "revenue uncertainty" (with McDonald and Siegel, 1986, Pindyck, 1988, and many more in this category) and "technological uncertainty" (with Grenadier and Weiss, 1997, and Farzin et al, 1998, in this category). He models the revenue stream as a geometric Brownian motion and innovations arrive according to a Poisson process. Innovations reduce the cost of investment, so the investor has to decide whether the investment cost is low enough and the revenue is high enough to exercise the option to invest, i.e. he solves the optimal stopping problem, where stopping refers to exercising the option (i.e. to stop holding it), arising from this setup. His results show that technological uncertainty itself does not matter decisively for the timing of investment. It only has an impact in combination with revenue uncertainty, i.e. when revenue streams are certain, technological uncertainty has no impact. The combined effect is to postpone investment. Murto (2007) shows that this has to do with the fact that in his model it is not the uncertainty, but technological progress itself that affects the optimal investment threshold. Only when revenue uncertainty is included, does technological uncertainty come into play therefore. In this thesis the treatment of technological change is similar. However, revenues are not assumed to rise necessarily. On the contrary, technologically mature, fossil-fuel-fired plants will eventually becomes less profitable due to increasing fuel costs while renewables enjoy more improvement in investment cost due to technical change and have therefore mostly rising revenues. We find that fuel price uncertainty is not a necessary condition for technological uncertainty to have an effect. However, we can confirm that the effect is a postponement of investment also in our real options model in Chapter 4. 


\section{Environmental Uncertainty}

Another area where real options theory has been applied, is the valuation of "environmental assets". These assets include inland waters and oceans, land, forests, species, the ozone layer and last but not least the atmosphere. The idea behind using real options frameworks for decisions concerning environmental assets is that damage to them will mostly be characterized by irreversibility. In the context of global warming, often cited irreversible damages are the potential shutdown of the thermohaline circulation, rise in sea levels as glaciers and the Antarctic melt, unforeseeable changes in weather and wind patterns, and so forth. The uncertainty surrounding these potential effects is magnified by the lack of knowledge of the thresholds, beyond which these scenarios become possible. Another complication is the long time horizon we have to look at and the time lags, with which actions take effect.

Arrow and Fisher (1974) and Henry (1974) have already been mentioned as pioneers in this area. In their case the irreversibility is due to the impossibility of cleaning up pollution. More recent applications are Ulph and Ulph (1997), Kolstad (1996a, 1996b) and Pindyck (2000). The first two derive conditions under which an option value associated with environmental preservation exists. Kolstad (1996a, 1996b) does not only consider irreversibility in terms of accumulated emissions, but also in terms of the sunk cost character of investment into abatement capital. He looks at what he calls "quasi-option value" in accordance with Hanemann (1989). That is the value that we can assign to the option to wait if our actions today could possibly constrain our opportunities tomorrow. In other words, if the accumulated emissions could compromise the utility in the future, then emitting today reduces the opportunities tomorrow. All, Arrow and Fisher (1974), Henry (1974) and Ulph and Ulph (1997) only consider environmental irreversibility and find that it always leads to a decision in favor of the environment. Kolstad (1996a) adds capital irreversibility and acknowledges the fact that the importance of irreversibility might be influenced by the rates of learning and capital depreciation. In a dynamic two-period model, where learning about the true value of a random parameter occurs between the two periods, he proves that only if the extent to which investors are uncertain and the rate of learning are such that negative emission rates would be optimal in the second period (i.e. such that the stock of emissions should be reduced from a utility point of view), then there is an irreversibility effect demanding preservative action in the first period. As regards the irreversibility of capital, there will be none unless the rate of depreciation is sufficiently large enough compared to the rate of learning.

While this area of tackling environmental uncertainty is definitely not exhausted research-wise, as more and more uncertainties about the behavior of the environmental system are resolved, the focus of this thesis is on the irreversibility arising in the context of investment or what Kolstad (1996a, 1996b) calls capital irreversibility. We are interested in the uncertainties that the investor faces and how it results in different patterns of investment because the power plants that are installed now are going to be the source of electricity for the next few decades to come. By continuously running these plants to fill the growing demand of industrialized (and even more so developing) 
countries, the trend in emissions will be predetermined through today's investment decisions. However, as will be seen in the following section, environmental uncertainty has an impact on the investor as well, namely by making the actions of policy-makers that have to cope with insufficient information uncertain as well.

\section{Policy Uncertainty}

As has been mentioned in the previous section, it is inherently uncertain how exactly the environment responds to the GHG emissions that increasingly accumulate in the atmosphere. While there is a growing body of evidence providing support that global warming is occurring and that the anthropogenic fraction of GHG emissions accelerates the rate at which this is happening, there is still disagreement about the exact extent of the damages associated with this process, the speed of the warming and the behavior of the system with respect to abatement measures. Although even the environmental awareness of the public has recently been stirred by Fourth Assessment Report (IPCC, 2007) again, lobbying of interest groups against $\mathrm{CO}_{2}$ policies is continuing. All this creates a more than difficult position for the policy maker, who is not an expert in the science of global warming and climate change. With a flood of more and less useful information and impressions from the media and counselors, it is difficult to form a clear opinion and to distill the right signs for policy action. Further down in the causal chain, investors in the electricity sector can therefore not be sure about how the government will behave in the future and how that might effectively reshape the business environment and the investment situation. Will the government join a post-Kyoto carbon agreement? If not, it would not be wise to invest into expensive, relatively carbon-free technology today that might be a stranded investment tomorrow. On the other hand, if the government turns out to follow a stricter, "green" policy stance than previously assumed, higher carbon prices will punish those that have invested into more carbon-emitting equipment.

This type of uncertainty is less "predictable" in the sense that policy, such as the level or trend of the $\mathrm{CO}_{2}$ price, could change quite drastically at some point in time. Modeling uncertainty by letting the price follow a stochastic process is not sufficient to account for such a large extent of uncertainty. In Chapter 3 an analysis is presented that investigates the effects of such more profound uncertainty on the investment decision. We think that this type of problem is not analyzed sufficiently in the field of real options modeling for investment in the electricity sector. An exception is by Reedman et al (2006). They look at the Australian electricity sector and try to find out whether the timing of introducing a $\mathrm{CO}_{2}$ tax has an effect on the investment decision concerning the addition of carbon capture facilities to existing plants emitting $\mathrm{CO}_{2}$. However, the only source of uncertainty in this setup comes from assuming that a constant carbon tax will be imposed with a $10 \%$ probability within the next ten years. The framework that is developed in Chapter 3 is much more complex, acknowledging the fact that carbon penalties - once introduced - are likely to increase over time. Also, permit trading and other processes will lead the $\mathrm{CO}_{2}$ price to rise stochastically. Furthermore, in our opinion, the timing of enacting the $\mathrm{CO}_{2}$ tax should not be the 
major source of uncertainty, since the dates of new negotiation rounds and policy agendas are publicly known (the next date being 2012). We think that uncertainty about the policy outcome itself is the main impact on investors in the electricity sector.

De Jong et al (2004) propose that the real options approach is a valuable method to analyze how fluctuations in future emissions prices affect investment patterns. In a simple and highly stylized example, they illustrate that if the NPV is adjusted for the options to defer and abandon an investment into a plant emitting less $\mathrm{CO}_{2}$, a more volatile emissions price will always lead to postponement of that investment, whereas we think that a distinction needs to be made between fluctuations around a known trend and uncertainty about the trend itself. Furthermore, we make a distinction between expected and actual fluctuations in the price of $\mathrm{CO}_{2}$, which allows us to make more precise statements about investment responses to uncertainty.

While De Jong et al (2004) present a good illustration of the principles involved, other authors have gone more in depth in modeling this problem. Laurikka (2006) and Laurikka and Koljonen (2006) acknowledge that emissions trading in the European Union will have a significant influence on investors' cost, on the market price of energy and on potential extra revenues coming from trading free emissions permits. In order to capture this in a real options framework and to evaluate the situation of Finland as a case study, they distinguish between three different categories of options: the option to switch between fuels (if the plant is multi-fired), the option to switch outputs (if the plant is a combined heat and power installation), and the option to alter the scale of operation. Comparing a coal-fired and a gas-fired power plant in the Finnish power market, they show that the valuation of the gas-fired plant depends heavily on the assumed price level of emission permits, which is confirmed by our analysis, and the allocation of free permits. In a scenario where the price of permits was relatively high, the option value of investing into the gas-fired plant became positive, while the option value of investing into the coal-fired plant was not affected at all. They conclude that the uncertainty about the EU Emissions allowance Trading Scheme's (ETS) (where allowance effectively means permit) influence on operational costs might well reduce the attractiveness of gas-fired plants. While Laurikka and Koljonen (2006) assume both electricity prices and $\mathrm{CO}_{2}$ permit prices to be mean-reverting processes, we think that a geometric Brownian motion is a much better representation of the $\mathrm{CO}_{2}$ price, since with increasing emissions (see e.g. the predictions in Riahi et al, 2007) and the need to stabilize them at a relatively low level, a continuous rise in the price of $\mathrm{CO}_{2}$ is the only way to achieve this. Also, our analysis comprises an investigation of uncertainty that cannot be represented by fluctuations around a mean (trend), but which is due to indecisiveness about the direction of the price path as well. Moreover, Laurikka and Koljonen (2006) focus very much on the trading scheme, i.e. they also include the impact on cash flows from having free permits allocated to the producers, where the number of these free permits is an uncertain number. In our framework, $\mathrm{CO}_{2}$ prices can be seen as a carbon tax that is progressively adjusted or as the price for a permit that you would have to buy on the carbon market. The number of permits that are freely distributed is therefore not a source of uncertainty in our analysis. 
A similar case study, but then for Japan, is conducted by Kiriyama and Suzuki (2004). They also investigate the uncertainty emanating from potential national emissions trading schemes. In particular, they compare nuclear power, wind power and photovoltaic power, since these types of power plants do not emit carbon dioxide and might thus become feasible earlier than traditionally assumed if emissions are a negative externality valued by the decision-maker. It turns out that nuclear power would be the most profitable alternative. The study differ from our work in various respects, however. In the Kiriyama and Suzuki (2004) framework, the value function explicitly includes the stock of $\mathrm{CO}_{2}$ emissions as a negative externality, so the benefit of installing carbon-free power plants does not just derive from cost savings due to lower expenses for $\mathrm{CO}_{2}$ permits. Furthermore, each project (nuclear, photovoltaic and wind) is valued separately. It is not an option to switch between alternatives, which is an important feature of our study. In our studies, we model this differently because we think that investors do not incorporate externalities into their objective functions voluntarily.

Outside electricity planning, Hassett and Metcalf (1999) also investigate a sort of policy uncertainty by looking at changes in investment tax credit. In their framework, a Poisson jump process describes discrete changes in the tax regime. This idea has been taken up for other applications such as foreign direct investment where uncertainty emanates from the legal instability of the host country, for instance. An example is by Chen and Funke (2003). They find that FDI decisions are indeed severely influenced by political instability and the resulting uncertainty for the business environment. ${ }^{25}$

This review shows that there is still scope for further research in the field of policy uncertainty, and particularly so in connection with climate change policy, which will have a grave impact on investment patterns in the electricity sector in the near future. It is worthwhile to analyze how investment responds to changes in the trend of a process and not only how different types of stochastic processes can be used to mimic policy uncertainty. Policy makers can then use this information to adapt their own behavior corresponding to the goals that they want to achieve, while investors can extract useful insights for their own way of forming investment strategies.

\section{Real Options Models in Electricity Planning}

Real options studies, which are explicitly designed to analyze investment behavior in the electricity sector are numerous and focus on very different issues: in their book, Dixit and Pindyck (1994, pp. 51-54) already demonstrate the usefulness of this approach to support decision-making in electricity planning. Tseng and Barz (2002) and Hlouskova et al (2005) and Deng and Oren (2003) amongst many others have analyzed the effects of e.g. variability in loads and the inclusion of specific operational constraints on investment. Especially recently, interest has shifted more to long-term planning again. One example is by Fleten et al (2007). They show that

\footnotetext{
${ }^{25}$ However, a shortcoming of their analysis is its partial equilibrium character because the investment strategy might be influenced even more heavily by the fact that there are many other firms that are able to seize considerable market share by moving early. Then, the option to wait would be much less valuable.
} 
investment in power plants relying on renewable energy sources will be postponed beyond the traditional NPV break even point when a real options approach with stochastic electricity prices is used.

A selection of some other interesting applications concern research financing, electricity trading and the importance of market structure. Davis and Owens (2003) optimize the amount of renewable energy $R \& D$ by valuing the potential savings from developing renewable energy in the face of fluctuating fossil fuel prices. Chaton and Doucet (2003) incorporate the trade of electricity and consider also demand and fuel price uncertainty, load duration curves and equipment availability. Keppo and Lu (2003) investigate how a large electricity producer forms his decision to produce some planned quantity of power and how this can affect the market price of electricity.

\subsubsection{Remarks on the Investment-Uncertainty Relation- ship in Real Options Modeling}

As a last group of papers in this section, it is important to mention that while the general conclusion from real options modeling has been that irreversibility leads to postponement of investment in the face of uncertainty, there have also been some contributions that have suggested that the investment-uncertainty relationship might actually be positive. Sarkar (2000), for example, presents a real options model, in which the probability of investment occurring within a specific time interval, in terms of the parameters of the economy as well as the project, is positively affected by higher uncertainty. More specifically, uncertainty has the effect of increasing the probability that the investment threshold will be passed. Therefore, the probability that investment occurs within a specified time period increases, i.e. it is actually the amplitude of the swings that triggers investment when uncertainty is high. In summary, Sarkar (2000) finds a negative relationship between uncertainty and investment.

Other examples include Abel and Eberly (1999), who point out that the effect of uncertainty on investment might be ambiguous in the long run. While irreversibility and uncertainty increase the user cost of capital and therefore reduce the capital stock, irreversibility can also prevent the firm from selling capital, even when the marginal revenue product is low and the firm would want to sell capital. Abel and Eberly (1999) call the latter effect the "hangover effect" and the former the "user cost effect" and find that neither of the two dominates globally, so effect of uncertainty and irreversibility remains ultimately ambiguous. ${ }^{26}$

In the models presented in Chapters 6 and 7, we also find a positive relationship between investment and uncertainty, but for different reasons than the ones mentioned here. In our case, the effect arises from the embodiment of technological change in new equipment, which is neglected by Sarkar (2000) and Abel and Eberly (1999).

\footnotetext{
${ }^{26}$ Ghosal and Loungani (2000) stress another source of non-linear or positive investmentuncertainty relationships - the degree of capital market imperfections that might impose financial constraints on firms.
} 


\subsection{Portfolio Theory}

\subsubsection{Theoretical Background}

Portfolio theory had been pioneered by Nobel laureate Harry Markowitz as early as 1952 in an article entitled "Portfolio Selection" in the Journal of Finance. ${ }^{27}$ Seminal work followed by Merton (1969, 1971, 1973a), Samuelson (1969) and Fama (1970). As much as the foundations of real options theory are rooted in finance originally, the same is true for portfolio theory. Even though there have been applications to investment in real assets as well lately and the focus of this thesis is not on financial assets either, it is still useful to present the main lines of thought underlying portfolio theory to begin with.

This theory starts out from the fact that most investors are generally risk averse, i.e. they refrain to a certain extent to buy assets that exhibit a large variance in their returns. To quote Markowitz himself:

[...] the investor does (or should) consider expected return a desirable thing and variance of return an undesirable thing (Markowitz, 1952, page $77)$.

Typically, an investor would therefore compose his portfolio of assets that exhibit lower expected rates of return, which are relatively certain to be realized, and assets that have a very high expected rate of return, but this rate is also more uncertain to materialize. It is the tradeoff between expected return and variance that matters for the investor and leads to a diversification of the portfolio.

Now, in order to explore this argument more deeply, we first need to define the variance of a portfolio. ${ }^{28}$ If we have a portfolio composed of $N$ assets, total portfolio variance is defined as:

$$
V_{p f}=\sum_{i=1}^{N} \sum_{j=1}^{N} \sigma_{i j} x_{i} x_{j} .
$$

where $x_{i}$ stands for the extent to which the portfolio is composed of asset $i$; likewise $x_{j}$ is the fraction of asset $j$ in the portfolio. $\sigma_{i j}$ is the covariance between assets $i$ and $j$, and if $i=j, \sigma_{i j}$ is just the variance of asset $i$. In finance, a stock's risk is then measured by its beta, which is the covariance between the stock's and the market return relative to the variance of the market return. ${ }^{29}$ A $\beta$ larger than 1 implies that this stock will amplify the movements in the market, whereas a stock with $\beta$ smaller than 1 will move in the same direction as the market, but at a lower rate. In general, the market portfolio exhibits a relatively low degree of variability, which is also more or less constant. We call it therefore "market risk". At the same time, smaller portfolios with only a few individual securities will be more risky. The difference between the two measures of volatility is called "unique risk". The more securities are added to the

\footnotetext{
${ }^{27}$ See also Varian (1993) about Markowitz' work.

${ }^{28}$ This part is rather formal for the sake of clarity and to make more transparent in later chapters, which elements we borrow from the theory of portfolio selection. The illustration draws heavily on the background provided by Brealey and Myers (2005).

${ }^{29}$ The market return is measured by the portfolio return of a large number of representative securities.
} 
portfolio, the more it becomes diversified and the more will this unique risk decline, until the portfolio risk is equal to the market risk. This is best illustrated in Figure 2.4.1.

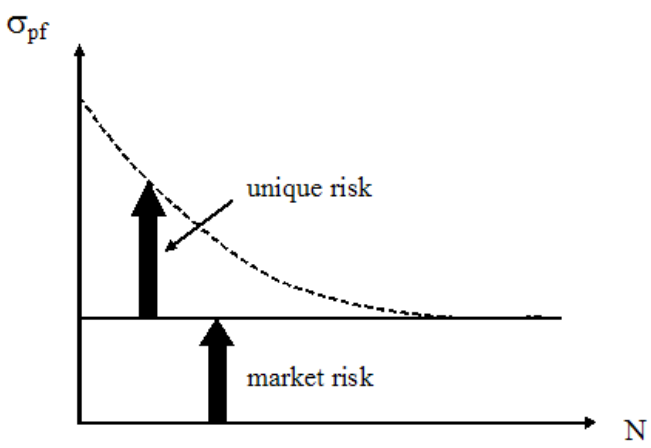

Source: adapted from Brealey and Myers (2005).

Figure 2.4: Increasing Diversification Leads to a Fall in Unique Risk

The more assets are added to the portfolio, the more does diversification help to reduce risk. However, it is not possible to reduce the unique risk beyond the market risk. This is because the more assets are included, the more covariance terms enter the calculation in Equation (2.4.1). In more general terms:

$$
V_{p f}=\frac{1}{N} \cdot \text { average variance }+\left(1-\frac{1}{N}\right) \cdot \text { average covariance }
$$

where $N$ is the number of securities. Average (co)variance is computed as the sum of all distinct (co)variances divided by the number of all distinct (co)variances, i.e. $\sum_{i=1}^{N} \frac{\sigma_{i}^{2}}{N}$ for the variance and $\sum_{i=1}^{N} \sum_{j=1, j \neq i}^{N} \frac{\sigma_{i j}^{2}}{N(N-1)}$. Then, as $N$ rises, the second term of the sum in Equation (2.4.2) increases in importance relative to the first term. In other words, there are more and more covariances and only a linearly increasing number of variances. Only if the covariances would all be equal to zero, would it be possible to construct a portfolio holding so many assets that the risk would tend to zero, but even though this is potentially valid as a theoretical consideration, this will never be a possible scenario in reality because there will always be non-zero covariances, which cannot be "diversified away". ${ }^{30}$

Now that we have defined and explained the concepts involved, we can continue to describe Markowitz' theory of portfolio selection. By suggesting that the average investor is a risk averse and profit-maximizing agent, he was referring to a relationship between return and risk that we will outline here. Looking at Figure 2.5, there are a number of securities listed in a graph with expected return $R$ on the vertical and return volatility measured by the standard deviation $\sigma_{p f}=\sqrt{V_{p f}}$ on the horizontal axis. By

\footnotetext{
${ }^{30}$ See page 173 in Brealey and Myers (2005) or pp. 109ff in Markowitz (1959) or page 58
} in Elton et al (2003). 
composing a portfolio with different shares of these securities, any point within the heavy line can be attained. However, what a risk averse and return-maximizing investor will do, is to opt for any possibility that moves him vertically up (higher return) and to the left (lower standard deviation). Consequently, he will always prefer a portfolio on the heavy line over one that lies inside the line. Markowitz therefore calls all portfolios along the heavy line "efficient" portfolios and the line itself is known as the efficient frontier. The reason why the efficient frontier (also called the portfolio possibilities curve) is concave above the point where the risk the minimal is straightforward: it can be shown (see e.g. Elton et al, 2003) that combinations of assets cannot exhibit more risk than the level of risk found on a straight line connecting two assets, i.e. the efficient frontier can never become convex above the point where we find the global minimum variance portfolio. If two points in Figure 2.5 were connected by a straight line, this would imply that their returns are perfectly correlated. For any correlation factor smaller than 1 , the curve must therefore be concave.

If the investor can lend at a risk-free rate, $\mathrm{r}_{f}$ (e.g. by buying treasury bonds), which is typically smaller than the risk-free rate at which he can borrow, $\mathrm{r}_{f}^{\prime}$ (e.g. from the bank), the shape of the efficient frontier will be different: all combinations of risk free lending and borrowing lie on straight lines with $\mathrm{r}_{f}$ and $\mathrm{r}_{f}^{\prime}$ as origins, as can be seen in Figure 2.5. The straight line emanating from $\mathrm{r}_{f}$ is tangent to the efficient frontier in point $B$ and the borrowing line touches the curve in point $A$. Beyond $A$ the efficient frontier will therefore be a straight line through point $C$ and before $B$ the frontier will be a straight line starting from $\mathrm{r}_{f}$. Only in between points $A$ and $B$ is a concave part, where it would be optimal for the investor to hold combinations of risky assets.

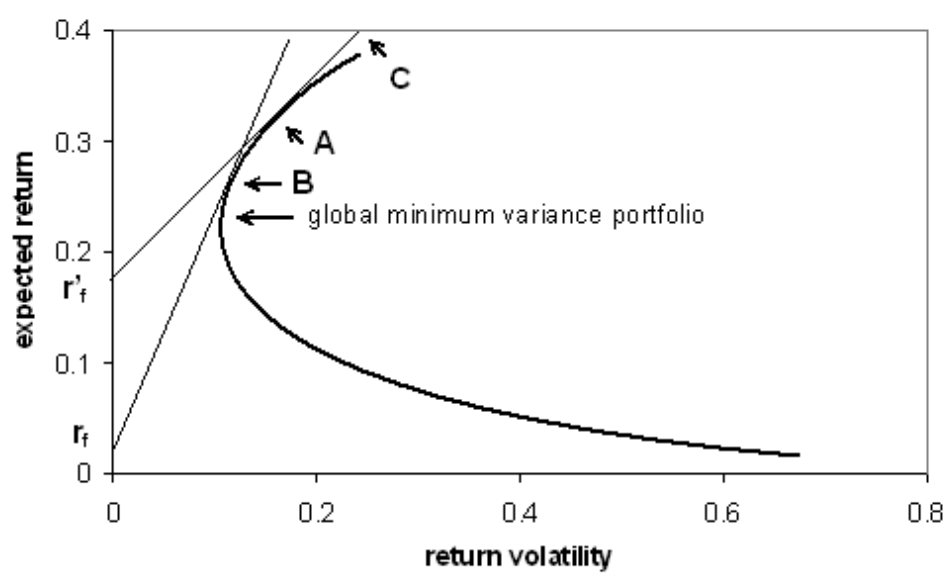

Risk averse investors prefer efficient portfolios along the frontier, which are therefore superior to the points marked inside the frontier.

Figure 2.5: Efficient Frontier 
In mathematical terms, let $R_{p f}$ be the total yield on a portfolio $p f$, i.e.:

$$
R_{p f}=\sum_{i=1}^{N} R_{i} \cdot x_{i}
$$

where $R_{i}$ is the random yield of a particular security $i$ and the rest of the notation is unchanged. To use Markowitz' (1952) own notation, let $\mu_{i}$ be the expected return on security $i$. Then, the expected return on the whole portfolio is

$$
\mathbb{E}\left(R_{p f}\right)=\sum_{i=1}^{N} \mu_{i} \cdot x_{i}
$$

And the corresponding variance is as in Equation (2.4.1) above.

For fixed (probability) beliefs about the development of $\mu_{i}$ and $\sigma_{i j}$, the efficient portfolio can then be calculated by maximizing Equation 2.4.4 subject to Equation (2.4.1). ${ }^{31}$ The different combinations of $\mathbb{E}\left(R_{p f}\right)$ and $V_{p f}$ that solve this problem will then trace out the efficient frontier introduced in Figure 2.5. Markowitz calls this the $\mathbb{E}-V$ rule:

The $\mathbb{E}-\mathrm{V}$ rule states that the investor would (or should) want to select one of those portfolios which give rise to the $(\mathbb{E}, \mathrm{V})$ combinations $[\ldots]$ with minimum $\mathrm{V}$ for given $\mathbb{E}$ or more and maximum $\mathbb{E}$ for given $\mathrm{V}$ or less (Markowitz, 1952, page 82).

Even though the mean-variance approach by Markowitz (1952) is capable of explaining diversification and the risk-return tradeoff in a very straightforward manner, there are a number of disadvantages associated with this sort of framework, which have led to multiple changes and extensions to the basic model over the last decades. The first flaw is that the mean-variance approach maximizes only quadratic utility, i.e. it is not a valid method to tackle problems involving preferences for higher-order return moments. As an example, return distributions might be skewed and have fat tails, which would imply higher losses beyond a certain threshold. Furthermore, and very important in the light of the purposes of this thesis, mean-variance portfolio theory is inherently myopic in the sense that it focusses on a portfolio at a single point in time. $^{32}$ In electricity planning, planning periods of more than 30 years are typically the rule, and there are dynamic developments that also call for a dynamic treatment of the portfolio of technologies. While we realize the benefits of portfolio theory as such for the application to the problems addressed in this thesis, we also know that we have to take into account these shortcomings. Therefore, we do not employ portfolio

\footnotetext{
${ }^{31}$ Conversely, it is also possible to minimize equation (2.4.1) subject to a given expected return. This will also deliver all optimal combinations of $\mathbb{E}\left(R_{p f}\right)$ and $V_{p f}$.

${ }^{32}$ It is true that Merton (1969) has developed an intertemporal version of the portfolio approach. However, since Merton's model is not trivial to solve and thus difficult to apply, it did not really displace the Markowitz framework in financial planning at that time. Only recent advances in analytical and numerical methods have changed this situation (Campbell, 2000) and enabled applications in e.g. pension fund management. More importantly for this thesis, the translation of these methods to investment into real assets such as electricity generating capacity has been difficult. In fact, most models continue to rely on mean-variance theory, see Table 5.1.
} 
theory in its completeness, but borrow only elements from the general approach and combine it with other investment modeling methods.

\subsubsection{Applications of Portfolio Theory to Real Assets}

Being a principle from finance very much like options theory was previously developed to value financial options, portfolio selection approaches have also been framed and applied to non-financial assets. The resulting literature is by far not as vast as that for real options yet, but there are a number of very interesting applications that need to be reviewed here. Examples include the valuation of offshore oil leases (Helfat, 1988) and the valuation of financing long-term projects (Seitz and Ellison, 1995). More interesting for this thesis, however, are the applications involving energy planning. Even though the first attempt dates back as long as 1976 (Bar-Lev and Katz, 1976), interest in the topic has only arisen again very lately (e.g. Awerbuch and Berger, 2003). A full account of this work is given in a recent article by Awerbuch (2006).

In general, these models use Equations (4.3) and (2.4.4) in the way described above to test whether the portfolios of electricity generating capacity used by a certain region or country are efficient. Bar-Lev and Katz (1976) find that in the United States electric utilities are more or less efficiently diversified in each region. However, their results show that utilities tend to combine high rates of expected return with high levels of risk. This willingness to accept more risk is attributed to the large number of regulations, which the authors claim to be a threat to investors, so that they feel forced to take on higher risks. In particular, the regulatory process that leads to this result is that utility services are priced by official authorities. If the suppliers then claim that output prices should be raised, they will have to go through a lengthy, official process. In order to evaluate the performance of the utility to get a judgement if a price increase would be warranted, the authorities generally place more weight on the ex post return based on the cost of the inputs rather than focussing also on the ex post risk. Therefore, it is in the interest of utilities to have the highest return possible, which entails accepting higher levels of risk.

Humphreys and McClain (1998) refine the approach by Bar-Lev and Katz (1976) by building a GARCH-type model, which allows the covariance matrix to be systematically updated over time as new events occur. This leads to the result that in times of e.g. oil price shocks (like the spike during the Persian Gulf War) a diversification away from oil-intensive generation equipment is found to be efficient. Moreover, even though the electric utilities in the United States have been operating at a minimum variance position by the end of the 1990s according to the authors, overall energy consumption has been far from efficient during that time. As a consequence, Humphreys and McClain (1998) recommend a higher portion of coal to be used in the fuel mix - a result which is changed, of course, once potential environmental regulations are taken into account.

Awerbuch and Berger (2003) conclude after a similar exercise, but without dynamic covariances, that the existing portfolio of EU power generating technologies is suboptimal and therefore inefficient, i.e. that there are portfolios combining lower risks 
with higher returns. Furthermore, they find that fuel price risk always dominates the other types of risk (e.g. about O\&M costs) that they examine, which has important implications for energy security. Awerbuch and Sauter (2006), for example, point out that the fluctuations in the prices of fossil fuels depress macroeconomic activity as measured by GDP growth, employment and inflation. Thus, energy portfolios that have high shares of fossil fuel technologies are more vulnerable to this volatility and therefore reduce energy security. ${ }^{33}$ This is taken up in Awerbuch (2006), who focusses on issues of energy security making a case for a higher proportion of renewable energy to be chosen for the overall energy mix. Using Figure 2.6 depicted below, he argues that if a country or a region starts from a portfolio based on fossil fuels (1), adding renewable energy carriers will reduce the risk (measured by year-to-year cost volatility) bringing the electricity sector to (2). Then, reshuffling the portfolio, so as to reproduce the initial level of risk, will bring the sector down to (3), where lower generating cost is combined with the same level of risk as before, i.e. (1) was not an efficient portfolio. In the terminology developed in the previous section, this means that the amount of electricity generated by the fossil portfolio can also be produced by the third portfolio, which exhibits the same level of risk, but is less costly than the fossil fuel portfolio.

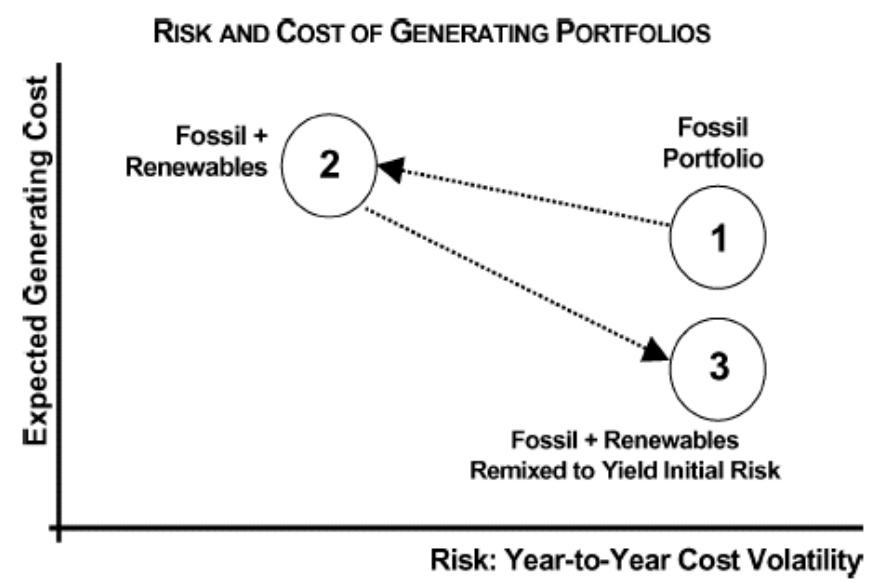

Source: Awerbuch (2006), page 699

Figure 2.6: Risk and Cost of Generating Portfolios

Empirically, he finds that compared to the performance of the EU and the US, Mexico and other developing countries have or plan to have much less efficient generating portfolios. There is no explanation for this result by the author. However, it is evident from the calculations that this result is (at least partially) due to the plan to

\footnotetext{
${ }^{33}$ Another way how to view energy insecurity is to associate it with sudden disruptions in the supply of fossil fuels as an input to the production process. However, this could also be captured by spikes in price levels.
} 
include a substantial portion of oil-based energy into the generation portfolio, which lowers the return at the same level of risk compared to the efficient frontier. This decision might have to do with strategic and political considerations, as much as with the fact that existing equipment might not be easily scrapped and costly to replace by renewable alternatives - especially in less advanced countries that might lack access to the most recent technology.

Roques et al (2006) apply a similar framework to UK diversification in electricity sector investment, but they extend their focus to include also the risks associated with carbon price fluctuations and electricity price volatility. Furthermore, they employ Monte Carlo simulation to obtain the corresponding NPVs for underlying stochastic electricity, fuel and carbon prices, where they pay particular attention to three scenarios. The first scenario has independent, stochastic price processes, while the second scenario also takes into account that the price processes might be correlated. The third scenario has a fixed electricity price in order to assess the impact of long-term purchase contracts. In terms of their conclusions, it remains questionable whether the market can provide incentives to investors to opt for a socially optimal fuel mix. At the same time, it becomes apparent that the correlations between the price processes influence the results significantly.

All these applications of mean-variance optimum portfolio theory in the style of Markowitz $(1952,1959)$ suffer from the disadvantages pointed out in the previous section: they neglect the dynamics underlying investment decisions in the electricity sector - a problem that we tackle in Chapter 6 by developing the vintage-portfolio model mentioned above and which we compare to "standard" mean-variance Markowitz applications to energy planning in Chapter 5.

\subsubsection{Remarks on the Investment-Uncertainty Relation- ship in Portfolio Modeling}

While we have concluded from our presentation of the real options approach that investment and uncertainty are mostly negatively correlated, a similar statement can be made about the investment-uncertainty relationship in optimum portfolio models: as the uncertainty associated with one asset increases, its proportion in the asset portfolio should be decreased by either decreasing investment into that asset or increasing investment in less risky assets in order to maintain the maximum expected return for a specified level of uncertainty or to minimize the uncertainty for a specified level of expected return.

For the case of volatile fuel prices, for example, we have already illustrated this concept with the help of Awerbuch (2006). He demonstrates that increasing the share of renewable energy sources in the generating portfolio can reduce the risk associated with the portfolio at the same level of expected return for a number of countries. This implies that the current energy mixes are not always efficient in the sense of Markowitz (1952, 1959). 


\subsection{Vintage Models}

There is another body of literature that provides useful insights into the dynamics behind investment behavior. While the models mentioned so far all treat the existing and future capital stock as being homogenous, vintage models take into account the fact that new vintages of capital typically embody the latest benefits of technological change. The core idea is that investors have to install a new piece of equipment, before they are able to benefit from the technical progress that has made that piece of equipment more efficient than the one that was previously used.

Neoclassical models, on the contrary, suggest that the capital stock will immediately be changed as the factor price ratio changes. This is of course unrealistic in the electricity sector because of the irreversibility involved in investment decisions. As early as 1973, Gregory and James therefore already pointed out the usefulness of vintage modeling for the electricity sector. The reason they mention is amongst others the substantial initial investment cost required to start production (Gregory and James, 1973, page 1134). Thus, even though vintage models per se do not deal with uncertainty and the composition of multiple capital stocks (as they would arise in the case of different technologies for the generation of electricity), we think that vintage modeling provides a very suitable framework that we want to combine with elements from portfolio theory in order to investigate investment patterns in the electricity sector. In this section we will first describe the basic model structure and sketch a brief history of vintage modeling and then continue to review some more recent applications.

In vintage models capital is heterogeneous, although it had been treated as if it was homogeneous in earlier growth models (e.g. Solow, 1956 and 1957). Vintages therefore do not only depreciate in the physical sense, but they will also become obsolete, as newer vintages arrive. The latter are more efficient by definition and will drive out the older ones eventually, which is referred to as "creative destruction" by Aghion and Howitt (1992). ${ }^{34}$ Figure 2.5 displays the evolution of output, $Y$, per unit of employed capital, $K$, in plants of vintage $t$. The arrival of an innovation opens up new capacity, thus more capital is accumulated. The width of each segment depends on the volume of investments, while the height of the columns reflects the efficiency of the vintages. The height of the columns is magnified by a factor representing the rate of (exogenous) technical change. The area of each rectangle is thus the capacity of the most recent investment. It is important to emphasize that in this setting, the full benefits of technical change can only be realized in response to a $100 \%$ immediate diffusion of the newly developed capital goods. In other words, technical change is embodied in the new capacity. ${ }^{35}$

Even though the earliest reference dates back to 1959, when Johansen developed the first vintage model, we start out with Solow (1960) here, who was also among the first economists criticizing not only the exogeneity of technical progress, but also its

\footnotetext{
${ }^{34}$ Actually, creative destruction is a phenomenon first found by Schumpeter (1942) and later "popularized" by Aghion and Howitt (1992).

${ }^{35}$ Note the similarity to the practice of ordering equipment according to ascending operating cost in the electricity sector - the co-called merit order (see Chapter 1).
} 


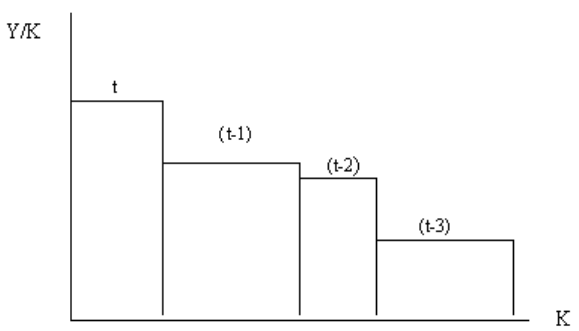

Source: adapted from Solow (2000).

Figure 2.7: Evolution of Output per Unit of Employed Capital for Successive Vintages

availability at zero cost. He consequently designed a more sophisticated conception of technical change and its transmission to the economy. Technology progresses at a constant rate, which only affects new capital goods. More specifically, the rate of new investment influences the rate of technical change because the latter is embodied in the new capital goods, at which this investment is directed. Old capital goods co-exist along with the new ones, until they have completely depreciated - in the physical sense.

The distinctive feature of Solow's (1960) model is that technical change does not occur as time proceeds, but according to the rate of arrival of new vintages. To be more precise, technical change itself is still exogenous, but the diffusion of new technology becomes endogenous. Once these vintages are put into operation, their productivity does not change anymore, i.e. disembodied technical change not taken into account. Solow (1960) further assumes the labor market to be perfectly competitive, where labor itself is homogeneous. Equilibrium therefore occurs when workers are allocated across vintages in such a way that their marginal productivities are the same in operating any vintage. Note that this implies that there is always perfect factor substitution. Solow (1960) thus assumes a putty-putty production structure, i.e. substitution possibilities ex ante and ex post are described by the same isoquant. Shifts in the isoquant are due to embodied technical change before instalment. ${ }^{36}$, This also means that there is no economic reason to scrap vintages, since the capital-labor ratio can always be changed, even after instalment. It is clear that the putty-putty structure represents an extreme form of substitutability, whereas the other extreme is no substitutability at all. In clay-clay model, input factors cannot be substituted for each other - neither ex ante, nor ex post. This can be represented by a single moving point in factor space. An example of such an approach is given by Kaldor and Mirrlees (1962), although their analysis is not focussed on a production function, but on a technical progress function, in order to emphasize their view that shifts in the production function cannot

\footnotetext{
${ }^{36}$ Disembodied technical change, which occurs after instalment due to e.g. learning by doing or the accumulation of technology-specific know-how, would shift this isoquant ex post investment.
} 
represent the effects of technical progress in a satisfactory way. In Chapters 6 to 7 we will adopt the same clay-clay structure for investment decisions in the electricity sector in order to account for the irreversibility of investment decisions. ${ }^{37}$

Since in the Kaldor and Mirrlees (1962) model coefficients are fixed ex post, economic scrapping becomes an issue. One way to investigate this is to apply the zeroquasi-rent condition. This condition simply states that a vintage should be scrapped if the variable costs it incurs are larger than the returns it generates. The second possibility of scrapping is formalized by Malcomson (1975) and therefore also usually referred to as Malcomson scrapping rule. With this rule, the total marginal cost of a new vintage is compared to that of an older vintage. Profits can be increased by substituting the new vintage for the older one if its marginal cost is lower than that of its predecessor. This ultimately leads to a lower lifetime of vintages under the Malcomson scrapping rule than under the zero-quasi-rent condition. ${ }^{38}$ It also implies that an increase in the rate of technical change will depress the lifetime of existing vintages, which is again a realization of the "creative destruction" effect mentioned above.

Greenwood and Jovanovic (2000) focus on the adoption of new technologies and show that productivity slowdowns occur because producers do not want to upgrade their technology portfolio too often, although they could do so easily. The problem is that the producer has acquired an associated level of expertise at operating his technology grade, and it increases over time due to learning by doing. Switching to a new grade then implies a loss of expertise. Adoption costs might thus be a considerable factor in an investment decision. While this can be seen as an effect due to the irreversibility of human capital investment and thus provides an explanation or the slow adoption of new (and sometimes more efficient) technologies, we think that - in the electricity sector - the slow diffusion of new technology is rather due to the irreversibility associated with the power generating capital stocks, where investments are lumpy and the larger part of technical change of the embodied type. By taking switching costs into account, Greenwood and Jovanovic (2000) overcome one of the most important deficiencies of traditional vintage growth models named by Soete and Turner (1984). This disadvantage of traditional vintage models is comparable to the shortcomings of the orthodox investment models without adjustment costs in a wider sense. Other points of criticism these authors mention are that vintage models neglect the uncertainty about its future pay-offs. The latter is particularly important for electricity-generating technologies. If you think of renewable energy carriers, it is not only the up-to-date high capital cost that has been an obstacle to more widespread diffusion of e.g. wind-or solar-based technologies, but also the uncertainty surrounding

\footnotetext{
${ }^{37}$ Johanson (1959) remarked that existing (non-vintage) models relying on fixed proportions ex ante and ex post or assuming complete substitutability between factors ex ant and ex post were far too extreme and thus unrealistic, so he developed another type of (and actually the first) vintage model assuming a putty-clay production structure, implying that substitutions ex ante can be described by an isoquant, which moves and changes its form due to embodied technical change. Ex post, there is only one point in factor space, which may move as a result of disembodied technical change. Another advocate of the putty-clay approach is Salter (1960), who finds that the rate of investment is a major determinant of the speed of adoption and the internalization of the gains from technical advance.

${ }^{38}$ In the models presented in Chapters 6 to 7 , we use the Malcomson scrapping rule.
} 
their future rate of technological improvement. In Chapter 6 we develop a model that adds elements from portfolio theory to take this aspect of a technology's "investment profile" into account. Another simplification by traditional vintage models is that there is only one (heterogenous) capital stock, while we would expect that there is a portfolio of different technologies and therefore different types of capital. What can be gained from combining elements from portfolio theory with elements from vintage modeling is therefore not only the valuation of diversification benefits across technologies, but also the gains from diversifying across time (by bringing investment forward or postponing it) and technologies.

With respect to diffusion rates, it is interesting to note that these are found to be particularly low in energy markets. More specifically, Jaffe and Stavins (1994) find that the diffusion of such new technologies is a lengthy process and that a lot of firms continue to invest in older vintages. This is what they call the "Energy Efficiency Paradox": although more efficient technologies do actually already exist, they might not be used, or only be adopted gradually, in small steps. The temporary loss in expertise, which Greenwood and Jovanovic (2000) and Jovanovic and Nyarko (1996) describe, is one of the traditional explanations for this paradox. Others are offered by Mulder et al (2003), for example that uncertainty and irreversibility considerations might create an option-value of waiting, which points to the usefulness of real options models in this context.

\subsection{Conclusion}

With this more detailed literature review in mind, it is more straightforward to put the contribution of this thesis into perspective. In particular, we will extend and apply two existing frameworks for investment decision making to investment in the electricity sector. We have chosen real options theory and portfolio selection in combination with vintage modeling as basis for our modeling approaches, since they allow us to take full account of the uncertainties and irreversibility pervading investment decisions. Moreover, real options theory is particularly suited to investment subject to irreversibility when the investment date can be chosen flexibly. Even though computations become complex relatively quickly, this approach has the advantage of being inherently dynamic, whereas portfolio theory produces "only" a myopic picture of the optimal investment decision. However, the advantage of portfolio theory is that it takes account of the benefits from diversification. In other words, investors can hedge against the impact of uncertainty arising from e.g. fuel prices and technological progress by adding technologies to their portfolio that have a more secure expected return. While portfolio theory has generally already been applied to investment in the electricity sector (e.g. Awerbuch and Berger, 2003, and Roques et al, 2006), the novelty of the models presented in this thesis is the combination with vintage modeling, which allows us to make the portfolio perspective dynamic while taking into account the irreversibility of investment and the embodiment of technological change at the same time. 
The innovation in the real options models presented in this thesis is the (relatively new) type of uncertainty that we incorporate, namely the uncertainty emanating from unclear policy signals with respect to climate change policy (see also Blyth and Hamilton, 2006). If investors do not know whether carbon emissions will be priced more heavily in a post-2012 carbon agreement, it will be difficult for them to make their decisions with respect to capacity expansion and replacement. We find that this type of uncertainty is more fundamental and needs to be clearly distinguished from the uncertainty that arises because of the fluctuations associated with input and output prices, which we call market uncertainty. From a methodological point of view the novelty is here that we make a distinction between the expected and the actual level of volatility. In other words, we allow for the circumstance that investors might have to choose a strategy (i.e. optimize) under uncertainty, which means that they have incomplete information to base their decision upon. It turns out that this leads to suboptimal decisions, which are costly for the investor, but need not jeopardize environmental objectives. In addition, we shed some light on the discussion about price caps and the right design of carbon prices.

We use both the vintage-portfolio model and the real options framework to analyze the impact of fuel price and technological uncertainty on investment patterns. What we find is that in the vintage-portfolio model, fuel price uncertainty leads to a decrease in investment into fuel-intensive technologies, while technological uncertainty is positively related to investment now and negatively related to future investment. This can be explained by the embodiment of technological change in the latest vintage of equipment: if technological improvements are more certain to be realized, the benefits of waiting and buying the improved equipment later on are high compared to a situation, where it is not clear whether and when such improvements will occur. In the real options framework this is different: larger uncertainty always leads to a higher option value of waiting, i.e. investment is postponed. Another interesting finding is that technological change itself has an adverse effect on investment, which can be explained by the same embodiment argument as before: if technical improvement needs to be bought and paid for, it pays off to wait and seize the benefits of what has been going on. The conclusion would be different if we had modeled technical change as a process of learning-by-doing, i.e. if it had been possible to realize cost reductions after the equipment had been installed.

By feeding real-world data into our models, we can test the validity of our findings for actual investments, even though the models remain highly stylized and the results should be taken as an illustration rather than as a numerical analysis to be taken at face value. Also the policy recommendations have a suggestive character, even though it is remarkable that we actually do not seem too far off in terms of our predictions: in Chapter 4, for example, we find that the price of one ton of $\mathrm{CO}_{2}$ would need to triple in order to make an early transition from coal-fired capacity to wind energy possible. The recent Fourth Assessment Report of the IPCC (2007) actually also forecasts that $\mathrm{CO}_{2}$ prices will have to rise to at least $100 \$$ per ton of $\mathrm{CO}_{2}$ in order to achieve stabilization of atmospheric $\mathrm{CO}_{2}$ concentrations at relatively "harmless" levels. One might take 
this an indication that the models presented in this thesis can be used as tools to develop a sound understanding of investment patterns in the electricity sector and thus as an aid for policy makers to provide the right incentives to support sustainable energy development as explained in Chapter 1. 


\section{Appendix A: Using Sensitivity \& Scenario Analy- sis in Investment Models for Electricity Planning}

The purpose of this appendix is to give an overview of investment models that have particularly been designed and used for decision-making and forecasting of investment patterns in the electricity sector in practice. These are typically linear programming models, and early versions did not consider uncertainty explicitly. Yet, there are some tools, which allow the analyst to consider the model's behavior under different circumstances, which conveys an idea about the impact that uncertainty can have on investment patterns. More specifically, we will first give a brief history of electricity planning models and then describe the merits of scenario and sensitivity analysis that can be used in combination with existing models or for the sake of robustness checks.

The first investment models for electricity planning were based on linear programming. Ku (1995) reviews the beginnings of capacity expansion modeling: the French electricity industry was first in using linear programming for its capacity planning process. This model comprised only five variables and four constraints. The whole approach is described by Massé and Gibrat (1957). However, already at that time, there were modeling efforts including much higher numbers of variables and constraints. Dantzig (1955) had a comparable model with 70 constraints and 90 variables.

Nowadays, small linear programming models are no longer used in energy modeling. Bigger econometric models such as the global E3 model (E3MG) designed to examine energy policies are used to analyze GHG mitigation policies under endogenous technological change, for example (UK Tyndall Center for Climate Change Research). Even more detailed are the systems engineering optimization models that can investigate the energy system on a national or regional level. MARKAL, for example, is a large-scale linear programming model computing the development of the energy sector (also including transportation) over a period of around 40 to 50 years. Usually, the objective function that is used for the calculations for the electricity sector is the minimization of the (mostly deterministic) cost of supplying electricity, but other objectives can be substituted if needed. The inputs that the model requires are energy demand and estimated future resource costs. This does not account for uncertainty, of course. As a first step into that direction, however, the MARKAL model can be run several times in order to analyze how the composition of the energy sector changes when an emissions cap is introduced, for example.

Alternative ways of incorporating uncertainty into decision-making in electricity planning in practice include scenario analysis, which is a useful method of dealing with demand uncertainty or uncertainty about the amount of emissions that need to be saved to decelerate global warming. Scenario analysis means that more than one and ideally many model runs are carried out in order to test the model with a variety of parameter sets. In this way, different scenarios of what the future could look like are created and policies can be tested for their robustness across these scenarios, for example. Rockafellar and Wets (1991) define scenario analysis as the process of modeling uncertainty about system parameters by a small number of (perturbed) 
versions of subproblems derived from an underlying optimization problem. Then, "[...] by studying the different subproblems and their optimal solutions one may be able to discover similarities and trends and eventually come up with a "well-hedged" solution to the underlying problem, something which can be expected to perform rather well under all scenarios, relative to some weighting of scenarios." (Rockafellar and Wets, 1991, page 119). The weights of the scenarios can be interpreted mathematically as (subjective probabilities). Van Asselt (2000) finds this to be a point of criticism: even though the weighting scheme will not be drawn completely arbitrarily (the IPCC for example analyzes scenarios, as well and the probabilities that are attached to these scenarios are based on expert opinion and thorough analysis by multiple instances), the final judgement remains subjective. ${ }^{39}$

Another - and more basic - way of testing whether and how investment patterns change in response to changes in the underlying parameters is to change one of the parameter values slightly, while keeping the others unchanged. Even though such a sensitivity analysis does not incorporate uncertainty into the optimization procedure, it gives us at least an idea of how higher or lower parameter values would influence the final investment decision. On the one hand, multiple uncertainties and different types of uncertainties cannot be investigated properly, since a sensitivity analysis rests on the requirement that all other variables have to be kept at their base run values. On the other hand, sensitivity analysis is a good way of determining ex ante, which variables' volatility will have the greatest influence on the outcomes and which should therefore be modeled stochastically in more sophisticated, but possibly smaller scale models. Ex post, this methodology can also provide conclusions about the magnitudes in response to higher uncertainty. It should therefore not be dismissed as a tool to elaborate on investment under uncertainty. It could for instance also be combined with scenario analysis, so that joint changes in system parameters could be examined. ${ }^{40}$ Also, it can serve to check how robust the results are to changes in the underlying assumptions with respect to parameter values.

\footnotetext{
${ }^{39}$ Large-scale systems engineering optimization models such as MARKAL described above can also be adapted to generate scenarios. A model that is typically used for this purpose is the MESSAGE model. MESSAGE can be used for medium- and long-term energy system planning (Messner and Strubegger, 1995). The model does not only consider the electricity sector, but overlooks the whole energy system and also its relations with other systems and minimizes the costs of operating the complete system subject to a vast number of constraints. The output of the computations is the development of the installation of capacity and composition thereof, production plans, transactions between sectors, emission paths, etc.

${ }^{40} \mathrm{As}$ an example, if we have different demand scenarios, across which we want to determine a robust GHG emissions reductions policy, we can vary another parameter as well. If the response to this sensitivity test is larger in one demand scenario compared to another one, this implies that the results are sensitive to changes in both items and that there is a correlation between them that warrants further investigation.
} 


\section{Appendix B: Value-Matching \& Smooth Pasting}

This section is based on the explanations in Dixit and Pindyck (pages 130-132, 1994). They consider an optimal stopping problem of the type described in this chapter with the following Bellman equation:

$$
F(x, t)=\max \{\Omega(x), \pi(x, t) d t+(1-\rho d t) F(x, t)+\varepsilon[d F]\} .
$$

where $x$ follows an Itô process, $\Omega(x)$ is the payoff upon termination (i.e. when the option to invest is exercised) and $\pi(x, t) d t+(1-\rho d t) F(x, t)+\varepsilon[d F]$ is the continuation value (i.e. the profit streams that will accrue if the investment option is not exercised or in other words the value from waiting). $\rho$ is the discount factor and $\varepsilon[d F]$ is the expectation of changes in $F$.

Let us define the threshold value of $x$ as $x^{*}(t)$, so that continuation is optimal for $x>x^{*}(t)$ and stopping is optimal if $x<x^{*}(t)$. By continuity, if we suppose $F\left(x^{*}(t), t\right)<\Omega\left(x^{*}(t), t\right)$, then $F(x(t), t)<\Omega(x(t), t)$ also holds for a value of $x$ slightly above $x^{*}$. However, this is a contradiction to our definition of $x^{*}$ as the investment threshold: if $F(x(t), t)<\Omega(x(t), t)$, it would be optimal to stop and realize the termination payoff, which exceeds the continuation payoff, but with $x>x^{*}(t)$ the investment option should not be exercised. The same argument applies the other way around, i.e. if $x<x^{*}(t)$. Therefore, the value-matching condition is necessary to ensure that the $x^{*}(t)$ that we find is really optimal.

The smooth pasting condition can be defended by means of Figure B.1. In the left panel, if $x$ was only marginally above the investment threshold $x^{*}$, then continuity would imply that $F(x(t), t)<\Omega(x(t), t)$, i.e. it would be optimal to terminate and invest rather than wait, even though $x>x^{*}$, which would imply the opposite. This contradiction shows that there cannot be an upward-pointing kink in the $F(x(t), t)$ and $\Omega(x(t), t)$-schedules.
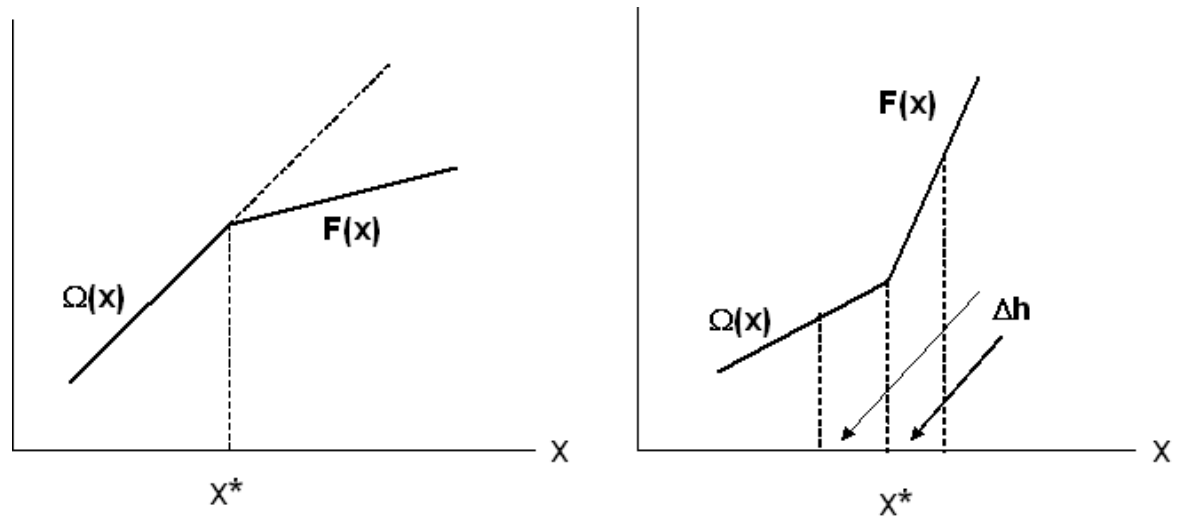

Source: from Dixit and Pindyck, 1994, page 131

Figure B.1: Argument for Smooth Pasting 
In the right panel, if you were at the kink, you could do better by continuing (i.e. by not exercising the option to invest) for a small time interval. Moreover, two points marginally above and below the threshold $x^{*}$ (denoted by $\Delta h$ in Figure B.1) constitute an average that exceeds the value at $x^{*}$. However, this means that $x^{*}$ cannot be the optimum investment threshold. One might think that this is not true because the value that is realized time $\Delta t$ later needs to be discounted and so the value is reduced by the effect of discounting. It is therefore important to note that the effect of discounting is proportional to $\Delta t$, while the gain from waiting is proportional to the square root of $\Delta t$, i.e. for small $\Delta t$ the gain more than outweighs the effect of discounting. ${ }^{41}$ We can conclude that there can also be no downwardpointing kink in the $F(x(t), t)$ - and $\Omega(x(t), t)$-schedules. Therefore, the two lines must meet tangentially, which demonstrates clearly the necessity of smooth pasting.

\footnotetext{
${ }^{41}$ Dixit and Pindyck (1994) prove this point algebraically, so the interested reader is referred to pages 131 and 132 of their book for the formal proof.
} 



\section{Chapter 3}

\section{Energy Investments under Market \& Climate Policy Uncertainty}

\subsection{Introduction ${ }^{\dagger}$}

The emissions from electricity generation, which are mostly $\mathrm{CO}_{2}, \mathrm{NO}_{x}$ and $\mathrm{SO}_{2}$, constitute a considerable fraction of total anthropogenic emissions on a global scale. In Europe (OECD) this fraction for the case of $\mathrm{CO}_{2}$ amounts to $26 \%$, while in the US this percentage is as high as $37 \%$ (Farrell, 2004). In addition, $\mathrm{CO}_{2}$ emissions are found to be the primary cause of global warming and there is mounting evidence of the extent of the damages and their irreversibility, such as the melting of the icecaps and the accompanying rise in sea levels. Even though there is still much uncertainty about the cause-and-effect relationships involved in global warming, there is common agreement among scientists that further accumulation of Greenhouse Gases (GHG) in the atmosphere will come at a considerable cost to nature and humanity. Stern (2006), for example, has recently given an estimate that has alarmed policy makers and the public. According to this estimate, $0.5-1 \%$ of GDP might be lost per year due to more extreme weather conditions by the year 2050. As temperatures rise further, so will the damages.

Therefore, policy makers have become alert regarding the urgency, with which preventive action must be taken. The President of the European Commission Barroso, for example, has made a proposal in 2007, in which he declares that the EU shall strive for a $20 \%$ cut of its $\mathrm{CO}_{2}$ emissions by the year 2020 . The aim of this action is to limit global warming to $2^{\circ} \mathrm{C}$. In a similar vein, the last G8 summit in Heiligendamm has called for stronger action on the emissions reduction side. Individual European

${ }^{\dagger}$ This chapter is based on the article "Investment under Market and Climate Policy Uncertainty" by Fuss et al (2008). 
countries have already taken measures to reduce their $\mathrm{CO}_{2}$ emissions. The United Kingdom, for example, has enacted the so-called Renewables Obligation, requiring a minimum percentage of electricity sales to be generated from renewable sources, starting at $3 \%$ in 2002 and rising to $10.4 \%$ by the year 2010 (Edge, 2006) and the new Energy White Paper from 2007 has spelled out even more ambitious goals for mitigation and abatement. Furthermore, international climate change agreements are negotiated in order to ensure collective action also internationally. Most notably, the Kyoto Protocol phase is coming to end very soon and there is large uncertainty as to the outcomes of new negotiations and the possible design of a 2012 post-Kyoto carbon agreement. If the US will join the EU in their stabilization efforts is not clear and China and India do not seem enthusiastic about drastic measures that would put them at an economic disadvantage compared to industrialized countries either. Even developed countries such as Canada will continue to rely on fossil fuels to a large extent, ranking second after Saudi Arabia in terms of extractable oil reserves these days (Drexhage, 2007). Considering all these different interests and the difficulties that have been encountered during previous climate change policy negotiations, it is by far not clear what direction climate change policy will take in individual countries after 2012 .

In liberalized electricity markets, this implies that investors do not only face uncertainty from volatile electricity prices, but also from potentially stricter climate change policy in the near future, i.e. both output prices and costs at the production side are subject to uncertainties. As we have already pointed out above, climate change policy is inherently uncertain. The main argument why policy-makers have not been urged to make clear commitments yet is that the science of climate change is still not sufficiently advanced to distill clear signals for action: predicting exactly the required timing and the extent of mitigation measures remains difficult. Thus, further down in the causal chain, climate policy signals to energy producers are highly uncertain. Un- or overambitious actions may - due to technological path-dependencies ${ }^{1}$ and lags of policy responses to uncertain global warming signals - fundamentally reshape future market positions of energy companies. The energy producer may want to avoid costly investments by waiting for climate policy uncertainty to diminish. On the other hand, this uncertainty may squander the chance to an early-mover advantage laying the foundation for a strong and possibly less volatile growth path. At the same time, overly ambitious actions can lead to scarce resources being irrecoverably committed, which might have been more profitably spent on other opportunities than implementing mitigation technologies.

To be more specific about the types of uncertainties that we will concentrate on in this chapter, the uncertainty that is associated with electricity prices could be called "risk" in a Knightian sense, since it deals with fluctuations in the electricity price. Market forces will eventually turn the electricity price back to its equilibrium, even if temporarily disturbed by small shocks. This is why we model electricity prices as a

\footnotetext{
${ }^{1}$ This ties back to the irreversibility of investment and the fact that if huge sunk costs are involved, as in the case with power plants, they will most likely also be fully utilized throughout their lifetime.
} 
mean-reverting process and call the uncertainty emanating from the volatility of the price process "market uncertainty".

However, even though we want to account for the volatility of output prices, we are mainly interested in the "market uncertainty" with respect to $\mathrm{CO}_{2}$ prices. The fluctuations associated with the $\mathrm{CO}_{2}$ price can have different origins. The most simple one would be a trading scheme, where the $\mathrm{CO}_{2}$ price is the price of an emissions permit. Alternatively, the volatility could arise from small changes in regulations on a regional or national scale, e.g. when procedures of measurement change. However, these fluctuations would be more sporadic and we prefer to think of the $\mathrm{CO}_{2}$ price as the outcome of permit trading.

More fundamentally, we are also looking at "policy uncertainty" and this is not about the fluctuations around a mean or a trend, but about the direction of the $\mathrm{CO}_{2}$ price development and the effect that shifts in prices can have on the investment behavior. The direction of the (previously rising) $\mathrm{CO}_{2}$ price can change, for example, if a government is engaged in post-2012 carbon agreement negotiations and the investor is not sure if these negotiations will be successful or not and if the government will ultimately commit to further increases in carbon prices or abolish such measures at all. While the government might initially have been raising the $\mathrm{CO}_{2}$ price slightly on a national basis, it might decide that more stringent (and thus further rising) $\mathrm{CO}_{2}$ prices are not an economic option for its country and therefore keep the $\mathrm{CO}_{2}$ price at the old level or even decrease it. Another explanation why the direction may change is a change in regulations such as an increase in the number of permits or a change in the allocation mechanism. Figure 3.1 shows such a sharp drop for the European $\mathrm{CO}_{2}$ price, for example. While prices had been rising from the end of 2005, they fell abruptly in the first half of 2006 and fluctuated widely around $16 €$ during the second half of 2006. The reason for this development was that some European countries distributed too many permits to their industries. The resulting surplus in permits and an announcement by the Commission that more $\mathrm{CO}_{2}$ emissions had been saved than necessary led to a sharp decrease in $\mathrm{CO}_{2}$ prices. So, another reason for such a shift can also be the way in which a policy is carried out. ${ }^{2}$ The fact that national allocation schemes were not monitored led to a very unstable $\mathrm{CO}_{2}$ price and thus uncertainty for the investor. Since such trading schemes and also other national policy instruments are still in their infancy, it is difficult to predict if another drop of this magnitude might occur again, even though Phase II prices have developed in a much more stable way so far. In the same vein, there might also be sharp increases, as more evidence about the urgency to reduce emissions accumulates. We find that the uncertainty-investment relationship is actually different for these different types of uncertainty. While market uncertainty typically leads the investor to act earlier (as long as prices are not exhibiting a decreasing trend), policy uncertainty raises

\footnotetext{
${ }^{2}$ The same is true for the way subsidies are handled. If they are determined periodically and the investor is not sure whether he will be eligible for the subsidy in the next period, there is a value to waiting for the decision to be revealed before investments are made. This has led to cyclical investment patterns in the German solar industry, for example (Bakshi, 2007).
} 
the option value of waiting substantially and therefore leads to a postponement of investment into environmentally friendly technology.

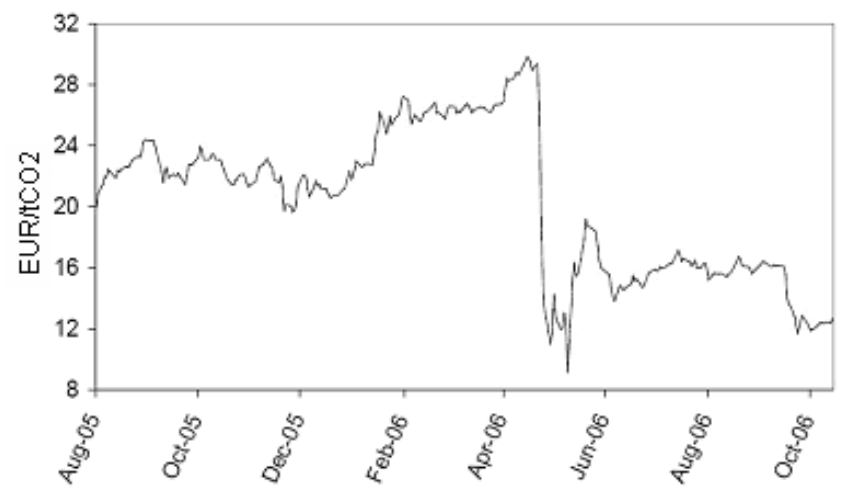

Source: European Energy Exchange Corporation (EEX) in Leipzig, Germany.

Figure 3.1: $\mathrm{CO}_{2}$ Permit Prices in $€ / E U A\left(1 \mathrm{EUA}=1\right.$ ton of $\left.\mathrm{CO}_{2}\right)$

In this chapter we illustrate the importance of stable climate policy signals for the diffusion of carbon capture and storage (CCS) technology in the electricity sector using real options theory. Furthermore, we analyze the effects of $\mathrm{CO}_{2}$ price volatility on investment decisions because it has been claimed that this type of market uncertainty, which could arise from permit trading, might lead investors to defer costly investments into environmentally friendly technologies. Chao and Wilson (1993), for example, study the market for emission allowances (i.e. permits) and find that a volatile market leads to postponement of investment into mitigation technology (in their case the installation of scrubbers).

We have chosen real options modeling as an approach because it is particularly suited for the analysis of uncertainty's effects on investment decisions. Real options modeling is especially suited for an analysis of investment under uncertainty in the electricity sector because of the investment setting that involves huge sunk costs up front. Noting the reluctance of investors to incur such large costs ex ante that will be irrecoverable ex post, the approach is based on the fact that, as more information about the uncertain variables relevant for the decision becomes available, staying flexible by postponing decisions has an option value if the degree of uncertainty faced is big enough. Real options theory thus explicitly associates a value with this opportunity to wait. ${ }^{3}$

${ }^{3}$ Please go back to Chapter 2 for more technical detail and an overview of the seminal literature. Note that a multi-stage stochastic programming model could be designed, which would result in the same outcomes as those presented here. However, stochastic programming tends to get computationally too intensive when there are many periods and scenarios, since it requires decision-making at each stage - based on the prior history of events and decisions. Similar problems of dimensionality arise in the case of stochastic optimal control problems 
Furthermore, we have decided to focus on the electricity sector because it makes up a major part of total anthropogenic $\mathrm{CO}_{2}$ emissions. Moreover, we choose to examine coal-fired electricity production because coal is the fuel, which will be affected most severely by the imposition of a $\mathrm{CO}_{2}$ tax or the introduction of emissions permit trading. Finally, since the debate of introducing permit trading in the US has resurfaced recently and price caps have been proposed as a safety valve for the investor fearing $\mathrm{CO}_{2}$ price uncertainty (e.g. Pizer, 2005), we also use the model developed in this chapter to analyze these issues in more detail.

In the remaining chapter, we will first give a very brief overview of the related literature and define our contributions to the existing work in this field. In Section 3.3, a description of the real options framework applied to the investment problem of the electricity producer is given. This is followed by a presentation of the model and continues with an explanation of the solution methods employed. Afterwards, the results are presented, including an overview of the data used and experiments conducted to analyze the impact of the different types of uncertainty mentioned above, followed by a conclusion.

\subsection{Related Literature and Contribution}

A disquisition of real options theory and its application to the electricity sector can be found in Chapter 2, which also provides an in-depth, general literature review and an outline of the contribution to the existing work in this field. In order to give a short overview of how this particular chapter fits into the literature, Table 3.1 briefly summarizes the studies most closely related to ours.

What can be concluded from Table 3.1 is that all but one of the studies focus on market uncertainty, by which we mean the fluctuations in a price path with known trend. Only Reedman et al (2006) investigate policy uncertainty, i.e. uncertainty whether there will be a price (on $\mathrm{CO}_{2}$ ) at all. They model this in a very simplistic way, however. Our framework is much more elaborate and allows us to clearly distinguish between the two types of uncertainty (market versus policy uncertainty) that all other studies only treat separately. While Reedman et al (2006) analyze uncertainty about the timing of policy, we will not cover this again, but focus on policy uncertainty where the date of the new policy is known (e.g. the end of an existing climate change agreement and the date of deciding about a new policy stance - such as it will be the case in 2012), but the policy itself is unknown (e.g. "Will the government commit to further increases in the $\mathrm{CO}_{2}$ price or will it have an own, national $\mathrm{CO}_{2}$ tax, which is much lower than the permit price was expected to be?").

such as real options models when there are many possible states. Since in the case at hand there are many periods and a modest state space, multi-stage dynamic programming is not the optimal solution method for our problem (see Cheng et al (2004) for a detailed comparison of the two approaches). 


\begin{tabular}{|c|c|c|c|}
\hline Author(s) & Model & Uncertainty & Investment Response \\
\hline $\begin{array}{l}\text { De Jong, Oosterom } \\
\text { and Walet (2004) }\end{array}$ & $\begin{array}{l}\text { Adjust NPV for options to defer and abandon } \\
\text { an investment into a plant emitting less } \mathrm{CO}_{2} \text {. }\end{array}$ & $\begin{array}{l}\text { Market } \\
\text { uncertainty }\end{array}$ & $\begin{array}{l}\text { More volatility in } \mathrm{CO}_{2} \text { price } \\
\text { leads to postponement of invest- } \\
\text { ment. }\end{array}$ \\
\hline $\begin{array}{l}\text { Laurikka } \quad(2006) ; \\
\text { Laurikka } \quad \text { and } \\
\text { Koljonen }(2006)\end{array}$ & $\begin{array}{l}\text { Stochastic electricity and } \mathrm{CO}_{2} \text { prices. Add op- } \\
\text { tion value (to switch between fuels, to switch } \\
\text { outputs (power vs heat), to alter operation } \\
\text { scale) to NPV instead of using asset pricing. } \\
\text { Focus on trading schemes. }\end{array}$ & $\begin{array}{l}\text { Market } \\
\text { uncertainty }\end{array}$ & $\begin{array}{l}\text { Permit price fluctuations might } \\
\text { make lower emission plants less } \\
\text { attractive. Results depend cru- } \\
\text { cially on permit price level. }\end{array}$ \\
\hline $\begin{array}{ll}\text { Kiriyama } & \text { and } \\
\text { Suzuki }(2004) & \end{array}$ & $\begin{array}{l}\text { Stochastic permit prices. Value function in- } \\
\text { cludes stock of } \mathrm{CO}_{2} \text { emissions as negative ex- } \\
\text { ternality. Compare value of different types of } \\
\text { power plants separately, i.e. no switching. }\end{array}$ & $\begin{array}{l}\text { Market } \\
\text { uncertainty }\end{array}$ & $\begin{array}{l}\text { Nuclear power plant outperforms } \\
\text { all others. }\end{array}$ \\
\hline $\begin{array}{l}\text { Reedman, Gra- } \\
\text { ham and Coombes } \\
(2006)\end{array}$ & $\begin{array}{l}\text { No stochastic process, but a } 10 \% \text { chance that } \\
\text { a (constant) } \mathrm{CO}_{2} \text { tax is levied within the next } \\
\text { ten years. }\end{array}$ & $\begin{array}{l}\text { Policy uncer- } \\
\text { tainty }\end{array}$ & $\begin{array}{l}\text { Uncertainty (about the timing } \\
\text { of a constant } \mathrm{CO}_{2} \text { tax) makes } \\
\text { investment into emission-saving } \\
\text { technologies unattractive. }\end{array}$ \\
\hline $\begin{array}{l}\text { Blyth and Yang } \\
(2007)\end{array}$ & $\begin{array}{l}\text { Stochastic electricity and carbon prices, where } \\
\text { there can be jumps in the price of carbon due } \\
\text { to new policy. }\end{array}$ & $\begin{array}{l}\text { Policy and } \\
\text { market } \\
\text { uncertainty }\end{array}$ & $\begin{array}{l}\text { Potential jumps in the carbon } \\
\text { price create uncertainty, which } \\
\text { raises the option value of invest- } \\
\text { ment and leads to postponement } \\
\text { of investment in emission-saving } \\
\text { technology. }\end{array}$ \\
\hline $\begin{array}{l}\text { Reinelt and Keith } \\
(2007)\end{array}$ & $\begin{array}{l}\text { Stochastic gas prices; regulatory uncertainty } \\
\text { modeled through different probabilities that } \\
\mathrm{CO}_{2} \text { prices of different magnitudes will be im- } \\
\text { plemented on different dates. }\end{array}$ & $\begin{array}{l}\text { Policy and } \\
\text { market } \\
\text { uncertainty }\end{array}$ & $\begin{array}{l}\text { Social cost of carbon abatement } \\
\text { increases with regulatory uncer- } \\
\text { tainty; effect is enhanced when } \\
\text { gas prices are low or plants that } \\
\text { can be retrofitted with CCS not } \\
\text { competitive. }\end{array}$ \\
\hline
\end{tabular}

Table 3.1: Real Options Literature on $\mathrm{CO}_{2}$ Price Uncertainty 
A more elaborate framework in that direction is by Reinelt and Keith (2007), who - similar to Reedman et al (2006) - consider both uncertainty about the date and the magnitude of the $\mathrm{CO}_{2}$ tax. They investigate the flexibility that CCS technology offers to the investor and find that the social cost of abatement is increased by regulatory uncertainty and that this effect is even enhanced when gas prices are low or IGCC plants that can be retrofitted with CCS are not sufficiently competitive.

The contribution of our paper is to illustrate explicitly how market uncertainty (about time-dependent electricity and $\mathrm{CO}_{2}$ price paths) and policy uncertainty influence the investment decisions in the electricity sector. To our knowledge, none of the existing energy planning literature has addressed the impacts arising from different qualities of uncertainty surrounding $\mathrm{CO}_{2}$ price policy in the specific way that we do this. Blyth and Yang (2007) also model carbon and energy prices as stochastic processes and point to the usefulness of analyzing the impact of carbon price jumps to model the uncertainties pervading the policy-making process.

Apart from analyzing the difference between market and policy uncertainty in one coherent framework, we add to the existing literature in a number of other respects. First, many studies focus on the type of trading scheme when they include stochastic permit prices. Laurikka and Koljonen (2006), for example, analyze the case where the number of permit is an uncertain number and where the cash flows from the allocation of free allowances matters therefore as well.

Even though this will be of importance when a country has to decide how to implement a trading scheme, we are not interested in the design of such schemes, but want to focus on the effect of a $\mathrm{CO}_{2}$ penalty as such - no matter whether it is interpreted as the price of a permit or an adaptable tax. We think that it is more important to first determine the direction of effects before analyzing the type of instrument.

With respect to the methodology, some studies use the so-called "dynamic cash flow" method to value the investment under consideration. In other words, they add the option value to the "standard" net present value (NPV), whereas we think that it is more appropriate (even though admittedly computationally more intensive) to use asset pricing theory, following the approach in Dixit and Pindyck (1994).

Another methodological innovation that is inherent in our approach is that we are able to investigate the investment response under different perceptions of the price paths ex ante and ex post, which relates back to the difference between market and policy uncertainty mentioned above. To be more precise, we make a distinction between the volatility perceived when deriving the optimal investment strategy for each possible price realization and the volatility that the investor actually faces when picking the decision. This is a method that none of the studies listed in Table 3.1 considers. What this basically means in real options terms is that the price thresholds, beyond which it becomes profitable to invest, are derived under a fixed "expected" volatility parameter. However, once the decision is picked according to a realized price path, we assume this volatility parameter to be zero, i.e. the actual investment decision is picked under certainty, according to the "actual" volatility parameter of zero. However, the 
set of available decisions was computed under uncertainty, i.e. under incomplete information. Therefore, the thresholds found in the optimization are not the same as when the investor optimizes under perfect information. In that case investment would occur later. However, additional experiments show that this decision-making under incomplete information does not hurt the investor considerably. An additional effect, which should be valued positively, is that a large amount of emissions can be saved in the meantime.

Furthermore, only Laurikka and Koljonen (2006) incorporate the possibility into their model that the fluctuations in the price can be smoothed out by passing some of the additional cost on to consumers. In our model we also take this into account by letting the correlation between the noises of the electricity and $\mathrm{CO}_{2}$ price process be correlated. Note that this is no contradiction to using mean-reverting prices, while $\mathrm{CO}_{2}$ prices are rising, since only the errors are correlated, i.e. only spikes can be passed on to the consumer to a specified degree.

To summarize, notwithstanding the importance of the design of permit trading schemes, taxes or the timing of policy measures, the focus and also the main novelty of our work is to add new insights to the different types of $\mathrm{CO}_{2}$ price uncertainty and to derive important implications for the behavior of both investors in the electricity sector and policy makers, who strive for a transition towards environmentally more friendly generation technologies. We find that the investment response to market uncertainty indeed differs quite substantially from that to policy uncertainty. More precisely, market uncertainty induces earlier investment into lower emission technology (because the lack of information under which the set of optimal actions is derived leads to lower $\mathrm{CO} 2$ price thresholds, i.e. investment into carbon capture becomes attractive sooner), while policy uncertainty increases the option value drastically and thus leads the investor to postpone investment until the new policy stance is realized, even if the investor is incurring losses in the meantime.

\subsection{A Real Options Framework for the Electric- ity Sector}

This model intends to determine the optimal investment plan for a single electricity producer facing stochastic electricity and $\mathrm{CO}_{2}$ prices. Furthermore, the possibility of learning about climate change policy and the potentially drastic changes to $\mathrm{CO}_{2}$ prices enables us to determine the effect of government pre-commitment to an environmentally sound policy agenda. A real options framework is especially suited for this purpose because it explicitly associates a value to acquiring information by waiting.

The planning horizon is 50 years. The options available to the investor are: (1) to determine whether to invest into the basic coal-fired power plant or into the plant including a CCS module, (2) to retrofit the existing plant with a CCS, (3) to switch the installed module on and off in the face of large $\mathrm{CO}_{2}$ price swings. If a CCS module is switched on, the amount of electricity generated is lower and the operational costs 
higher, but the cost arising from carbon payments is lower. ${ }^{4}$ Note that only for high initial $\mathrm{CO}_{2}$ prices investors would prefer to build the plant including the CCS module immediately. But what happens when producers cannot be sure of the future level of $\mathrm{CO}_{2}$ prices? International, post-2012 carbon agreements are still under debate and may or may not result in commitments to stricter levels of emissions reductions and higher $\mathrm{CO}_{2}$ prices.

\subsubsection{The Model}

The uncertainties that arise in the context of the electricity generator's investment problem are two-fold. On the one hand, there is uncertainty with respect to electricity prices. On the other hand, the production cost is influenced by fluctuations in the price of $\mathrm{CO}_{2}$ emissions. On top of this, two types of uncertainty are analyzed, as mentioned before. The first one is market uncertainty, which is represented by the risks involved in the volatility of a price path, while the second type is policy uncertainty, which concerns not the fluctuations, but the direction of a price path depending on the actions of the government. Also, there are different types of cost that influence the optimal investment plan, which are not treated as uncertain. The cost of capital is taken to be constant and deterministic, which ignores the possibility of technical improvements. However, we omit this on purpose in order to get as clear a picture as possible of the effect of uncertain policy and prices - i.e. free of interaction effects. ${ }^{5}$

Moreover, capital is not divisible in this model implying that the investor has the choice to invest either into the complete plant (with or without CCS module), or to leave the investment opportunity open. Other prices that are neither growing nor stochastic are coal prices, ${ }^{6}$ operations and maintenance cost (O\&M) and the cost of switching between technologies. Furthermore, the assumption is made that installing a power plant also implies that is immediately used, i.e. there is no delay in the realization of the payoffs. ${ }^{7}$

When analyzing the impact of market uncertainty, the assumption is that electricity prices follow a mean-reverting process, which has generally been found to be a

\footnotetext{
${ }^{4}$ Since it is assumed that a fixed amount of output has to be supplied, this output deficit needs to be balanced by the import of electricity from external sources at the current electricity spot market price.

${ }^{5}$ Uncertainty of technical change in a real options framework is analyzed in Chapter 4.

${ }^{6}$ This can be justified considering the possibility of engaging in long-term supplier contracts, especially in the case of coal, which is often traded forward. In addition, the planning period is only 50 years and coal prices have been projected to remain rather stable in the near future.

${ }^{7}$ Construction times could be included easily, but we leave them aside for the moment, since this is not our focus and would not change the results qualitatively (if we expand the planning horizon), unless lead times would be dramatically different between different types of plants. Chladná et al (2004), who use a similar setup to investigate the pulp and paper sector, also claim that disregarding this aspect has no impact on the interpretation of the simulation results (Chladná et al (2004), pages 22-23).
} 
good approximation. ${ }^{8}$

$$
d P_{t}^{e}=\alpha \cdot\left(\mu^{e}-\ln P_{t}^{e}\right) \cdot P_{t}^{e} \cdot d t+\sigma^{e} \cdot P_{t}^{e} \cdot d W_{t}^{e}
$$

So, the price of electricity $P^{e}$ will revert to its long-term level $e^{\mu^{e}}$ at a speed of $\alpha . d W_{t}^{e}$ is the increment of a standard Wiener process and $\sigma^{e}$ is the corresponding volatility parameter. For $\mathrm{CO}_{2}$ prices, a geometric Brownian motion has been chosen, even though it is difficult to predict future $\mathrm{CO}_{2}$ price behavior, which is the very topic of this paper. However, a rise in $\mathrm{CO}_{2}$ prices is in accordance with projections by most forecasts (see e.g. the GHG shadow prices of the GGI Scenario Database (IIASA, 2007)).

$$
d P_{t}^{c}=\mu^{c} \cdot P_{t}^{c} \cdot d t+\sigma^{c} \cdot P_{t}^{c} \cdot d W_{t}^{c}
$$

where $\mu^{c}$ is the drift parameter, $\sigma^{c}$ is the volatility parameter and $d W_{t}^{c}$ is the increment of a Wiener process again. Furthermore, the increments of the two Wiener processes are correlated, where the correlation parameter is denoted by $\rho$. A positive value for $\rho$ implies that swings in $\mathrm{CO}_{2}$ prices are positively reflected in those of electricity prices, which makes intuitive sense thinking of producers, who will try to pass these extra costs - at least partially - on to consumers. Laurikka and Koljonen (2006) also acknowledge this possibility and allow for a correlation parameter of 50\%. Reinard (2007) reviews several studies that find empirical evidence for the fact that $\mathrm{CO}_{2}$ costs are passed on to power prices by suppliers. Estimates lie in between $40 \%$ and $72 \%$. Even though it is emphasized that the results depend crucially on marginal price setting, country characteristics, loads and other factors, we have decided to take the results as evidence of positive correlation and pick a value of $70 \%$ for our analysis. ${ }^{9}$

Market uncertainty (which could also be called risk in a Knightian sense) can be analyzed by varying the values for $\sigma^{e}$ in Equation (3.3.1) and $\sigma^{c}$ in the second equation. ${ }^{10}$ Policy uncertainty, on the other hand, concerns the form of Equation (3.3.2). In the experiments that we will conduct in Section 3.4, we investigate what happens to investment, when the $\mathrm{CO}_{2}$ price first rises and investors are not sure if it will continue to do so. We implement this by starting out with a positive value for the drift parameter $\mu^{c}$, which turns negative or remains positive with equal probabilities at a specified date later on. This will enable an analysis of investors' reactions to policy uncertainty.

The investor thus faces an optimization problem of timing his/her decision to

\footnotetext{
${ }^{8}$ Bodily and Del Buono (2002) actually show that, to be even more realistic, the meanreverting process should be combined with a geometric Brownian motion, so that priceproportional volatility can be taken into account as well. They call this the mean-reverting proportional volatility (MRPV) model, but we refrain from such complex processes for now, since our focus is primarily on the uncertainty connected to the $\mathrm{CO}_{2}$ price process.

${ }^{9}$ This is of course arbitrary, but sensitivity analysis has shown that the results are not decisively determined by the value of $\rho$. It should be noted that there is no contradiction when assuming rising $\mathrm{CO}_{2}$ prices, mean-reverting electricity prices and a positive value for $\rho$, since $\rho$ only denotes the correlation between errors and thus only $\mathrm{CO}_{2}$ price spikes are partially passed on to consumers and not the trend per se.

${ }^{10} \mathrm{We}$ will restrict ourselves to analyze the market uncertainty arising from stochastic $\mathrm{CO}_{2}$ prices in this paper. This enables us to make a clear comparison with the effects of policy uncertainty, which also works through the $\mathrm{CO}_{2}$ price.
} 
invest into the CCS module so that the sum of discounted expected future profits is maximized. The yearly profit $\pi$ consists of income from electricity generation and heat less the cost of fuel and the payments for $\mathrm{CO}_{2}$ emissions, operational costs and costs associated with the action, $c\left(a_{t}\right)$. The production function is of the Leontieff type, which means that coefficients are fixed. Since we can assume that all electricity (and heat), which is generated can be sold to the grid inelastically, ${ }^{11}$ the installed plant will be run continuously thereby producing a fixed amount of output for a fixed amount of inputs per year. Therefore, as quantities are not influenced, any deviations in investment behavior must be due to price uncertainty.

So the yearly profits of the power plant can be calculated as

$$
\begin{aligned}
\pi\left(x_{t}, a_{t}, P_{t}^{e}, P_{t}^{c}\right) & =q^{e}\left(m_{t}\right) \cdot P_{t}^{e}+q^{h}\left(m_{t}\right) \cdot P^{h}-q^{c}\left(m_{t}\right) \cdot P_{t}^{c} \\
& -q^{f}\left(m_{t}\right) \cdot P^{f}-O C\left(m_{t}\right)-c\left(a_{t}\right)
\end{aligned}
$$

where $P^{f}$ is the price of coal, $P^{h}$ is the price of heat, $O C$ is the operational cost per year, the $q$ refer to annual quantities of electricity, heat, carbon dioxide and fuel respectively, and $m_{t}$ denotes the type of power plant that is operational at time $t$ determined by state and action, $\left(x_{t}, a_{t}\right)$. If $m_{t}=1$, the coal-fired power plant without CCS is active. For $m_{t}=2$, the CCS module is switched on as well. It is important to take note of the tradeoffs involved in this profit equation: while the amount of electricity generated will be lower and the operational cost higher if a CCS module is added, the cost arising from carbon payments will be lower, since $q^{c}(2)<q^{c}(1)$. In order to give the reader a feeling of how significant this difference in carbon emissions is, please consider that in our case the coal-fired power plant without CCS emits about $740 \mathrm{~g}\left(\mathrm{CO}_{2}\right) / \mathrm{kWh}$, whereas the one with CCS produces only $133 \mathrm{~g}\left(\mathrm{CO}_{2}\right) / \mathrm{kWh}$ for the same amount of combusted coal, ${ }^{12}$ which is more than seven times less than the plant without CCS emits.

Moreover, as described by Equations (3.3.1) and (3.3.2), the investor assumes that prices for electricity and $\mathrm{CO}_{2}$ both follow stochastic processes with known starting values. The investor has to solve the problem

$$
\begin{gathered}
\max _{a_{t} \in A_{t}\left(x_{t}\right)}\left\{\sum e^{-r \cdot t} \cdot \mathbb{E}\left[\pi\left(x_{t}, a_{t}, P_{t}, P_{t}^{c}\right)\right]\right\} \\
x_{t+1}=F\left(x_{t}, a_{t}\right) \\
d P_{t}^{c}=\mu^{c} \cdot P_{t}^{c} \cdot d t+\sigma^{c} \cdot P_{t}^{c} \cdot d W_{t}^{c} \\
d P_{t}^{e}=\alpha \cdot\left(\mu^{e}-\ln P_{t}^{e}\right) \cdot P_{t}^{e} \cdot d t+\sigma^{e} \cdot P_{t}^{e} \cdot d W_{t}^{e},
\end{gathered}
$$

where $A_{t}\left(x_{t}\right)$ is the set of feasible actions for a given state $x_{t} \cdot{ }^{13} r$ is the discount rate

\footnotetext{
${ }^{11}$ This assumption can be justified by acknowledging that distributors will engage into output contracts with generators, specifying amounts of electricity and heat that will be bought off for a prolonged period of time.

${ }^{12}$ These data have been derived from the yearly emissions and electricity generated, see Table 3.2.

${ }^{13}$ Switching the CCS module on when it has not been installed is an example of an infeasible action.
} 
and therefore $e^{-r \cdot t}$ is the discount factor, i.e. the factor by which future profits to be received at time $t$ must be multiplied in order to obtain the present value. The actions can be summarized as follows: the investor has to install a power plant in the first period by constraint. This could be the coal-fired type without CCS or immediately the one with CCS. In the first case the CCS module can be added later on. In any case, the module can be switched off at any subsequent point in time. Of course, doing nothing is an option as well. ${ }^{14}$

\subsubsection{Solution Methods}

Based on the outline of the model, the investor's problem is to determine the optimal investment strategies $\{a(t)\}_{t=1}^{T}$. The planning horizon is $T$ and in our application $T$ will be equal to 50 . The optimum decision in each year can be obtained recursively by solving the Bellman equation:

$$
\begin{aligned}
V_{t}\left(x_{t}, P_{t}^{e}, P_{t}^{c}\right) & =\max _{a_{t} \in A_{t}\left(x_{t}\right)}\left\{\pi\left(x_{t}, a_{t}, P_{t}^{e}, P_{t}^{c}\right)\right. \\
& +e^{-r} \cdot \mathbb{E}\left(V_{t+1}\left(x_{t+1}, P_{t+1}^{e}, P_{t+1}^{c}\right) \mid P_{t}^{e}, P_{t}^{c}\right)
\end{aligned}
$$

The right-hand-side of the equation can be decomposed into the sum of the immediate profit, $\pi\left(x_{t}, a_{t}, P_{t}^{e}, P_{t}^{c}\right)$, which the producer receives upon investment, and the expected, discounted continuation value: $e^{-r} \cdot \mathbb{E}\left(V_{t+1}\left(x_{t+1}, P_{t+1}^{e}, P_{t+1}^{c}\right) \mid P_{t}^{e}, P_{t}^{c}\right)$. It is important to note that this term is evaluated for the state the producer is in, which changes contingent on the actions undertaken.

The optimal action to be taken at time $t$ shall be called $a_{t}$. In other words, $a_{t}$ is the decision that maximizes the sum in Equation (3.3.4). For the computation of the term $\mathbb{E}\left(V_{t+1}\left(x_{t+1}, P_{t+1}^{e}, P_{t+1}^{c}\right) \mid P_{t}^{e}, P_{t}^{c}\right)$ forward Monte Carlo simulation has been chosen. ${ }^{15}$ The advantage of the Monte Carlo approach is that it is relatively easy to extend. Also, it has proven to remain efficient in this framework for a rather high degree of complexity and delivers the same results as the partial differential equations approach. Although the method of using partial differential equations along with appropriate boundary conditions is mathematically the most elegant way, this approach has proven - once numerically implemented - to be inflexible to variations and extensions and also computationally intensive when using a finer grid. The third method to find the optimum decisions involves binomial lattice frameworks or binomial decision trees. Even though these are very intuitive and rather flexible when introducing multiple uncertainties and concurrent options, they also tend to get computationally very intensive and therefore not very suitable for our purposes. Of the work reviewed in the introduction, there are various studies that also use Monte Carlo simulation for real options modeling in the electricity sector, e.g. Tseng and Barz (2002), who focus

\footnotetext{
${ }^{14}$ This implies that the set of feasible actions at $t+1$ is essentially a fraction of all actions taken previously. You can switch off a module only if has previously been installed, for instance.

${ }^{15}$ Note that this numerical method - as well as the partial differential equations approach requires the discretization of prices, so a relatively fine price grid is needed in order to obtain precise results.
} 
on short term generation, and Laurrika and Koljonen (2006), who adopt long term planning horizons. ${ }^{16}$

The output of the recursive part is a multidimensional matrix containing the optimum action $a_{t}$ for every $t, x_{t}, P_{t}^{e}$ and $P_{t}^{c}$. These optimum actions are further referred to as "strategies." In order to analyze the final outcome, possible price paths are simulated and the corresponding decisions are extracted from the output (this is called "picking decisions"). By plotting the distribution of the optimal investment timing for all the different price paths, the final results are generated. These results are therefore obtained in two independent steps: the first is the recursive optimization part that computes the strategies representing the optimal decision of the producer for each possible state. The second step is the simulation of future price paths and "picking" the decisions out of the previously obtained strategies. It will therefore be possible to conduct experiments, in which the expected volatility is positive, while the actual volatility turns out to be zero. That implies that the optimal strategies are computed under uncertainty, but when the actual decisions are picked, there is only one true price path. By comparing this outcome to the result when both steps are conducted without volatility, a measure of the uncertainty effect (or lack of information), that has kept the investor from finding the same optimal strategies as in the deterministic case, can be obtained.

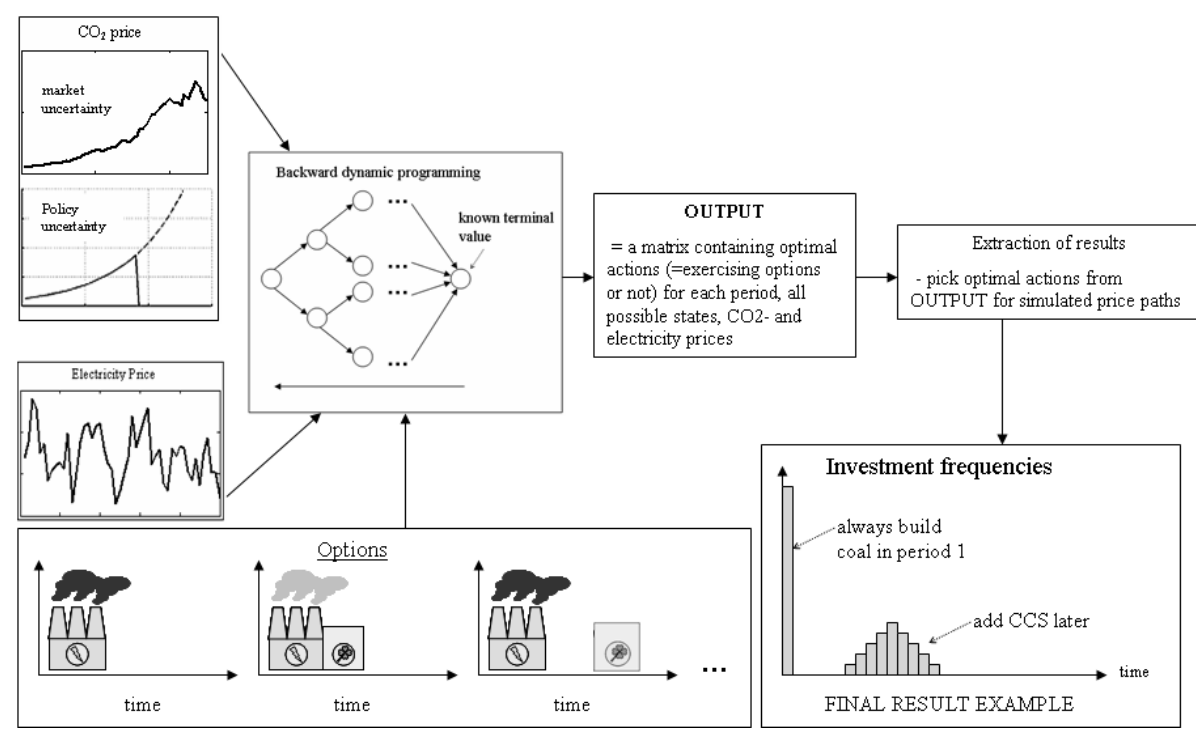

Figure 3.2: Diagram of the Solution Method

This is all summarized in Figure 3.2, where the price processes (Equations (3.3.1) and (3.3.2)) and the options ${ }^{17}$ are inputs to the optimization part, solving Equation

\footnotetext{
${ }^{16}$ More on these methods can be found in Kaminski et al (2004), who elaborate on the pricing of energy options and the methodologies involved.

${ }^{17}$ The options shown are building the coal-fired power plant in the first period, building it
} 
(3.3.4). The results are extracted from the output of this optimization by simulating many different price paths and picking the optimal decisions previously calculated. One example of the resulting investment frequencies is displayed in Figure 3.2.

\subsection{Experiments and Results}

It has been suggested that increased uncertainty about the future price of $\mathrm{CO}_{2}$ emissions might reduce the firm's investment incentives with respect to abatement capital and less carbon-intensive technologies (see e.g. Chao and Wilson, 1993). However, we think that one has to make a distinction here between two types of uncertainty. On the one hand, there is uncertainty due to stochastically moving prices, where trend and volatility are known to investors. This kind of uncertainty can result from trading emissions permits, minor amendments to national policies aimed at reducing $\mathrm{CO}_{2}$ emissions, and changes in the cost structure of particular technologies. Therefore, we call this type of uncertainty "market uncertainty" - it is uncertainty generated by market processes. The question then is if a higher degree of market uncertainty will lead to less or later investment into carbon-saving equipment or not. On the other hand, there is also uncertainty emanating from the fact that investors cannot be sure how e.g. a post-2012 carbon agreement will be designed. More precisely, investors do not know in advance how international climate change negotiations will turn out and whether their own government will commit to further raising $\mathrm{CO}_{2}$ prices (i.e. a continuation of the trend) or whether it will deem climate change mitigation a goal inferior to economic aspirations and decrease the $\mathrm{CO}_{2}$ price subsequently. Such a change in trend has significant implications for the investment pattern with respect to mitigation technology, as we will see in the analysis of this section.

In terms of our experimental setting, if climate change policy negotiations fail, investors will most probably not want to be "stuck" with a CCS module, which is an irreversible investment, as it cannot be resold without considerable losses once installed. At the same time, if they postpone investments into CCS, they will face losses if prices continue to be positive during the negotiation period. It has to be determined, which of the two effects dominates to find out if investments are really postponed in response to this type of uncertainty, which we call "policy uncertainty."

In the following, we will first describe the data for the two power plants and then conduct a series of experiments to shed some light on the investment responses to market and policy uncertainty.

\subsubsection{Data Description}

As already explained above, this analysis is about a coal-fired power plant, which can be retrofitted with a CCS module. Switching the CCS module on and off is relatively inexpensive compared to installing the full module (it comprises only $1 \%$ of total

immediately with CCS and first building the coal-fired power plant and later adding the CCS (from top to bottom). The three dots indicate that there are more options not displayed here, such as switching the CCS module off and on. 
capital costs). Apart from the electricity, a certain amount of heat is generated as a byproduct of the power generation process. Heat is a byproduct of power generation. Although the heat rate is the same for the coal-fired power plant with and without CCS and thus does not change the results in favor of any of the two, heat profits are included for two reasons: (1) The data are from a survey of real-world power plants and the goal is to remain as close to reality as possible. (2) Heat is an additional profit source for the coal-fired power plant owner, which provides more time for retrofitting, i.e. there will be a longer time span during which a higher amount of $\mathrm{CO}_{2}$ is emitted into the atmosphere. Excluding heat profits from the analysis would create a distorted picture, where the investor would choose the CCS module much earlier than in reality. We therefore assume that the producers are able to sell the full amount of this heat at the current spot market price. Table 3.2 below gives an overview of the data that are used for this analysis.

\begin{tabular}{lrll}
\hline Parameters & & Coal & Coal with CCS \\
\hline Electricity Output & {$[\mathrm{TJ} / \mathrm{yr}]$} & 36,188 & 29,107 \\
$\mathrm{CO}_{2}$ Emissions & {$[\mathrm{tCO} / \mathrm{yr}]$} & $7,442,050$ & $1,079,097$ \\
Fuel Consumption & {$[\mathrm{TJ} / \mathrm{yr}]$} & 78,669 & 78,669 \\
Fuel Cost & {$[\$ / \mathrm{TJ}]$} & 1,876 & 1,876 \\
O\&M Fixed Cost & {$[\$ / \mathrm{yr}]$} & $57,375,000$ & $70,581,522$ \\
Switching Cost & {$[\$]$} & $1 \%$ of capital cost & $1 \%$ of capital cost \\
Installed Capacity & {$[\mathrm{MW}]$} & 1,530 & 1,231 \\
Efficiency (Power & {$[\%]$} & 46 & 37 \\
Efficiency (Heat) & {$[\%]$} & 34 & 34 \\
Heat Price & {$[\$ / \mathrm{TJ}]$} & $11,347.48$ & $11,347.48$ \\
Capital Cost & & & \\
Common Parts & {$[\$]$} & $1,664,240,721$ & $1,664,240,721$ \\
Cost CCS Module & {$[\$]$} & & $849,822,693$ \\
Total Capital Cost & {$[\$]$} & $1,664,240,721$ & $2,514,063,414$ \\
\hline
\end{tabular}

Source: World Energy Model of the IEA (2005) and IEA MINUIT Model (2006). Remark: Building the coal-fired power plant without CCS costs 1,664,240,721\$. Adding the CCS module later on costs $849,822,693 \$$. Building the full version right away costs $1,664,240,721 \$$ $+849,822,693 \$=2,514,063,414 \$$.

Table 3.2: Power Plant Data

Furthermore, the parameters of the price processes have to be calibrated. The $\mathrm{CO}_{2}$ prices are modeled based on the projections for GHG shadow prices taken from the GGI Scenario Database (IIASA, 2007). Referring back to Equation (4.1), $\mu^{c}$ is estimated to be 0.0568 and $\sigma^{c}$ as $0.0287\left(\mathrm{CO}_{2}\right.$ prices are measured in $\$ /$ ton of $\left.\mathrm{CO}_{2}\right)$. As for electricity, the estimates for the parameters are based on spot market data (source: EEX time series until 2006). The average price is $37 \$ / \mathrm{MWh}, \alpha$ is estimated to be 0.45564 and $\sigma^{e}$ is 0.092376 . The correlation between electricity and $\mathrm{CO}_{2}$ prices, $\rho$ , is assumed to be 0.7 , which means that electricity producers are able to pass on spikes in the price of $\mathrm{CO}_{2}$ to end consumers to an extent of $70 \%$, as previously explained. More detailed information on the data used to estimate the parameters can be found in the appendix. 


\subsubsection{Effects of Different Types of Uncertainty}

As already explained, a clear distinction is made between uncertainty coming from fluctuations $\left(\sigma^{c}\right)$ around a known trend $\left(\mu^{c}\right)$ of $\mathrm{CO}_{2}$ prices and the uncertainty arising in situations where investors cannot even be sure of the direction that price process will take (i.e. whether $\mu^{c}$ remains positive or becomes zero or even negative), mostly connected with unclear government commitment plans. Keeping the electricity price process unchanged, experiments with both types of uncertainty have been conducted, which lead to quite different results. The experiments are listed in Table 3.3 for reference.

\begin{tabular}{l|l|ll}
\hline Type of uncertainty & & expected $\sigma^{c}$ & actual $\sigma^{c}$ \\
\hline (deterministic) & Experiment 1 & 0.00 & 0.00 \\
(stochastic) & Experiment 2 & 0.0287 & 0.0287 \\
market uncertainty & Experiment 3 & 0.0287 & 0.00 \\
\hline \hline & & $\mu^{c}$ until period 37 & $\mu^{c}$ after period 37 \\
\hline policy uncertainty & Experiment 4 & 0.0568 & 0.0568 or 0 \\
\hline
\end{tabular}

Table 3.3: $\mathrm{CO}_{2}$ Price Experiments

In experiment 1 investors optimize (i.e. find their optimum strategies) under certainty, and pick decisions under zero price volatility as well. Experiment 2 analyzes what happens when investors find optimum strategies under stochastic prices and also face stochastic prices when picking decisions. In experiment 3 investors optimize strategies under stochastic prices, but pick decisions under deterministic prices. Experiment 3 thus serves the analysis of market uncertainty as described before. Experiment 4 looks for the investment response when there is a $50 \%$ chance that the government remains committed to rising $\mathrm{CO}_{2}$ prices $\left(\mu^{c}=0.0568\right)$ and a $50 \%$ chance that it does not $\left(\mu^{c}=0\right)$ after an arbitrary period. This is for the analysis of policy uncertainty and the experiment is repeated for different levels of probabilities and commitment periods.

\section{Market Uncertainty}

Figure 3.3 shows that, in all cases to be considered, the first investment will be into the coal-fired power plant without CCS, since it is cheaper to install and operate, and initial $\mathrm{CO}_{2}$ prices are too low to trigger investment into the CCS module immediately. If $\mathrm{CO}_{2}$ prices were known with complete certainty, i.e. there would be only one upwardsloping line in the lower left panel, investors would add the CCS module in period 29. In Figure 3.3 however, prices are stochastic and therefore there is a spread in CCS investment time (i.e. when the investment option of adding CCS is exercised). Once the CCS module is installed, it is used throughout the whole planning period, as $\mathrm{CO}_{2}$ prices continue to rise. Volatility would have to be large compared to the values used here in order to give the producer an incentive to switch the module off and on later in the planning period. Obviously, if $\mathrm{CO}_{2}$ prices temporarily dropped due to e.g. 
excess supplies of permits or changes in expectations, the CCS module would indeed be switched off.

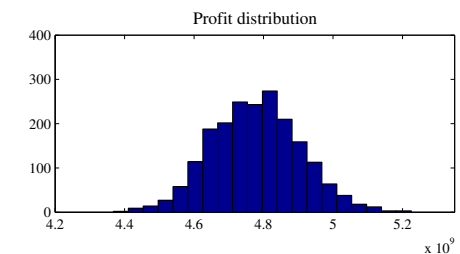

Switching the CCS module on

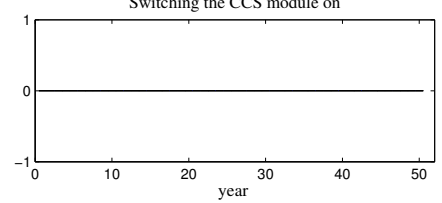

$\mathrm{CO}_{2}$ price

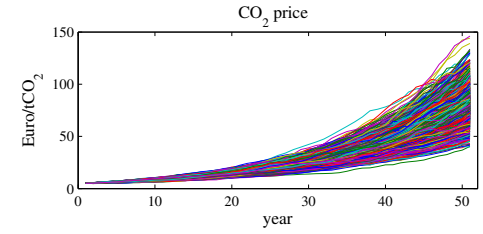

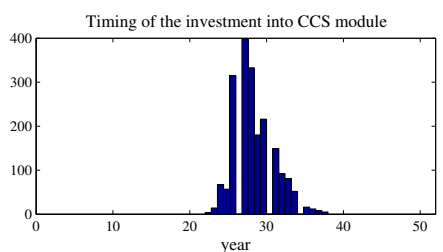

Switching the CCS model off
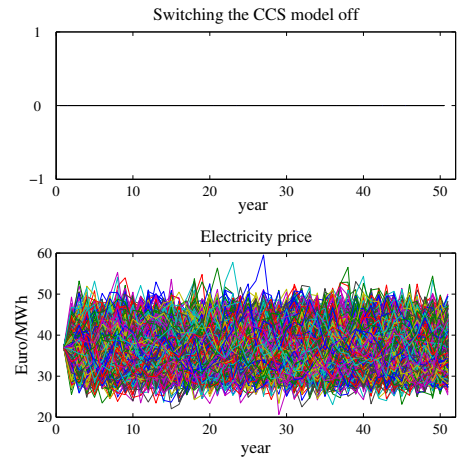

Panel 1: profit distribution peaks around 4.8x109\$. Panel 2: the frequency with which CCS is added peaks in year 29. Panels 3 and 4: the CCS module is not switched off and on. Panel 5: sample of simulated $\mathrm{CO}_{2}$ prices. Panel 6: sample of simulated electricity prices

Figure 3.3: Profit and Investment Frequency Distribution for Stochastic Prices

To analyze to what extent uncertainty affects investment behavior, first note again that if they optimize under complete certainty, they will add the CCS module in period 29. If they optimize under uncertainty with known $\mu^{c}$ and $\sigma^{c}$, Figure 3.3 shows that they will mostly invest somewhere between period 25 and 35 . However, if they optimize under uncertainty, but later on (when they actually pick a decision) there is only one (deterministic) price path, they will invest in period $27 .{ }^{18}$ This implies that the uncertainty is an obstacle for them in finding the same optimum strategies as in experiment 1 . This outcome is due to the lack of information under which the optimum strategies have been found: in the "perfect information" case in experiment 1 , investment occurs later because the true price outcome has been known ahead of time. In the "imperfect information" case, on the other hand, the stochasticity of the price paths that are simulated will also generate $\mathrm{CO}_{2}$ prices that are high enough to trigger investment into the CCS earlier. In this way, optimum strategies are found that lead to earlier investment than in the deterministic case. Moreover, the fact that

\footnotetext{
${ }^{18}$ In terms of our methodology depicted in Figure 3.2, this means that the backwardoptimization conducted with stochastic prices, but instead of the forward-moving Monte Carlo simulation, only the deterministic price path is used.
} 
they invest earlier rather than later depends crucially on the type of price process used in the analysis: the upward trend in $\mathrm{CO}_{2}$ prices means that producers will always face positive costs in terms of expenses for carbon emissions, even if the deviations from the trend are negative; therefore, upward deviations hurt them even more than in the case of constant or decreasing prices. Table 3 summarizes these results.

\begin{tabular}{c|ccc}
\hline Experiment & expected $\sigma^{c}$ & actual $\sigma^{c}$ & investment year \\
\hline 1 & 0.00 & 0.00 & 29 \\
2 & 0.0287 & 0.0287 & $25-35$ \\
3 & 0.0287 & 0.00 & 27 \\
\hline
\end{tabular}

Table 3.4: Market Uncertainty Experiments for $\mathrm{CO}_{2}$ Prices

Linking this back to the analysis outlined in Chapter 2 about the value of the plant, note that there are two important differences between the example provided there and the one presented in this chapter. The first difference is that we are not dealing with the volatility of profits or revenues here. The $\mathrm{CO}_{2}$ price represents a cost to the producer and the value of the first plant is therefore decreasing in $P_{t}^{c}$, which rises over time. This is illustrated in Figure 3.4 by the downward-sloping line $V 1\left(P_{t}^{c}\right)$, which is already adjusted for the investment cost. Furthermore, we do not optimize the installation timing of a specific plant, but we actually consider the adoption of a CCS module when first installing a coal-fired power plant without CCS is profitable. The CCS module becomes more and more attractive only with rising $\mathrm{CO}_{2}$ prices because the value of the coal-fired plant with CCS falls more slowly with increasing $P_{t}^{c}$, since it emits relatively less $\mathrm{CO}_{2}$.

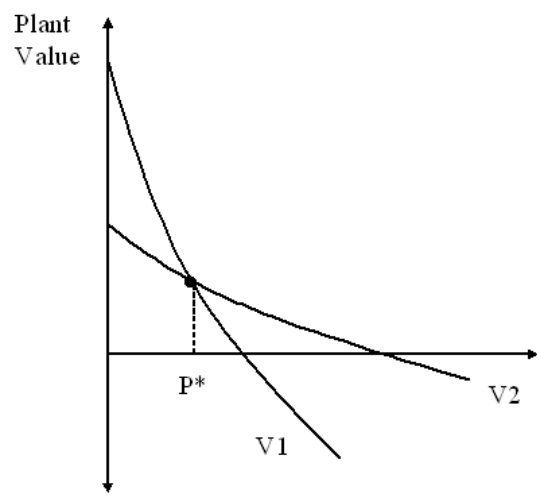

Figure 3.4: Values of the Coal-fired Plant Only and of the Coal-fired Plant with $C C S$ )

In Figure 3.4 the two lines for the values of the plant with and without CCS cross at the threshold $P^{*}$. When prices are simulated with a positive $\sigma^{c}, P^{*}$ is reached sooner than if we had followed a deterministic path. This situation is depicted in Figure 3.5. Therefore, the optimum strategy that is found for the investor to pick 
from is not the same optimal decision as what it had been with complete information: it has been derived under imperfect information and does not correspond to the true price that the investor is now facing. ${ }^{19}$

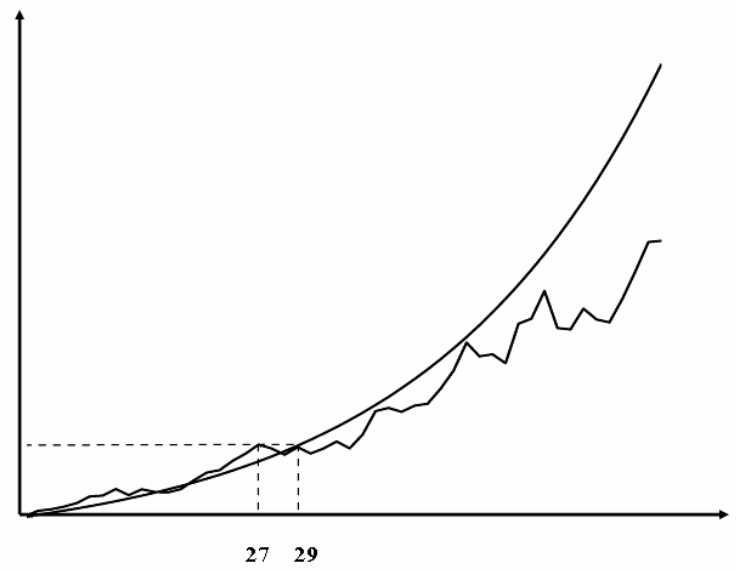

Figure 3.5: The Impact of Stochasticity on the Determination of the Optimum Timing Strategy

Some authors find that investment should be postponed in the face of uncertain input prices because they have shutdown conditions. This means that they only reap the benefits of the downward deviations of the fluctuating price process, but every time the price hits an upward spike, they shut down operations if the input price exceeds the output price. We think that this is no realistic assumption for electricity companies, who have to fulfill their supply contracts and who face considerable switching costs in terms of starting up a plant and maintaining it during the shutdown.

These findings imply that the concern that fluctuations in permit prices might reduce a firm's incentive to invest in abatement capital or "cleaner" technologies is not warranted in this framework. On the contrary, the uncertainty about the future development of $\mathrm{CO}_{2}$ prices - knowing that they will not be decreasing - drives the investors to act sooner rather than later.

\section{Policy Uncertainty}

Concerns have recently been uttered that politicians being vague about future climate change policy and their commitment to that can have unfavorable effects such as the

\footnotetext{
${ }^{19}$ In addition, it can be observed in Table 3.4 that the investment option is exercised one year later on average when $\sigma^{c}$ is positive. While this is not a significant delay when we look at the considerable spread, this can be explained by the fact that increases in the volatility raise the option value of waiting and even though this does not make a considerable difference with our parametrization, note that this would be represented by a slight upward rotation of the $V 1$-line in Figure 3.4, which does not change the dominant effect of optimizing under incomplete information, obviously.
} 
extension of the life of existing plants rather than investing into new and less carbonintensive equipment. As already mentioned, Blyth and Yang (2007) also acknowledge that policy uncertainty should be modeled more drastically, e.g. by the inclusion of jumps in the price of carbon. Other authors have looked at different areas of policy-making, such as agriculture, and have modeled uncertainty as a tax credit parameter that can be zero or non-zero according to a probability derived from a Poisson process (e.g. Boyarchenko and Levendorsky, 1998). Finally, there are studies, which model policy uncertainty about obligatory payments by considering that there will be a reform and representing the post-reform amount of payment and the date of the policy implementation as random variables (Lagerkvist, 2005). Our representation of policy uncertainty is a bifurcation in price paths and thus much simpler for the sake of making our results more transparent.

In the experiment conducted here, investors in the electricity sector are uncertain with respect to the actions of their government. Suppose that the government has enacted some sort of $\mathrm{CO}_{2}$-reducing policy on a national scale. This could be a national trading scheme or an escalating emissions tax. Initially, producers therefore face a rising $\mathrm{CO}_{2}$ price, but they are not sure that this path will be continued. Then the government engages in international climate change negotiations such as will be the case for post-2012 climate policy, for example. If the negotiations are successful, the government will commit to further increases in the $\mathrm{CO}_{2}$ price. However, it might also turn out that the government decides to drop out of the carbon-reducing scheme completely. $^{20}$ So the investor faces two scenarios: in the first one, the price will continue to rise, in the second one the price will drop (either to zero or to a relatively low level, where it stabilizes). If officials are not clear about their direction, investors will face a $50 \%$ chance of ending up in either of the two scenarios. The main finding of our analysis is that - under this type of uncertainty - investors will postpone their decision until the year, in which they learn about the government's (non)commitment. In case the government commits to a stricter emissions reduction target, they will add the CCS module, as soon as they learn about their government's commitment. Otherwise, they will keep producing with the coal-fired power plant that has no CCS module. The first case is shown in Figure 3.6, where the new policy is announced and implemented in period 37. Action 1 refers to "Do Nothing", action 2 stands for "Build the power plant without CCS" and action 5 is about adding the CCS module to an existing coal-fired power plant.

This result clearly demonstrates that there is a large option value involved when the investor is flexible. Remember that with perfect information ex ante, investors would have installed the CCS module in period 29, i.e. if they would have been sure that their government would remain committed. So, while they are waiting for the government decision to be revealed (at the publicly known end of the climate change negotiations round, for example), they are incurring losses, as soon as they pass period 29. In Figure 3.6 they postpone their investment for eight consecutive years, during

\footnotetext{
${ }^{20}$ This is a somewhat extreme supposition, but the results also hold for commitments to lower $\mathrm{CO}_{2}$ prices.
} 

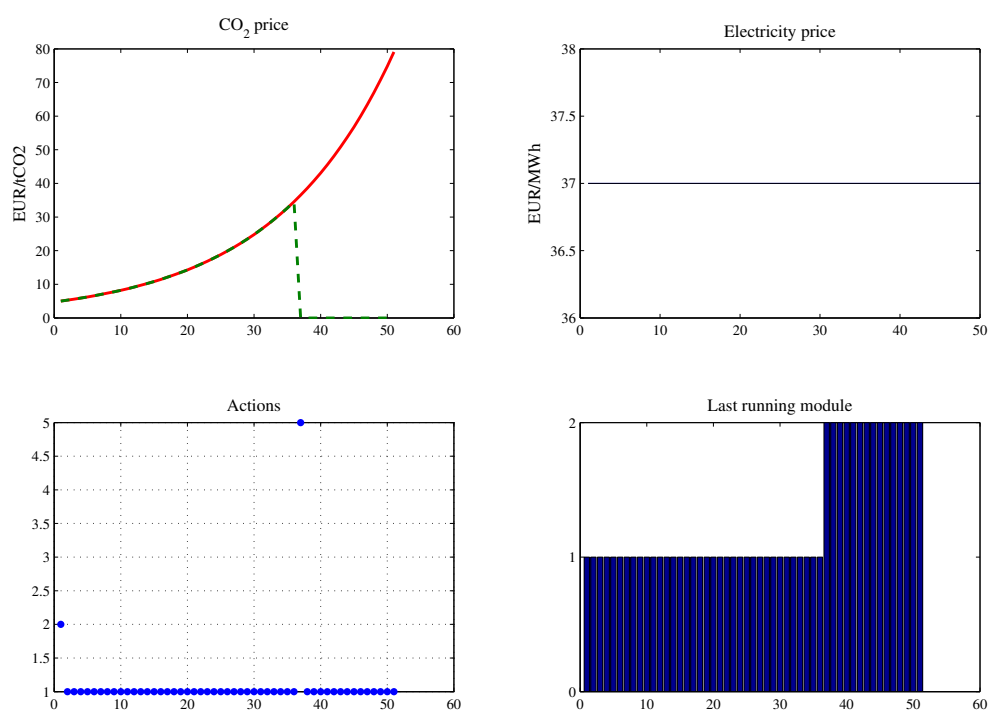

Panel 1: with commitment, $\mathrm{CO}_{2}$ prices continue to rise (dotted line), otherwise they fall (solid line). Panel 2: electricity price is stable (stochasticity is left aside here to avoid cross effects, but further tests have shown that the result remains the same also with stochastic prices). Panel 3: government commits to climate change policy in period 37, so investment in CCS also occurs in period 37. Panel 4: the coal-fired power plant runs until period 36, then CCS is added.

Figure 3.6: Learning about Government Commitment in Period 37

which they suffer increasing losses because they have constant revenues, but increasing expenses for emissions. These losses must therefore be lower than the option value attached to waiting.

In real options terminology, this means that the threshold of investing when there is no uncertainty is passed in year 29 , when both plants have the same value. This situation is depicted in Figure 3.4 at $P^{*}$. We have seen that small fluctuations in the price path can then lead to earlier adoption of the CCS module when optimization occurs under uncertainty (see Figure 3.5 and accompanying text). When there is uncertainty about the direction of the price path, however, the deviation in costs in case the policy will be less strict is huge. So there are considerable benefits to reap from waiting with the switch. While waiting, these benefits diminish, as the prices continue to grow. At the same time, it would have been optimal to install the CCS module in year 29 in order to save on $\mathrm{CO}_{2}$ costs. So the investor is incurring losses in these terms as well. In year 37 , the benefits from waiting do no longer exceed these losses. If people know that the new policy will become official later than year 37 , they will invest into the CCS module in year 29. If they know that it will be announced in between year 29 and 37, they will wait. This can also be seen in Figure 3.7, which is 
an extension of Figure 3.4 in that it shows the option value of the investment.

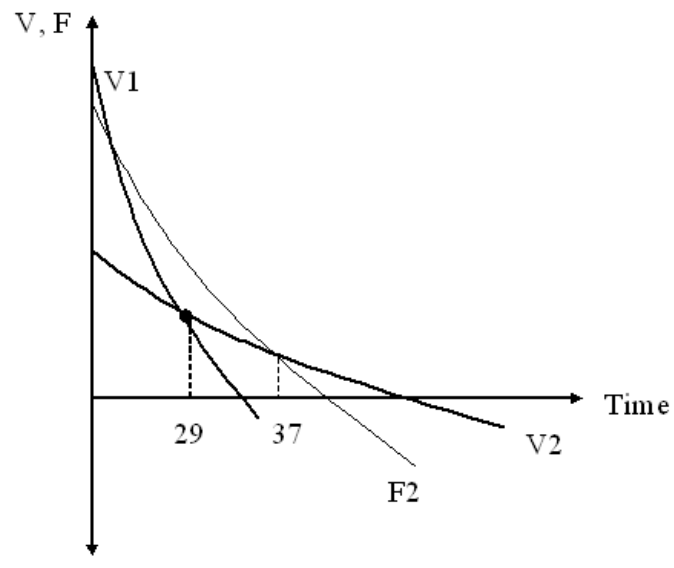

Figure 3.7: Option Value of the Plant with CCS exceeds the Difference between V1 and V2 after Year 29 until Year 37

The principal drivers of this result are (a) the perceived probability that the government will commit to a policy of further raising $\mathrm{CO}_{2}$ prices (further called commitment probability) and (b) the year that this commitment will be made. Figure 3.8 shows how the different combinations of these two parameters influence the investment decision of adding the CCS module.

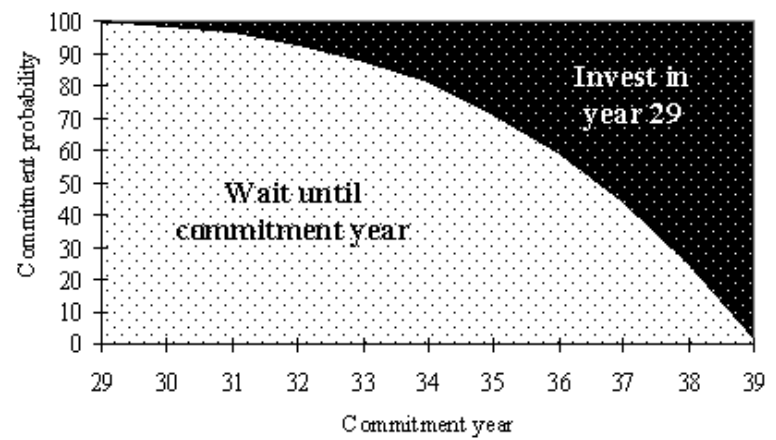

Figure 3.8: Timing of CCS Investment under Policy Uncertainty (sensitivity analysis with respect to commitment probability and commitment year)

It is important to note that there are only two outcomes in this experiment: either the investor invests in year 29 (which he would do if he was $100 \%$ sure that the price would keep rising) or he postpones the investment until the year the government commits or does not commit and acts accordingly. Figure 3.8 shows that a higher 
perceived probability of government commitment is needed for CCS investment to take place when the commitment year is relatively early. However, the farther into the future this commitment is, the lower is the perceived probability needed to induce the investor to add the CCS module. This is because $\mathrm{CO}_{2}$ prices continue to rise during the time the investor waits for the true $\mathrm{CO}_{2}$ price path to be revealed. In other words, the investor will wait, as long as the option value exceeds the losses incurred through rising $\mathrm{CO}_{2}$ expenses. The later the commitment year, the smaller this difference becomes - until the point in time when it is optimal again to act as if commitment was $100 \%$ probable, i.e. to invest in year 29 . In the fourth experiment, the investor had no signal from policy makers with respect to the future trend of the $\mathrm{CO}_{2}$ price, so he attached a $50 \%$ probability to both scenarios and waited up to eight years for this information to become revealed. Only for a commitment year farther away than year 37, CCS investment would have taken place in year 29.

Regarding policy-making, it is thus evident that increased uncertainty about the direction of future policies is relatively more harmful for the environment and the investor than market uncertainty because environmentally friendlier (and more expensive) technologies will be installed at a later point in time only.

\subsection{Cap \& Trade System with Price Ceilings?}

We have found above that fluctuations in the $\mathrm{CO}_{2}$ price can lead to earlier investment than optimal under perfect information. Even though this might seem desirable from an environmental point of view, it is clear that investors will not be in favor of rising carbon costs in the first place and the associated volatility of these costs in particular. They will thus be against a so-called cap and trade system, where emissions are capped and the corresponding number of permits traded like in the European Trading Scheme.

It has therefore been proposed to introduce $\mathrm{CO}_{2}$ price caps, which are thought to reduce the cost uncertainty emanating from market-based mechanisms (e.g. Pizer, 2005). As early as the late 1990s, so-called "hybrid" systems of emissions trading supplemented with a price ceiling have been proposed (Pizer, 1997). Pizer (2002) focusses on uncertainties in abatement costs and aggregate economic costs of such a hybrid approach and finds that it can lead to economic benefits close to those reached by a comparable tax. Another argument that has been advanced in favor of price caps is the facilitation of compromises both in international negotiations and between governments and national industries. The US administration, for example, has had severe doubts about the stringency of the Kyoto (quantity) targets and a price cap could have acted as a "safety valve" that allows for more flexibility concerning those targets. The aims of proposing a safety valve are therefore two-fold: "avoiding excessive cost by relaxing the emissions target and moving from a quantity to a price penalty" (Jacoby and Ellerman, 2004, page 484).

Discussion about $\mathrm{CO}_{2}$ price ceilings became muted when the US with-drew from the Kyoto Protocol in 2001, but has resurfaced lately: at least 26 utilities have recently signed a letter to Congress, in which they demand a safety valve as part of any $\mathrm{CO}_{2}$ 
permit trading scheme to be implemented (The Wall Street Journal, 17 Oct. 2007). Being responsible for more than $40 \%$ of US emissions, a trading scheme will have a large impact on the electricity sector, which fears that market volatility will intervene with the very aims of policy makers by providing disincentives to commit resources to expensive yet less carbon-intensive technologies such as wind power and nuclear energy. According to utilities, a safety valve would facilitate a "more predictable price signal" and thus lead to better investment planning. In this section we show, however, that the initial level and trend of the $\mathrm{CO}_{2}$ price is price signal enough to ensure efficient planning and that price fluctuations do not harm profits excessively and do furthermore not alter the timing of investments significantly. A price cap on the other hand will severely reduce the effectiveness of the $\mathrm{CO}_{2}$ price and thus delay investment in carbon-reducing or less carbon-intensive technology by protecting the interests of "old" $\mathrm{CO}_{2}$-intensive utilities. Investors that might have been ready to commit to environmentally friendlier technology will feel discouraged to do so in the face of price caps. In fact, the opinion has recently been put forward that total economic costs and benefits (such as in Pizer's analyses) do not represent investment incentives or disincentives for the individual company. What matters for the investors is the carbon price and the uncertainty that surrounds it. Capping this price will most likely only reduce the risks for high-carbon investments and might even reduce investment incentives for "green" technologies, especially when it is not clear for how long the price cap will be active (Blyth and Hamilton, 2006, page 9).

To summarize, the debate about $\mathrm{CO}_{2}$ price caps in a permit trading scheme is far from resolved in the US and also in other countries. In addition, with the end of the first commitment period approaching, any post-2012 carbon agreement will likely be prone to similar dispute, involving also stakeholders from less developed countries. Even though some $40 \%$ of the electricity generates nowadays comes from coal-fired power plants and $97 \%$ thereof is based on pulverized coal, less carbon-intensive technologies are available and have further scope for technological improvement. Moreover, the existing power plant stock in OECD countries is ageing and will need replacement over the next 10 to 20 years (IEA, 2006). While this replacement demand differs between countries and some of the existing plants might also be refurbished to extend plant life, growing energy demand will add to the amount of capacity needed in the near future. Therefore, investment into new capacity will be decisive for the carbonintensity of the future electricity mix.

We follow this line of thought here and take on the view of an individual electricity producer again. After all, investors in the electricity sector are the actors, who will decide what types of plants will be installed in the near future. The US Department of Energy's National Energy Technology Laboratory (NETL), for example, reports that the American electricity industry plans to replace their aging capacity by 154 gigawatts (GW) of new coal-fired power plants over the coming two decades (Morgan, 2006); and less advanced countries such as China build up coal-fired capacity even more rapidly. The specific choice for coal is also motivated by the volatility that gas prices have exhibited lately. These issues (the ageing of existing capacity and concerns about 
energy security) are important for most advanced nations at the moment or in the near future. With considerable expenses that have to be made upfront, the investment into new power generation equipment is largely irreversible and what is installed these days will be around for decades and continue to add to cumulative GHG emissions in the meantime. It is therefore important to provide the right incentives to power plant investors, so that they at least build up capacity, which can be retrofitted with carbon capture and storage (CCS) modules or other mitigation technologies, or even phase a larger proportion of renewable energy into the electricity mix.

To investigate these issues we will employ the same real options model as before. The only difference is that we consider an electricity producer, who needs to replace existing coal-fired capacity with either coal-fired capacity that can be extended to include a CCS module or a biomass-fired power plant with the same extension possibility. Nowadays, the biomass power plant is still much more expensive than the coal-fired power plant. However, with increasing $\mathrm{CO}_{2}$ prices, biomass becomes more attractive, since the biomass plant produces zero (without CCS) and negative (with CCS) emissions. This can be explained by the fact that biomass-based electricity production requires that additional biomass is grown, which will extract more $\mathrm{CO}_{2}$ from the atmosphere, and we assume this to be subsidized or rewarded by extra $\mathrm{CO}_{2}$ allowances. We further assume that the amount of $\mathrm{CO}_{2}$ emissions for a biomass plant without CCS technology is equal to these subsidies/allowances. ${ }^{21}$. Also, it can be expected that the high O\&M costs will be somewhat reduced over the next decades. ${ }^{22}$

Even though real options modeling has previously been applied to investment in the electricity sector, none of the existing real options studies has actively addressed the policy debate about price caps outlined above. The purpose of this exercise is therefore to do exactly that: to find out whether and when an individual electricity producer will replace old coal-fired capacity with another coal-fired power plant or if he will switch to either a extendable coal plant where CCS can possibly be added or a biomass-fired plant of the type described above under different policy regimes. Our analysis shows that a price cap does indeed not provide the right incentive scheme to phase in renewables. A particularly low price cap would even forestall the introduction of a coal-fired plant that could be retrofitted with CCS.

Moreover, the fluctuations in the price of carbon indeed turn out to depress the producer's profits, as feared by the proponents of price caps. However, these losses are not excessive, and as a positive side effect, the fluctuations in the $\mathrm{CO}_{2}$ price can even lead to earlier adoption of "green" technologies even with a moderately increasing $\mathrm{CO}_{2}$ price when the volatility is large enough. Interestingly, the timing of adding the CCS module when a coal-fired plant is built to replace the old capacity does not depend on

${ }^{21}$ Uddin and Barreto (2007), amongst others, show that the negative emissions of a biomassfired power plant with CCS are large, even if the decrease in efficiency, the extra emissions from the transport of biomass and $\mathrm{CO}_{2}$ and many other factors are considered. According to their estimates, the emissions sequestered during the fuel growth phase are almost equal to the emissions produced by combusting it.

${ }^{22}$ We assume a $20 \%$ decrease in total O\&M costs over the planning horizon of 50 years, which is not exaggerated given recent forecasts concerning future cost improvements of renewable energy technologies, see e.g. the estimates of overnight investment costs by the European Commission (2006) presented in Chapter 4. 
the level of the price cap, if the price cap is not prohibitively low.

We will first present the data that we use to find the optimal investment decisions of the electricity producer under different policy regimes. Then we analyze the results. This presentation will be divided into two parts, where we first focus on the effects of applying price caps and then on the impact of more slowly growing $\mathrm{CO}_{2}$ prices. Finally, some policy recommendations will be given.

\subsubsection{Replacing Coal-Fired Capacity}

As already described above, we are looking at a situation, where the electricity producer owns a coal-fired power plant that has to be replaced after it expires (here in year 21). The possibilities for replacement are another coal-fired power plant with a possibility to add a CCS module later, and a biomass-fired power plant, which is also extendable with CCS. Bear in mind that the special feature of the biomass plant is that the growing of biomass as a fuel sequesters carbon from the atmosphere and if emissions are in addition captured and stored during the electricity generation process, this type of plant ultimately ends up with "negative emissions". In terms of cost, we can think of this as a subsidy that is granted to the users of biomass on the grounds of their positive externality of sequestering carbon in the fuel-generation process. The data for the two power plants can be found in Table 3.5, where the specific fuel cost of the coal-fired plants are to be taken as the initial prices, which will be rising subsequently. ${ }^{23}$ Moreover, the high O\&M costs for the biomass-fired plant are due to its relative technological immaturity. As time passes, technical change will improve the operational processes, so we expect the O\&M costs to fall.

\begin{tabular}{ll|l|l|l|l}
\hline Parameters & Unit & Coal & Coal+CCS & Bio & Bio + CCS \\
\hline Electricity Output & TWh $/ \mathrm{yr}$ & 3,285 & $2,642.3$ & 3,285 & 2,628 \\
$\mathrm{CO}_{2}$ Emissions & $\mathrm{kt} \mathrm{CO} / \mathrm{yr}$ & 2,155 & 292.3 & 0 & $-2,691$ \\
Fuel Consumption & $\mathrm{TJ} / \mathrm{yr}$ & 23,188 & 23,188 & 29,565 & 29,565 \\
Specific Fuel Cost & $1,000 € / \mathrm{TJ}$ & 1.515 & 1.515 & 2.292 & 2.292 \\
O\&M Fixed Cost & $1,000 € / \mathrm{yr}$ & 40,250 & 48,450 & 77,000 & 91,568 \\
Efficiency (Heat) & $\%$ & 34 & 34 & 16 & 16 \\
Heat Price & $€ / \mathrm{MWh}$ & 52.424 & 52.424 & 52.424 & 52.424 \\
Capital Cost & & & & \\
Common Parts & $1,000 €$ & 686,500 & 686,500 & 402,029 & 402,029 \\
Cost CCS Module & $1,000 €$ & 137,946 & & 320,333 \\
Total Capital Cost & $1,000 €$ & 686,500 & 824,446 & 402,029 & 722,362 \\
\hline
\end{tabular}

Table 3.5: Power Plant Data for Coal- and Biomass-Fired Plants and CCS

It is important to note that we are in fact analyzing two different cases, where the control variable is the optimal timing of investing into the CCS module after they have replaced the expired old coal plant: we investigate this separately for the

\footnotetext{
${ }^{23}$ In accordance with the predictions by German power plant owners from the same survey that has been used to generate the data in Table 3.5 by the IEA, we assume that fuel prices are increasing at a relatively moderate rate (compared to e.g. gas or oil), whereas biomass can be acquired at a stable price, which initially exceeds the coal price.
} 
coal-fired power plant and for the biomass-fired power plant because we are interested in the investor's behavior in both cases. By comparing the profits ex post we can still determine the "winner" in terms of the ultimate investment choice. However, by first investigating the CCS decisions for coal and biomass separately we can make statements about the impact of uncertainty not only on the timing of investment, but also on the level of profits in different scenarios.

\subsubsection{Policy Experiments}

Price Caps

In this section we will conduct a number of different policy experiments to assess the effects that stochastic $\mathrm{CO}_{2}$ prices coupled with price caps have on the investment pattern of a coal-fired power plant owner in contrast to his behavior under a gradually rising, but deterministic $\mathrm{CO}_{2}$ price. The experimental setup is such that we first conduct four experiments are for deterministic $\mathrm{CO}_{2}$ prices, i.e. with $\mu^{c}=0.0568$ and $\sigma^{c}=0$. The other four experiments are for stochastic prices, i.e. with $\mu^{c}=0.0568$ and $\sigma^{c}=0.0287$. Moreover, the first experiment in each category will be without a price cap; the others have price caps of 40, 50 and $60 € / \mathrm{t}$ respectively. ${ }^{24}$ In other words, when we investigate a price cap, we basically look at a minimum function of the actual $\mathrm{CO}_{2}$ price and the pre-specified price ceiling. Finally, we have chosen $5 € / \mathrm{t}$ as a starting price because a $\mathrm{CO}_{2}$ price of $7 \$ / \mathrm{t}$ had been discussed for the potential setup of a permit trading system in the US.

Figures 3.9 and 3.10 show the outcomes of the different policy experiments that we have conducted. The first Figure corresponds to simulations with deterministic $\mathrm{CO}_{2}$ prices. Without a price cap, this can be interpreted as a gradually escalating tax, i.e. a continuously rising $\mathrm{CO}_{2}$ price, but without the volatility resulting from permit trade. We see that this would effectively lead to higher profits for the biomass plant, which would then be chosen over the coal-fired plant on the basis of its profits. With a cap on the $\mathrm{CO}_{2}$ price, the biomass profits would be considerably reduced, while those of coal would be increased. In fact, the reduction in the biomass profits is $33 \%$ ( $34 \%$ in the stochastic case), while coal gains $5 \%$ in terms of profits. A cap of $40 € / t$ would already be enough for coal to beat biomass. However, that cap is still high enough to trigger investment into the CCS module. ${ }^{25}$

Turning to the experiment series conducted under stochastic prices, the investment timing stays on average the same, which is why we refrain from reporting it here, but profits are somewhat reduced, as feared by opponents to permit trading. However, these profit reductions are smaller for the coal-fired power plant owner. In the scenario with the highest price cap, for example, the biomass plant looses $1.5 \%$ of its profits

\footnotetext{
${ }^{24}$ The results for deterministic prices combined with price caps are computed for reasons of comparison, even though in reality price caps usually supplement stochastic $\mathrm{CO}_{2}$ prices (this is the result of a so-called "cap-and-trade" system, where prices fluctuate due to permit trade, but the safety valve can never be exceeded by regulation).

${ }^{25}$ With a cap of $20 € /$ ton of $\mathrm{CO}_{2}$ there will neither be an incentive to build a biomass plant nor will a CCS module be added, so emissions will continue to be as high as before replacement and the policy has not provided the right incentive scheme for emissions reduction, i.e. welfare is decreased.
} 
compared to the deterministic case, while the coal plant looses "only" half a percent of its deterministic profits. Given the difficulty of enacting taxes in some countries as opposed to market-based mechanisms, however, these losses are not too large to represent a valid excuse for inaction. Moreover, the results show that the owners of fossil-fuel-fired plants will not be comparatively worse off than their renewable energy competitors, here the biomass-fired power plant owner. On the contrary, the biomass plant has proved to be much more prone to loose from fluctuations in the $\mathrm{CO}_{2}$ price than the coal plant.

As can also be seen from the results, when considering the application of a price cap policy, deciding on the level of that price cap is crucial. In our analysis, in case of a lower price cap than $40 € / \mathrm{t}$, the impact of the climate policy is significantly weaker. However, as the whole problem is very data-specific, it is very difficult to compute a general level of the price cap that would not cause the renewable technology (here biomass) to become uncompetitive.

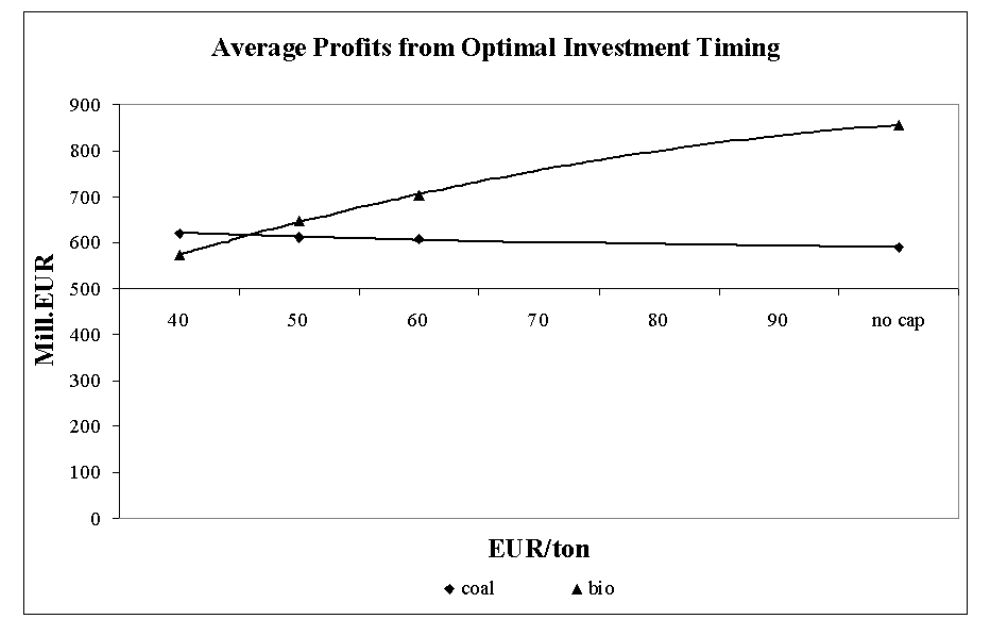

Figure 3.9: Average Profits in $€$ from Optimal Timing of Investments: The Deterministic Case

From the point-of-view of the policy maker, who strives to reduce emissions, it is also interesting to compute total emissions in tons of $\mathrm{CO}_{2}$. In the deterministic scenario without a price cap, these amount to $22,641,000$ tons for coal and $-81,718,000$ tons for biomass. Introducing a price cap of $60 € / \mathrm{t}$ increases those emissions to $22,697,000$ tons and $-81,545,000$ tons respectively. Interestingly, because the investment timing does not change with lower price caps, the total amount of emissions is not progressively higher for lower caps. This implies that the investor's optimal decision with respect to adding CCS is not influenced by a price cap (50€/t or higher). The only effect of the policy is that the power plant owner has lower profits. However, this finding should not be interpreted to mean that the level of the price cap is unimportant, since the CCS module is added at the same time anyway. On the contrary, the analysis 


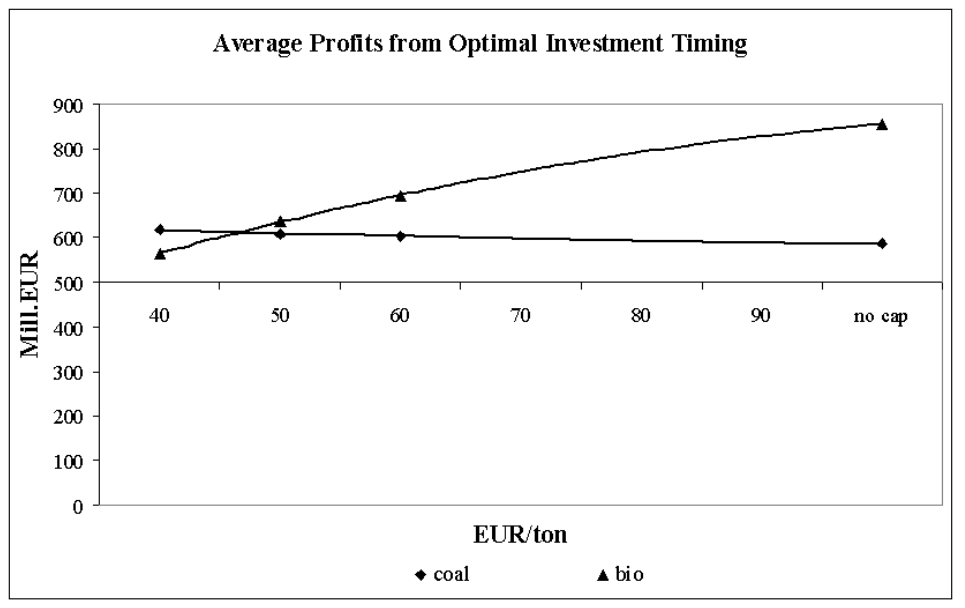

Figure 3.10: Average Profits in $€$ from Optimal Timing of Investments: The Stochastic Case

above shows that the price cap forestalls the phasing in of renewable technologies (here biomass-fired generation) by making it less profitable than coal, even though it would lower emissions considerably more compared to the CCS module on coal-fired capacity. ${ }^{26}$

\section{Lower Increase in $\mathrm{CO}_{2}$ Prices}

As regards the formulation of compromises and agreements in national, regional and international climate policy debates, another conceivable scenario is an agreement to limit the growth in $\mathrm{CO}_{2}$ prices. In the case of a gradually escalating tax, this is easily implemented. In a permit trading system, this could be achieved by increasing the supply of permits, whenever there is upward pressure on the $\mathrm{CO}_{2}$ price as suggested in some Congressional Bills in the US.

Figure 3.11 shows the results for an experiment, where we have reduced the rate of growth of $\mathrm{CO}_{2}$ prices to half of its original value. In the deterministic case, we observe that coal has much higher profits than biomass. Furthermore, for none of the two technologies a CCS module is added. The result is therefore that a second coal-fired power plant is built to replace the expiring one and that emissions continue to be generated at the same high level as before replacement.

When we analyze the results for the same experiment with stochastic $\mathrm{CO}_{2}$ prices, we see that biomass still produces much lower profits than coal, which is why the investor will install a new coal-fired power plant again. However, due to the stochasticity of the price path, the critical $\mathrm{CO}_{2}$ price level, which triggers investment into the CCS module, is reached relatively often now, as can be seen in the investment frequency distribution in Figure 3.12. This implies that the uncertainty emanating

${ }^{26}$ Another disadvantage is that low price caps could also be used to grant benefits to the coal-fired power plant owners, while renewable energy does not have such protection against down-ward fluctuations in terms of e.g. a price floor. 


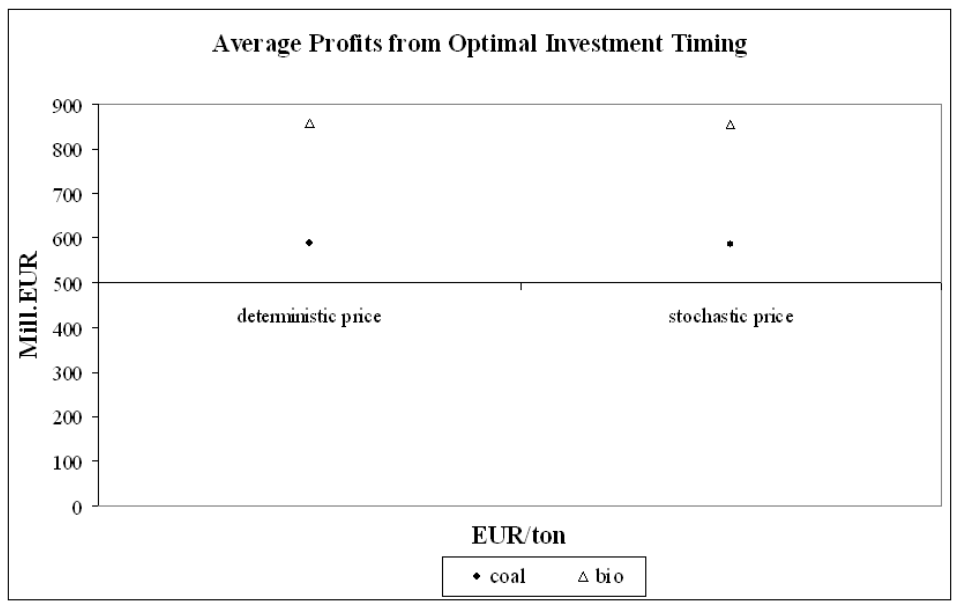

Figure 3.11: Average Profits in $€$ from Optimal Timing of Investments when the $\mathrm{CO}_{2}$ Price Grows More Slowly
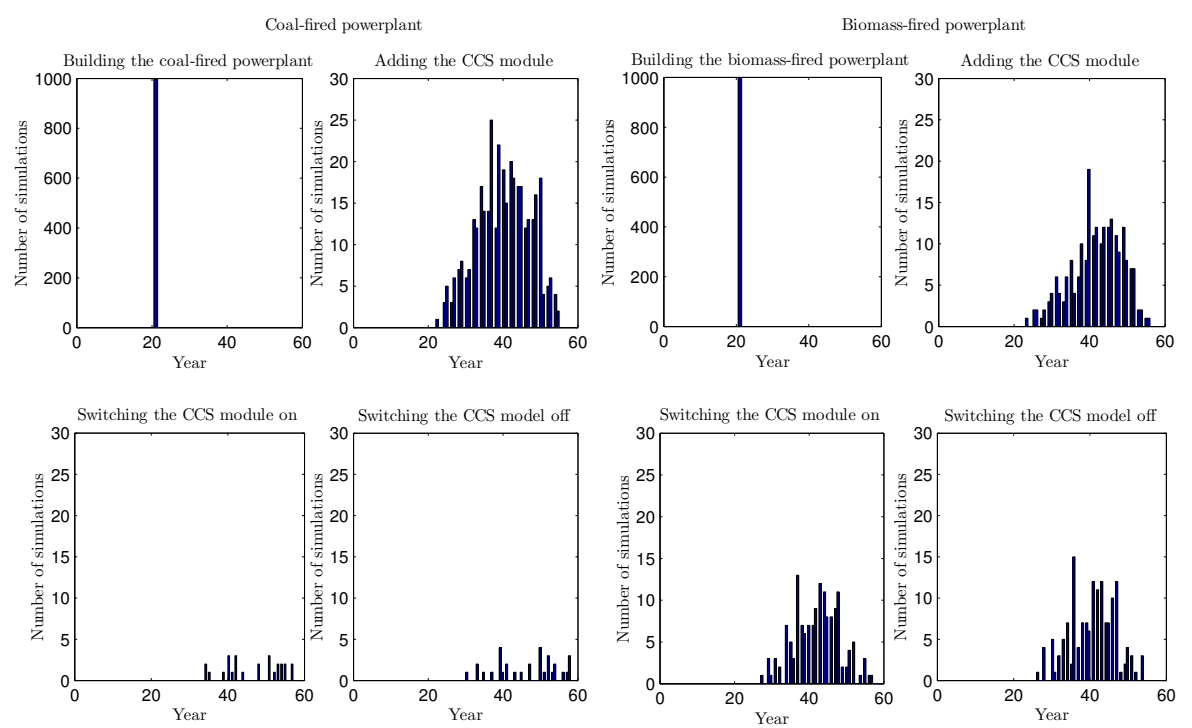

Panel 1 shows that in year 21 (when the old coal-fired power plant expires) the new one is always built. The second panel shows that the CCS module is added relatively often (compared to the deterministic case, where it is never added). Panels 3 and 4 show that the frequency of switching the module on and off is negligible for coal-fired capacity and not high for biomass-fired capacity either.

Figure 3.12: Simulation Results for Experiment with Lower $\mathrm{CO}_{2}$ Price Growth for the Coal-fired (left) and the Biomass-fired (right) Power Plant 
from the fluctuations in the $\mathrm{CO}_{2}$ price, which could arise from permit trading, does not only have negative effects. On the contrary, from the point of view of the goal to reduce carbon emissions, the addition of a CCS module in a relatively large number of cases is desirable. Moreover, profits are $2 \%$ higher in the stochastic setting than in the deterministic one, so firms also gain. Since for biomass the critical $\mathrm{CO}_{2}$ price, beyond which investment occurs, is higher than in the case of coal, there are only relatively few instances, where that threshold is surpassed, as can be seen in Figure 3.12.

\subsection{Conclusion}

The uncertainties in the science, economics and politics of climate change translate to even deeper uncertainties for actors in the energy sector regarding the extent, timing and cost of emission controls. The market for emission permits carries the potential to become the first global environmental market, with permits being traded internationally in considerable quantities. The capital-intensive energy sector is particularly vulnerable to policy uncertainties affecting the income stream from (irreversible) investment. Future control on emissions is a key risk for the economic viability of sector investments, which policy aims to regulate. At the same time, governments should have a strong interest in an effective and efficient investment response to its policy signals.

While people have often expressed the concern that the volatility in $\mathrm{CO}_{2}$ prices that e.g. a permit market would convey could potentially provide an incentive to actors in the energy sector to postpone investments into less carbon-intensive, but also more costly technologies, the results presented here actually indicate that this market-driven uncertainty is more "harmless" from an environmental (and also from the investor's) point-of-view than the uncertainty emanating from unclear government commitments.

In this paper a real options framework has been developed for analyzing investment decision-making under these different types of uncertainty in the electricity sector, where investments are largely associated with high sunk cost, but the timing of investment is flexible. A distinction has been made between uncertainty coming from fluctuations around a known trend, which could arise from permit trading, and uncertainty emanating from the absence of clear policy signals. It has been shown that market uncertainty - up to a reasonable degree - should actually not be as much of concern as it has been so far. In fact, some market uncertainty will induce the investor to invest earlier into CCS equipment than in the case of perfect information. On the other hand, policy uncertainty leads to investment decisions resulting in a prolonged accumulation of $\mathrm{CO}_{2}$ emissions in the atmosphere, since investors hold on to their waiting option in order to learn about the final decision of government and do not invest in environmentally friendly technologies. Emissions abatement activities would have started earlier if government had developed a clearer, long-term commitment plan. In addition, investors' profits are reduced during the waiting time when government continues to raise $\mathrm{CO}_{2}$ prices subsequently. 
Notice that the message from the analysis presented in this paper is therefore twofold: energy producers have to adapt their decisions about investment in generation equipment not only to market-driven uncertainties, but also to uncertainty involved in the process of policy making. At the same time, uncertainty is pervasive in the analysis of climate change and will persist to be an essential feature of the international climate policy debate. Regulators will have to learn over time how their policy signals translate into changes in the pattern of investment behavior, which in turn will determine the viability of their very policies. Robust climate policies should provide investors with opportunities aiming at learning from positive carbon price shocks. Finally, regulated entities will have to acquire experience as to the way of learning more effectively about the irreducible uncertainties emerging from the climate policy process with the aim to exploit uncertainties to their own advantage. $21^{\text {st }}$ century energy and mitigation technologies are one opportunity to give energy sector managers more flexibility to adapt to more predictable - but still uncertain - climate policy, while policy makers will have to adapt their ways of regulation as much as possible, too.

Furthermore, the idea of a price cap or "safety valve" on the $\mathrm{CO}_{2}$ price that arises from permit trading has often been forwarded (e.g. Pizer, 1997). One proposal for the US was, for instance, to start out with a price ceiling of $7 \$$ per ton of $\mathrm{CO}_{2}$. Experts judge that this is "a level virtually certain to be exceeded and that would result in rising emissions at least through 2020." (Doniger, et al (2006), page 764). The merits of such an approach would be that parties that are otherwise strictly opposed to taxes and also permit trading would feel protected against sudden price spikes. In this way, agreements might still be achieved. At the same time, the uncertainty emanating from permit trading could be kept under control.

In order to shed some light on this debate we have investigated the replacement decision of a coal-fired power plant owner, who can either replace the expiring capacity with a new coal-fired power plant that can be retrofitted with a CCS module or with a biomass-fired power plant, which has the extra bonus of sequestering $\mathrm{CO}_{2}$ during the fuel-generation process and can be adjusted to capture carbon as well. This analysis is performed for different policy regimes (fluctuating and deterministic $\mathrm{CO}_{2}$ prices, different levels of price caps and slower growth rates of $\mathrm{CO}_{2}$ prices) in order to assess the effectiveness of the policies considered.

There are four main conclusions that we can draw from our analysis: (1) Under a gradually escalating tax (i.e. without fluctuations), biomass-fired power plants are more profitable than coal-fired power plants. However, the introduction of a price cap reduces the profits of biomass enormously (33\% loss of profits), while benefitting the coal plant(5\% gain in profits). (2) Fossil-fuel-fired power plant owners are not necessarily worse off than their renewable energy competitors in the face of $\mathrm{CO}_{2}$ price volatility. In our setting, the biomass plant has been shown to be much more sensitive to fluctuations in the $\mathrm{CO}_{2}$ price than the coal plant. (3) The timing of investment into CCS is not influenced by the level of the price cap, as long as this cap is not so low that it depresses investment into CCS completely. (4) Volatility in $\mathrm{CO}_{2}$ prices can often trigger investment into CCS, when this would not have occurred in the case of 
deterministic $\mathrm{CO}_{2}$ prices. This reduces average emissions considerably.

These four conclusions convey important messages for policy makers, and especially policy makers who are concerned about climate change. From (1) we can see that increasing $\mathrm{CO}_{2}$ prices provide an incentive to investors to phase in renewable energy, as old capacity ages and needs to be replaced. However, compromises entailing caps on the price of $\mathrm{CO}_{2}$ jeopardize this incentive scheme and make coal-fired capacity more attractive in terms of profits. Still, this capacity will be retrofitted with a CCS module, if the price cap is not too low, which will contribute to emissions savings by capturing and storing part of the emitted $\mathrm{CO}_{2}$.

With respect to the fossil-fuel-using industry's concern that they will suffer considerably more from $\mathrm{CO}_{2}$ price fluctuations, conclusion (2) shows that the biomass-fired plant is even more disadvantaged by such volatility. The sensitivity of the biomass profits to the volatility in $\mathrm{CO}_{2}$ prices can also be demonstrated by looking at Figure 3.10. At the same time, while coal-fired power plant owners will be protected by the safety valve against upwards fluctuations in the $\mathrm{CO}_{2}$ price, biomass-fired power plant owners cannot rely on a symmetric "insurance mechanism" for downward fluctuations through e.g. a price floor.

Conclusion (3) shows that emissions will still be somewhat reduced, independent of the level of the price cap, since the timing of adding the CCS module does not change across different price caps. However, the price caps still make the biomass alternative less competitive and thus less attractive for adoption. Moreover, since our analysis rests on data-specific experiments, it would in reality be too difficult to compute a price cap that would be just high enough to induce investment into the biomass plant. Evidently, the replacement decision is sensitive to the level of the price cap: if the price cap is too low, the threshold price triggering investment into a biomass-fired power plant will never be reached thus resulting in investment into another coal-fired power plant.

The argument against permit trading based on the inefficiencies due to the volatility of the $\mathrm{CO}_{2}$ price is not always warranted from an "emissions-reduction" pointof-view. In fact, the larger the fluctuations in the $\mathrm{CO}_{2}$ price, the more often the investor will be enticed to add CCS to an existing coal-fired power plant, which reduces emissions considerably compared to the deterministic case. While this should not be understood as policy advice to foster uncertainty about $\mathrm{CO}_{2}$ price development, it clearly demonstrates that the volatility produced by permit trading can have positive side effects, which need to be weighed against its costs. 


\section{Appendix: Explanations on Data and Data Sources}

The data used to calibrate the parameters for the mean-reverting electricity price process are taken from the European Energy Exchange Corporation (EEX) in Leipzig, Germany. Since the data available are short-term (monthly here), the data had to be aggregated to obtain yearly prices. The price development is shown in Figure A.1. Furthermore, the series has been tested for the presence of unit roots, as that would imply that mean-reversion would not be an appropriate model for the electricity price. However, the null hypothesis on the unit root can be rejected, so mean-reversion can be assumed.

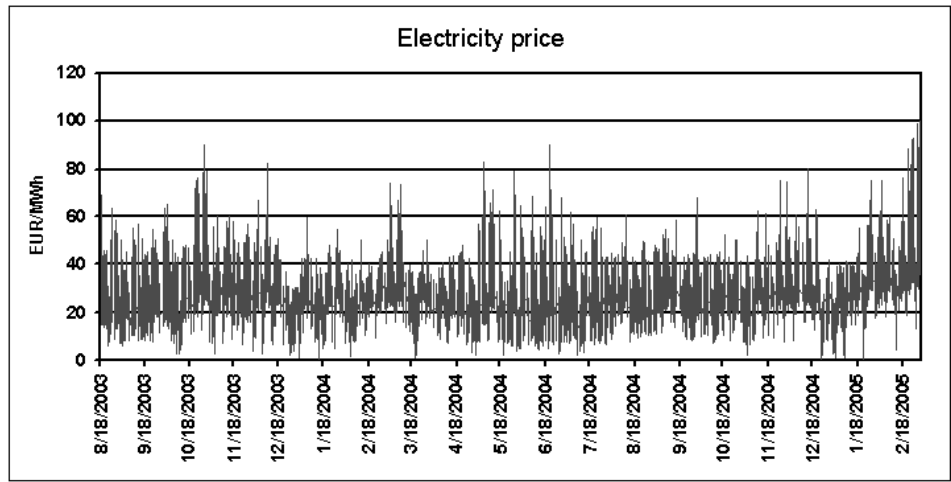

Figure A.1: Electricity Price Data (Source: EEX spot market prices)

$\mathrm{CO}_{2}$ price are more difficult to model: the market for $\mathrm{CO}_{2}$ allowances has only been established recently and there are no long-term data available. Also, since the market is still in its infancy, policy failures and changing expectations have led to disruptions in the price development, as shown in this chapter in Figure 3.1.

Evidently, both the short-term nature of the time series and the swings due to starting difficulties make these data very inappropriate to estimate the parameters of a price process for the long run. Therefore, we have chosen to use long-term projections rather than historical time series. In particular, we use scenarios with different rates of population growth, urbanization, technical change etc aiming at a relatively ambitious stabilization target. The source is the GGI Scenario Database (IIASA, 2007). More on the assumptions and resulting projections of this database can be found in Riahi et al (2007). The parameters were estimated for a geometric Brownian motion, since for the (shadow) price series taken from the GGI Scenario Database (IIASA, 2007) the null hypothesis on the unit root could not be rejected. 


\section{Chapter 4}

\section{Fuel Price \& Technological Uncertainty in a Real Options Model for Electricity Planning}

\subsection{Introduction}

As indicated in the last chapter already, investors in the electricity sector will decide what types of plants will be installed in the near future. Those plants will then be used for the coming decades and contribute to cumulative emissions while combusting fossil fuels. This problem is relevant to both industrialized countries with rising replacement demand and developing and transition countries, where quickly rising energy demand propels the need for more generating capacity. The last chapter has mentioned the US and China as examples, but in Europe a lot of existing capacity will have to be retired and replaced by new plants soon as well. The question that arises for the environmentally concerned policy-maker then relates to the type of power plants by which the old (mostly coal-fired) capacity will be replaced. Will coal-fired power plant owners opt for coal-fired power plants again? Or will renewable energy be phased in, as old capacity is phased out? In addition to answering these questions, we are interested in the role of technical change. Can technological progress in less carbonintensive generation technologies be a savior of last resort? Or is it possible that the prospect of technological improvements could delay investment in immature plant types? ${ }^{1}$ Or will the volatility of fossil fuel prices maybe make producers reluctant to switch to another generation of fossil-fuel-fired power plants?

\footnotetext{
${ }^{1}$ This is actually the case in our vintage-portfolio model in Chapter 6.
} 


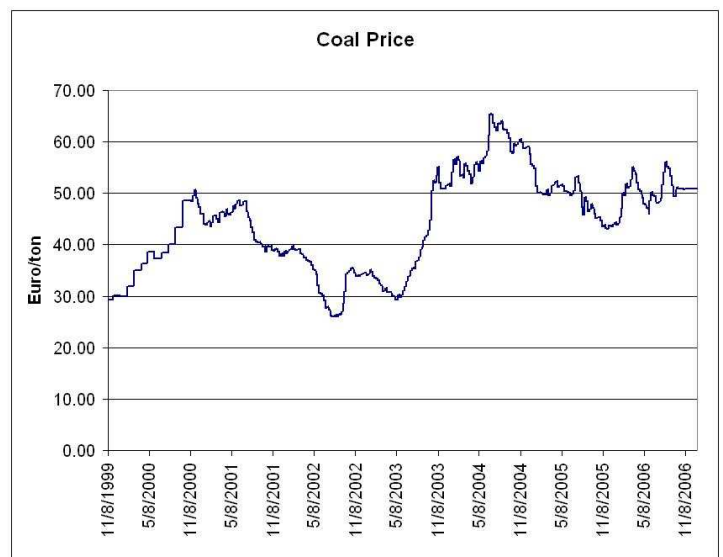

Source: European Electricity Exchange (EEX)

Figure 4.1: Daily spot prices for coal in EUR/t

These considerations illustrate that electricity planning is surrounded by a number of uncertainties. The previous chapter has explored the effects of uncertainty about regulation and fluctuating $\mathrm{CO}_{2}$ prices on investment decisions. Another source of uncertainty - most imminent in the case of power plants fired by fossil fuels - is the risk associated with the volatility of (growing) fuel prices. As an example, Figure 4.1 shows the evolution of the spot price of coal (source: EEX, 2006) for the time period 1999-2006. Oil and gas prices fluctuate even more sharply. ${ }^{2}$ This can lead to considerable losses for the individual power producer, but also to a significant loss in terms of a country's GDP. Awerbuch and Sauter (2006) present results that point to elasticities of GDP with respect to oil prices of about $10 \%$, for example. It is therefore important to understand how the volatility of fuel prices influences the decisions of installing new generating capacity.

The uncertainties involved in fuel price processes (usually accompanied by an upward trend) might lead to the conclusion that renewable, "zero-fuel-price" technologies might also outperform the conventional power plants on these grounds, in addition to their advantage of emitting zero $\mathrm{CO}_{2}$. This would imply that the external problems associated with the generation of emissions by fossil fuel plants would vanish simultaneously, as a transition to renewable energy would take place with ongoing technical change and uncertainty about rising fuel prices. However, the main disadvantage of such "green" technologies is their high fixed cost (capital cost and fixed O\&M costs),

\footnotetext{
${ }^{2}$ Even though there might be contracts allowing the producer to procure a certain amount of gas or coal for a longer period of time than a day, these contracts will typically cover only relatively short periods of time: gas producers are reluctant to engage in longer-term contracts, since a standard well is usually depleted in about a year and engaging into longerterm contracts would mean that gas producers would have to be sure about future wells' productivity. Coal miners, who were facing increasing costs at the beginning of the 2000s and could not take advantage of high spot prices because they were tied up in relatively long-term contracts (like in the previous chapter), might also be reluctant to engage in such long-term commitments in the future.
} 
which has so far inhibited the large-scale diffusion of renewable technologies in the electricity sector amongst other factors. Proponents of renewable energy have pointed to the fact that these costs will still be subject to major reductions as technological change progresses. ${ }^{3}$ To illustrate the vast scope for improvement, consider Figure 4.2 , which shows several renewable power technologies' projected change in overnight investment cost over the next decades based on the TECHPOL database (European Commission, 2006).

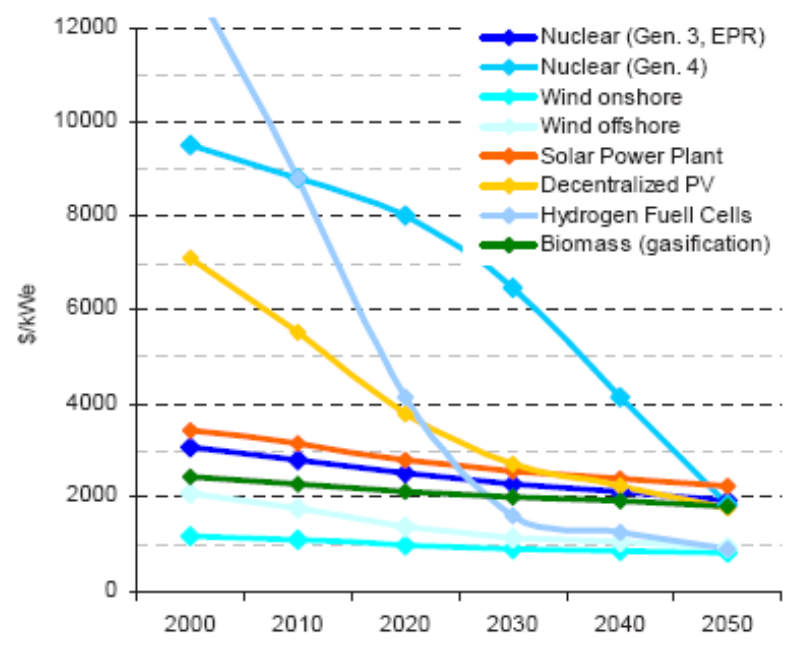

Source: TECHPOL Database, European Commission, 2006

Figure 4.2: Evolution of Overnight Investment Cost of Renewable Power Technologies

It can be observed that technologies, which have to date been uneconomical such as decentralized photovoltaics (PV) and hydrogen fuel cells, are expected to experience considerable reductions in their investment cost according to the Commission's study. Even (offshore) wind will be only half as expensive 40 years from now. Furthermore, biomass technologies are expected to undergo reductions in investment costs of about $28 \%$, solar PV of $33 \%$ and (onshore) wind of $25 \%$. This draws a very optimistic picture for future power investments. However, technological improvement itself is an inherently uncertain process, which needs to be taken into account when making investment decisions. Whether research really results in the projected cost reduction and at which point in time it would do so exactly, can never be determined with absolute certainty. Therefore, the arrival of cost-reducing innovations must be treated

\footnotetext{
${ }^{3}$ The fact that today's installations will be used for the next decades shows that a sustainable energy mix needs to be found already now in order to avoid lock-in or path-dependencies. The expectation of technological improvements, however, might provide a disincentive for the investors to irrevocably commit resources now and wait for improved versions instead. Our model shows that this is a plausible outcome.
} 
as a stochastic process.

With respect to the technological prospects of established technologies relying on fossil fuels, it can be said that most of them are already in a later stage of maturity than renewable technologies, which still have large scope for improvements that might also occur at a relatively fast pace initially. As explained in Chapter 1, there are studies that indeed find evidence for this hypothesis. They look at so-called progress ratios (PR), which is the percentage of initial costs (per unit of output) that current costs will reach as a result of doubling their output (of installed capacity). It is found that gas turbines had a lower PR during their R\&D phase than during their commercialization phase, i.e. costs were reduced by a lower percentage for each doubling of cumulative output than before. This suggests that technological progress decelerates, as technologies mature. For comparison, the European Wind Energy Association (2004) projects a relatively low PR for the capital costs of onshore wind generation. ${ }^{4}$ However, they do not report a precise number, but a range of $\mathrm{PR}$ projections. This indicates a large potential of wind energy in the future, but the wide range in the projections also points to the uncertainty associated with these promising rates of progress. It is important to emphasize at this point that - while the computation of these PR ratios often also accounts for the effects of learning by doing (i.e. improvements after instalment) - the nature of technical change in our framework is purely embodied. This implies that new equipment has to be bought and installed in order to enjoy the latest technological improvements. Once the new power plant is installed, there is no scope for reductions in the cost of investment. This is important because it creates further value to waiting, as technical change is exogenous. In the case of learning by doing, investment could occur earlier and costs could be further reduced by e.g. advances in know-how ex post. In the latter case, the waiting value would be much less pronounced.

We have decided to analyze the effect of the above-mentioned uncertainties on investment in a real options framework, as this allows us to take into account that the capital invested into a specific power plant is sunk and the investment decision irreversible. Furthermore, real options modeling considers the flexibility of the investor to invest earlier or gain more information by postponing investment. The real options literature of primary interest for this study deals with uncertainty about technological change and input cost or revenue uncertainty (see Chapter 2). Table 4.1 summarizes this strand of literature with particular focus on the findings with respect to the relationship between uncertainty and investment.

Among these studies, only two deal with technological and revenue/input cost uncertainty simultaneously, which is of major interest in this chapter. Both Pindyck (1993) and Murto (2007) can only derive analytical solutions for very special cases. ${ }^{5}$ In the model presented in this chapter, an analytical solution can generally not be obtained either, and we want to abstract from special cases, which do not seem to

\footnotetext{
${ }^{4}$ Please refer to Chapter 1 for the exact projections.

${ }^{5}$ In Pindyck (1993), the interest rate needs to be zero and fuel price uncertainty absent in order to find an analytical solution; Murto (2007) also solves analytically for extreme cases only, such as the complete collapse of investment cost.
} 
have realistic applications in the first place. ${ }^{6}$

This model adds to the existing work in this field by formulating a more general framework than Pindyck (1993) and Murto (2007) and applying it to the case of investment in the electricity sector. To our knowledge, applications of real options theory to technological change in the electricity sector with derived climate change policy implications are rare, apart from attempts to capture learning effects by including learning curves into real options models. ${ }^{7}$ However, such an approach to technological change does not take into account the embodiment of technological change that we want to incorporate in our framework by focusing on improvements in investment cost. While Pindyck's (1993) model is simple and therefore straightforward, it is not suited for our purpose because it relies on sequential investments, where the project can be abandoned midstream. It is true that this might explain the canceling of many nuclear power plants in the US in the early 1980s because there was large uncertainty about construction cost at that time. However, the construction costs of nuclear power plants is enormous compared to the power plant types that we consider. Therefore, we do not think that midstream abandonment is a relevant strategy for the standard plants we focus on. Since we exclude this possibility, technological uncertainty has a much more profound effect in our model.

Murto (2007) models technical change with a Poisson process, in which we follow him closely, but he makes some assumptions that we do not regard appropriate for the electricity sector. For example, he assumes that upon investment, the producer will receive a perpetual revenue stream (which is practical when looking for an analytical solution), while in the case of power plants, the stream of profits ensuing investment is evidently limited by the lifetime of the plant. Furthermore, as mentioned before, we do not want to restrict ourselves to examine the timing of investment in a particular facility, but we want to focus more on the switch or transition from an established (fossil fuel) power plant to an environmentally more friendly plant (based on renewable energy carriers) under the described uncertainty. ${ }^{8}$ If technological advance and the risks associated with stochastic fossil fuel prices do not result in earlier investment into low- or zero-emission plants, policy makers have to provide another investment trigger for earlier adoption. This could take the form of $\mathrm{CO}_{2}$ taxes or subsidies for producing renewable energy.

\footnotetext{
${ }^{6}$ The appendix shows that, even though it is possible to set up the problem analytically with the help of the Kummer function, it is not possible to find an analytical solution for the fuel price when the option to invest is not perpetual.

${ }^{7}$ Kumbaroğlu et al (2004) include learning curves for renewable energy into their real options model. They find that for Turkey the diffusion of renewable energy technologies will only occur if policies are directed to that cause because they suffer from high capital cost. On the other hand, active promotion of green technologies will accelerate learning and result in faster adoption of these technologies because costs will decrease more quickly.

${ }^{8}$ However, we will first also adopt a simpler experimental setting with only one plant, which improves due to uncertain technical change, in order to distill the effects of technological progress itself (i.e. the rate) and the uncertainty surrounding it (i.e. the fluctuations in the path of improvement), before considering the more elaborate framework with existing capacity suffering from fuel price uncertainty.
} 


\begin{tabular}{|l|l|l|}
\hline Author(s) & Model & Investment Response \\
\hline \hline $\begin{array}{l}\text { Balcer and Lippman } \\
(1984)\end{array}$ & $\begin{array}{l}\text { Technical change modeled as cost reduction. Profits linear } \\
\text { in technology level. Innovation potential evolves according } \\
\text { to discrete time semi-Markov process. }\end{array}$ & $\begin{array}{l}\text { More uncertainty leads to postpone- } \\
\text { ment of investment. }\end{array}$ \\
\hline Pindyck (1993) & $\begin{array}{l}\text { Stochastic (fixed) input costs. Technological change de- } \\
\text { creases cost. Project can be abandoned during construction } \\
\text { stage. }\end{array}$ & $\begin{array}{l}\text { Input cost uncertainty depresses invest- } \\
\text { ment } \\
\text { certainty leads to slightly earlier invest- } \\
\text { ment. }\end{array}$ \\
\hline $\begin{array}{l}\text { Grenadier and Weiss } \\
(1997)\end{array}$ & $\begin{array}{l}\text { The state of technological progress is a random variable } \\
\text { following a geometric Brownian motion. Once it surpasses } \\
\text { a specified threshold, an innovation arrives. Sequential in- } \\
\text { vestments possible. Learning in the sense that investors } \\
\text { become better at benefitting from innovations. Different } \\
\text { innovation adoption strategies. }\end{array}$ & $\begin{array}{l}\text { Larger volatility leads to postponement } \\
\text { of investment. }\end{array}$ \\
\hline Farzin et al (1998) & $\begin{array}{l}\text { Technical change improves production efficiency and is } \\
\text { modeled as a jump process, where there can be uncertainty } \\
\text { about the speed of technical change, but also about the } \\
\text { magnitude of improvement. Multiple switching possible. }\end{array}$ & $\begin{array}{l}\text { Larger degree of uncertainty leads to } \\
\text { delay in technology adoption. This ef- } \\
\text { fect diminishes if technical change is } \\
\text { slow/the improvements are small be- } \\
\text { cause the benefits from waiting for the } \\
\text { next arrival will be smaller. }\end{array}$ \\
\hline Murto (2007) & $\begin{array}{l}\text { Revenue stream follows geometric Brownian motion. Tech- } \\
\text { nical change follows Poisson process and decreases invest- } \\
\text { ment costs. }\end{array}$ & $\begin{array}{l}\text { Technological uncertainty has only an } \\
\text { effect in the presence of revenue uncer- } \\
\text { tainty: investment is postponed. }\end{array}$ \\
\hline
\end{tabular}

Table 4.1: Real Options Literature on Technological and Input Cost Uncertainty 
The IEA/OECD data we use indeed suggest that a typical coal-fired power plant will only be scrapped in favor of a wind farm when an additional investment incentive (here $\mathrm{CO}_{2}$ prices) is introduced by policy makers. With increasing fuel prices and positive rates of technological change for the wind technology, a constant $\mathrm{CO}_{2}$ price of $70 € /$ ton will trigger investment into a wind farm in the second half of the planning period. At current $\mathrm{CO}_{2}$ permit prices of around $23 € / \mathrm{EUA}^{11}$ at EEX, this implies that today's $\mathrm{CO}_{2}$ prices would need to triple to achieve a transition to renewables within the next 35 years. ${ }^{12}$ At $23 € /$ EUA the wind farm is only phased in when the coal-fired power plant's lifetime is over, namely in period 40 . Raising the price to $75 € /$ ton of $\mathrm{CO}_{2}$ leads to much earlier discarding of the coal-fired plant. The wind farm would then already be adopted within the next five years. An escalating tax or a $\mathrm{CO}_{2}$ permit trading system with upward trending $\mathrm{CO}_{2}$ prices will achieve such a transition within 24 years for a rate of $\mathrm{CO}_{2}$ price growth equal to $5 \%$. An interesting study by Viebahn et al (2007) shows that depending on the development of carbon capture technologies for coal-fired power plants, rates of technical change of renewables, coal prices and market development, renewable energy (they use a mix of technologies) could become competitive within the next 15 to 45 years. They assume a $\mathrm{CO}_{2}$ price level of $35 € /$ ton.

It is therefore up to the potential negotiators of a post-2012 carbon agreement to keep in mind that the market itself will not provide sufficient incentives for private investors to make a shift towards renewable energy in the absence of technological breakthroughs. Many European countries have proclaimed the aim to achieve that a pre-specified portion of the electricity supply shall be generated from renewable sources (e.g. more than $10 \%$ in the UK). In order to speed up the diffusion of technologies based on renewables, $\mathrm{CO}_{2}$ prices would need to be tripled instantly or raised successively, where the latter policy leads to earlier diffusion than the former and has the advantage of easier implementation.

The rest of the chapter is organized in three sections: the first one outlines the model and describes the techniques that we use to solve it. Afterwards, we provide an overview of the data used and an analysis of the results obtained. Finally, we draw conclusions, provide possible policy implications and point out areas for future research.

${ }^{9}$ With technical uncertainty, there is always the chance that the cost to completion is sufficiently low to make an investment profitable. The true cost will only be revealed upon investment, but there is always the option to abandon the project when the cost evolves unfavorably. Thus, the critical cost threshold, at which investment is profitable, is higher, i.e. investment is brought forward in time. For a more detailed description of this model, please return to Chapter 2 .

${ }^{10}$ This might be due to the fact that with smaller improvements also the maximum attainable technology level is lower. So this result could really be the effect of a change in the rate of technical change and not in the extent of uncertainty. To avoid this in our model, we follow Murto (2007) in keeping the rate of technical change constant and focus on the variance to analyze the effects of uncertainty.

${ }^{11} \mathrm{An}$ EUA is an allowance for emitting one ton of $\mathrm{CO}_{2}$.

${ }^{12}$ This does not seem to be far off the estimates of the IPCC, who suggest that a $\mathrm{CO}_{2}$ price of $\$ 100$ /ton will be necessary to stabilize cumulative $\mathrm{CO}_{2}$ emissions at levels associated with relatively moderate global warming. 


\subsection{The Real Options Model}

The model that we develop here focusses on two power plants: a coal-fired power plant (representative of the fossil fuel technologies) and an offshore wind farm (representative of renewable energy technologies), see Section 4.2.2. With respect to uncertainty, the coal-fired power plant suffers from fluctuations in the price of coal. At the same time, it is a relatively mature technology in the sense that we do not expect further decreases in cost. The wind farm, on the other hand, has promising expected rates of technical change and is obviously not subject to fuel price volatility. However, even though the scope for technical change might be high, the realization of such progress is uncertain. ${ }^{13}$

We model technical change as a reduction in the investment cost of a wind farm that could provide the same amount of electricity as the coal-fired power plant. There are two ways to look at this. First, with the arrival of an innovation, investment costs are reduced by a specified percentage. The uncertainty here concerns the arrival rate: the higher the arrival rate, the more certain investors can be that an innovation will arrive within a relatively short period of time. On the other hand, with a certain arrival rate, the magnitude of the improvement is a source of uncertainty. If technical change is to be realized by multiple arrivals of innovations that improve costs only marginally, this might be preferable to a situation where very few innovations lead to huge drops in cost. This is visualized in Figure 4.3, where the plant value of the wind farm (i.e. the immediate and discounted future revenues less the investment cost at each point in time of the planning horizon) is shown for a low arrival rate combined with a high reduction in costs (i.e. the step size is large) by the bold dotted line.

The solid line shows a large number of arrivals, but then each arrival reduces the cost only by a low proportion, i.e. the plant value does not increase substantially, but more "continuously". Both lines end up at the same level at the end of the planning period. That is, the cumulative "amount" of technical change remains the same. However, the thin line that grants more continuous improvements might be preferred over the big jumps at arbitrary points in time that the bold, dotted line exhibits. Fixing the level of cumulative technical change and varying only the arrival rate or step size leading to this level therefore provides a way to analyze uncertainty about technical change without confusing the effect with the result of changing the rate of technical change; see Section 4.2.1 for the mathematical framework. ${ }^{14}$

Fuel price uncertainty is represented by letting the coal price follow a geometric Brownian motion (GBM), which takes into account that prices are rising slightly over time and that this price path is volatile rather than smooth, as can be verified in

\footnotetext{
${ }^{13}$ Moreover, wind suffers from a low capacity factor and is therefore not a reliable candidate for providing large-scale base loads. Even though we account for the capacity factor, we abstract from the distinction between peak and base load provision in this chapter. Wind is taken as a representative technology for all renewable energy carriers. Our focus is on the phasing in of renewable energy as a replacement for fossil fuel technologies when investors face uncertainties. Therefore, the technologies under consideration have been chosen for illustrative purposes and not to claim that the electricity sector should exclusively rely on wind.

${ }^{14}$ We will typically be changing the arrival parameter, $\lambda$, to analyze uncertainty. However, when fixing $\lambda$ and changing the step size, the investment pattern shows the same response.
} 


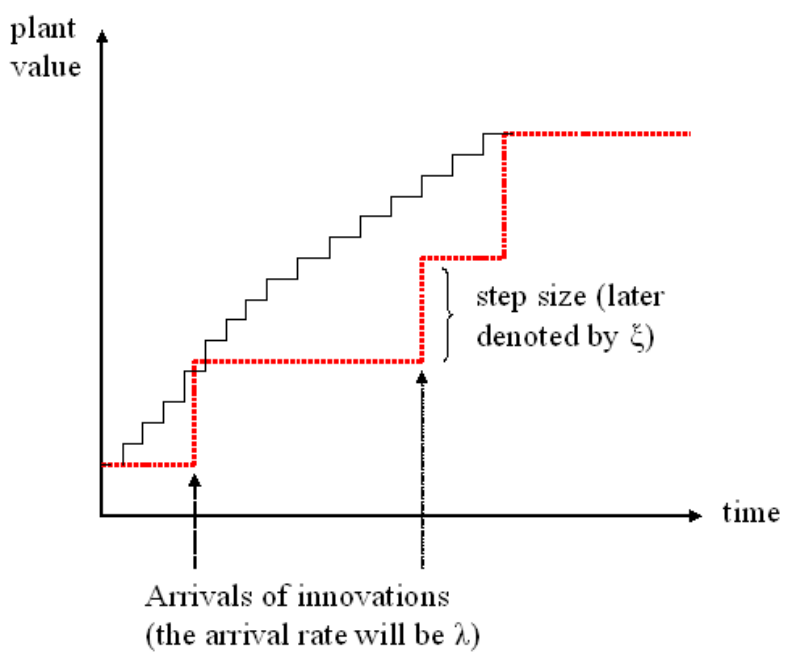

Figure 4.3: The Plant Value of the Wind Farm

Figure 4.1. This volatility would be much larger for gas. However, a gas-fired power plant has very low investment costs, even compared to coal, which would require us to examine a much longer time horizon in order to observe a transition to (offshore) wind. The choice for wind as our renewable technology is due to the fact that it is (a) still very expensive in terms of the capacity that needs to be installed, (b) ongoing research efforts lead us to expect a decrease in costs in the near future, and (c) even though it might be space-wise restricted eventually, there is still a lot more scope for expansion (especially offshore) than for other technologies such as large-scale hydro-dams. ${ }^{15}$

\subsubsection{Framework}

As has already been mentioned above, fuel price uncertainty will be examined by letting the fuel price (here the price of coal) follow a GBM. Equation (4.1) represents the change in the fuel price, $p^{f}$, where $\alpha$ is the drift parameter, $\sigma^{f}$ is the volatility parameter and $d z$ is the increment of a standard Wiener process.

$$
d p_{t}^{f}=\alpha \cdot p_{t}^{f} d t+\sigma^{f} p_{t}^{f} d z
$$

The effect of uncertainty can then be investigated through the volatility parameter, $\sigma^{f}$. The expected value of $p_{t}^{f}$ is $p_{0}^{f} \cdot e^{\mu \cdot t}$.

Technical change in the alternative technology, wind, is occurring in response to the arrival of innovations. This arrival follows a Poisson process in the way that also

\footnotetext{
${ }^{15}$ Other representative technologies that we could have used are biomass-based technologies or solar PV, for example. Biomass (and also biofuels) have non-zero and therefore potentially uncertain fuel prices, however. Solar PV's capital costs still exceed those of traditional technologies by far (see Chapter 1) and are thus not appropriate for an illustration with a relatively short planning horizon.
} 
Murto (2007) models it. Let us denote the investment cost by $C_{t}$ evolving according to:

$$
C_{t}=C_{0} \cdot \xi^{W_{t}}
$$

In Equation (4.2), $W_{t}$ is a Poisson random variable, with an average arrival rate (of innovations) of $\lambda .0 \leq \xi \leq 1$ determines the size of the step or - in other words - the magnitude of the technological improvement achieved through the innovation. The expected value of $C_{t}$ is therefore $C_{0} \cdot e^{-\lambda \cdot t \cdot(1-\xi)}$. This is easy to see when noting that $\lambda_{t}$ counts the number of innovations (arrival rate times periods). If $\xi=0.05$, for example, -0.95 would be multiplied by the number of innovations in order to find the corresponding fraction of $C_{0}$ that is $C_{t}$. For $\lambda=0.1$, this would be $91 \%$ at $t=1$.

It is important to note that only if $\lambda(1-\xi)$ remains constant, the expected path of technological progress is unchanged. Equation (4.3) shows the variance of the investment cost (see also Murto (2007), page 1480):

$$
\operatorname{Var}\left(C_{t}\right)=C_{0}^{2} \cdot\left(\left(e^{-\lambda(1-\xi) t}\right)^{(1+\xi)}-\left(e^{-\lambda(1-\xi) t}\right)^{2}\right)
$$

The implication from Equation (4.3) is that a decrease in $\lambda$ and $\xi$ (so that $\lambda(1-\xi)$ remains constant) increases the variance of costs, while an increase in the parameters decreases the variance until the point where the cost is reduced to zero by the very first innovation. ${ }^{16}$ Murto (2007) considers this polar case along with some other simplifications because it allows him to derive an analytical solution. However, we do not regard this to be a realistic scenario for our application and want to focus on cases, where the cost is reduced in accordance with general expectations for the corresponding technologies.

Immediate profits are composed of the revenues from selling electricity, $p^{e} \cdot q^{e}$, and the revenues from providing heat, $p^{h} \cdot q^{h}$, both of which are constant over the planning period. ${ }^{17}$ Furthermore, we have to subtract the costs for the amount of fuel used in the generation process in the case of coal, $q^{f} \cdot p^{f}$. Other costs involve the outlays for operations and maintenance, $O M C$, which are fixed for the amount of electricity that is generated per year, and the $\mathrm{CO}_{2}$ taxes and/or expenses for the purchase of emissions permits. Finally, the costs of the action taken by the investor at time $t$ need to be considered as well: these are zero in case no investment is made and equal to the cost of installing new capacity if the decision is taken to invest. Note that these costs depend on the advance of technical change and the uncertainty associated with

\footnotetext{
${ }^{16}$ This requires that $\xi=0$ : to keep $\lambda(1-\xi)$ equal to a constant, the innovation probability has to be low, but once the innovation arrives, the investment cost drops to zero.

${ }^{17}$ We have chosen to include the profits from selling heat because many existing coal-fired power plants are actually able to sell the heat that they generate during the generation of electricity and therefore these revenues represent a further advantage over renewable energy technologies that do not have this extra source of revenue. Renewables therefore need to overcome an even higher barrier than "only" their high overnight investment and O\&M cost. (Biomass-based technologies are the exception, but even they have lower heat profits due to lower efficiency in generating heat).
} 
this. Equation (4.4) summarizes this as the immediate profit.

$$
\begin{aligned}
\pi\left(m_{t}, a_{t}, p_{t}^{f}, C C_{t}\right) & =q^{e}\left(m_{t}\right) \cdot p_{t}^{e}+q^{h}\left(m_{t}\right) \cdot p^{h}-q^{c}\left(m_{t}\right) \cdot p^{c} \\
& -q^{f}\left(m_{t}\right) \cdot p_{t}^{f}-O M C\left(m_{t}\right)-C C_{t}\left(a_{t}, \lambda, \xi\right),
\end{aligned}
$$

where $m_{t}$ is the state the investor is currently in. In Section 4.3.1 this is either a situation where there is no plant or where the wind farm has already been deployed. In Section 4.3.2 this is a setting where a coal-fired power plant already exists at first. At a later stage it can be a state where a new coal-fired power plant has replaced the old one or where a wind farm has been built instead. Table 4.2 gives a brief overview of this setting. $C C_{t}$ is equal to $C_{t}$ in Equation 4.2 when an investment is made $\left(a_{t}=1\right)$ and equal to zero when $a_{t}=0$, i.e. when the option is not exercised.

\begin{tabular}{|l||l|l|l|}
\hline & $\mathrm{m}_{t}=0$ & $\mathrm{~m}_{t}=1$ & $\mathrm{~m}_{t}=2$ \\
\hline \hline Setting & nothing has & $\begin{array}{l}\text { wind farm has } \\
\text { been built }\end{array}$ & - \\
$\mathbf{4 . 3 . 1}$ & been built & & \\
\hline $\begin{array}{l}\text { Setting } \\
\text { Section }\end{array}$ & the coal-fired & wind farm has & wind farm not \\
$\mathbf{4 . 3 . 2}$ & power plant is & $\begin{array}{l}\text { replaced coal } \\
\text { plant }\end{array}$ & $\begin{array}{l}\text { adopted = new } \\
\text { coal-fired plant } \\
\text { after 40 years }\end{array}$ \\
\hline
\end{tabular}

Table 4.2: Experimental Settings in Sections 4.3.1 and 4.3.2

Very much like in Chapter 3, the investor's problem can be formulated as an optimal control problem and restated in a recursive functional form, so that we can use dynamic programming to determine the optimal action for the above model. In other words, this means that we will be screening all possible values of the value function depending on all the possible states that the decision-maker can be in depending upon all realizations of prices and thereby determine the optimal action in each stage for each realization of prices and technical change. Mathematically, we formulate a value function in Equation (4.5), which has to be maximized by determining the optimal investment strategy $\left\{a_{t}\right\}_{t=1}^{T}$, where $T$ is the planning horizon.

$$
\begin{aligned}
V\left(p_{t}^{f}, C C_{t}\right) & =\max _{a_{t} \in A\left(m_{t}\right)}\left\{\pi\left(m_{t}, a_{t}, p_{t}^{f}, C C_{t}\right)\right. \\
& \left.+e^{-\gamma \cdot \Delta t} \mathbb{E}\left(V\left(t+\Delta t, p_{t+\Delta t}^{f}, C C_{t+\Delta t}\right) \mid p_{t}^{f}, C C_{t}, m_{t}\right)\right\},
\end{aligned}
$$

where $\gamma$ is the discount rate and $a_{t} \in A\left(m_{t}\right)$ is an action in the set of feasible actions. $^{18}$ The value function has a straightforward interpretation. The first part is the immediate profit, $\pi\left(m_{t}, a_{t}, p_{t}^{f}, C C_{t}\right)$, which the producer receives upon investment. The second part represents the discounted expected continuation value $e^{-\gamma \cdot \Delta t} \mathbb{E}\left(V\left(t+\Delta t, p_{t+\Delta t}^{f}, C C_{t+\Delta t}\right) \mid p_{t}^{f}, C C_{t}, m_{t}\right)$. This term is evaluated for the spe-

\footnotetext{
${ }^{18}$ In this chapter's model all actions are feasible actions by definition, since instalment of a plant also implies its use, and so if a wind farm is added later in the planning period, the coal-fired power plant will be switched off.
} 
cific state the producer is in, which changes as actions are undertaken. For example, at the end of the lifetime of the coal-fired power plant the wind farm could replace the coal-fired power plant. Then fuel costs would drop to zero. However, it could also be that the coal-fired technology is still cheaper than the wind farm. In this case the investor would build another coal-fired power plant to replace the expired one and thus make no transition towards renewable energy.

$\mathbb{E}(V(\cdot))$ can be numerically computed in three different ways as explained in Chapter 3. The first one would be through partial differential equations, the second one involves multinomial lattice frameworks and the third one (which we choose here again) is Monte Carlo simulation. Please refer to Figure 3.2 in the previous chapter for the exact methodology used. Before presenting the experiments, we will first describe the technologies we are focussing on in more detail and provide the data used in the simulations.

\subsubsection{Coal and Wind Plant Data}

The first technology selected for our study as a representative of the fossil-fuel-based plants is a coal-fired plant with an integrated module capturing and storing a portion of its $\mathrm{CO}_{2}$ emissions (therefore the capital costs appear to be higher than for a standard coal-fired power plant). More specifically, the data are for an Integrated Gasification Combined Cycle (IGCC) plant, which are typically more expensive to build, but have very satisfactory efficiency. We are using data from the International Energy Agency/OECD (2005). The choice for coal with carbon capture is targeted at making the plants more comparable in effective emission terms. With a positive $\mathrm{CO}_{2}$ price, coal is already at a disadvantage compared to renewable energy with zero emissions. Since we want to focus on the effects of fuel price uncertainty and technological uncertainty on the investment pattern and not on $\mathrm{CO}_{2}$ prices as the main trigger for a transition in the first instance, we will first keep $\mathrm{CO}_{2}$ prices low and by choosing in addition a coal-fired power plant that emits relatively less than the standard, we grant the coal-fired power plant a certain degree of competitiveness versus the renewables-based technology on these grounds. Using an old-fashioned coal-fired power plant makes the coal-fired power plant much less profitable in our experiments where we introduce $\mathrm{CO}_{2}$ prices, even though the general results still hold. A transition to wind energy is much more rapid in this case.

The other technology is an offshore wind plant (a Danish brand). It is considerably more expensive than coal in terms of capital and O\&M costs and also its capacity factor is not very attractive (see Table 4.3). We have opted for offshore instead of onshore wind, even though it has higher costs of installation, and O\&M because the space to build the farm is less restricted than onshore, and the wind can propel the mills with less obstacles in its way and thereby achieve a higher capacity factor than onshore wind mills, which only run at full capacity $25-27 \%$ of the time. The data are from the same IEA report as the coal data and are assembled in Table 4.3. Still, the capacity factor compares very unfavorably to that of the IGCC plant. 


\begin{tabular}{|c|c|c|c|}
\hline Parameters & & IGCC Coal & Offshore Wind \\
\hline Electricity Output & {$[\mathrm{TWh} / \mathrm{yr}]$} & 3,285 & 3,285 \\
\hline $\mathrm{CO}_{2}$ Emissions & {$\left[\mathrm{kt} \mathrm{CO}_{2} / \mathrm{yr}\right]$} & 2,155 & 0 \\
\hline Fuel Consumption & {$[\mathrm{TJ} / \mathrm{yr}]$} & 23,188 & 0 \\
\hline Fuel Cost & {$[€ / \mathrm{TJ}]$} & 1,970 & 0 \\
\hline O\&M Fixed Cost & {$[1,000 € / \mathrm{yr}]$} & 40,250 & 49,392 \\
\hline $\begin{array}{l}\text { Effective Installed Ca- } \\
\text { pacity }\end{array}$ & {$[\mathrm{MW}]$} & 500 & 833.33 \\
\hline Capacity factor & {$[\%]$} & 75 & 45 \\
\hline Heat Efficiency & {$[\%]$} & 34 & 0 \\
\hline Heat Price & {$[€ / \mathrm{TJ}]$} & 11,347 & - \\
\hline Investment Cost & {$[1,000 €]$} & 686,500 & $1,049,358$ \\
\hline Lifetime & [years] & 40 & 25 \\
\hline
\end{tabular}

Table 4.3: Power Plant Data for Coal and Wind

\subsection{The Results}

The analysis of investment sensitivity to uncertainty about fuel prices and technological improvements is divided in two experiments. First, we want to focus exclusively on technological uncertainty. The experiment that we have designed for this purpose therefore presents only one investment option, namely to invest into the wind farm. We first start out by investigating the effects of different rates of technological progress on the timing of investment. Varying the degree of uncertainty by adjusting $\lambda$ and $\xi$ correspondingly (see Equation (4.3)), we can then also analyze how the investor reacts to these changes.

The setting of the second experiment is such that we consider an established coal plant, ${ }^{19}$ which has no prospect of cost reductions due to technological improvements. Furthermore, the price of coal is stochastic and (slightly) rising (see Equation (4.1)). The analysis will then determine how the optimal date of replacing existing capacity with the wind farm responds to changes in fuel price and technological uncertainty. If the wind farm is not competitive, the coal-fired plant will be kept until it expires and will then be replaced by another IGCC plant. Refer back to Table 4.2 for an overview of the experimental setting.

\subsubsection{Technological Change and Uncertainty}

Let us first analyze the impact of different rates of technical change on the timing of investment and interpret it in terms of plant and option value. In Figure 4.4 the plant and investment option values for a modest rate of technical change $(\lambda(1-\xi)=0.2 \%)$ and for a relatively higher rate $(\lambda(1-\xi)=0.5 \%)$ are plotted. Uncertainty is kept low by setting $\lambda=1$ in order to avoid cross-effects.

From Chapter 2 we know that the investor will exercise the option to install the plant, as soon as the plant value (i.e. the value of the immediate profits that accrue

\footnotetext{
${ }^{19}$ Coal-fired plants are always preferred over renewables in the beginning because of their current cost advantage as explained above, see Section 4.2.2.
} 


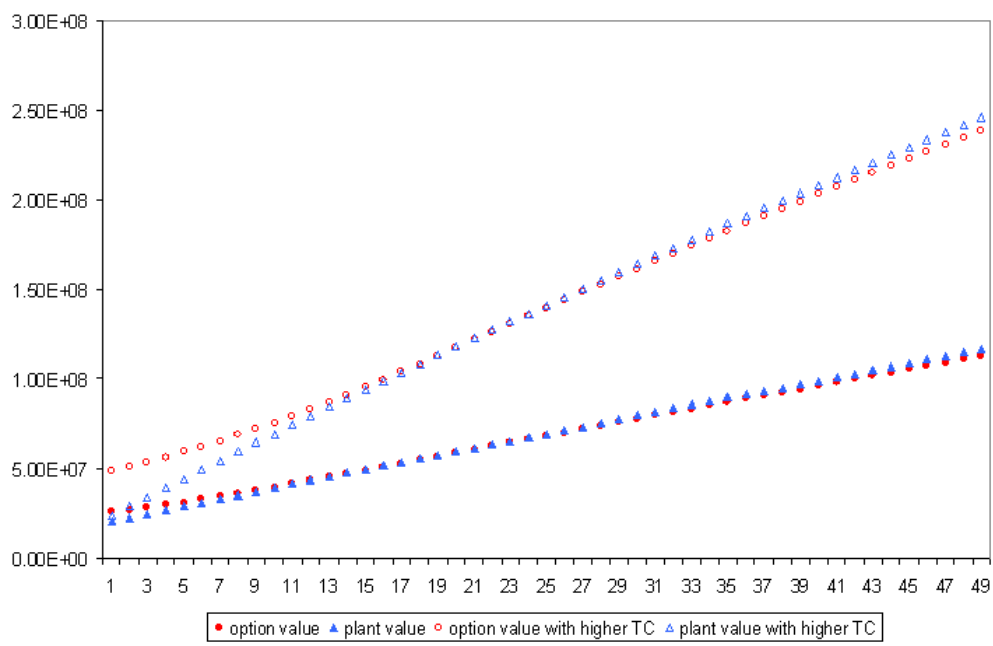

In the low-progress scenario investment occurs around year 11. In the high-progress scenario, the investment option is exercised much later.

Figure 4.4: Option Values (circles) and Plant Values (triangles) for Low (Solid) Rate of Technical Change (TC) and High (transparent) Rate of Technical Change in (€)

upon investment) exceeds the option value of waiting. This is the case around year 11 for the low rate of technical change, i.e. where the solid circles and triangles meet in Figure 4.4. For higher technological progress, the plant and also the option to invest into the plant reach a much higher level, as shown by the transparent circles (option value) and triangles (plant value). In addition, the option value rises more sharply relative to the plant value. This can be explained by the fact that technological improvements are embodied in the latest capacity; once investment has taken place, no further cost reductions can occur. Therefore, if a larger decrease in costs can be expected at the same level of certainty, it pays off to wait longer and reap the benefits of ongoing technological change. Higher rates of technical change therefore lead to a postponement of investment.

We now turn to the analysis of uncertainty and use the results obtained above for $\lambda(1-\xi)=0.5 \%$ and $\lambda=1$ as a reference scenario. As already pointed out, a relatively high $\lambda$ lowers uncertainty about the future technological advances with respect to investment cost. The high number of innovations that arrive over the planning horizon is compensated by a relatively smaller step size. More specifically, $\xi$ will be $99.5 \%$, which means that costs fall by only $0.5 \%$ each time a new innovation is found. If we have a planning horizon of 50 years, there will in total be 50 innovations, i.e. there will be a fall of $25 \%$ in investment costs over 50 years, which is not unrealistic looking back at the projections displayed in Figure 4.2.

In Section 4.2.1 we have explained how increasing the arrival rate of innovations, along with a decrease in the size of the steps that this implies for the actual cost 
reduction, decreases the variance of technical change and thereby the uncertainty associated with the cost of investment. We fix $\lambda(1-\xi)$ at 0.005 , and choose $\lambda=0.1$ for the beginning. This gives us a step size of $\xi=95 \%$, which leaves ultimately the same "amount" of technical change, but makes costs much more volatile in terms of the variance given in Equation (4.3).

With such a low value for $\lambda$, this is a situation of great uncertainty, since the investor cannot be sure when the innovations will exactly arrive. Since the cost reductions are quite substantial, waiting for them gets more valuable. The outcome of this simulation $^{20}$ is that, on average, the wind farm is built after year 26 (more precisely the mean building time is at $t=26.5134$ ). Please note that this result is obtained without any fuel price uncertainty, since we are focussing on only one type of plant (the wind farm) and there is no existing capacity ex ante investment in this setting.

As we can see in Figure 4.5, the option value is higher with more technological uncertainty, while the plant value is largely unaffected. This is the reason why investment occurs later than in the lower uncertainty case. The analysis implies that we find a negative relationship between investment and uncertainty, as is typical in the real options literature: the higher the variance, the later the investment option is exercised.

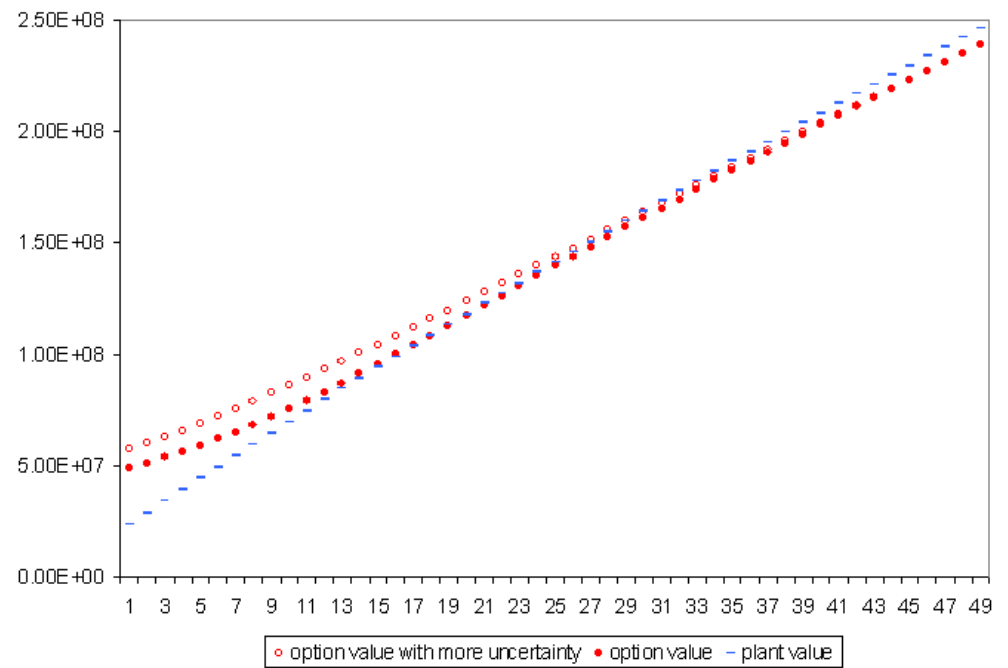

In the low-uncertainty scenario investment occurs earlier than in the high-uncertainty case.

Figure 4.5: Option Values (circles) and Plant Values (steps) for High Uncertainty (transparent circles) and Low Uncertainty (solid circles) in (€)

This is quite logical from an intuitive point of view. If the expected decrease in costs over a specific time horizon is quite substantial, but the investor cannot be sure how late it will be realized, it will pay off to wait for that improvement to materialize because the profits that accrue thereafter are higher and more than compensate for the

\footnotetext{
${ }^{20}$ The number of simulated technology paths is 10,000 .
} 
costs of waiting. ${ }^{21}$ On the other hand, if the investor knows that a lot of innovations will arrive during the planning horizon, he can be sure that at least some of them will arrive in the beginning of the planning period and that he does not forgo much by investing relatively early. Moreover waiting for smaller increments in plant value to arrive over the planning horizon is not as lucrative as waiting for a huge cost drop, which becomes ever more probable to occur, the longer investors have been waiting already.

It is important to note that this result hinges crucially on our definition of technical change, which we model as a decrease in investment cost. This takes into account that you have to irreversibly commit resources in order to take advantage of the latest technology. This principle is generally known as embodied technological progress (see Chapters 1 and 2) in the literature. If we had modeled technical change as learning-bydoing, i.e. if current operations decreased the costs through improvements in knowledge of how to handle existing processes, the outcome would be different. Even with irreversible investment, cost reductions would then be possible after instalment, which would reduce the incentive to wait for (exogenous) technological improvements.

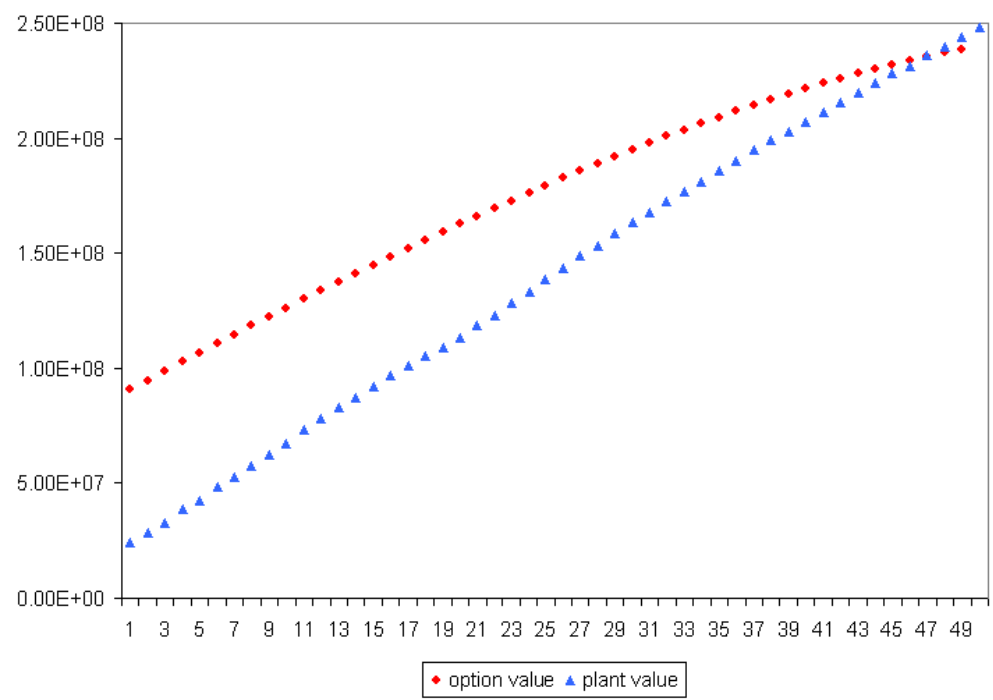

With very high uncertainty $(\lambda=0.01)$ the option value increases at a diminishing rate.

Figure 4.6: Option Value (circles) and Plant Value (triangles) for Very High Uncertainty in (€)

Another interesting finding is that an even higher arrival rate leads the rate of increase in the option value to diminish, see Figure 4.6. This illustrates nicely how the framework works: for an unchanged rate of technical change, the value of the plant is unchanged as well. With a fixed end benefit, the option value of waiting in the final

\footnotetext{
${ }^{21}$ Remember Figure 2.3 from Chapter 2 where the cost of waiting (i.e. foregoing the immediate profits) were also smaller than the extra gains (i.e. the avoided losses) that could be realized later on.
} 
period cannot be different either. Therefore, a larger option value induced by higher uncertainty earlier in the planning period needs to be compensated by a diminishing rate of increase later on.

The existence of technological progress, when it occurs at a relatively certain rate, thus leads to a postponement of investment. This is an embodiment effect because the benefits of technological progress can only be reaped once - namely when the wind farm is installed. Uncertainty, modeled through a reduction of the arrival rate and an increase in the size of the cost drops, further delays adoption because the option value rises, i.e. it more valuable to wait for technical improvements to materialize. As we will see in the second set of experiments (when we look at the problem of replacing an existing IGCC capacity with wind capacity), this result still holds when fuel price uncertainty is introduced as well.

\subsubsection{Technological Change \& Fuel Price Uncertainty}

In this section the experimental setting is such that we consider an established coalfired power plant with ongoing O\&M and fuel costs, which needs to be replaced. The possible replacement candidates are either another coal-fired power plant or an offshore wind farm of the same capacity.

What real options models typically find for input cost uncertainty is that higher uncertainty (usually modeled by increasing the volatility parameter) leads to a postponement of investment (see Chapter 2 and Table 4.1 in Section 4.1) because higher volatility leads to a higher option value of waiting. In our setting, this is much more complicated, since the option value is composed not only of waiting and keeping the profit flows from having the coal plant operational. At the same time, the wind farm's overnight investment costs are reduced due to ongoing (exogenous) technological progress, which creates additional value to waiting.

To illustrate this, we have left the fuel prices at a constant level in the first experiment. In Figure 4.7 the option value is therefore clearly upward-sloping, since the only reason why there actually is an option value (given that fuel prices are constant) is that there is ongoing technical change benefitting the wind farm. And since the benefits of technical change are embodied in the latest version of the plant only, the gain from waiting is positive and increasing. Another important remark that has to be made about Figure 4.7 is that without a price on $\mathrm{CO}_{2}$, the option value line would be enormously far removed from the plant value line, and investment would never occur. Only a $\mathrm{CO}_{2}$ tax (or permit price) leads to eventual adoption of the wind farm. The upper option value line corresponds to $\mathrm{CO}_{2}$ price of $70 € /$ ton, while increasing this price by $5 €$ depresses the option value and leads to earlier adoption of the wind farm. From the policy-maker's perspective, this implies that the cost disadvantages of renewable energy (here wind power) will not be overcome by technological advance in the short run according to current projections. So if emissions reductions need to be achieved quickly, the investment trigger for renewable energy needs to be lowered by either introducing a penalty for $\mathrm{CO}_{2}$ emissions (as in this example), by subsidizing "green" technologies or introducing other regulations. 


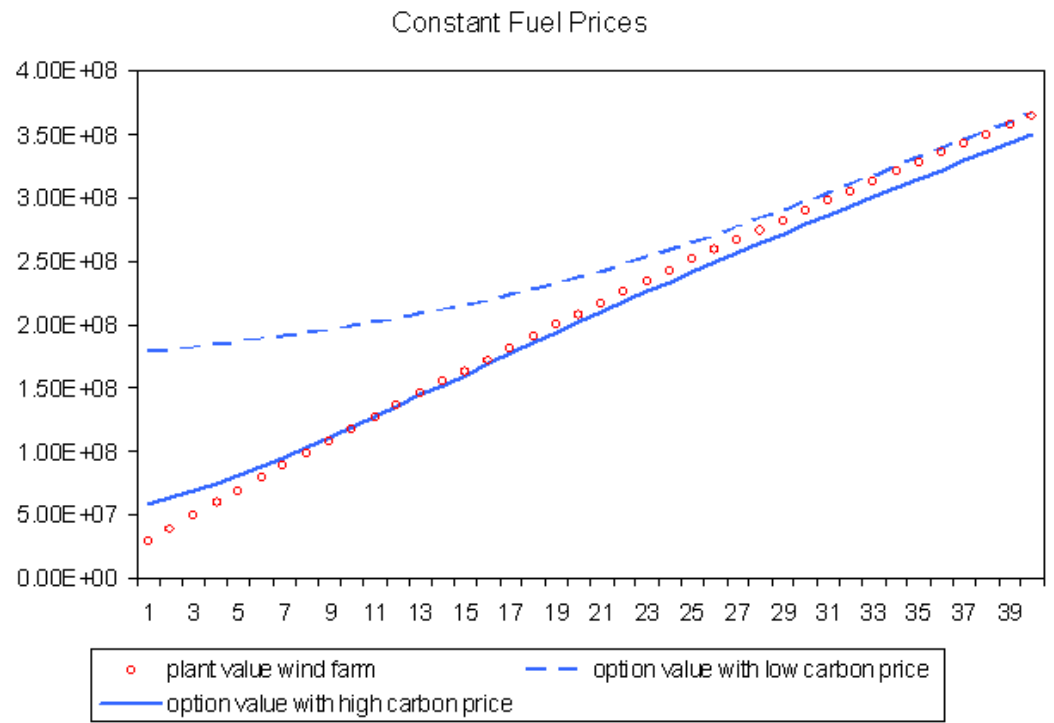

With low $\mathrm{CO}_{2}$ prices, investment occurs at the end of the planning period. With lower $\mathrm{CO}_{2}$ prices, the investment threshold can be moved forward significantly.

Figure 4.7: Plant Value (circles) and Option Values (lines) for Low (dashed line) and High (solid line) $\mathrm{CO}_{2}$ Prices in (€)

The next step in our analysis is to add rising fuel prices, which rise deterministically in the next experiment. Figure 4.8 demonstrates what has been mentioned before: the option value is influenced by two forces - the rising fuel price, which decreases the option value of keeping the coal-fired plant operational and brings the option value closer to the wind farm's plant value, and the option value of waiting for more technological improvement to materialize, so that less has to be spent to set the wind farm up. In the beginning of the planning horizon, the first effect more than outweighs the second influence and the option value line slopes downward. Only later, the increase in the value of waiting for further cost reductions starts to exceed the decrease in the value of keeping the coal-fired power plant, which suffers from higher fuel costs. Again, we can observe that the rate of increase in the option value line diminishes, as we approach the end of the planning period. ${ }^{22}$

Furthermore, the difference between the dashed line and the solid line in Figure 4.8 demonstrates that the option value is shifted downwards when coal prices rise more quickly. Investment is therefore brought forward in time, consistent with expectations.

Now we can finally turn to the full experimental setting with rising and stochastic coal prices, as described in Equation (4.1). In Figure 4.9 the plant value of the wind farm and the option value with deterministic fuel prices are plotted again. The crosses

\footnotetext{
${ }^{22}$ If we would only depict the option value of keeping the coal-fired power plant on the basis of rising fuel prices, the option value line would slope downward completely and the investment threshold would be much lower.
} 


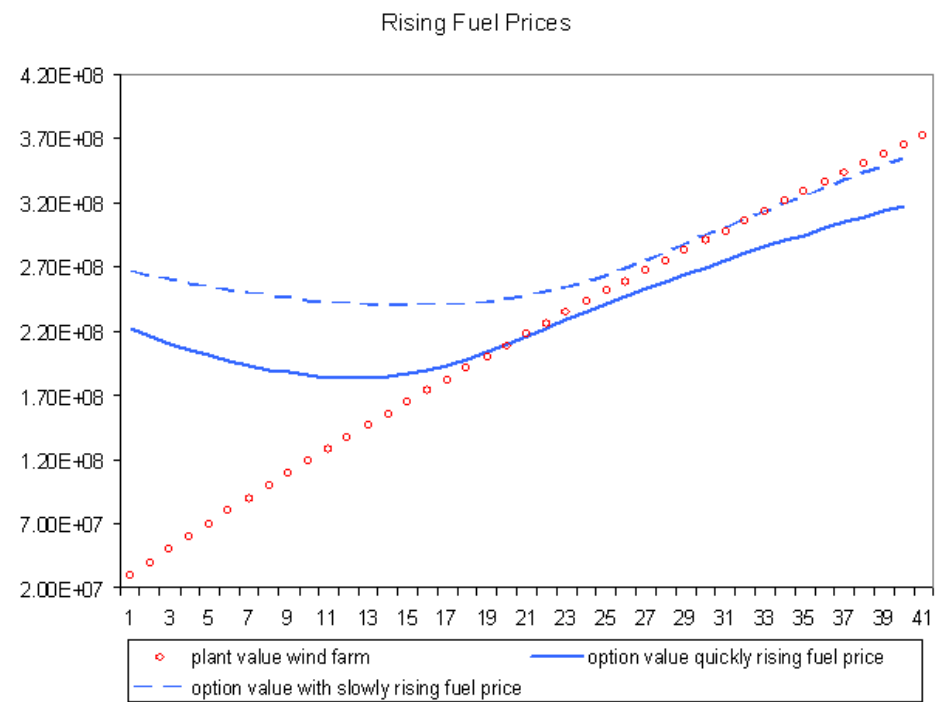

With slowly rising coal prices, investment occurs around year 32. With coal prices rising at twice their forecast rate, the moment at which the investment threshold is surpassed, is moved forward to approximately year 19. The $\mathrm{CO}_{2}$ price is fixed at $70 € /$ ton of $\mathrm{CO}_{2}$.

Figure 4.8: Plant Value (circles) and Option Values (lines) for Slowly (dashed line) and Rapidly (solid line) Rising Fuel Prices in (€)

refer to the option value with stochastic coal prices. ${ }^{23}$

We can observe that with stochastically rising prices, the option value is shifted slightly upwards. However, the option value converges back to the level of the "deterministic" option value after the "waiting for more technical change"-value starts to exceed the falling option value of keeping the coal plant. This is because the fluctuations in the coal price have no effect on that part of the option value. The average investment threshold therefore remains unchanged in this experiment. However, if policy makers trust in fuel price uncertainty to provide sufficient incentives for investors in the electricity sector to retire fossil-fuel-based capacity in favor of renewable energy, these results provide no support for such hypotheses. Even if we would exclude the possibility of technological improvements in wind, which leads to the convergence of the two option value lines in Figure 4.9, the net effect would not deviate much from the average. If anything at all, it would lead to a postponement of investment. In our setting, where the wind farm is only phased in towards the end of the planning period, this could imply that there is no transition to renewable energy at all.

Finally, we want to examine the difference that technological uncertainty with respect to the investment cost of the wind farm makes in the full setting. Figure 4.10 below shows the plant values and option values for a $\lambda$ of 0.1 and 0.8 respectively.

\footnotetext{
${ }^{23}$ We have inflated $\sigma^{f}$ by a factor of 10 in this experiment, since the low volatility of coal made no visible difference in the graph. For gas, the gap between the deterministic and the stochastic option value line would be much larger, since the volatility of gas is greater and the fuel costs represent a much higher proportion of total costs of gas-fired power plants.
} 


\section{Stochastic Fuel Prices}

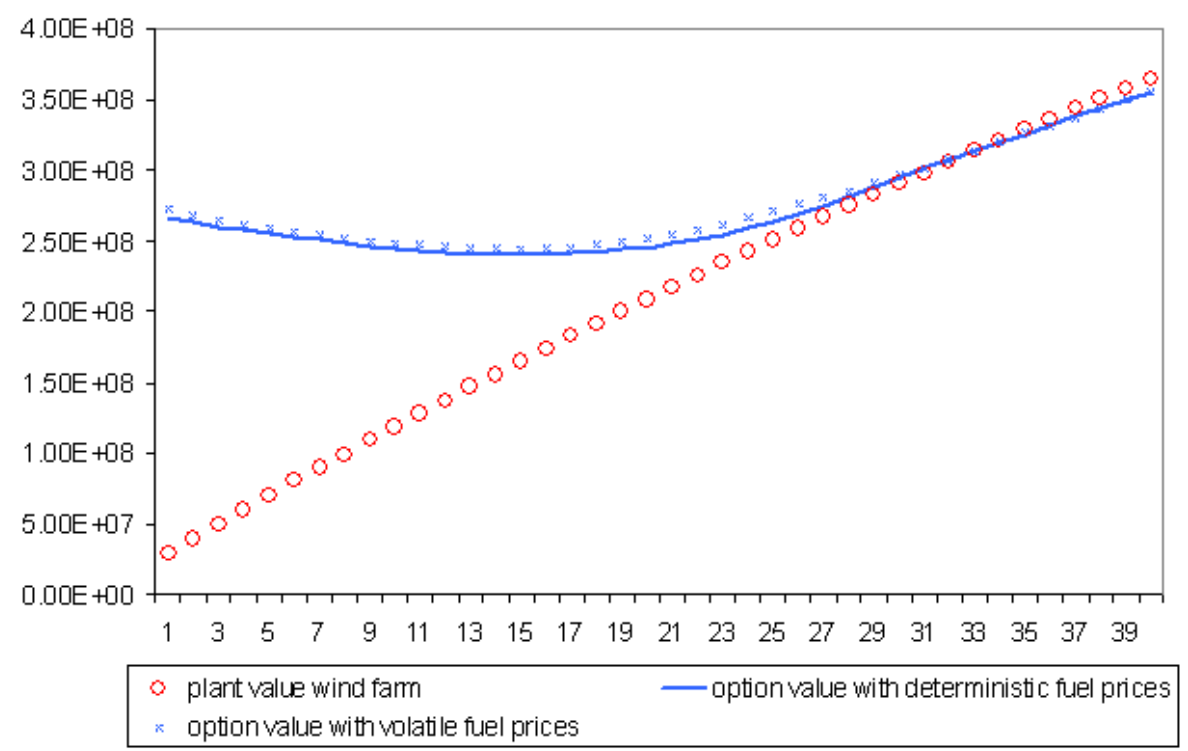

With slowly rising coal prices, investment occurs around year 32. With coal prices rising at twice its forecasted rate, the investment threshold is moved forward to approximately year 19. The $\mathrm{CO}_{2}$ price is fixed at $70 € /$ ton of $\mathrm{CO}_{2}$.

Figure 4.9: Plant Value (circles) and Option Values (lines) for Slowly (dashed line) and Rapidly (solid line) Rising Fuel Prices in (€)

The former case corresponds to a situation where arrivals occur only sporadically but reduce costs a lot, while a $\lambda$ of 0.8 stands for more continuous, but also less dramatic improvements. ${ }^{24}$ Note that both values for $\lambda$ ultimately lead to the same plant value, only the line for the plant value with $\lambda=0.1$ evolves more erratically than the one with $\lambda=0.8$. The option value is influenced much more heavily by the change in technological uncertainty, however. As could be expected from our analysis in Section 4.3.1, the option value with higher uncertainty (dashed line) is above the one with lower uncertainty (solid line) in Figure 4.10. This leads to a postponement in the adoption of the wind farm by approximately five years in this case.

In Figure 4.11 we display the investment and profit distributions for this last experiment. We see that with higher technological uncertainty, the investment distribution does not only have a wider spread, but is also more skewed to the left. This is in line with the conclusions about the option value drawn from Figure 4.10.

In order to test the robustness of the results, a sensitivity analysis has been conducted. We have found that the shape of the option value depends on the choice of the $\mathrm{CO}_{2}$ price level. For a higher $\mathrm{CO}_{2}$ price (e.g. $75 € /$ ton of $\mathrm{CO}_{2}$ ) the impact of rising fuel prices on the option value is diminished and the option value line slopes

\footnotetext{
${ }^{24}$ We have chosen a price of $70 € / \mathrm{t} \mathrm{CO} 2$ again, with $\lambda(1-\xi)$ at 0.005 .
} 
Stochastic Technical Change

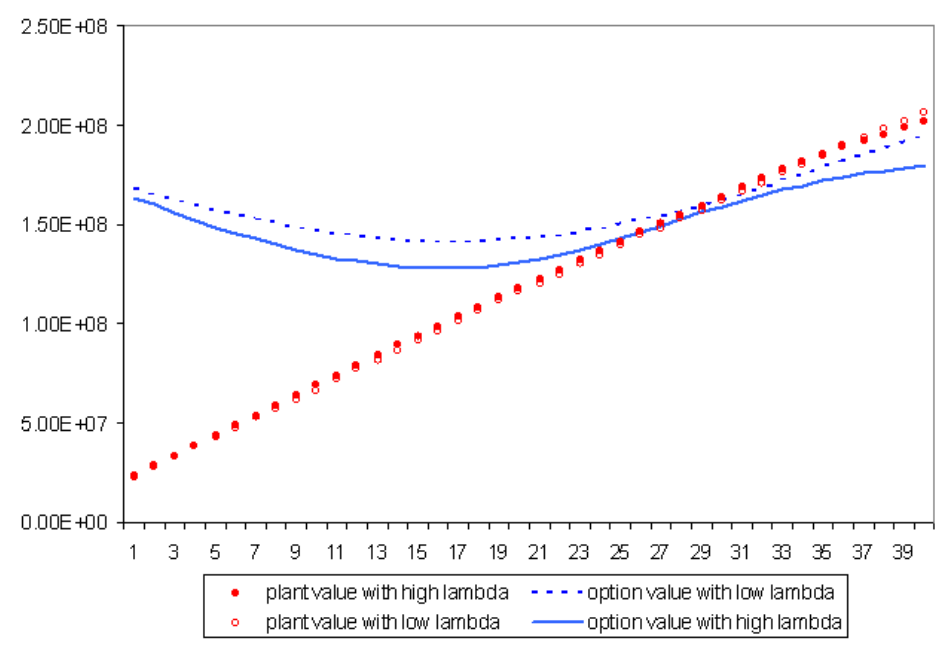

More technological uncertainty leads to a postponement of investment.

Figure 4.10: Technological Uncertainty: Plant Values with Less Uncertainty (filled circles) and Higher Uncertainty (transparent circles) and Option Values (lines) for Lower (solid line) and Higher (dashed line) Uncertainty in (€)

upward from the beginning. ${ }^{25}$ This is because the high $\mathrm{CO}_{2}$ price makes the coal-fired power plant relatively more unprofitable even at initially low fuel price levels. There is therefore no positive value to keeping the coal plant, apart from making use of it during the waiting period where technological progress reduces the costs of installing the wind farm. While this does not change the quality of the results, it is important to keep in mind the extent of the impact the policy-maker can have on the option value of waiting to install the wind farm.

To summarize the results of the experiments conducted in this section, we find that the option value is now composed of (a) the value of keeping the coal-fired power plant in the face of increasing (and potentially volatile) coal prices and (b) the value of waiting for technological progress to increase the plant value of the wind farm by decreasing the cost of investment. In the beginning, the first effect dominates the latter and the option value graph therefore slopes downwards. Later on, this relationship is reversed and the option value slopes upwards. With constant (and also with rising) coal prices, there is no point of intersection between the option line and the plant value, as the option value exceeds the plant value of the wind farm by far. This means that even when the coal-fired plant expires, the choice will not be for wind, but for another coal-fired power plant of the same type that had been installed before. Only by tripling the $\mathrm{CO}_{2}$ price, at which a ton of $\mathrm{CO}_{2}$ is currently traded, the investor can be induced to make the transition to wind. Marginal increases beyond this price will bring investment into wind considerably forward in time. In an experiment where the

\footnotetext{
${ }^{25}$ Remember that these cost items are separate, additive entities.
} 

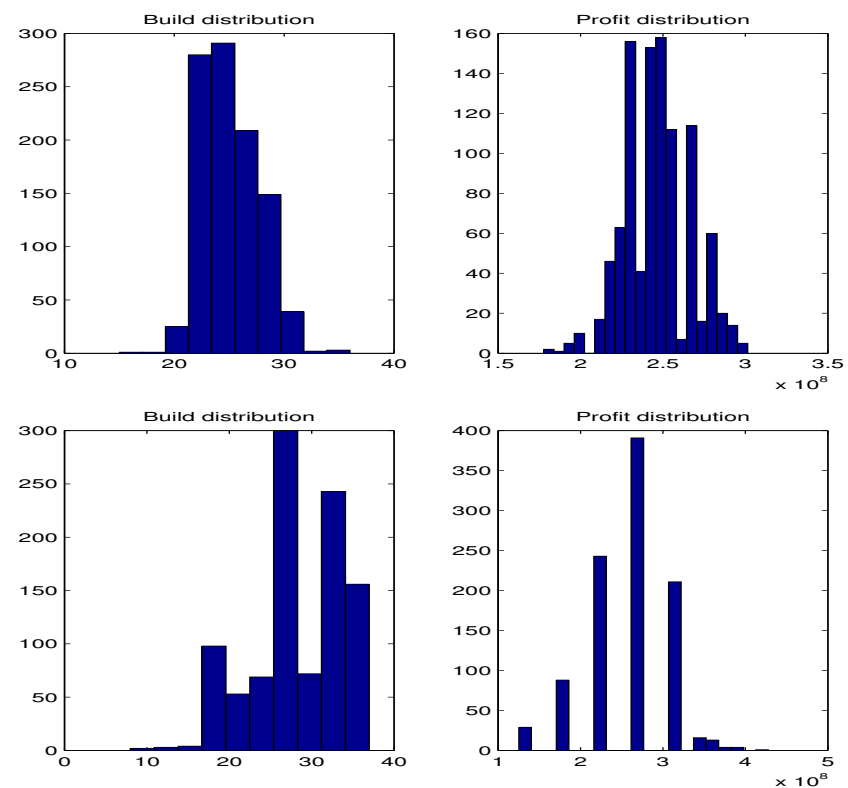

Figure 4.11: Investment and Profit Distributions for 1,000 Simulations. Profits are in $(€)$.

coal price rises more quickly than forecasted, the option value line shifts downward and the investment threshold is reduced. This means that more quickly rising fuel prices will induce earlier investment into renewable technologies. However, given that coal reserves have rather been increasing than decreasing lately ${ }^{26}$ it is difficult to imagine that there will be severe price surges over the long term that might trigger such investment behavior. The volatility of fuel prices does not add to the effect of rising fuel prices either, as it contributes relatively little to the total generation cost and given the modest forecasted increase in fuel prices themselves. Furthermore, such volatility would rather raise the option value of keeping the coal plant and waiting for more technological change to occur and therefore lead to a later adoption of the wind farm. Finally, adding technological uncertainty leads to postponement again, where the total impact appears to be smaller than in the experiments with the wind farm only. This is because the coal-fired power plant owner is now confronted with a larger cost of waiting in terms of the higher fuel cost that he increasingly faces as time progresses.

\subsection{Conclusion}

This chapter has presented a real options model with stochastic fuel prices and stochastic technical change in the electricity sector to explore the effects of uncertainty on the

\footnotetext{
${ }^{26}$ This is due to technical improvements, which make the exhaustion of previously uneconomical deposits possible.
} 
behavior of investors. As some authors have mentioned (e.g. Awerbuch and Sauter, 2006) volatile fuel prices might cost economies more than generally expected. It appears that renewable energy carriers, which come at a zero "fuel" cost, such as wind in this chapter, have a large advantage over fossil fuel technologies in this respect. Furthermore, even though they might still be expensive in terms of their capital and O\&M costs, renewables have bright prospects in terms of their technological improvement over the next decades (see Section 4.1 for forecasts). At the same time, renewables do not generate $\mathrm{CO}_{2}$ emissions, which implies that a transition to their use is desirable from an environmental point-of-view (and in the very long run also from an economic point-of-view, as fossil fuel prices continue to rise). More precisely, an early adoption of renewable energy will assist most governments' striving for sustainable energy development.

However, it stands to question whether the combination of rising, uncertain fuel prices and technological advance in the area of renewables will really provide sufficient incentives for investors to switch from an established fossil fuel plant (here coal) to a renewable technology (here wind). The application of our model to recent data from the IEA (2005) suggests that this may not be the case. Without an additional trigger (here $\mathrm{CO}_{2}$ prices), the transition is not profitable for the investor in the short run, even if the rate of technical change had been higher.

Furthermore, the analysis of the effect that uncertainty has on the investment pattern suggests that uncertainty about fuel prices does not have a significant effect of the timing of renewable energy phase-in. If anything at all, the price fluctuations will lead to a slightly higher option value, as long as this option value is dominated by the value of keeping the coal-fired plant operational. As soon as the value of waiting for more technical change to materialize dominates the option value, fuel price volatility will no longer play a role for the optimal investment date. ${ }^{27}$ Betting on fuel price uncertainty to provide sufficient disincentives for investors in the electricity sector to replace old coal-fired capacity with new coal-fired power plants does therefore not seem to be a promising policy to effectively reduce $\mathrm{CO}_{2}$ emissions.

Including technological uncertainty complicates matters further: if we abstract from the effect that rising (and possibly stochastic) fuel prices have on the option value of waiting to install the wind farm, larger uncertainty will raise the option value of waiting as illustrated in Figure 4.5 and therefore lead the investor to postpone the adoption of the wind farm. This is because technological progress is modeled to be embodied in the latest version of capacity. Therefore, if the investor can expect a relatively large fall (and the fall will be large, if the arrival rate is low, as we keep the rate of progress constant) in the cost of installing the wind farm, it will pay off to postpone the decision for a while and wait for that big cost drop to occur.

Changing the setting, so that we either keep an existing coal-fired plant or replace it with a wind farm (before or after expiration) or another coal plant (after expiration), adds another influence on the option value of waiting. More precisely, the rising fuel

\footnotetext{
${ }^{27}$ In Chapter 3, this was different, as both technologies were affected by the stochastic $\mathrm{CO}_{2}$ prices, even though to a different extent.
} 
prices reduce the value of keeping the coal-fired power plant. If we would not include the value of waiting for more technological progress to improve the costs of the wind farm, the option value line in Figures 4.8 and 4.9 would cross the plant value line much earlier and trigger investment already in year 7 . However, the value of waiting for the benefits of technical change raises the option value and even starts to dominate the development of the option value later during the planning period, so that the option value slopes upward and adoption occurs later than if we had not taken the waiting benefits into account. This implies that - contrary to the hopes that policy makers might have for the role of technical change - the mere existence of cumulative, embodied technological progress leads to a later transition to renewable energy.

Such an analysis is interesting in the light of US energy policy, for example. In 1973, when the US were hit by an oil embargo imposed by the Organization of Petroleum Exporting Countries (OPEC) after Israel's victory in the Yom Kippur War, employment and economic growth were dearly affected by surging fuel prices. Nixon then proclaimed that science and industry were supposed to provide for a technological revolution that would free the country from the dependence on fossil fuels from other countries. However, that technological leap was never made and existing infrastructure was not transformed in favor of non-oil technology. The current US Administration has also demonstrated that it sees a solution in the gradual improvement of existing technologies. Even though the initiatives that have been taken in the area of energy have been motivated by considerations of energy security, the measures are not exclusively targeted at a transition to renewable energy: examples of such policies include the extension of oil exploration activities in the Arctic National Wildlife Refuge, subsidies for the testing of modern oil drilling techniques, finance for new gas pipelines and research funds for fusion energy. For the future, tougher GHG reduction initiatives are expected and utilities have started to actively include carbon regulatory risk in their portfolio analysis (Barbose et al, 2008).

With respect to technological uncertainty in the presence of coal-fired capacity, which looses attractiveness as fuel prices rise, we also find a "typical" real options result. In particular, we find a negative uncertainty-investment relationship again: when the investor can be sure that innovations will arrive within the next few years to reduce the investment cost, the investment option is exercised earlier than if there is uncertainty, which increases the option value of waiting. This result hinges crucially on the way how technical change is modeled, since a reduction in investment cost can only be gained once, namely at the time the investment is made. This is an embodiment effect, without which the value to waiting would be much less important (if we abstract from another effect, namely the intrinsic technological differences between coal and wind, which could be termed "heterogeneity effect").

To summarize, technological uncertainty leads to the postponement of investment into the wind plant in the presence of coal-fired capacity that is influenced by (stochastic) fuel price growth. Furthermore, reasonable rates of technological change alone are not capable of making the wind farm competitive versus the established coal-fired power plant. The message for policy makers is that an additional trigger in the form 
of $\mathrm{CO}_{2}$ taxes or permit trading must be maintained in order to induce an earlier transition to renewable energy.

Finally, a few words need to be said about the limits of the analysis presented: the exogeneity of technical change is a simplification, of course, because progress is endogenous insofar that the $R \& D$ needed to drive the progress must be financed as well. In fact, Davis and Owens (2003) use real option pricing techniques to estimate the current value of expected future supply from renewable electric technologies, net of federal R\&D expenditures, when fossil fuel prices are uncertain. They find a large positive value of $\$ 30.6$ billion, of which a large part is attributed to past federal $R \& D$ efforts, and continued federal R\&D funding is assumed. The value would even be higher, if future federal R\&D levels were projected to be higher as well. In the ideal framework, however, the private investor would value an R\&D option to further develop immature technologies in the presence of the option to make a transition to that same technology - thus taking into account that also technical change needs to be paid for. However, the endogeneity of technical change is beyond the scope of this chapter, where we the focus is on the effects of technological uncertainty as such in the presence of uncertainty about fossil fuel prices. Therefore, we have assumed that the individual investor does not carry out the R\&D necessary for progress, even though endogenizing technical change in real options models is definitely an interesting and important topic for further research. One interesting question to be addressed, for example, concerns how uncertainty in the productivity of the R\&D process will affect both the rate of technical change and the uncertainty surrounding it, thus creating not only endogenous technical change, but also endogenous risk. 


\section{Appendix: Analytical Approach to Option Valu- ation Under Fuel Price Uncertainty}

The fuel price $p^{f}$ follows a geometric Brownian motion with drift parameter $\alpha:^{28}$

$$
d p_{t}^{f}=\alpha \cdot p_{t}^{f} d t+\sigma p_{t}^{f} d z
$$

$\sigma$ is the volatility parameter and $d z$ is the increment of a standard Wiener process as in Section 4.2.1. Abstracting from heat profits and $\mathrm{CO}_{2}$ penalties, we focus exclusively on the price of electricity and the price of fuel. The value of the plant can then be calculated as

$$
V(P)=\int_{t}^{T} e^{-r \cdot \tau} \cdot\left(p^{e}-p^{f} \cdot e^{\alpha \cdot \tau}\right) d \tau
$$

where $p^{e}$ is the electricity price, $t$ is the installation date, $T$ is the lifetime of the plant and $p^{f}$ is normalized such that it measures the fuel cost of producing one unit of electricity. Using the technique of replicating a portfolio (see Dixit and Pindyck, 1994), we can set up a differential equation of the following form

$$
\left(p^{f}\right)^{2} \cdot F^{\prime \prime}+\left(m \cdot p^{f}+q\right) F^{\prime}+s \cdot F=0
$$

where $F$ is the option value of the investment and $m=s$ and $q$ are constants, composed of the volatility parameter $\sigma$, the dividend parameter, the interest rate $r$ and $p^{e}$. More specifically, $m=s=2 \cdot r / \sigma^{2}$ and $q=2 \cdot p^{e} \cdot(\delta-r) / \sigma^{2}$.

This differential equation has to be transformed in order to find a solution. Therefore, we set $p^{f}=z^{-1}$ and $F=z^{k} \cdot e^{z} \cdot w$, where $k$ is the relevant root of $k^{2}+(1-m)$. $k+q=0$, i.e. $\frac{2 r-\sigma^{2}+\sqrt{\left(4 r^{2}-12 r \sigma^{2}+\sigma^{4}\right)}}{2 \sigma^{2}}$. This leads to another differential equation:

$$
\begin{gathered}
\frac{1}{\sigma^{2}}\left(\left(2 r\left(p^{e}(k+z)-1\right)-2 p^{e}(k+z) \delta+(2+2 k+z) \sigma^{2}\right) w+\right. \\
\left.2\left(p^{e} z \delta-r-p^{e} z \delta+(1+k+z) \sigma^{2}\right) w_{z}^{\prime}+z \sigma^{2} w_{z z}^{\prime \prime}\right)=0
\end{gathered}
$$

This differential equation can be solved by bringing it into the following form: $\left(a_{2}\right.$. $\left.z+b_{2}\right) \cdot w_{z z}^{\prime \prime}+\left(a_{1} \cdot z+b_{1}\right) \cdot w_{z}^{\prime}+\left(a_{0} \cdot z+b_{0}\right) \cdot w$ (see Polyanin and Zaitsev, 2003). To achieve this transformation, we have to have $a_{2}=1, b_{2}=0, a_{1}=2+\frac{2 p^{e}(r-\delta)}{\sigma^{2}}, b_{1}=2+2 k-\frac{2 r}{\sigma^{2}}$, $a_{0}=\frac{2 p^{e} r-2 p^{e} \delta-\sigma^{2}}{\sigma^{2}}$ and $b_{0}=2\left(1+k-\frac{r-k \cdot r \cdot p^{e}+k \cdot p^{e} \cdot \delta}{\sigma^{2}}\right)$. The general solution to such a differential equation is $w=e^{g \cdot z} \cdot x(y)$, where $y=\frac{z-\mu}{\lambda}$. The form of the function $x(y)$ must be determined using the solution to the degenerate hypergeometric equation, of which the Kummer function is a particular solution. Polyanin and Zaitsev (2003), for example, provide a detailed overview of exact solutions for ordinary differential equations (ODE). If the ODE has the form $\theta v^{\prime \prime}+(b-\theta) v^{\prime}-a v=0$, then for $b>a>0$ the Kummer function can be written as $\phi(a, b, \theta)=\frac{\Gamma(b)}{\Gamma(a) \Gamma(b-a)} \int_{0}^{1} e^{\theta t} t^{a-1}(1-t)^{b-a-1} d t$, where $\Gamma(\varrho)=\int_{0}^{\infty} e^{-t} t^{\varrho-1}$. If $b$ is not an integer, the solution can be formulated as $v=C_{1} \cdot \phi(a, b, \theta)+C_{2} \cdot x^{1-b} \cdot \phi(a-b+1,2-b, \theta)$. This is what we use in this appendix

\footnotetext{
${ }^{28}$ The notation in the appendix does not necessarily coincide with the notation of the main text because this is a simplification of the problem.
} 
to find a solution. In our case $a=\frac{1}{2}\left(1+\frac{p^{e}(r-\delta)\left(r-\sigma^{2}\right)}{\sqrt{\left(p^{e}\right)^{2}(r-\delta)^{2} / \sigma^{4}} \sigma^{4}}+\frac{\sqrt{4 r^{2}-12 r \sigma^{2}+\sigma^{4}}}{\sigma^{2}}\right)$ and $b=1+\frac{\sqrt{4 r^{2}-12 r \sigma^{2}+\sigma^{4}}}{\sigma^{2}}$.

Substituting back for $w$ and $z$, we can derive all constants by using the smooth pasting and value matching conditions and $F\left(p^{f} \rightarrow \infty\right)=0$, but it is analytically not possible to solve for the optimal $p^{f}$. 



\section{Chapter 5}

\section{An Integrated Vintage-Portfolio Approach to Electricity Investment}

\subsection{Introduction}

While the first part of the thesis has been occupied with real options modeling, this part's models are based on portfolio selection. In this chapter we first present a "standard" Markowitz portfolio application to electricity investments and then develop a simple portfolio framework in a vintage setting for the same application. In this way, it will become clear what the benefits of the new approach are.

As already explained in Chapter 2, standard (financial) portfolio theory has been applied to (real) investments in the electricity sector before. Awerbuch and Berger (2003), Awerbuch (2006) and Roques et al (2006) have contributed significantly to this literature, which is summarized briefly in Table 5.1 (and has already been reviewed in more detail in Chapter 2). While real options theory focusses on the optimal timing of investing into particular power plants and is thus an appropriate framework to analyze individual investment decisions, portfolio selection is a useful tool for large investors, who want to diversify a portfolio with respect to the risks imminent to certain technologies. Another application is the optimization of the energy generating mix at the country level. As Awerbuch and Sauter (2006) emphasize, fluctuations in fuel prices can be costly in terms of GDP losses, so energy security becomes an important issue for countries depending on fossil fuels for energy generation. A portfolio approach hedging these risks thus appears to be a very suitable decision framework. 


\begin{tabular}{|c|c|c|}
\hline Author(s) & Features & Findings \\
\hline $\begin{array}{l}\text { Bar-Lev \& } \\
\text { Katz }(1976)\end{array}$ & $\begin{array}{l}\text { Mean-Variance (M-V) Portfolio Model; utilities can } \\
\text { cover fossil fuel needs partially by long-term con- } \\
\text { tracts, the rest is bought on the spot market; min- } \\
\text { imize expected increase in fossil fuel cost for given } \\
\text { fuel cost risk. }\end{array}$ & $\begin{array}{l}\text { Utilities are efficiently diversified, but they accept very high risk } \\
\text { for high returns, which might be due to regulation forcing them } \\
\text { to accept a higher level of risk to achieve a sufficient amount of } \\
\text { return. }\end{array}$ \\
\hline $\begin{array}{l}\text { Humphreys } \\
\& \quad \text { McClain } \\
(1998)\end{array}$ & $\begin{array}{l}\text { Minimize risk to domestic economy from fuel price } \\
\text { shocks; use (co)variances that vary with time (esti- } \\
\text { mated through a GARCH model). }\end{array}$ & $\begin{array}{l}\text { Electricity sector has operated close to minimum-variance position } \\
\text { during the 90s. Overall, US electricity consumption is inefficient. } \\
\text { More coal should be used. }\end{array}$ \\
\hline $\begin{array}{l}\text { Awerbuch } \\
\& \quad \text { Berger } \\
(2003)\end{array}$ & $\begin{array}{l}\text { M-V portfolio framework, which is used to evaluate } \\
\text { current and planned EU generating mixes with un- } \\
\text { certain fuel, O\&M and construction costs. }\end{array}$ & $\begin{array}{l}\text { Existing EU portfolio is suboptimal/inefficient. Fuel price risk } \\
\text { dominates the other risk types (uncertainty about variable and } \\
\text { fixed O\&M costs and construction costs), so including renewables } \\
\text { might help. }\end{array}$ \\
\hline $\begin{array}{l}\text { Awerbuch } \\
(2006)\end{array}$ & $\begin{array}{l}\text { Extended version of Awerbuch and Berger (2003) } \\
\text { with applications to EU, US and developing coun- } \\
\text { tries' portfolios. Focus on fossil fuel price risk, which } \\
\text { claimed to be an important issue in energy security. }\end{array}$ & $\begin{array}{l}\text { Countries should be adding renewables to make generating port- } \\
\text { folios more efficient. Compared to US and EU portfolios, Mexico } \\
\text { and other developing countries have/plan to have much less effi- } \\
\text { cient energy mixes. }\end{array}$ \\
\hline $\begin{array}{l}\text { Krey } \quad \& \\
\text { Zweifel } \\
(2006)\end{array}$ & $\begin{array}{l}\text { Use seemingly unrelated regression estimation to } \\
\text { compute time-invariant covariance matrices for their } \\
\text { M-V model. Application to Switzerland and the US. }\end{array}$ & $\begin{array}{l}\text { Maximum expected return portfolio for Switzerland should con- } \\
\text { tain more nuclear and solar energy and less hydropower, while } \\
\text { the minimum variance portfolio would have more hydropower, but } \\
\text { also more nuclear. The US maximum expected return mix would } \\
\text { have more coal and wind. The minimum variance mix would con- } \\
\text { tain coal, wind, nuclear and oil. }\end{array}$ \\
\hline $\begin{array}{l}\text { Roques et al } \\
(2006)\end{array}$ & $\begin{array}{l}\text { M-V portfolio model where return distributions for } \\
\text { the different technologies are generated by Monte } \\
\text { Carlo simulation to serve as input for the calcula- } \\
\text { tion of the covariance matrix. Application to UK } \\
\text { data. Uncertainty about fuel, electricity and carbon } \\
\text { prices. }\end{array}$ & $\begin{array}{l}\text { Questionable whether the market provides sufficient incentives to } \\
\text { install a socially-optimal fuel mix. Correlations between the price } \\
\text { processes influence the results significantly: diversification bene- } \\
\text { fits of a nuclear plant for a power company operating gas- and } \\
\text { coal-fired plants are low for price correlations observed in the UK. }\end{array}$ \\
\hline
\end{tabular}

Table 5.1: Mean-Variance (M-V) Portfolio Frameworks for Investment in the Electricity Sector 
All of the studies listed in Table 5.1 have the strength of valuing diversification gains and draw a clear tradeoff between risk and return (or cost). However, as explained in Chapter 2, they rely exclusively on $\mathrm{M}-\mathrm{V}$ portfolio selcetion and thus suffer from several shortcomings - most notably their static nature, which makes it difficult to analyze the effects of inherently dynamic processes such as technical change and the consequences of irreversibility. This is the main motivation for developing a new approach here, which will be extended and applied in the following two chapters. ${ }^{1}$

While e.g. Awerbuch (2006) finds that the portfolio share of renewables should be increased in most countries according to portfolio considerations and one might wonder why this is not the case in reality, we find that renewables should be phased in at a later point in time when taking into account the dynamics and the irreversibility underlying investment in the electricity sector.

The basic idea is that the possibilities by which fuels can be converted into electricity correspond to one "family" of technologies, defined by the type of fuel they use. Hence we have the "gas-fired-turbine-family", the "coal-fired-turbine-family", renewables using fuels such as wind or solar energy and so forth. Each family in turn consists of different generations of similar technologies, as in a vintage model of production. ${ }^{2}$ Within a family, each generation embodies the level of knowledge that was cutting edge at the time the generation came into existence. Each of these - in turn - will become outdated as new vintages arrive.

The reason why we are emphasizing this structure within a technology family is that technical change does not fall as "manna from heaven" (Robinson, 1962). Instead, it needs to be bought and paid for in the form of new machines and equipment. In electricity production, the most important type of technical change is embodied and comes about in the form of quality improvements of machinery and equipment. As efficiency usually does not change substantially ex post, we will disregard disembodied technological improvements that could be achieved through learning-by doing, and focus on embodied technical change through improved capital productivity in a clayclay vintage setting. As laid out in Chapter 2 in Section 2.5, the clay-clay structure of vintage models implies that factor proportions are fixed ex ante and ex post. The improvements made through technological progress can therefore only be realized by buying the new equipment. Ex post, no additional efficiency enhancement is possible, i.e. there are no substitution possibilities. The novelty of the approach presented here

\footnotetext{
${ }^{1}$ Another contribution to the problem of electricity planning is by Madlener et al (2005). In their model uncertainty pertains to fluctuations in demand, peak load capacity, generation costs and the price of electricity. They use a dynamic programming approach and actively value waiting in the face of uncertainty. Their work thus falls more into the category of real options frameworks as in the first half of the thesis. However, their approach to maximize the net present value of optimal vintages is - at least to some extent - similar to ours, which is why we did not want to ignore it at this point. Their results are based on data for the Turkish electricity sector, where a large amount of gas-fired capacity has been installed lately, which is found to be a suboptimal choice because coal prices are a lot less volatile than gas prices in Turkey.

${ }^{2}$ See Gregory and James (1973) for further arguments why vintage modeling is appropriate for the electricity sector, such as the substantial initial investment outlays required to start production (Gregory and James, 1973, p. 1134). A more extensive literature review about vintage modeling is provided in Chapter 2.
} 
is the way in which uncertainty surrounding the rate of technical change will have an impact on investment behavior, while fuel price uncertainty leads to the outcomes one would expect from "standard", static mean-variance portfolio theory.

Furthermore, we emphasize the fact that there are different technology families used in electricity production by one and the same firm at the same point in time. Since most providers do not rely on a single production technique, the various technologies must thus be imperfect substitutes for each other because the most efficient family would otherwise drive out the other families. The question then arises why producers prefer to employ a mix of technology families. There are several reasons for this. First, some families perform the best under constant production circumstances. Their output levels can only be changed at a relatively high cost, which causes significant problems if forecasts fall short of actual demand. ${ }^{3}$ Other families can be used to meet peaks in demand because their output levels can be easily adjusted. Gas turbines, for example, have high generation costs, but require only low instalment expenses, while coal-based technologies have much higher capital costs, but lower generation costs. More specifically, gas turbines have capital costs of only half the amount than that of coal-fired turbines and a quarter of that of nuclear capacity. At the same time, fuel costs of gas-fired plants constitute up to $80 \%$ of total costs, while the corresponding percentages for coal and nuclear are around $30 \%$ and $10 \%$ respectively. Other reasons for using technology mixes are that prices of fuels can be quite volatile, which is especially evident in the case of oil. This might lead to considerable gains from diversification and thus warrants a portfolio approach.

Evidently, the return to electricity production depends on price movements and the corresponding composition of the electricity capital stock in terms of technology families. However, the profitability of electricity production also depends on the sizedistribution of generations within families, since that determines the efficiency of the family in meeting its production goals. The above-mentioned diversification gains do thus not only apply across different technology families, but also across vintages of the same family that differ with respect to their productivity characteristics, where we focus on fuel price and technological uncertainty as the causes of return volatility. ${ }^{4}$

In our framework, we combine elements from portfolio theory (so we can introduce the gains from diversification described above and in Chapter 2) and vintage modeling (so we can overcome the static nature of mean-variance portfolio selection also explained in Chapter 2).

The beginnings of vintage modeling and later applications have been documented

\footnotetext{
${ }^{3}$ For the sake of transparency and to illustrate the new approach with as little potential cross effects as possible, this chapter does not investigate stochastic fluctuations in demand, even though this could be implemented as in Chapter 7. Chaton and Doucet (2003) take both fuel price uncertainty and demand uncertainty into account, but their approach ignores the effect that prices might have on demand, which could be important if we think of recent efforts to further liberalize electricity markets. Uncertainties emanating from market liberalization have been analyzed by e.g. Dyner and Larsen (2001).

${ }^{4}$ Other factors such as the anticipation of new regulations, supply security and environmental considerations all add to overall uncertainty in capacity planning as well, as described by $\mathrm{Ku}$ (1995). For the same reasons that we do not explicitly consider demand fluctuations, however, we will also disregard these sources of uncertainty for the moment.
} 
at length in Chapter 2. Let us recall here that the basic idea of a vintage model is that the potential of technical change as an idea can only be realized in practice by first incorporating that idea in a piece of machinery and subsequently using that machinery to produce output. Because technical change is therefore embodied in individual pieces of machinery and equipment, vintage models emphasize the fact that complementary investment has to take place in order to realize the productivity potential of new ideas. The main focus of a vintage model, therefore, is on the diffusion of technical change. The embodiment of technical change results in a capital stock that is heterogeneous in terms of the unit operating cost associated with individual vintages.

While Chapter 2 has also reviewed putty-putty (Solow, 1960) and putty-clay (Johansen, 1959; Salter, 1960) models, a clay-clay (Kaldor and Mirrlees, 1962) model applied to individual technology families is best suited for our purposes, as it implies the absence of alternative choices of production techniques within a family, and the absence of possibilities to change factor proportions (among which the fuel output ratio) ex post. A clay-clay model therefore also reflects the irreversibility of investment decisions that is typical of investment in the electricity sector.

From a policy point of view, the irreversibility of investment is important, as it implies that the hope that technical change will solve problems such as global warming may involve high and irrecoverable investment costs that many investors might be reluctant to incur - especially in the face of uncertainties. Moreover, adjustments may take a long time to complete, as the effective pace of technical change (in as far as the latter is indeed embodied in machinery and equipment) crucially depends on the rate of investment. Thus, investors would either be forced to bear large adjustment costs, or, from a risk diversification point of view, government would have to promote investment in new energy-saving technologies sooner rather than later.

With respect to the economic scrapping of old equipment, there are basically two "rules", where one is a special case of the other. Remember from Chapter 2 that the most general rule is the one formulated by Malcomson (1975), which states that an existing vintage should be used up to the point in time where its variable unit cost rises above the unit total cost of the newest vintage. By replacing old capacity with new capacity, one "saves" the difference between the unit total cost on the newest vintage and the unit variable cost on the old ones. A "derivative" of the Malcomson scrapping rule is the "negative quasi-rent" rule, which states that a vintage should be scrapped as soon as its quasi-rents become negative, that is to say, as soon as its unit variable cost are not completely covered by the selling price of the product. Under perfect competition and marginal cost pricing, where the marginal cost of production are represented by the unit total cost on the newest vintage, the Malcomson scrapping rule implies the "negative quasi-rent" rule. In the model developed here, we (implicitly) use the Malcomson scrapping rule as the more general one of the two, also because it allows us to state the portfolio objective function in terms of costs and variance of that cost. More precisely, as we are using variance-adjusted costs, we are implicitly comparing the variance-adjusted contributions of new and old vintages to total variance-adjusted costs in order to decide whether to keep on using old vintages or replacing them by 
the newest ones for each individual technology family.

As vintages explicitly and simultaneously deal with the cumulative character of technical change and the irreversibility of investment, we find this approach to be a valuable alternative to real options theory, providing new insights into the dynamics of investment under uncertainty. The outcomes are in between the "standard" predictions of portfolio theory and real options theory: producers postpone investment into technologies that exhibit lower degrees of (technical) uncertainty in our model, whereas M-V portfolio theory generally predicts that assets with a lower associated risk will make up for a larger part of the portfolio immediately. A typical result we have seen in real options frameworks was that it is beneficial to wait and invest later in the face of uncertainty, and to invest more when volatility is reduced. Our findings are in contrast with this because by linking portfolio selection to vintage modeling we explicitly incorporate the embodiment character and cumulative nature of technical change into the investment decision. Whereas in real options theory the option value of waiting and keeping the investment opportunity open falls with a decrease in the variance, our approach recognizes potential benefits to be reaped from cumulative processes that are now occurring with more certainty. In other words, our "option value" is adjusted for the benefits that can be realized through the cumulativeness of technical change and, as we will show later on, this can more than outweigh the immediate gains from lower variance.

The purpose of this chapter is to present a simple version of the new vintageportfolio framework. We also want to analyze the differences and compare it to the "standard" mean-variance portfolio approach. To this end we will focus on three hypothetical technologies that have the characteristics of (a) fossil-fuel fired power plants such as coal, (b) nuclear generators, and (c) technologies based on renewable energy such as (onshore) wind farms. Furthermore, both models - the M-V portfolio framework as well as the vintage-portfolio model - will feature the same variables and parameters. In order to make the comparison clearer, we have chosen to focus on one type of price uncertainty and one type of technological uncertainty: fuel price uncertainty and uncertainty about the rate of capital-saving technical change. A more complete version of the vintage-portfolio model will be presented in the next chapter; this one is restricted because we want to avoid cross-effects in order to be able to clearly disentangle the cause-and-effect relationships leading to the differences in the results between the two approaches.

The chapter proceeds as follows. First the technology families will be described and analyzed in a "standard" M-V portfolio model. We then develop a simple vintageportfolio model and test it with a set of technologies with the same characteristics as before. The comparison of both models' results illustrates the advantages of the new vintage-portfolio approach. Section 5.5 summarizes the main results and concludes. 


\subsection{A Mean-Variance Portfolio Approach to In- vestment in the Electricity Sector}

Let us first start out by analyzing an investment problem with three typical power plant types in a "standard" Markowitz portfolio setting. This exercise is very similar to the studies listed in Table 5.1. More precisely, it is closest to the paper by Roques et al (2006) because we also use Monte Carlo simulations to find the covariance matrix and the unit expected cost per technology. This works by generating 10,000 realizations of fuel prices and capital-saving technical change and computing the present value of investing into the plant and subsequently operating it throughout the planning period. In this way, a frequency distribution for each power plant's cost is created, which can be used to calculate the expected cost and the variance for each technology's cost and the covariance between them.

The cost structure of the three typical power plants is given in Table ??, which will be the same used for the analysis in Section 5.2. Rather than providing numerical estimates of applications to a specific electricity sector, we are here more interested in an illustration of the principles of the new approach and - in particular - in a comparison with the results of a "standard" Markowitz M-V portfolio framework. Therefore, we restrict our technology dimension to three technology "families", which have different characteristics. The first one is the fossil-fuel-based technology family. With fuel costs representing a relatively low fraction of total costs, which are in our framework merely composed of fuel and capital costs for the sake of transparency, this category is representative of coal-fired capacity. Furthermore, this technology has volatile fuel prices and only a very modest prospect for technical change to improve its capital coefficient over time. At the same time however, this low rate of technical change is relatively certain to materialize. In other words, its volatility parameter is low.

The latter is also true for the second technology family, which features lower fuel costs, but requires very high investment outlays. This cost structure is typical of nuclear power plants. A note of caution needs to be spelled out here about our simplification, since it ignores the risks emanating from nuclear waste disposal and potential reactor accidents. Taking this characteristic into account would probably lower the attractiveness of nuclear power. However, we think that for the sake of illustration such a representation is passable because we do not want to recommend the installation of nuclear power plants as such, but of technologies that have similar features with respect to the composition of total costs, i.e. that are very capitalintensive.

The third and last technology family can best be described to represent technologies based on renewable energy carriers because fuel costs are set equal to zero. Hence there is no volatility associated with the variable cost of such a plant. Furthermore, even though capital costs are high, the technological outlook is very promising, i.e. the expected rate of capital-saving technical change is high, so that initial capital costs will decrease over time. On the other hand, however, the realization of this improve- 
ment is relatively uncertain, which might decrease the attractiveness of this technology somewhat. These characteristics resemble many renewable energy technologies such as solar or wind power. Due to their low capacity factors, large amounts of capacity are needed to generate sufficient amounts of electricity and this puts them at a clear cost disadvantage with traditional technologies such as coal and nuclear. Since the cost structure is most similar to that of an onshore wind farm, we will call this category "wind" in the following.

\subsubsection{The Framework}

The framework is the simple M-V model developed by Markowitz $(1952,1959)$ and applied to electricity investments by the studies listed in Table 5.1. As we will also do so in the vintage-portfolio model, we focus on minimal costs instead of maximal returns here. The expected total portfolio cost per unit of electricity is equal to

$$
\mathbb{E}(U T C)=\sum_{i=1}^{3} \mu_{i} \cdot x_{i}
$$

where $x_{i}$ is the share of technology $i$ in the portfolio and $\mu_{i}$ is the same technology's expected cost per unit of electricity. Furthermore, the variance of the portfolio is given by

$$
\operatorname{Var}(U T C)=\sum_{i=1}^{3} \sum_{j=1}^{3} \sigma_{i j} x_{i} x_{j}
$$

where $\sigma_{i j}$ is the covariance between technologies $i$ and $j$ and the variance of a particular technology if $i=j$. UTC stands for (unit) total cost.

We minimize Equation (5.2.2) subject to Equation (5.2.1) and thereby trace out the efficient frontier for this problem. In other words, we determine $x_{i}$. However, in order to find the covariance matrix corresponding to $\sigma_{i j}$ and the expected cost per unit $\mu_{i}$ of each technology we will first run a Monte Carlo simulation generating cost distributions for technologies with the characteristics displayed in Table ??.

In the Monte Carlo framework both capital-saving technical change and fuel prices will follow geometric Brownian motions, where the drift for fuel prices is positive and the drift for the change in the capital coefficient is negative. The volatility parameter for technical change is higher in the case of wind than for nuclear and coal. Total expected costs for generating one unit of electricity are composed of the investment costs incurred upon installation and the discounted stream of costs arising from operating the installed capacity throughout the planning period. 10,000 simulations for the fuel price and the rate of technical change will then result in a cost distribution for the corresponding technology. Please note that there is no optimization involved in this process: while it could have been optimal to exercise investment at a later point in time, we are merely interested in the net present value of investing on the spot and operating the equipment subsequently. Additional experiments will show how the results that we obtain change in response to postponing investment by an arbitrary 
period. ${ }^{5}$

The discount rate is $5 \%$, which is the same rate used in the vintage-portfolio analysis later on. The capacity of wind has been adjusted for its low capacity factor, i.e. more wind capacity has to be installed to achieve the same levels of output as coal and nuclear. ${ }^{6}$ Figure 5.1 presents all three cost distributions for the base run, which computes the present value of expected costs upon investment for each technology: $\mathbb{E}\left\{P V\left[U T C_{i}\right]=C C_{0}+\frac{1}{(1+r)^{t-1}} \cdot \sum_{t=0}^{T} F C_{t}\right.$, where $C C$ is the cost of investment, $F C$ is the fuel cost, $T$ the length of the planning period and $r$ the discount rate.
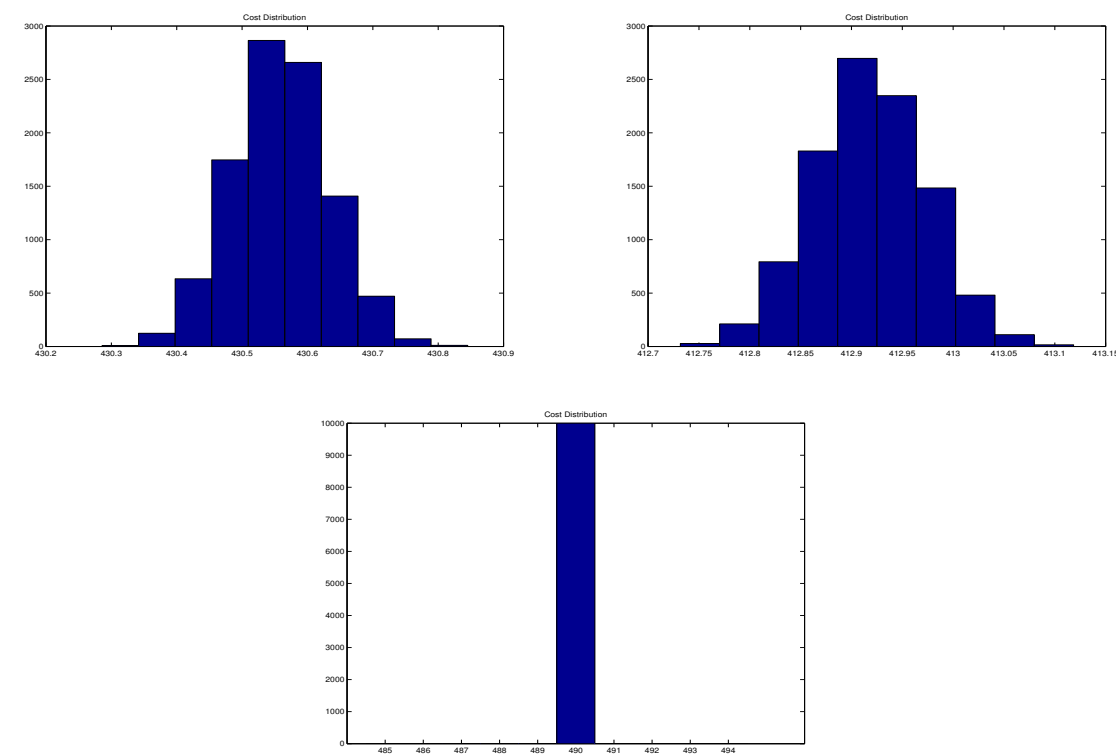

(The $\mathrm{x}$-axis represents total expected costs for a fixed amount of generated electricity; the $\mathrm{y}$-axis is the frequency. Distributions are ordered from left to right and from top to bottom. Please note that the costs are not representative of particular technologies: only the cost structure corresponds to reality, the absolute amounts do not necessarily coincide with specific power plants).

Figure 5.1: Cost Distributions for Coal, Nuclear and Wind

While it is difficult to see from the Figure, the calculations show clearly that coal has a slightly higher variance than nuclear. The volatility of wind is zero, of course, since investment occurs in the beginning, i.e. technical change has not had an impact

\footnotetext{
${ }^{5}$ The planning period is 25 years, although nuclear and coal-fired power plants have longer lifetimes. Wind farms and other types of renewables, however, have lower expected lifetimes. If we had chosen a longer planning horizon, it would have been necessary to account for this difference by requiring additional capacity to be installed towards the end of the horizon. This would have been an unnecessary complication, which does not add further insights here.

${ }^{6}$ More precisely, the capacity has been normalized to produce 3,285,000 MWh per year; costs are in millions of dollars. However, since our endeavors are of an purely illustrative character here, the magnitudes should not be of primary interest and are just mentioned for the sake of completeness.
} 
on the costs of the wind technology yet and fuel costs are zero in the first place. In the next section we will also present results using Monte Carlo distributions where the investment has been made later ( 5 and 10 years later respectively). It turns out that in this case the cost distribution exhibits a very large variance leading to a smaller proportion of wind in the overall generating portfolio because there will be 10,000 realizations of capital costs. The covariance matrix derived from the above distributions (in Figure 5.1) is given by:

$$
\sigma_{\mathbf{i j}}=\left\{\begin{array}{ccc}
0.005372 & -0.000011 & 0.000000 \\
-0.000011 & 0.003116 & 0.000000 \\
0.000000 & 0.000000 & 0.000000
\end{array}\right\}
$$

where the column/row corresponds to coal, the second to nuclear and the third to wind.

\subsubsection{Results}

The results from feeding the covariance matrix and expected cost values derived from the Monte Carlo cost distributions into the M-V portfolio model have been summarized in Figure 5.2. In particular, we have computed the cost distributions for investment on the spot, i.e. in year 1 (see Figure 5.1), in year 5 and in year 10 respectively. $^{7}$

In the first panel of Figure 5.2 the investor faces the distributions displayed in Figure 5.1. Therefore, the portfolio in the upper left corner, which combines the highest expected total cost, but also the lowest variance, is composed of wind only. As we move downwards and to the right on the efficient frontier, more variance is accepted at a lower expected cost, so the proportion of wind shrinks, while the shares of coal and nuclear, which are both cheaper and have more volatile costs, increase. When the share of wind has been reduced to zero at a variance level of 0.00212484 , the fraction of coal also begins to diminish. At the same time nuclear continues to gain until it completely dominates the generating portfolio for a minimum expected cost of 412.919558 million dollars.

The second panel shows how the efficient frontier looks when investment occurs in the fifth year. It is clear that wind has uncertain costs then as well, because technical change reducing the capital coefficient - and thereby capital costs - is stochastic. In fact, wind has the largest cost variance of the three technologies in this case. Coal is the least risky option. The covariance matrix has only non-zero entries. In terms of the expected cost, $\mu_{i}$, wind is still the most expensive technology, followed by coal and then nuclear. The reason is that technical change has reduced the cost of wind too little, while coal and nuclear prices have not risen substantially. In particular, $\mu_{\text {nuclear }}<\mu_{\text {coal }}<\mu_{\text {wind }}$, while $\sigma_{\text {coal }}<\sigma_{\text {nuclear }}<\sigma_{\text {wind }}{ }^{8}$ It is clear that this leads to an outward shift of the efficient frontier: the minimum possible variance is no longer equal to 0 , but positive. The minimum variance portfolio with the highest expected

\footnotetext{
${ }^{7}$ The planning period has been adjusted accordingly, so that production takes place for an equally long period of time to ensure that the outcomes remain comparable.

${ }^{8} \sigma_{\text {coal }, \text { nuclear }}=0.000973, \sigma_{\text {coal }, \text { wind }}=0.003425$ and $\sigma_{\text {nuclear }, \text { wind }}=-0.011938$.
} 

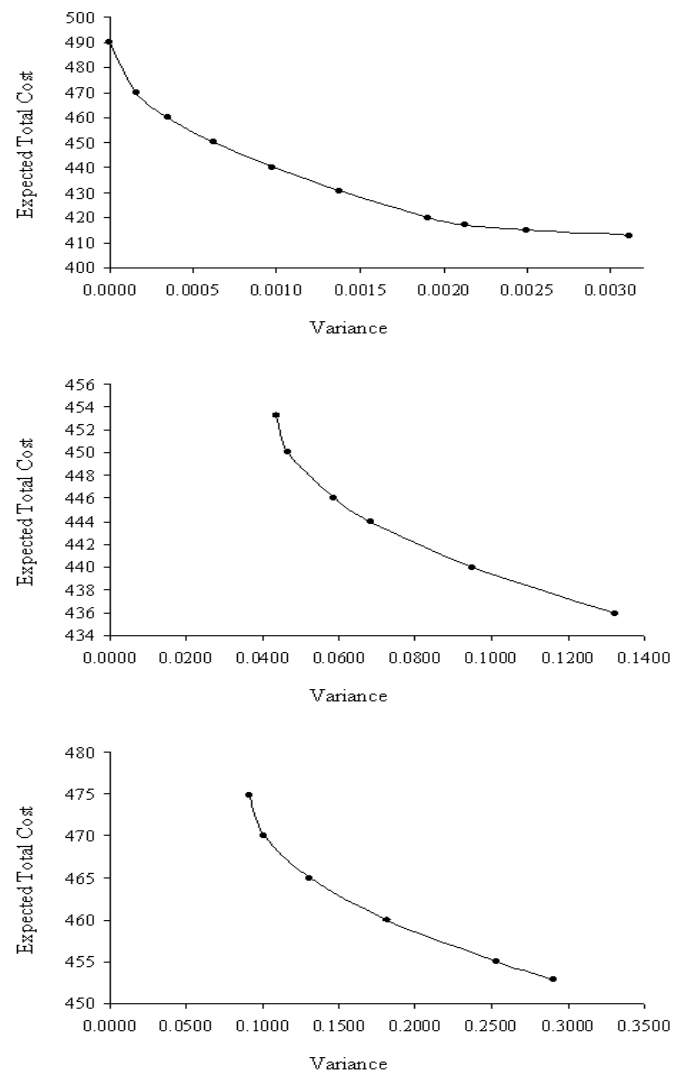

The cost-risk trade-off shifts outwards, as time progresses.

Figure 5.2: Efficient Frontiers for Investment at $t=0, t=5$ and $t=10$ (top to bottom)

cost is dominated by coal, but has also nuclear and a small share of wind. However, coal and wind are phased out, as the share of nuclear grows towards a share of $100 \%$ for the minimum cost portfolio.

The third panel is based on cost distributions arising when the plants are installed in the tenth year. This further increases the variance of wind, but brings its expected costs almost down to the level of coal-fired capacity, while nuclear is still least costly compared to wind and coal but also more expensive in absolute terms than before (when investment occurred immediately). The expected costs can thus be ranked as $\mu_{\text {nuclear }}<\mu_{\text {coal }} \leq \mu_{\text {wind }}$. The variance is generally higher, but the ranking remains the same: $\sigma_{\text {coal }}<\sigma_{\text {nuclear }}<\sigma_{\text {wind }} .{ }^{9}$ With this characterization in mind it is no surprise that, from left to right, the portfolio starts out with $67.67 \%$ coal, $31.25 \%$ nuclear and $1.08 \%$ wind for the minimum variance portfolio. As more variance is accepted, coal and wind are phased out in favor of nuclear. Again, the efficient frontier

\footnotetext{
${ }^{9} \sigma_{\text {coal }, \text { nuclear }}=0.000499, \sigma_{\text {coal }, \text { wind }}=-0.009957$ and $\sigma_{\text {nuclear }, \text { wind }}=0.021038$.
} 
is shifted outwards.

Interestingly, the highest possible cost (i.e. the most upper left point on the efficient frontier) in this setting is higher than that of the second setting, while the first setting has the highest possible cost of all three "scenarios". This can be explained by the fact that technological change reduces the cost of wind at a slower pace than fuel prices make coal and nuclear more expensive between year 5 and 10, whereas the opposite is true for the period between year 1 and year 5 .

In summary, larger variance - regardless whether generated through fluctuating fuel prices or stochastic rates of technical change - has a negative effect on investment. More precisely, technologies with higher variance dominate the portfolio only for minimum levels of expected cost. For positive rates of risk aversion, technologies exhibiting lower variance are favored over more risky technologies.

\subsection{The Vintage-Portfolio Approach}

This version of the model is very simple and abstracts from uncertainty on investment prices and fuel-saving technical change, since our main motivation here is to illustrate the basics of the new approach and to compare it to the "standard" approach used in the previous section.

\subsubsection{The Setting}

The investment framework uses a two-dimensional clay-clay vintage model. The first dimension is the technology-family dimension mentioned before, while the second dimension is the quality dimension, proxied by the installation time of a vintage. The technology families are characterized by the type of fuel they use. Different vintages belonging to a family embody the different states of the technology at the moment they were installed.

An important feature that we are able to incorporate in our framework is the dynamic nature of technological change: some technologies may have limited scope for productivity growth, but that growth itself may be relatively certain to occur, while other technologies seem to be highly promising in terms of productivity growth, but also fairly risky in terms of the actual achievement of these promises. This suggests that, from a longer-term perspective, in which uncertainties regarding technological development become highly relevant, portfolio theory provides a suitable modeling framework for investment in the electricity sector. Since we are dealing with physical rather than financial capital, we need to take into account that a physical capital portfolio can change only gradually through investment at the margin, i.e. investment in new vintages embodying the latest versions of a technology. Due to the ex post sunk cost character of physical investment, it is necessary to adopt an intertemporal perspective rather than the myopic perspective that is used in the type of model outlined in the previous section. We do this by developing a simultaneous investment and production plan for different technology families over a given planning horizon 
using the (expected) user cost of capital.

There are three types of costs to consider per family. The first includes fixed costs, which depend on the amount of installed capacity. The second type is variable fuel cost, based on the capacity actually used. The third type is quasi-rents forgone due to capacity shortages that occur due to unexpected demand peaks, but we disregard the latter item here for reasons of transparency. ${ }^{10}$

\subsubsection{The Vintage Model}

We use several indexed variable names. The index $f$ denotes a technology family (characterized by its fuel type), the index $v$ the moment in time at which the vintage under consideration has been installed, and $t$ the present moment in time. The variables $K^{f}, Y^{f}, X^{f}$ and $F^{f}$ are the (vintage) level of investment, capacity output, actual output and fuel consumption per technology, respectively. We allow for embodied capital-saving technical change at a proportional rate with a given expected value and a given (expected) variance of that rate. For the development of the amount of capital associated with each vintage, we then have:

$$
K_{v, t}^{f}=e^{\delta^{f} \cdot(t-v)} \cdot K_{v, v}^{f}
$$

where $K_{v, t}^{f}$ measures the amount of capital still left of a vintage after $(t-v)$ periods of time have passed since its installation. In Equation (5.3.3), $\delta^{f}$ is the (constant) exponential rate of physical decay. Hence Equation (5.3.3) states that the amount of capital associated with a vintage installed at time $(t-v)$ will fall at a rate of $\delta^{f} \%$ per year due to technical wear and tear. For capacity output associated with a vintage we have:

$$
Y_{v, t}^{f}=\frac{K_{v, t}^{f}}{\kappa_{v}^{f}}
$$

In Equation (5.3.4) $\kappa_{v}^{f}$ is the capital-output ratio associated with a vintage installed at time $v$. Assuming zero ex post disembodied technical change, $\kappa_{v}^{f}$ does only depend on $v$. However, embodied capital-saving technical change takes place at a given expected proportional rate and with given variance. We therefore have:

$$
\kappa_{v}^{f}=\kappa_{0}^{f} \cdot e^{\hat{\kappa} f \cdot v}
$$

where $\hat{\kappa^{f}}$ is the expected proportional rate of change of the capital-output ratio. The fuel-output ratio $\varphi^{f}$ will be fixed at its initial level. ${ }^{11}$ Hence, for fuel consumption per vintage we find:

$$
F_{v, t}^{f}=\varphi^{f} \cdot X_{v, t}^{f}
$$

\footnotetext{
${ }^{10}$ In Chapter 7 , where we introduce different demand scenarios, quasi-rents are lost, or at least cost increases associated with excess capacity or an alternative technology family composition of capacity installed and used become part of the investment decision.

${ }^{11}$ Fuel-saving technical change is a feature that we implement in the next chapter.
} 
We can use (5.3.4) to find the "demand" for capital per vintage in function of the level of installed capacity:

$$
K_{v, t}^{f}=\kappa_{v}^{f} \cdot Y_{v, t}^{f}
$$

Given the factor requirements above, there are now two problems to solve. The first concerns the question of how much to invest per technology family, given its specific characteristics. The second problem is the timing of investment. Since investment is irreversible ex post (i.e. capital costs are sunk), the investment planning process should involve both forward-looking expectations as well as a measure of risk aversion in order to accommodate this irreversibility. Therefore, we assume that producers maximize the weighted sum of the expected present value (PV) of total cost and the variance of that cost by composing their vintage portfolio in both the technology family dimension and the quality dimension: as rational, risk averse investors they are able to diversify risks by spreading investments both over technologies and time.

In order to calculate the portfolio variance of the PV of buying and using the vintage portfolio, we first describe how fuel costs are expected to develop and what the corresponding variance of these expectations will be.

\subsubsection{Expected Variance in Fixed \& Variable Cost Com- ponents}

The two sources of uncertainty in this model thus emanate from fuel price growth, which is distinctive of the corresponding technology families, and capital-saving technical change. The PV of total costs is:

$$
P V=\sum_{f} \sum_{v=1}^{\theta} \sum_{t^{\prime}=v}^{\theta} e^{-\rho \cdot t^{\prime}}\left(P^{f} \cdot\left(r_{v}+\delta\right) \cdot \kappa_{v}^{f} \cdot Y_{v}^{f} \cdot e^{-\delta^{f} \cdot\left(t^{\prime}-v\right)}+Q_{t}^{f} \cdot \varphi^{f} \cdot X_{v, t^{\prime}}^{f}\right) .
$$

In Equation (5.3.8) $\rho$ is the rate of discount and $r_{v}$ is the interest rate at the time the vintage is installed. $P^{f}$ is the cost of a unit of investment, which is constant. $t^{\prime}$ is an absolute moment in time within the planning period, i.e. $1 \leq t^{\prime} \leq \theta$. Equation (5.3.8) shows that depreciation charges are valued at historic cost-prices rather than at replacement value. ${ }^{12}$ Since there is no disembodied technical change ex post by assumption, the capital-output ratio does not change once a vintage has been installed. $Q_{t}^{f}$ is the user price of a unit of fuel $f$ used at time $t$. The price of fuels does not depend on the vintage $v$, for which it is used. Hence, for all vintages $v, Q^{f}$ only depends on t. $\varphi^{f}$ is the corresponding fuel-output ratio. $Y_{v}^{f}$ is the total capacity of vintage $v$ at its time of installation. That amount will decrease due to depreciation, given by the term $e^{-\delta^{f} \cdot\left(t^{\prime}-v\right)} \cdot X_{v, t^{\prime}}^{f}$ is the amount of capacity of vintage $v$ that is actually used at time $t^{\prime}$.

\footnotetext{
${ }^{12}$ Note that a change in investment prices then affects only the marginal vintage in a technology family, as opposed to changing fuel prices that would affect all vintages in a technology family at the same time. So valuation at historic cost-prices introduces a qualitative difference between capital and fuel costs that would partially vanish if capital would be valued at replacement costs. Of course, there would still be the qualitative difference arising from capital costs being associated with capacity installed and fuel costs with capacity used.
} 
In order to calculate the variance of the PV of total cost as given by (5.3.8), it should be noted that for constant expected values (and forecasting errors) of the growth rates of fuel prices and capital coefficient, a first order approximation of Equation (5.3.8) is given by: ${ }^{13}$

$$
\begin{aligned}
P V & \approx \sum_{f} \sum_{v=1}^{\theta} \sum_{t^{\prime}=v}^{\theta} e^{-\rho \cdot t^{\prime}}\left(P^{f} \cdot \kappa_{0}^{f} \cdot e^{\hat{\kappa}^{f} \cdot v} \cdot\left(1+S_{1, v}^{f}\right) \cdot\left(r_{0}+\delta^{f}+S_{2, v}^{f}\right)\right. \\
& \left.\cdot Y_{v}^{f} \cdot e^{-\delta \cdot\left(t^{\prime}-v\right)}+Q_{0}^{f} \cdot e^{\hat{Q}^{f} \cdot t^{\prime}} \cdot \varphi^{f} \cdot\left(1+S_{3, t^{\prime}}^{f}\right) \cdot X_{v, t^{\prime}-v}^{f}\right)
\end{aligned}
$$

where the "S-terms" are the sums of the forecasting errors for the corresponding variables associated with a technology family over time. Note that $\hat{\kappa}^{f}$ is the rate of capital-using technical change, i.e. improvements will require this rate to be negative. More precisely, $S_{1, v}^{f}=\sum_{j=1}^{v} \varepsilon_{j}^{\hat{\kappa}, f}, S_{2, v}^{f}=\sum_{j=1}^{v} \varepsilon_{j}^{r, f}$, and $S_{3, t}^{f}=\sum_{j=1}^{v} \varepsilon_{j}^{\hat{Q}, f}$, and where $\varepsilon_{j}^{x, f}$ is the forecasting error for variable $x$ associated with technology family $f$ for time $j$. In Equation (5.3.9), $\hat{Q}^{f}$ is the expected growth rate of fuel prices for technology family $f$. All forecasting errors $\varepsilon_{j}^{x, f}$ are assumed to have zero expectation. ${ }^{14}$ Note the subscript $t^{\prime}$ in $S_{3, t^{\prime}}^{f}$ - the only error sum not depending on $v$. After simplifying Equation (5.3.9) it can be used to calculate the (approximated) expected forecasting error in the PV of total capital and fuel costs. The expectation of its squared value will then be the total variance of the PV.

$$
\sum_{f 1} \sum_{v 1=1}^{\theta} \sum_{k 1=1}^{3} \sum_{f 2} \sum_{v 2=1}^{\theta} \sum_{k 2=1}^{3} C_{k 1, v 1}^{f 1} \cdot C_{k 2, v 2}^{f 2} \cdot \sigma_{k 1, k 2}^{f 1, f 2} \cdot \min (v 1, v 2)
$$

where $\min (v 1, v 2)$ represents the minimum of $v 1$ and $v 2$, and where $k 1, k 2=1 \ldots 3$ refer to the variables $\hat{\kappa}^{f}, r$, and $\hat{Q}^{f}$ respectively, corresponding to technology families $f 1$ and $f 2$. The " $C$-terms" in (6.6) are defined in terms of the " $S$-terms" associated with (5.3.9). For further details, see the appendix.

\subsubsection{The Objective Function}

As stated before, we assume that producers minimize a weighted sum of the expected $\mathrm{PV}$ of their total production cost and its corresponding variance.

$$
\Phi=P V+\lambda \cdot \operatorname{var}(P V)
$$

where $\lambda$ is the relative contribution of the variance of the PV of total costs to the objective function. We will further assume that $\lambda$ is a nonnegative constant and refer to it as the risk aversion parameter.

Producers minimize (5.3.11) by choosing the optimum values of both initial vintage capacity, $Y_{v}^{f}$, per family $f$ for all vintages to be installed during the planning period and a corresponding production plan $X_{v, t}^{f}$ for each planned vintage to be installed.

\footnotetext{
${ }^{13} \hat{\varphi}^{f}$ and $\hat{P}^{f}$ will be constant at zero.

${ }^{14}$ It should be noted that the forecasting errors in the interest rate are really independent of the technology family. However, for uniformity of notation we act as if they do depend on $f$.
} 
$Y_{v}^{f}$ and $X_{v, t}^{f}$ are chosen conditional on the expected values and (co)variances of the stochastic variables in this setting, i.e. fuel price growth and the proportional rate of change of the capital coefficient due to embodied technical change.

The full model now consists of the objective function (5.3.11) that needs to be minimized subject to Equations (5.3.9) and (6.6), where (5.3.9) is evaluated for all "S-terms" equal to zero in order to obtain the expected value of the PV of total cost. For each vintage in each technology family, we also have to consider that actual output cannot be larger than capacity output. Hence, as additional constraints we first have the capacity constraint:

$$
X_{v, t^{\prime}}^{f} \leq e^{-\delta^{f} \cdot\left(t^{\prime}-v\right)} \cdot Y_{v}^{f}
$$

Finally, the aggregate demand constraints are given by:

$$
\sum_{f} \sum_{v=0}^{t^{\prime}} X_{v, t^{\prime}}^{f} \geq D_{t^{\prime}}
$$

where $t^{\prime}$ again refers to an absolute moment in time within the planning period, i.e. $1 \leq t^{\prime} \leq \theta$. We assume that demand will be rising at a moderate, but continuously positive rate, which is realistic for the majority of OECD countries over the next coming decades.

\subsubsection{Results and Interpretation}

The results that we obtain from the vintage-portfolio model demonstrate very clearly that this framework does not only allow for diversification over technologies, but also for the fact that there are diversification effects over time and vintages. In Figure 5.3 the initial composition of the capacity stock is imposed. In particular, it is assumed that most of the existing power plants are coal-fired, while only a small portion is nuclear. Renewable energy is not used at all. We see that coal is then phased out over time. However, coal becomes unattractive rather quickly and the performance of wind improves at a relatively slow pace. Moreover, it has been noted in the previous section that the rate of technical change that applies to wind is volatile. Therefore, we can observe that nuclear energy temporarily dominates the portfolio. In fact, the share of nuclear rises well into the second half of the planning period and is only reduced after period 30. It is thus only in the last five years of the planning horizon that wind picks up and starts to be the primary technology in the generating portfolio.

The more than exponentially rising trend that can be observed in the last years, might be misleading at first glance. It arises because of the low capacity factor of wind capacity. To meet increasing demand, relatively more wind capacity than previously coal or nuclear capacity needs to be installed. ${ }^{15}$

Figure 5.4 displays the development of net investment. In particular, the existing stock of coal-fired capacity is scrapped slowly, which is presented as small amounts of negative net investment. Net investment in nuclear is positive, but not excessive.

\footnotetext{
${ }^{15}$ In other words, effective capacity would not show this increase in the last five years.
} 
Scrapping of nuclear and abandonment of the remaining coal-fired capacity occurs only when wind is phased in on a larger scale.

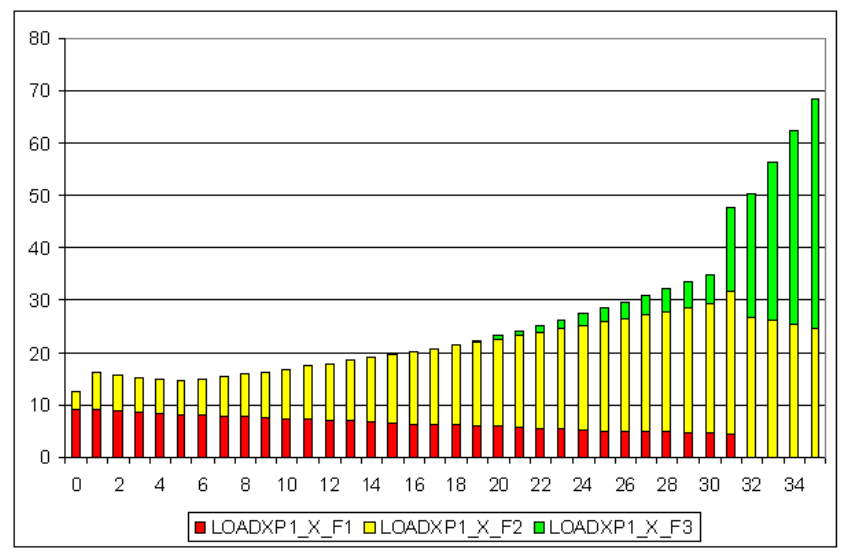

The dark area is coal, the light one is nuclear and the medium one is wind.

Figure 5.3: Evolution of Capacities in the Base Run

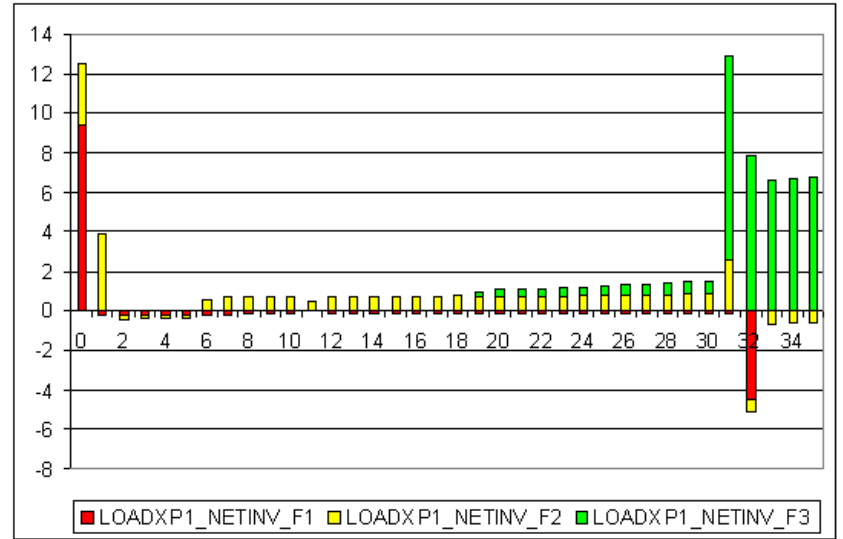

The dark area is coal, the light one is nuclear and the medium one is wind.

Figure 5.4: Net Investment in the Base Run

In the light of practical constraints such as space requirements and peak load demands that will be difficult to cover in times of calm, it is of course not realistic that wind would take over such a large proportion in a large producer's, region's or country's energy mix. However, we have already pointed out that these results serve illustrative purposes and should not be taken at face value. Wind stands representative here for a number of renewables with similar characteristics as in Table ?? and could be seen as a basket of technologies rather than a single one. The Figure thus shows clearly that nuclear is used as a placeholder for wind, as coal is phased out. Wind outperforms the other two technologies because of its zero fuel price growth and thus also zero fuel 
price risk after a sufficient "amount" of technological change has materialized. Please note that - here as well - as large amounts of coal that are scrapped and nuclear capacity are replaced by wind capacity, more of the latter needs to be installed than is scrapped of nuclear and coal due to the low capacity factor. ${ }^{16}$

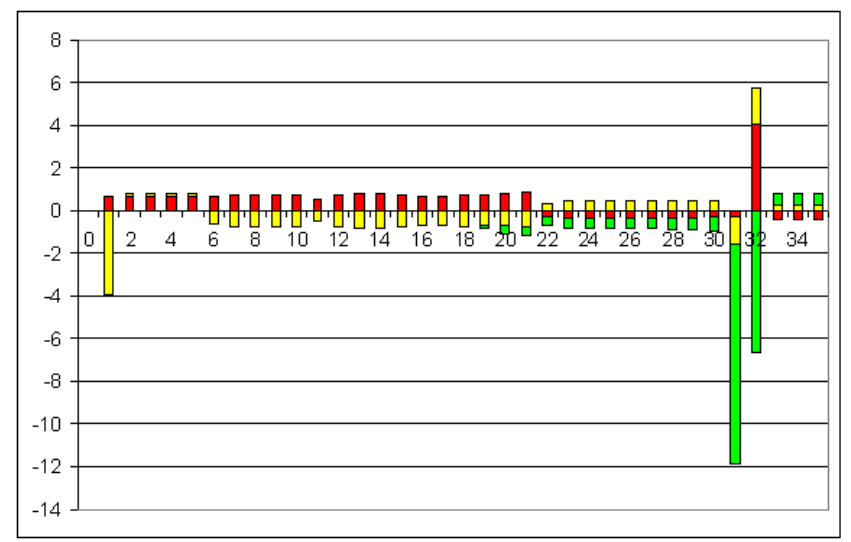

The dark area is coal, the light one is nuclear and the medium one is wind. Deviations are absolute. The negative deviations in wind investment in periods 31 and 32 are due to the fact hat no investment occurs in the experiment in these years, while it was positive then in the base run.

Figure 5.5: Deviations from Base Run Net Investment for Less Coal Price Uncertainty

Figure 5.5 displays the deviations from base run investment when coal price volatility is zero: coal is no longer scrapped, but there is indeed positive net investment into coal - a development, which goes at the expense of nuclear capacity in the beginning. The transition to wind still occurs during the same time as in the base run. The differences are that (a) nuclear is no longer an important placeholder and gets phased in much later than in the base run and (b) wind does not dominate the generating portfolio at the end of the planning period, but comprises less than $50 \%$ of the mix, while coal is still quite important and nuclear also occupies a share of little less than a third. In summary, fuel price uncertainty is negatively related to investment. ${ }^{17}$

\footnotetext{
${ }^{16}$ Another factor that contributes to the investment spike at the end of the planning period is an echo effect, which arises because coal and nuclear have expected technical lifetimes of 30 and 35 years respectively. Note that extending the planning period will change the picture, since a longer investment and production horizon opens up new opportunities that the rational investor will also make use of. However, in accordance with $\mathrm{Ku}$ (1995) 30-40 years is the typical investment horizon in electricity capacity planning, which is why we refrain from analyzing the very long run at this point. Furthermore, we will add another term to the total cost function, which will remove the bias to install relatively capital-intensive technologies towards the end of the planning period (because they will be used for a shorter period of time) in Chapter 7 and ongoing research is occupied with implementing rolling planning horizons (see e.g. Wagner and Berman (1995) for an application of rolling planning horizons to capacity expansion planning) in order to further investigate this issue.
}

${ }^{17}$ Additional experiments have shown that a complete transition to wind requires a much 


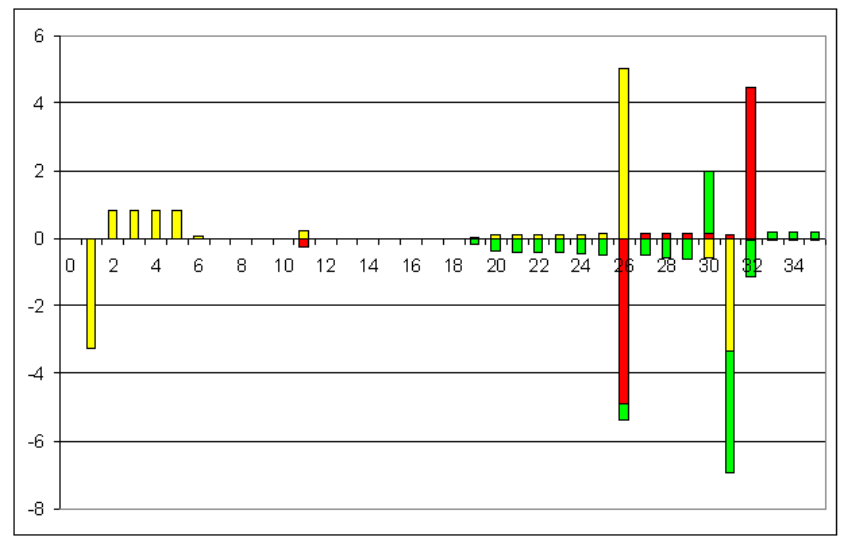

The dark area is coal, the light one is nuclear and the medium one is wind. Deviations are absolute.

Figure 5.6: Deviations from Base Run Net Investment for Less Nuclear Technological Uncertainty

With respect to technological uncertainty we find a positive relationship in the beginning. In Figure 5.6 net investment into nuclear power generation equipment, which has zero volatility in technical change in this experiment, deviates negatively from base run investment in the beginning of the planning period with larger upward deviations only in the second half of the planning period. The negative deviation in period 31 might seem contradictory to the conclusion that technological certainty provides an incentive for investors to wait and reap the benefits of technical improvements that are now more certain to materialize. However, we should not forget the role of nuclear as a placeholder for wind in this context. Wind will still be developed enough to take over around year 30, so if more nuclear has been installed before, some needs to be scrapped in favor of wind, which will still make up about half of the portfolio in the final year, while the other half will be composed of nuclear capacity. ${ }^{18}$ In summary, certainty about technological change depresses investment today for the sake of higher investment at a later point in time, which can be seen as a negative tradeoff between minimum cost and variance. Overall, when taking the time dimension into account, the uncertainty-investment relationship is thus still negative: the energy mix will be composed of a larger share of nuclear energy in the end, even though investment will first be lower than in the base run.

longer planning horizon. The patterns of investment remain the same- only the role of nuclear as a placeholder is somewhat reduced, since coal and nuclear are otherwise quite similar.

${ }^{18}$ Please note that the upward deviation of coal in year 32 should not be mistaken for positive net investment. Coal is completely phased out already earlier in this experiment, while in the base run a significant amount of coal was scrapped in year 32 . With a net investment of zero in the experiment at hand, the deviation from the base run must be positive. 


\subsection{Evaluation and Comparison of the Two Ap- proaches}

Both frameworks - the vintage-portfolio model in Section 5.3 and the M-V approach in Section 5.2 have two advantages in common. First, they both account for the gains from diversification. By combining technologies or technology families with different expected costs, variances and other characteristics it becomes less costly and more secure to produce a certain amount of electricity. A portfolio framework is therefore not only well suited to explain diversification, but also to analyze the tradeoff between risk and return (or in this case the tradeoff between risk and cost). Both approaches are thus particularly useful for large investors or for the optimization of a region's or country's generating portfolio.

However, the above analysis has also revealed that the new vintage-portfolio model has a number of advantages over the standard Markowitz approach as used in the studies presented in Table 5.1 and in Section 5.2. Most importantly, the M-V framework as traditionally applied to energy investment is inherently static and myopic with respect to potential future developments, whereas the combination of portfolio selection and vintage modeling allows for a dynamic setting. This is particularly important when we want to investigate the effects of technological change and the uncertainties associated with the same. As the discussion of Figure 5.1 shows, neither technical change nor its volatility enter the cost distribution generated in the Monte Carlo simulation, which we use to calculate the (co)variances and expected costs as an input for the $\mathrm{M}-\mathrm{V}$ model. The width of the distribution of coal-fired and nuclear capacity depends exclusively on the variance in fuel price growth and wind has no distribution at all because it does not use fossil fuels. ${ }^{19}$

In a somewhat artificial exercise we have tried to circumvent this shortcoming by computing the present value of total (unit) costs when the investment is made at different points in time. ${ }^{20}$ Wind has also volatile costs then, which is due to the different realizations of technical change and thereby capital coefficients that have been generated in the Monte Carlo simulation. The result in terms of the portfolio optimization is that the share of wind in the total generating portfolio is low and decreasing along the efficient frontier because it still has relatively high costs, but also a much higher variance now. This implies that technological uncertainty has a negative effect on investment in the $\mathrm{M}-\mathrm{V}$ framework. ${ }^{21}$

\footnotetext{
${ }^{19}$ Remember that the PV underlying the Monte Carlo simulation has the form $\mathbb{E}\left\{P V\left[U T C_{i}\right]\right\}=C C_{0}+\frac{1}{(1+r)^{t-1}} \cdot \sum_{t=0}^{T} F C_{t}$, i.e. there is only one instance of $C C$ at the beginning of the planning period.

${ }^{20}$ If this exercise would be repeated for each time instance of the planning period, we could compute a net investment series from that, showing the amount of capacity that should be installed or scrapped to give the optimal mix of technologies. However, keep in mind that this would not account for the irreversibility of investment and most likely result in an infeasible strategy.

${ }^{21}$ In addition, this is not desirable from a low-carbon-policy point of view. Policy makers interested in promoting the use of renewables would want investors to take the effects that technical change will have on future costs into account in order to see some attractiveness in technologies that might otherwise still seem expensive.
} 
In the vintage-portfolio model the opposite is true. Here, technical change is embodied and this leads to the result that lower uncertainty about the rate of technical change triggers less investment into the concerned technology because it pays off to wait and reap the benefits of ongoing technological improvements that will happen with higher certainty now. In other words, there is a positive relationship between technological uncertainty and investment in the beginning, which is due to the value that waiting has in the face of embodied, ongoing technical change. Even though we have modeled technical change in the same way - namely as an increasing but volatile reduction in the capital coefficient - in the M-V framework, it can neither account for the dynamics nor for the full embodiment effect of technical change and can thus not incorporate the benefits from waiting. This can also be seen as an "implicit option value". Real options theory is also dynamic and explicitly values the investment option by asking how much could be gained by postponing investment. However, as we have seen in Chapter 4, technological uncertainty is related negatively to investment in the real options model we use there. The reason is that uncertainty is modeled by a small arrival rate compensated for by larger cost reductions. This makes it valuable to wait for the next arrival because technical change is again embodied in the latest equipment.

Another advantage of the vintage-portfolio model that arises from its dynamic nature is that it diversifies not only across technologies, but also across time or - more specifically - vintages. ${ }^{22}$ Sometimes it pays off to keep older equipment and machinery if improvements are to be expected for other technologies. In this chapter it has proven useful to invest into nuclear capacity just to bridge the time, during which wind would become more profitable, for example. Such strategies cannot be found with static $\mathrm{M}-\mathrm{V}$ portfolio selection. An investment is seen as a once-and-for-all opportunity and is either exercised or discarded for good. ${ }^{23}$

Furthermore, the M-V framework presented here (but also the studies summarized in Table 5.1) use covariance matrices and expected returns or costs based on empirical estimates (e.g. Awerbuch, 2006) or computed from Monte Carlo simulations like we do (e.g. Roques, 2006). While this might entail interesting information for large investors, it is important to note that this does not ensure that individual investors and power plant owners behave optimally. Exercising an investment option at once does not take into account the benefits from waiting for technological improvements, for example. In the Monte Carlo simulations conducted in this paper it is assumed that investors compose their portfolio at once in the first year. However, waiting some time would decrease the costs of wind and thereby increase its attractiveness, so investment in year 1 might not have been optimal. Fortin et al (2007) overcome this shortcoming by using a real options model that ensures that the return distributions that they use to compute the inputs for their portfolio model are the result of optimizing behavior.

\footnotetext{
${ }^{22}$ In addition, this feature allows us to form a much more realistic model of the electricity sector taking into account differences in initially installed capacity stocks, for example. This is much less straightforward in the static framework.

${ }^{23}$ The best one can do, is to find optimum portfolios at different points in time and interpret developments with the help of these results, but this is of course not a straightforward and coherent optimization procedure.
} 
The same paper uncovers another disadvantage of standard M-V portfolios, which rely on their first two moments: mean and variance. This is no problem as long as the distributions are normal. Fortin et al (2007) examine all their marginal return distributions and the joint distribution making use of the corresponding copulas. $^{24}$ Results from estimating a restricted symmetric version of a fairly flexible copula show that the null hypothesis of symmetry can be rejected most of the time. This seems to be clear evidence of non-normality in the total joint return distribution and thus implies that the $\mathrm{M}-\mathrm{V}$ approach is often not appropriate. In response to these findings, the authors recommend the use of other risk measures than the variance - in particular the Conditional Value-at-Risk $(\mathrm{CVaR}) .{ }^{25}$ While such considerations are beyond the scope and interest of our comparison exercise, it is important to keep this in mind for further research in this field.

Finally, the new vintage-portfolio model naturally accounts for the irreversibility of investment through its clay-clay vintage structure: it can only be updated at the margin by either scrapping or replacement of technically decayed equipment. Because standard M-V models only look at a portfolio at a specific point in time, they cannot incorporate irreversibility and the effects it might have on the composition of the portfolio because they rely on low or zero adjustment costs. Also by looking at M-V portfolios at different points in time this shortcoming cannot be overcome.

\subsection{Summary and Conclusion}

In this chapter we have analyzed three hypothetical technologies or technology families that have the cost structures of coal-fired capacity, nuclear generators and wind-based equipment. To this end we have employed two different approaches: the new vintageportfolio model, which will be expanded in the following chapter, and the "standard" Markowitz approach, which has (re)gained popularity in electricity applications lately (see Table 5.1).

The vintage-portfolio model has delivered two main insights. (1) Nuclear energy might be used as a bridge between a capacity portfolio dominated by fossil-fuel-fired technologies and an energy mix relying on renewable energy carriers. Even though we have abstracted from carbon penalties and emission caps in this study, it is clear that environmental considerations will only add more substance to this insight. (2) Technological uncertainty will lead to larger investment in the beginning and a lower portfolio share of the concerned "asset" only later in the planning period, whereas fuel price uncertainty has a clear, negative effect on investment.

Furthermore, it has become very clear that it is the dynamic nature of the vintageportfolio framework that allows for such conclusions and that it therefore outperforms

\footnotetext{
${ }^{24}$ The copula is that part of the joint distribution function, which captures everything describing dependence (after factoring out the marginal distributions). See e.g. Nelsen (2006) for a background on the use of copulas.

${ }^{25}$ According to Rockafellar and Uryasev $(2000,2002)$ the $\beta$-CVaR is the conditional expectation of losses above an amount $\alpha$, where $\beta$ is a specified probability level. This measure is therefore particularly useful when return or cost distributions have fat tails.
} 
the static M-V model used in Section 5.2 on various accounts (see Section 5.4). We have found that the efficient frontier shifts outward as time progresses, which is in line with expectations. Such exercises of evaluating portfolios at different points in time can be used to - partially - overcome the disadvantages of the static framework. However, these points in time are chosen arbitrarily and do not correspond to optimal timing of investment decisions as in a real options model, for example.

We conclude that static Markowitz portfolios are not appropriate if we want to analyze the effects of dynamic processes such as technical change and the uncertainty surrounding it. The omission of (the diffusion aspect of) technical change and the uncertainties surrounding it is one explanation why other M-V studies find that more renewable energy should have been installed, which has not happened in reality. In our M-V analysis where investment occurs at the beginning, risk averse investors would even go so far as to adopt a portfolio, which relies exclusively on wind. When we impose a later investment date, this picture changes dramatically, as the cost of installing a wind farm becomes very uncertain due to volatility in the rate of technical change. The vintage-portfolio model, on the other hand, can capture such features, accounts for irreversibility of investments and is thus suitable to develop more efficient investment programs and production plans. Diversification is not only possible across the available "assets", but also across existing vintages and between installed capacity and capacity that is yet to develop. The vintage-portfolio model is therefore not only conceptually more suitable for investment analysis in the electricity sector, but it is also - more importantly - closer to reality. 


\section{Appendix}

Equation (5.3.9) can be simplified by noting that the sums of all the error terms should be relatively small in absolute terms. This holds a fortiori for terms containing products of those sums. We can now approximate (5.3.9) by assuming terms containing products of at least two sums of error terms to be equal to zero. In that case, the expected forecasting error of $\mathrm{PV}$ will be given by:

$$
\begin{gathered}
\varepsilon^{P V} \approx \sum_{f} \sum_{v=1}^{\theta} \sum_{t^{\prime}=v}^{\theta} e^{\rho \cdot t^{\prime}} \cdot\left(P ^ { f } \cdot \kappa _ { 0 } ^ { f } \cdot e ^ { \hat { \kappa } ^ { f } \cdot v } \cdot Y _ { v } ^ { f } \cdot e ^ { \delta ^ { f } \cdot ( t ^ { \prime } - v ) } \cdot \left(\left(r_{0}+\delta^{f}\right)\right.\right. \\
\left.\left.\cdot\left(S_{1, v}^{f}+S_{2, v}^{f}\right)\right)+Q_{0}^{f} \cdot e^{\hat{Q}^{f} \cdot t^{\prime}} \cdot \varphi^{f} \cdot X_{v, t^{\prime}}^{f} \cdot S_{3, t^{\prime}}^{f}\right)
\end{gathered}
$$

It should be noted that Equation (A.1) can be written in a more condensed way as:

$$
\varepsilon^{P V}=\sum_{f} \sum_{v=1}^{\theta} \sum_{t^{\prime}=v}^{\theta}\left(\sum_{k=1}^{2} A_{k, v, t^{\prime}}^{f} \cdot S_{k, v}^{f}+A_{3, v, t^{\prime}}^{f} \cdot S_{3, t^{\prime}}\right)
$$

with

$$
\begin{gathered}
A_{1, v, t^{\prime}}^{f}=Y_{v}^{f} \cdot P^{f} \cdot \kappa_{0}^{f} \cdot e^{-\delta^{f} \cdot\left(t^{\prime}-v\right)-\rho \cdot t^{\prime}+\hat{\kappa}^{f} \cdot v} \cdot\left(r_{0}+\delta^{f}\right), \\
A_{2, v, t^{\prime}}^{f}=Y_{v}^{f} \cdot P^{f} \cdot \kappa_{0}^{f} \cdot e^{-\delta^{f} \cdot\left(t^{\prime}-v\right)-\rho \cdot t^{\prime}+\hat{\kappa}^{f} \cdot v}, \\
A_{3, v, t^{\prime}}^{f}=X_{v, t^{\prime}}^{f} \cdot Q_{0}^{f} \cdot \varphi^{f} \cdot e^{-\rho \cdot t^{\prime}+\hat{Q}^{f} \cdot t^{\prime}} .
\end{gathered}
$$

Then, it immediately follows that Equation (A.2) in turn can be rewritten as:

$$
\varepsilon^{P V}=\sum_{f} \sum_{v=1}^{\theta} \sum_{t^{\prime}=v}^{\theta}\left(\sum_{k=1}^{3} A_{k, v, t^{\prime}}^{f} \cdot S_{k, v}^{f}+A_{3, v, t^{\prime}}^{f} \cdot S_{3, t^{\prime}}\right)=\sum_{f} \sum_{v=1}^{\theta} \sum_{k=1}^{3} C_{k, v}^{f} \cdot S_{k, v}^{f}
$$

where $\left.C_{k, v}^{f}\right|_{k=1 \ldots 2}=\sum_{t^{\prime}=v}^{\theta} A_{k, v, t^{\prime}}^{f}$ and $\left.C_{k, v}^{f}\right|_{k=3}=\sum_{t^{\prime}=1}^{v} A_{3, t^{\prime}, v}^{f}$.

Equation (A.3) defines the expected forecasting error in the PV of total costs over the entire planning period in terms of the individual error terms associated with the stochastic variables in the model. It should be noted that the "weighting parameters", $C_{k, v}^{f}$, depend explicitly on the capacity choices and (ex ante) production plans that need to be formulated at the beginning of the planning period. The actual values that these choice variables will indeed depend on the forecasting errors of the stochastic variables if we would be using an objective function that depends not only on the expected value of the PV of total costs, but also on the (expected) variance. This variance is calculated as the expectation of the square of the error-term given by (A.3): 


$$
\begin{aligned}
\operatorname{var}(P V) & =E\left(\left(\varepsilon^{P V}\right)^{2}\right) \\
& =E\left(\sum_{f 1} \sum_{v 1=1}^{\theta} \sum_{k 1=1}^{3} C_{k 1, v 1}^{f 1} \cdot S_{k 1, v 1}^{f 1} \cdot \sum_{f 2} \sum_{v 2=1}^{\theta} \sum_{k 2=1}^{3} C_{k 2, v 2}^{f 2} \cdot S_{k 2, v 2}^{f 2}\right) \\
& =E\left(\sum_{f 1} \sum_{v 1=1}^{\theta} \sum_{k 1=1}^{3} \sum_{f 2} \sum_{v 2=1}^{\theta} \sum_{k 2=1}^{3} C_{k 1, v 1}^{f 1} \cdot S_{k 1, v 1}^{f 1} C_{k 2, v 2}^{f 2} \cdot S_{k 2, v 2}^{f 2}\right) \\
& =\sum_{f 1} \sum_{v 1=1}^{\theta} \sum_{k 1=1}^{3} \sum_{f 2} \sum_{v 2=1}^{\theta} \sum_{k 2=1}^{3} C_{k 1, v 1}^{f 1} \cdot C_{k 2, v 2}^{f 2} \cdot E\left(S_{k 1, v 1}^{f 1} \cdot S_{k 2, v 2}^{f 2}\right)
\end{aligned}
$$

The final step in calculating the variance of the PV of total costs is to define the covariances between the different sums of error terms, $S_{k, v}^{f}$. These obviously depend on the covariances between the individual error terms regarding the forecasts of the rates of technical change, but also the rates of growth in fuel prices, as well as changes in the interest rate. With respect to these covariances, we assume first that they are constant over time, and secondly that the forecasting errors are serially uncorrelated. Hence, defining $\sigma_{k 1, k 2}^{f 1, f 2}$ as the covariance between the contemporaneous error-terms associated with variable $k 1$ of TF1 and variable $k 2$ of technology family TF2, we have:

$$
\operatorname{var}(P V)=\sum_{f 1} \sum_{v 1=1}^{\theta} \sum_{k 1=1}^{3} \sum_{f 2} \sum_{v 2=1}^{\theta} \sum_{k 2=1}^{3} C_{k 1, v 1}^{f 1} \cdot C_{k 2, v 2}^{f 2} \cdot \sigma_{k 1, k 2}^{f 1, f 2} \cdot \min (v 1, v 2)
$$

where $\min (a, b)$ represents the minimum of $a$ and $b$, and where $k 1, k 2=1 \ldots 3$ refers to the variables $\hat{\kappa}^{f}, r$, and $\hat{Q}^{f}$ respectively, corresponding to technology families $f 1$ and $f 2$. The minimum function arises here, since under our assumption of zero noncontemporaneous correlation between error terms, two forecasts for the same variable for two different points in time in the future $v 1$ and $v 2$, can be correlated with each other only through their common "history". Hence, when both forecasts are formulated at time zero and counting time from time zero, the time-length of their common history would be the minimum of $v 1$ and $v 2$.

In order to simplify simulation (and interpretation) matters even further, we have assumed that all individual variables are uncorrelated. ${ }^{26}$ In that case, (A.5) becomes:

$$
\operatorname{var}(P V)=\sum_{f 1} \sum_{k 1=1}^{3} \sum_{v 1=1}^{\theta} \sum_{v 2=1}^{\theta}\left(C_{k 1, v 1}^{f 1} \cdot C_{k 1, v 2}^{f 1}\right) \cdot \sigma_{k 1, k 1}^{f 1, f 1} \cdot \min (v 1, v 2)
$$

\footnotetext{
${ }^{26}$ Typically, the growth rates of fuel prices associated with different families would be correlated depending on the degree of substitution between fuels.
} 



\section{Chapter 6}

\section{Technological \& Price Uncertainty in the Vintage-Portfolio Model}

\subsection{Introduction*}

In the previous chapter, we have sketched a very basic version of the new vintageportfolio approach. Even this relatively simple framework already helps to gain new insights about investment planning in the electricity sector and has proven to have several important advantages over standard portfolio models approaching electricity planning. It is therefore worthwhile to expand the model to allow for different types of costs and also to take into account the different types of technical change that affect electricity-generating equipment.

More precisely, what has been disregarded in Chapter 5 is that not only fuel prices fluctuate, but that investment prices might be uncertain as well. Even more importantly, technical change has been modeled so as to be capital-saving, which was improving the relative attractiveness of the renewable technology greatly. However, there is also fuel-saving technical change, which benefits the traditional, fossil-fuelusing technologies by improving their fuel-output ratio. In other words, the parameter $\varphi^{f}$ in the previous chapter is most probably also dependent on the vintage. By reducing the amount of fuel that is used to generate the same amount of electricity, the variable costs of fossil-fuel-fired power plants can be decreased as well, which might lead to a later transition to renewable energy, which can then be developed and refined for a longer period of time.

Incorporating fuel-saving technical change and the corresponding uncertainty and

${ }^{*}$ This chapter is based on the submitted working paper "Investing in Energy Conversion Technologies - An Optimum Vintage Portfolio Selection Approach" by van Zon and Fuss (2005). 
stochastic investment prices does not only serve the purpose of making the framework more realistic and applicable to investment problems in the electricity sector, but also sheds further light on the underlying mechanisms at work in the new model. We therefore refrain from adding even more features to the model for now and also rely on theoretical exercises with stylized data rather than implementing this version of the model with real-world data already. The next chapter will overcome this omission and provide a broader framework, which is the tested with UK data.

We find that the distinction between uncertainty in investment and fuel prices and in capital-saving and fuel-saving technical change is indeed important, since they trigger a different investment response. In particular, less fuel price variance leads to larger investments immediately and also later on capacity is increasingly replaced by a larger fraction of the more technology that is more secure in terms of fuel prices. For less variance in investment prices, we observe an immediate drop in investment into the concerned technology, but then large upward deviations, which decrease over time. This difference in response to uncertainty in different types of costs has to do with the fact that fuel prices matter for production on all vintages and therefore also the installed ones, while investment prices are only important for equipment that is to be installed now or in the future. A similar mechanism is at work when it comes to the different types of technical change, where we find a negative response to less uncertainty in both cases at first, but then increasingly positive deviations in investment in the case of fuel-saving technical change and decreasingly positive deviations in the case of capital-saving technical change.

An experiment with asymmetric technologies illustrates again the gains from diversification across technologies and vintages. This exercise also serves to investigate the effects of increasing risk aversion and lays the foundation for the more complex analysis in Chapter 7.

The setup of the rest of the chapter is as follows: in the next section we provide a brief outline of the model. Section 6.3 is devoted to a number of illustrative model simulations. The final section summarizes and evaluates the new insights from the extended model.

\subsection{The Vintage-Portfolio Model With Uncer- tain Investment \& Fuel Prices and Capital- \& Fuel-Saving Technical Change}

The model has the same structure as the model developed in the previous chapter. The only difference is that the fuel-output ratio will no longer be constant and the same is true for investment prices. With the same notation as before, capital develops according to $K_{v, t}^{f}=e^{\delta^{f} \cdot(t-v)} \cdot K_{v, v}^{f}$ and capacity output is $Y_{v, t}^{f}=\frac{K_{v, t}^{f}}{\kappa_{v}^{f}}$, where $\kappa_{v}^{f}$ is again the capital-output ratio associated with a vintage installed at time $v$. Assuming zero ex post disembodied technical change, $\kappa_{v}^{f}$ grows at a given expected proportional 
The Vintage-Portfolio Model With Uncertain Investment \& Fuel Prices and

rate with given variance:

$$
\kappa_{v}^{f}=\kappa_{0}^{f} \cdot e^{\hat{\kappa} f \cdot v} .
$$

where $\hat{\kappa^{f}}$ is the expected proportional rate of change of the capital-output ratio. By analogy, the fuel-output ratio $\varphi_{v}^{f}$ is:

$$
\varphi_{v}^{f}=\varphi_{0}^{f} \cdot e^{\hat{\varphi^{f}} \cdot v}
$$

Fuel consumption per vintage is therefore:

$$
F_{v, t}^{f}=\varphi_{v}^{f} \cdot X_{v, t}^{f}
$$

The capital required per vintage in function of the level of installed capacity is unchanged at $K_{v, t}^{f}=\kappa_{v}^{f} \cdot Y_{v, t}^{f}$.

Given these changed factor requirements, we can now rewrite the present value (PV) of total costs as:

$$
P V=\sum_{f} \sum_{v=1}^{\theta} \sum_{t^{\prime}=v}^{\theta} e^{-\rho \cdot t^{\prime}}\left(P_{v}^{f} \cdot\left(r_{v}+\delta\right) \cdot \kappa_{v}^{f} \cdot Y_{v}^{f} \cdot e^{-\delta^{f} \cdot\left(t^{\prime}-v\right)}+Q_{t}^{f} \cdot \varphi_{v}^{f} \cdot X_{v, t^{\prime}}^{f}\right),
$$

with the same notation as before. Note that $P_{v}^{f}$ is no longer constant, but depends on $v$ now as well.

The first order approximation of Equation (6.4) changes accordingly:

$$
\begin{aligned}
P V & \approx \sum_{f} \sum_{v=1}^{\theta} \sum_{t^{\prime}=v}^{\theta} e^{-\rho \cdot t^{\prime}}\left(P_{0}^{f} \cdot e^{\hat{P}^{f} \cdot v} \cdot\left(1+S_{1, v}^{f}\right) \cdot \kappa_{0}^{f} \cdot e^{\hat{\kappa}^{f} \cdot v} \cdot\left(1+S_{2, v}^{f}\right)\right. \\
& \cdot\left(r_{0}+\delta^{f}+S_{3, v}^{f}\right) \cdot Y_{v}^{f} \cdot e^{-\delta \cdot\left(t^{\prime}-v\right)}+Q_{0}^{f} \cdot e^{\hat{Q}^{f} \cdot t^{\prime}} \cdot \varphi_{0}^{f} \cdot e^{\hat{\phi}^{f} \cdot v} \cdot\left(1+S_{4, v}^{f}\right) \\
& \left.\cdot\left(1+S_{5, t^{\prime}}^{f}\right) \cdot X_{v, t^{\prime}-v}^{f}\right)
\end{aligned}
$$

where $S_{1, v}^{f}=\sum_{j=1}^{v} \varepsilon_{j}^{\hat{P}, f}, S_{2, v}^{f}=\sum_{j=1}^{v} \varepsilon_{j}^{\hat{\kappa}, f}, S_{3, v}^{f}=\sum_{j=1}^{v} \varepsilon_{j}^{r, f}, S_{4, v}^{f}=\sum_{j=1}^{v} \varepsilon_{j}^{\hat{\varphi}, f}$ and $S_{5, t^{\prime}}^{f}=\sum_{j=1}^{t^{\prime}} \varepsilon_{j}^{\hat{Q}, f}$, and where $\varepsilon_{j}^{x, f}$ is the forecasting error for variable $x$ associated with technology family $f$ for time $j .{ }^{1}$ So there are two additional error sums due to the inclusion of volatile, fuel-saving technical change and investment prices. Recall that $\hat{\kappa}^{f}$ is the expected rate of capital-using technical change, which now also applies for $\hat{\varphi}^{f}{ }^{2}$. All forecasting errors $\varepsilon_{j}^{x, f}$ are again assumed to have zero expectation.

Equation (6.5) can be used again to calculate the (approximated) expected forecasting error in the PV of total capital and fuel costs; the expectation of its squared value will be the total variance of the $\mathrm{PV}$ again:

$$
\operatorname{var}(P V)=\sum_{f 1} \sum_{v 1=1}^{\theta} \sum_{k 1=1}^{5} \sum_{f 2} \sum_{v 2=1}^{\theta} \sum_{k 2=1}^{5} C_{k 1, v 1}^{f 1} \cdot C_{k 2, v 2}^{f 2} \cdot \sigma_{k 1, k 2}^{f 1, f 2} \cdot \min (v 1, v 2)
$$

where $\min (v 1, v 2)$ is the minimum of $v 1$ and $v 2$, and where $k 1, k 2=1 \ldots 5$ refer to the

\footnotetext{
${ }^{1}$ Equation (6.5) is again evaluated for all "S-terms" equal to zero in order to obtain the expected value of the PV of total cost.

${ }^{2}$ Negative values of these rates imply capital- and fuel-saving technical change.
} 
variables $\hat{P}^{f}, \hat{\kappa}^{f}, \hat{\varphi}^{f}, r$, and $\hat{Q}^{f}$ respectively now, corresponding to technology families $f 1$ and $f 2$. The computations are the same as in the previous chapter's appendix.

Again, producers minimize the weighted sum of the expected PV of their total production cost and its corresponding variance by choosing the optimal $Y_{v}^{f}$ and $X_{v, t}^{f}$.

$$
\Phi=P V+\lambda \cdot \operatorname{var}(P V)
$$

where $0 \leq \lambda$ is the risk aversion parameter.

The additional constraints for capacity and demand are unchanged:

$$
\begin{aligned}
X_{v, t^{\prime}}^{f} & \leq e^{-\delta^{f} \cdot\left(t^{\prime}-v\right)} \cdot Y_{v}^{f} \\
\sum_{f} \sum_{v=0}^{t^{\prime}} X_{v, t^{\prime}}^{f} & \geq D_{t^{\prime}}
\end{aligned}
$$

where $t^{\prime}$ again refers to an absolute moment in time within the planning period, i.e. $1 \leq t^{\prime} \leq \theta$.

\subsection{Model Simulations}

In order to illustrate the portfolio principles involved in the most transparent way possible, we want to avoid any effects that could arise from asymmetries in the characteristics of the technology families at first. Also, we choose to focus on three technology families because - on the one hand - this already provides very interesting insights, while on the other hand remaining simple enough to present the model outcomes in a tractable manner.

In the symmetric, three technology families case, where the cost of investment and fuels, capital and fuel coefficients and initially installed capacity are all equal between families, we indeed find a portfolio that is evenly spread across families. However, this only occurs if investors are risk averse $(\lambda>0)$. Otherwise, the distribution of investment across families appears to be totally random, even though total investment is the same in all cases, as it is implicitly defined by the total demand constraint. To explain the source of randomness, one should realize that in the absence of risk aversion and under complete symmetry, all technology families are perfect substitutes for each other, and so there are infinitely many optimum investment portfolios.

The even distribution of investment over technology families for $\lambda>0$ is caused by the convexity of the objective function that arises due to the inclusion of the variance term. As, roughly speaking, the variance of the total cost associated with each technology family depends quadratically on the size of the family, we have a lower total portfolio variance if capacity is distributed over all families rather than being concentrated in just one of them. After all, this is how risk diversification in a traditional portfolio setting works. The evenness of the investment distribution simply arises due to the imposed symmetry.

Given this basic setup, we conduct a sensitivity analysis concerning the responsiveness of investment behavior towards changes in the variances of the stochastic variables 
associated with just one of the families, thus breaking the symmetry between families. ${ }^{3}$ Before discussing these results, note that the valuation of investment at historic cost prices causes a significant qualitative difference between fuel price variance experiments and capital cost variance experiments. Higher fuel price variance at some moment in time affects all vintages within a family that are in existence at that time, whereas higher capital cost variance at a point in time only affects the vintages bought from that period on, just like more uncertainty about the productivity growth rate at some point in time does not affect the vintages installed before that period. In that sense, capital cost variance and embodied technical change variance have some features in common with respect to the timing of investment.

\subsubsection{Experimental Setting}

For the experiments we have used a 30-year planning period. This is in line with real investment considerations in the electricity sector. ${ }^{4}$ Initial prices are 1 for investment and 0.1 for fuels, ${ }^{5}$ whereas the rate of interest is $10 \%$, the discount rate is $5 \%$ and the rate of technical decay $8 \%$.

Please note that these "data" do not correspond precisely to any real world technologies and serve the mere purpose of illustrating how the new methodology works. Evidently, real world technologies are never completely symmetric as will be seen in the extension and application of the new framework to electricity generation in the UK in Chapter 7.

The expected rates of embodied factor-saving technical change are equal to $0.1 \%$. The variance in expected capital cost and fuel price growth is 0.01 , and the variance factor in productivity growth is equal to 0.01 as well. Variance in interest rate growth is left aside for the first experiments because interaction effects lead to less clear-cut results, even though they remain qualitatively the same. Finally, total demand is equal to 10 growing by $3 \%$ per year. At the beginning of the planning period, installed capacity is equal to 10 as well, and evenly distributed over the three technology families, while in a real world situation the amount of fossil-fuel-fired generators generally outstrips other technologies by far. Such considerations have been taken into account already in Chapter 5 and will be analyzed in detail in Chapter 7.

\subsubsection{A Reduction in Fuel Price Variance}

A zero variance in fuel price growth of $\mathrm{TF}^{6}$ (all else equal) brings investment into that family forward in time at the expense of investment in the other two technology

\footnotetext{
${ }^{3}$ These results are obtained for zero covariances between expected price growth and expected rates of technical change, both within and across technology families, even though this model has been specified for the non-zero covariance case, again because this makes the results more transparent.

${ }^{4} \mathrm{Ku}(1995)$ claims a period of 30 to 40 years to be a typical investment horizon in electricity capacity planning (page 73 ).

${ }^{5}$ This is to make the capital and fuel cost of the same order of magnitude, since we use the user cost of capital and therefore multiply investment prices with $\left(r+\delta^{f}\right)$, which is of the order of 0.1 .

${ }^{6} \mathrm{TFi}$ is short for "technology family i".
} 


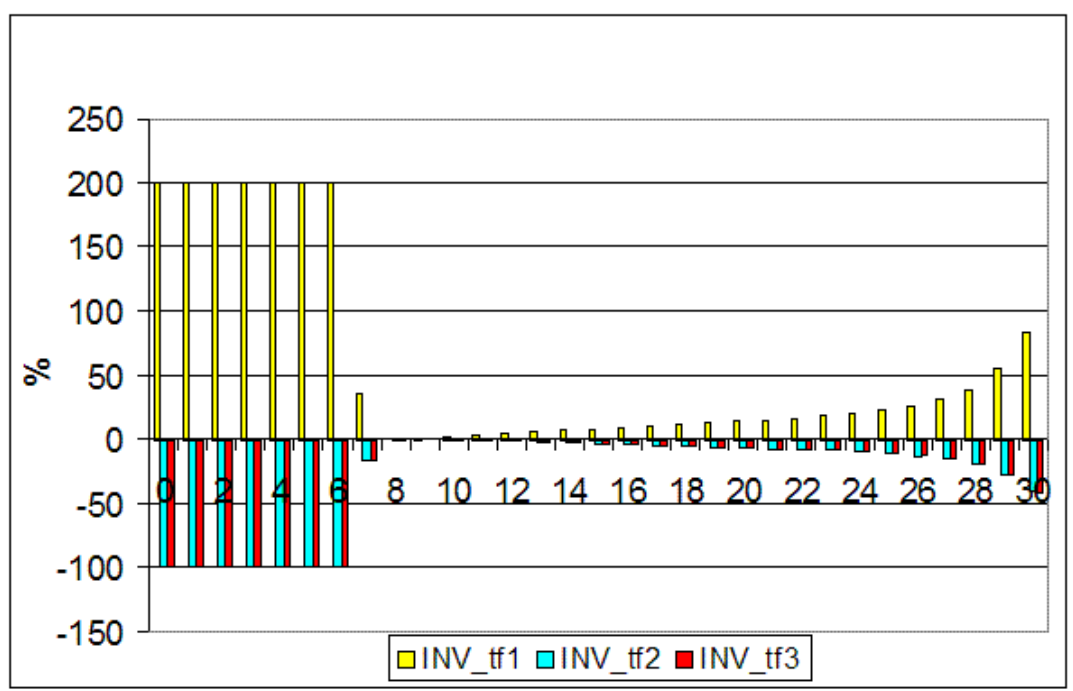

Figure 6.1: Deviations of Net Investment for Zero Fuel Price Growth Variance in $T F 1$

families. This is illustrated in Figure 6.1, which shows the percentage deviations of net investment relative to the base run. This finding is in line with the standard results known from portfolio and real options theory, i.e. we also find a negative relationship between uncertainty and investment in this case as we did in the previous chapter. Facing higher uncertainty associated with investment in some technology family, investors will reduce investment in that family, since the risk-adjusted returns fall, which is the typical portfolio result. In real options theory terms, the value of waiting and postponing investment in that technology family is reduced if uncertainty decreases.

When fuel-saving technological change makes it gradually more profitable to install new vintages, we see that the positive deviations increase again, making the portfolio biased towards the more secure technology. In general, however, we can conclude that the investment portfolio is reshuffled over both the family and the quality or vintage dimension. In this particular case, the quality of the aggregate capital stock falls due to the fact that aggregate investment in the more secure technology is brought forward in time.

\subsubsection{A Reduction in Investment Price Variance}

For the experiment with zero variance in the rate of growth of investment prices we find the opposite effect at the beginning of the planning period: less investment into the more secure technology, but then a gradual increase above base run investment from period 5 on.

This postponement in investment can be explained by the difference in influence 


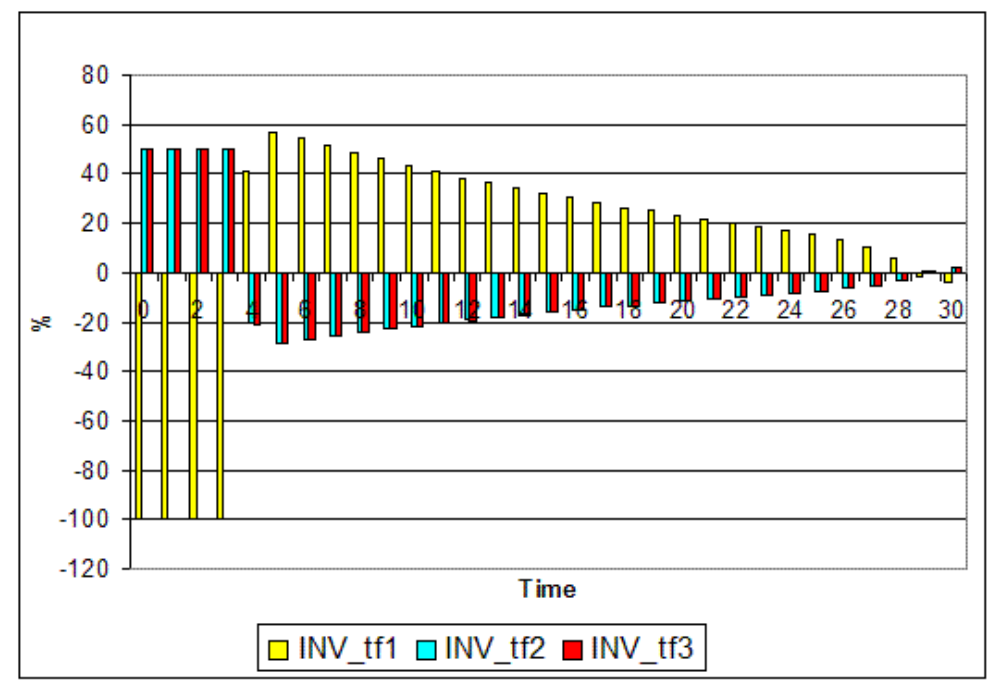

Figure 6.2: Deviations of Net Investment for Zero Investment Price Growth Variance in TF1

that investment prices and fuel prices have on total cost. Fuel prices affect production costs on all existing and future vintages, while investment prices are only important for the next vintage to be installed. Therefore, it is profitable to always have more investment into a technology that has less variance in fuel price growth, whereas for less investment price volatility, it pays off to have less investment first and more later on, since investors can then profit from better developed technologies - as technological change continues to take place - as long as investment prices will not exceed their expected values dramatically. There is a tradeoff involved here that is not inherent in the fuel price experiment, however: as investors wait to install new vintages, investment prices continue to grow and this will eventually more than outweigh the benefit of falling unit capital requirements to produce the same amount of electricity because of embodied capital-saving technical change at a certain point in time. This is the reason why we see the positive deviations in Figure 6.2 decline over time.

\subsubsection{A Reduction in the Variance of Embodied Capital- Saving Technical Change}

The same mechanism is at work when we conduct the experiment for less variance in the rates of capital-saving technical change: it pays off to wait until some of this technical change (that is now more certain to occur) has materialized. However, the longer investors postpone investment, the more costly it becomes in terms of higher investment prices and more certain productivity gains foregone, which is why we observe a decrease in positive deviations towards the end of the planning period.

This is again very different from "standard" mean-variance portfolio selection and 


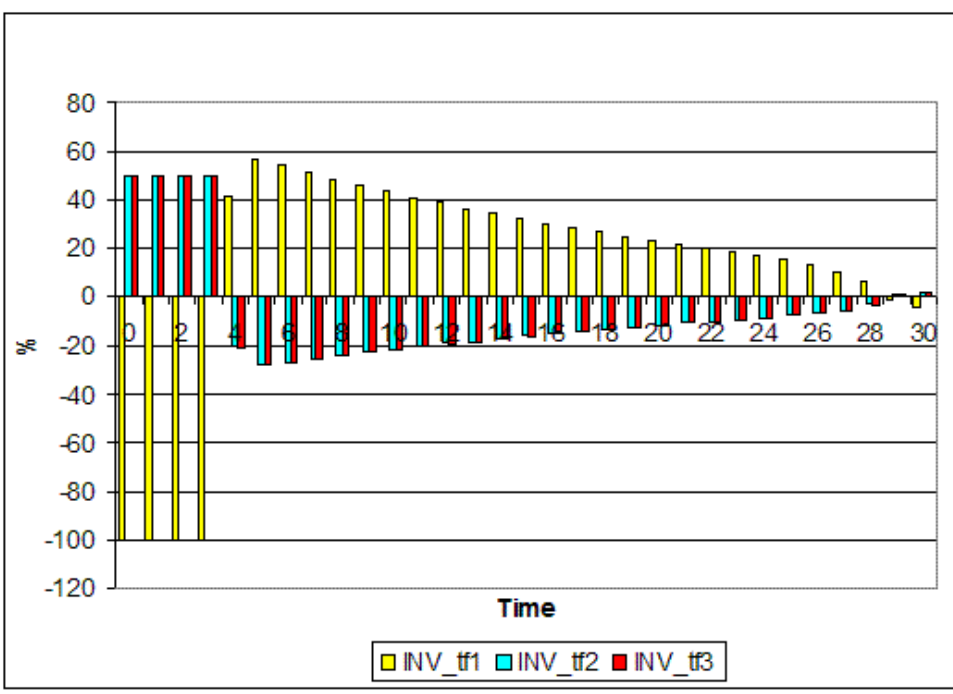

Figure 6.3: Deviations of Net Investment for Zero Variance in Capital-Saving Technical Change of TF1

contrasts with real options theory as well. The latter predicts that less uncertainty lowers the option value of waiting, and hence that investment has to take place sooner rather than later. We have seen in the real options model in Chapter 4 that while embodied technological change itself leads to a preference for investment later in the planning period, technological uncertainty only intensifies these incentives for postponement because producers feel it is worthwhile to wait for a major technological breakthrough if the arrival rate of innovation is low but potential improvements large.

\subsubsection{A Reduction in the Variance of Embodied Fuel-Saving Technical Change}

For more certain fuel-saving technical change in TF1, we see the opposite from what we have observed in the fuel price growth case: a postponement in investment, even though the technology gets more "secure" in portfolio terms. This is because fuel prices are important for operations on all installed and future vintages, while technical change matters only for the latest vintage to be installed. The effect is still different from more certain capital-saving technical change, as can be seen in the increase in positive deviations over the course of the planning period. This can be explained by the fact that there is no such tradeoff involved here as with investment prices. Fuel prices also grow, but they have to be paid for all existing vintages, so it always pays to have as much investment as affordable towards the end of the planning period implying that less fuel has to be bought to operate the latest vintages, whereas the old ones consume as much fuel as before, getting gradually more expensive. 


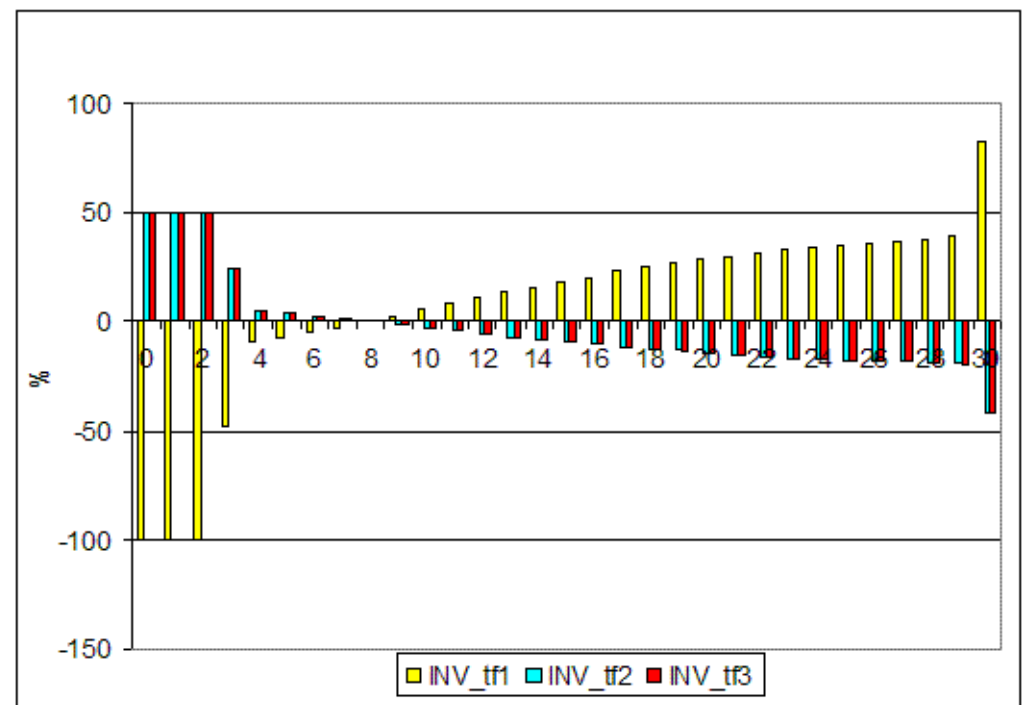

Figure 6.4: Deviations of Net Investment for Zero Variance in Fuel-Saving Technical Change of TF1

\subsubsection{An Asymmetric Case}

We have now collected some qualitative theoretical results - namely that fuel price uncertainty and investment are negatively related, as could have been expected from the analysis in the previous chapter. Furthermore, we have found that this relationship does not hold for investment prices because investment and fuel cost affect the total cost structure in quite different ways. The same is true for capital-saving and fuelsaving technical change, where a reduction in the uncertainty surrounding either of the two leads to less investment in the beginning and more later on, which might seem to be at odds with standard portfolio and real options theory at first glance, but is completely rational in our model given the cumulative but marginal nature of technical change. We can now turn to a more interesting case, where we introduce an asymmetry between technologies.

Table 6.1 presents the parameter values we have used in the asymmetric case, where TF1 and TF2 are relatively similar. The main difference is that TF2 uses more expensive fuels, with a fuel price variance that is greater than that of TF1. TF3 is different from the others in that it has low capital productivity, high unit capital costs, but low fuel prices and relatively strong rates of capital- and fuel-saving technical change. However, for TF3 technological expectations with respect to capital-saving technological change are more uncertain than those of TF1 and TF2.

The technologies can thus be characterized as follows: TF1 and TF2 are established technologies with limited scope for productivity improvements, possibly representing fossil-fuel-based conversion methods, such as coal-fired capacity (high capital costs, low fuel costs as with TF1) and gas-fired capacity (high fuel costs, low capital costs 


\begin{tabular}{|c|ccc|}
\hline Parameter & TF1 & TF2 & TF3 \\
\hline \hline$\kappa_{0}$ & 1.0 & 1.0 & 1.5 \\
$\varphi_{0}$ & 1.0 & 1.0 & 1.5 \\
$p_{0}$ & 1.5 & 1.0 & 1.7 \\
$q_{0}$ & 0.10 & 0.15 & 0.05 \\
$\hat{p}$ & 0.05 & 0.05 & 0.05 \\
$\hat{q}$ & 0.10 & 0.10 & 0.10 \\
$\sigma_{\hat{p}}^{2}$ & 0.01 & 0.01 & 0.01 \\
$\sigma_{\hat{q}}^{2}$ & 0.10 & 0.15 & 0.10 \\
$\hat{\kappa}$ & -0.0010 & -0.0025 & -0.0035 \\
$\hat{\varphi}$ & -0.0010 & -0.0025 & -0.0035 \\
$\sigma_{\hat{\kappa}}^{2}$ & 0.15 & 0.15 & 0.30 \\
$\sigma_{\hat{\varphi}}^{2}$ & 0.15 & 0.15 & 0.30 \\
\hline
\end{tabular}

Table 6.1: Parameter Values

as with TF2). The variance of the growth in fuel costs in TF2 is considerably higher than that in TF1, which is comparable to gas and coal again. The third technology family is expensive in terms of capital costs, does not cost much in terms of fuels, and has plenty of scope for technological improvements (even though it is not certain whether it will live up to these promises) and may thus represent a promising, yet underdeveloped technique based on a renewable resource such as biomass.

Not surprisingly, for the case of zero risk aversion displayed in Figure 6.5, we find that net investment (negative values refer to scrapping) is initially completely focussed on TF1, and only after TF3 has sufficiently improved, it is phased in. TF2 is not considered at all, although being more "secure" than TF3. However, since the variance has zero weight in this case, this does not increase TF2's value.

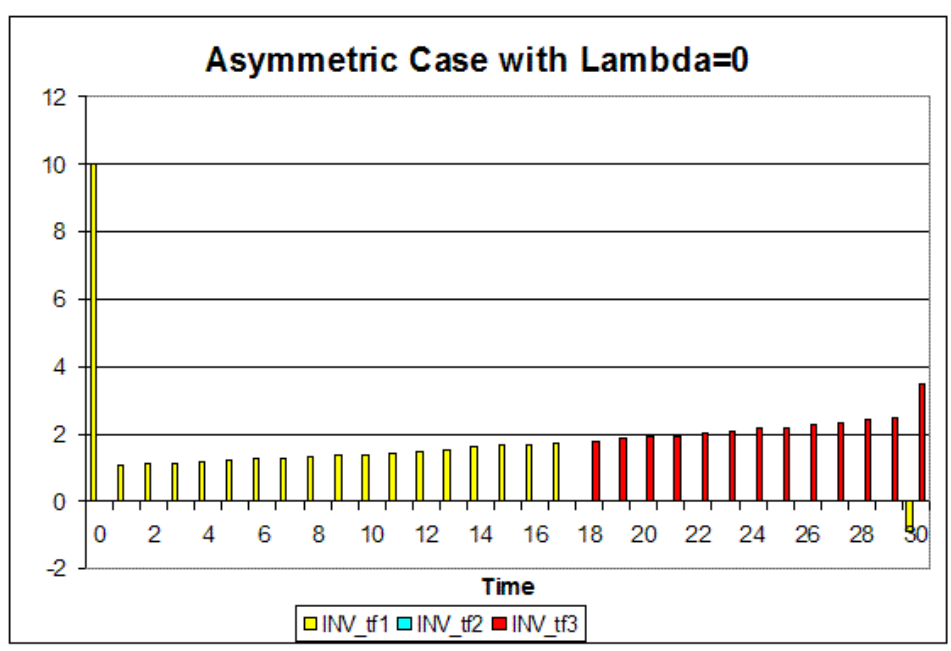

Figure 6.5: Base Run Investment With Zero Risk Aversion 
However, from the description of the data above, we know that TF3 should look less attractive for investors, who are risk averse. The variance associated with technological change is high compared to the other two candidates. By increasing the weight of the variance in total cost in the objective function, we can investigate what happens to the investment portfolio as investors begin to care more about the risks involved in their investments.

Figures 6.6 and 6.7 show that not only the spread across technology families increases, as $\lambda$ rises, but that there are also strong effects with respect to the distribution of investment over time. In particular, we observe that most of the investment is brought forward in time, the more risk averse investors grow. This is in line with our findings from the symmetric case. The more investors dislike uncertainty, the lower the "option value" of waiting. They rather invest in the beginning, when they face relatively certain circumstances, than wait and be confronted with less favorable and unexpected outcomes over the course of the planning period. If they are very risk averse, they would even go so far as to invest into capacity only at the beginning of the planning period, have a huge degree of underutilization during most of the planning period, and start investing only marginally again at the very end of the planning to make up for depreciation and demand growth (cf. Figure 6.7). ${ }^{7}$ Note that TF3 capacity in Figure 6.7 is actually scrapped in the end (negative net investment). This is because TF3 is still not superior to TF2 and TF1 in terms of fuel and capital coefficients, even though its rates of improvement have been higher.

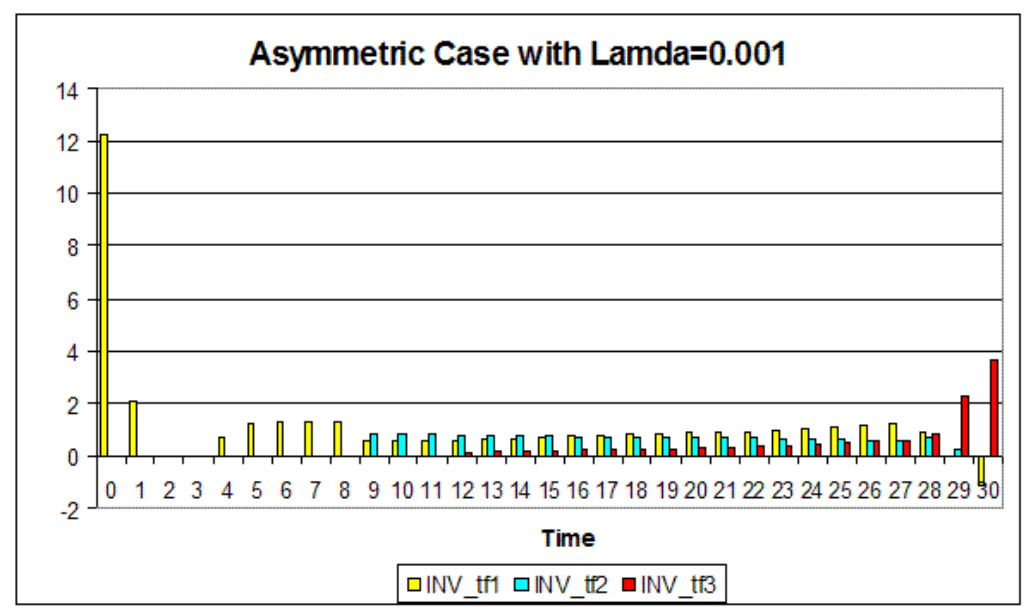

Figure 6.6: Base Run Investment With Moderate Risk Aversion

In Figure 6.6 that corresponds to the low risk aversion case, we see that TF3 is phased in a little earlier, but in much more modest amounts than without risk aversion. This is a rational choice when looking back at Table 6.1. TF1 is less volatile than TF2

\footnotetext{
${ }^{7}$ This makes even more sense in the case where fuel costs represent only a small fraction of total costs, and little cost savings can be gained by waiting for cumulative embodied fuelsaving technical change to materialize.
} 
and TF3. However, its prospects of technological improvement are not as positive as the those of the others. On the other hand, TF3 starts out with very unfavorable fuel and capital coefficients and has volatile technical change. Therefore, TF2 is now used as a sort of "bridge" between the TF1-biased portfolio and an investment plan that focusses more on TF3, which is the same phenomenon we have observed in the previous chapter for the "nuclear-like" technology family. Here, it becomes even clearer that TF2 hedges the risks emanating from TF3, while the latter is developing a cost advantage over TF1. This resembles the present interest of phasing in nuclear energy again in countries like the UK to buy some necessary "research and development time" to be able to make the switch towards renewables as low-carbon policies become more stringent.

For reasons of completeness, Figure 6.7 shows investment behavior in the case of relatively strong risk aversion. In that case, all investment takes place under the most certain circumstances, i.e. at the beginning of the planning period.

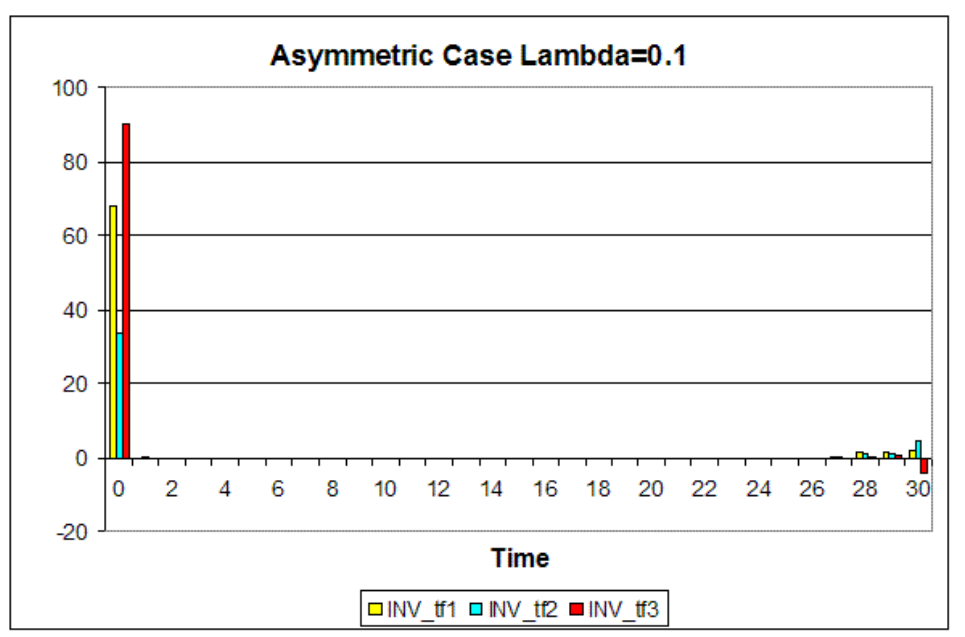

Figure 6.7: Base Run Investment With High Risk Aversion

From the exercises above, we conclude that portfolio selection is a useful analytical tool to investigate investment choices in a context of uncertain embodied technical change - in the sense that it generates a priori intuitive results, that are to some extent "richer" than the results one would obtain from a "standard" portfolio model without a vintage framework, as has been worked out in detail in the previous chapter. We found that if we let one technology family differ from the others by having higher expected rates of technical change, but if at the same time there is uncertainty that this technical change will indeed be realized, investors will prefer this family only if they are not risk averse. Additionally, we have shown that there are not only portfolio effects across technologies, but also across time and vintages. The intertemporal effect does not exclusively depend on discount rates, but also on the degree of risk version. Furthermore, it is important to distinguish between the different types of costs and 
technical change, since the uncertainty surrounding them triggers different investment patterns over the course of the planning period.

\subsection{Summary and Conclusion}

In this chapter we have extended the basic vintage model of portfolio investment developed in the precious chapter, so that there are not only two but four sources of uncertainty regarding future costs. We make a distinction between fixed and variable production costs. The fixed costs are associated with investment. They are only fixed ex post but variable ex ante, and need to be decided upon in the context of an investment portfolio problem that involves simultaneous investment in multiple production technologies or technology families in a wider sense. Each family is defined using a vintage setting that allows for technological improvements to have cost-reducing effects through embodied technical change. However, realization of these potential cost reductions requires investment, which is why we have chosen to develop an intertemporal, variance-adjusted, minimum cost function that borrows elements from financial optimum portfolio theory.

The four sources of uncertainty are the volatility of user prices of fuel and capital and the volatility of productivity changes of the same. Our experiments have shown that the reaction of the model to changes in technological and investment price uncertainty is qualitatively different from its reaction to changes in fuel price uncertainty. A decrease in uncertainty favors current investment in the case of lower fuel price uncertainty, but it favors future investment in the case of a reduction in technological and investment price uncertainty.

The reason for this seemingly "perverse" reaction is that a decrease in the variance of the rate of technical change provides an incentive to actually postpone investment. The latter enables the power plant owner to reap the productivity benefits of the cumulative nature of technical change that continues regardless of the rate of investment, i.e. the uncertainty surrounding the benefits of waiting decreases. In other words, the initially negative but later positive relationship between investment and uncertainty derives from the fact that the investor will be able to reap the benefits of technical change that will continue on regardless of people's individual investment actions.

Reductions in the uncertainty surrounding the variable costs of operating a vintage (i.e. fuel costs) have the expected effects. We observe an increase in investment in the technology, which has become less risky to operate and a decrease in the installed capacity of the other technologies.

Furthermore, in performing the simulation experiments we found that a change in the temporal distribution of investment generally also changes the technology family distribution of investment, and vice versa, because both dimensions become interconnected in this setting. The new approach therefore adds to the existing mean-variance portfolio applications to real investments by adding a dynamic perspective to an otherwise myopic framework. In this way it becomes possible to analyze the effects of inherently dynamic processes (like technological change) and the uncertainty surround- 
ing them. While this is in line with what we have found in the previous chapter, this chapter's contribution is more in the distinction between the investment responses to changes in uncertainty in fuel and investment prices and in fuel-saving and capitalsaving technical change.

First, the difference in the investment response that less investment and fuel price uncertainty trigger can be explained by the difference in influence that investment prices and fuel prices have on the composition of total cost: whereas fuel prices affect production costs on all vintages that have been installed and will be installed, investment prices only matter for the vintages to be installed from now on. Less fuel price uncertainty is thus always beneficial and should trigger more investment immediately, while less investment price volatility should only result in more investment later on when investors can benefit from better developed technologies, as technological change continues to occur. With respect to the different behavior in investment subsequently, one has to notice that there is a tradeoff involved with investment prices that does not apply to fuel costs - namely that investment prices continue to grow while investors are postponing investment. So the benefit of falling unit capital requirements to produce the same amount of electricity will be exceeded by higher investment costs at a certain point in time. Consequently, for the case of less investment price volatility, we see a decrease in the positive net investment deviations from the base run over time, while the opposite is true for less fuel price uncertainty.

Second, a similar picture can be observed in the cases of less variance in fuel-saving and capital-saving technical change: while both experiments first depress investment in favor of higher investment in the future, less uncertainty in capital-saving technical change leads to gradually decreasing positive deviations from the base run due to the tradeoff described above, whereas less variance in fuel-saving technical change leads to increasingly positive deviations from base run investment. The explanation for the latter is that fuel prices are incurred on all existing vintages, so it is beneficial to invest as much as possible towards the end of the planning period because it means that producers have to buy less fuel to operate the latest vintages. The old vintages consume the same amount of fuel as they always have been (ex post, no substitution is possible in a clay-clay vintage setting), but newer vintages allow for increasing cost savings.

Finally, let us emphasize the parallels with Chapter 4 here. In that chapter we incorporated uncertainty about technical change and fuel prices into a real options model. We found that technological uncertainty led to a postponement of investment because the option value of waiting increased substantially in response to a less certainty about the arrivals of innovations that would reduce investment costs. Please note that we also have an "implicit option value" in the vintage-portfolio model: its value derives from the cumulativeness of (exogenous) technical change. If it is not certain when or whether this technical change will materialize, the value of waiting for it decreases, which leads to the opposite result than in the real options model. ${ }^{8}$ Fuel

\footnotetext{
${ }^{8}$ Technical change itself, however, leads to later investment also in the real options model, which shows that there are similar embodiment effects at work.
} 
price uncertainty, on the other hand, shows a similar effect in both frameworks. Note that this occurs for different reasons again: in the portfolio model, more uncertainty about fuel prices makes the corresponding technology unattractive because variance is valued negatively in the objective function, whereas in the real options model it is again the option value of waiting that increases with higher uncertainty. 



\section{Chapter 7}

\section{Extended Vintage-Portfolio Approach to Electricity Investment \& Climate Change Policy in the UK}

\subsection{Introduction ${ }^{\ddagger}$}

In this chapter we extend the vintage-portfolio framework sketched out in Chapter 5 and further developed in Chapter 6 and apply it to investment in the UK electricity sector with a special focus on the effects of climate change policy.

During the 1990s the UK electricity mix, which up to that time had mainly been based on coal-fired capacity, became more diversified as the share of gas in fuels used for power generation started to rise. At the end of the 1990s the share of nuclear energy fell substantially, which was due to more frequent outages at nuclear power stations for repairs, maintenance and safety case work. By 2004 still less than $4 \%$ of all electricity produced in the UK came from techniques based on renewable energy. The fraction of electricity coming from oil-fired generators had been falling from the late 1970s on and was negligible by the year 2004. Figure 7.1 illustrates the current UK electricity mix.

Figure 7.2 shows that, over the last decades, $\mathrm{CO}_{2}$ emissions from power generation have been decreasing, while electricity production has continued to increase. This favorable trend was mainly due to the switch from coal to gas, efficiency improvements

${ }^{\ddagger}$ This chapter is an updated and extended version of the submitted working paper "Irreversible Investment under Uncertainty in Electricity Generation: A Clay-Clay-Vintage Portfolio Approach with an Application to Climate Change Policy in the UK" by van Zon and Fuss (2006) 


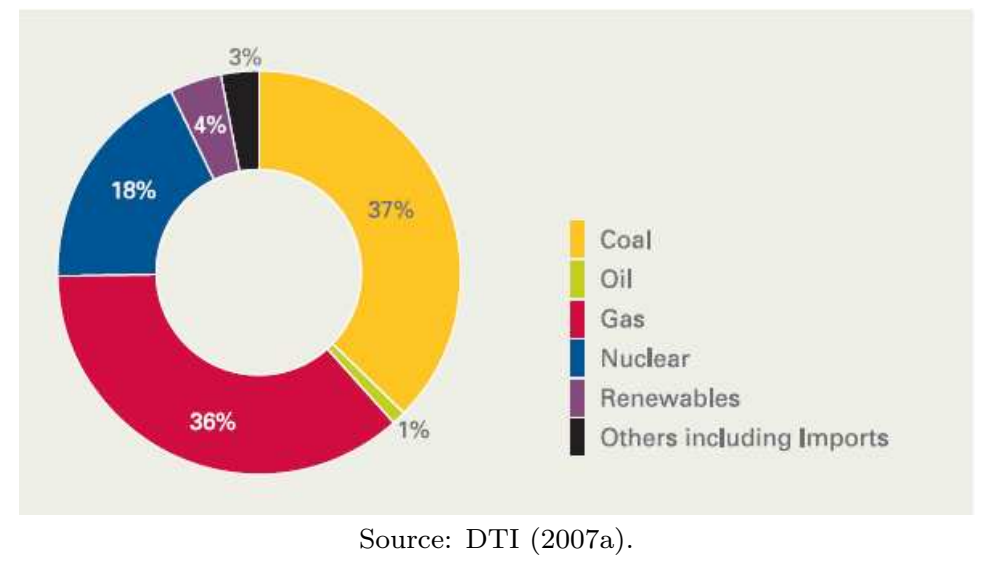

Figure 7.1: 2006 UK Electricity Generation Mix

at the plant level and - over the last few years - an increasing contribution of nuclear and renewable power to the overall electricity mix. However, greenhouse gas (GHG) emissions are a stock externality, and there is now wide agreement that further GHG emissions will lead to considerable (and potentially irreversible) damages related to global warming. ${ }^{1}$ The Stern Review (2006) provides first estimates of the economic costs of the envisaged warming: "With $5-6^{\circ} \mathrm{C}$ warming - which is a real possibility for the next century - existing models that include the risk of abrupt and large-scale climatic change estimate an average $5-10 \%$ loss in global GDP, with poor countries suffering costs in excess of $10 \%$ of GDP." (Stern, 2006). ${ }^{2}$ Consequently, UK policy makers have taken up the challenge of realizing further emissions reductions and have set out clear goals in a first Energy White Paper in 2003, which has recently been updated - or rather replaced - by the Energy White Paper 2007 (DTI, 2007a).

In line with the European Council's climate change and energy package from March 2007, the UK has adopted the target to reduce GHG emissions by $30 \%$ by 2020 compared to 1990 levels with a view to reducing them by $60 \%$ to $80 \%$ by 2050 . To this end, two instruments are emphasized to be of particular importance for policy makers in the Energy White Paper (2007): (1) Capping and trading, which means that a cap is fixed for emissions, which determines the number of emissions permits that are then traded. ${ }^{3}$ The EU Emissions Trading Scheme (ETS) is the first implementation of this principle and actively prices $\mathrm{CO}_{2}$ emissions for the first time. The UK sees this as a step forward to provide incentives to investors to improve energy efficiency and/or invest into "green" energy. (2) Since 2002, the UK has been following a policy of promoting renewable energy through the so-called Renewables Obligation (RO), which

\footnotetext{
${ }^{1} 2^{\circ} \mathrm{C}$ is already thought to be a critical threshold, beyond which dangerous climatic consequences can be expected (see e.g. Azar and Rhode, 1997). For more information about the climate and the effects of its change see Chapter 1.

${ }^{2}$ Chapter 1 analyzes the relationships between the economy/the electricity sector, the climate and the government in more detail.

${ }^{3}$ See Chapter 3 for more background to the debate about cap and trade schemes versus taxes.
} 


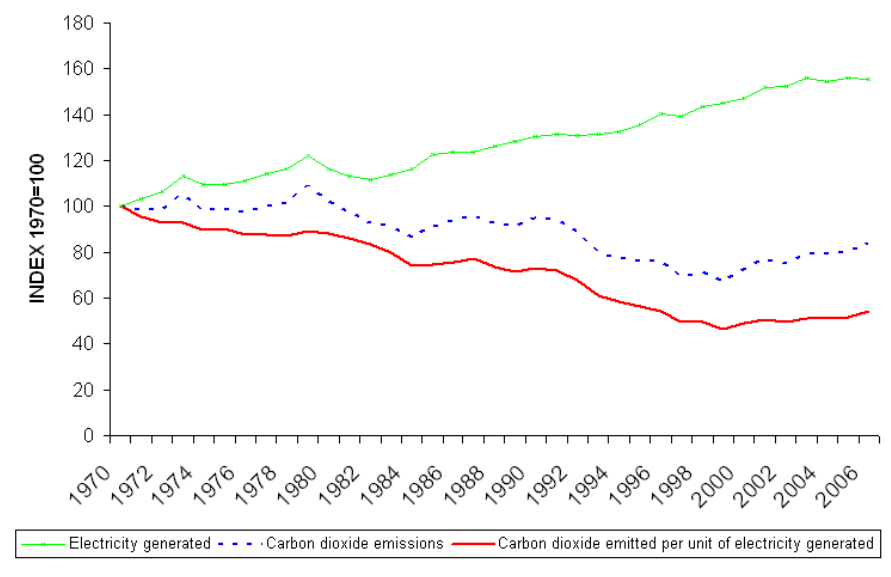

Source: DTI (2007b).

Figure 7.2: Power Station Emissions of Carbon Dioxide

requires electricity retailers to eventually acquire at least $10 \%$ of their electricity from renewable sources. ${ }^{4}$ Currently, at a level of $6.7 \%$, this percentage has been updated to reach $15.4 \%$ by 2015 in the new Energy White Paper and to remain at that level until 2027, with an option to raise the level up to $20 \%$ if necessary (DTI, 2007a). ${ }^{5}$

Due to technological uncertainties with respect to the development of renewable technologies and high capital and O\&M costs, investors in the electricity sector may still be reluctant to adopt renewable technologies on a large scale, even though they may have to expose themselves to a higher degree of fuel price risk by doing so. By carefully composing a portfolio of technologies with different (co)variances in the respective price changes and rates of technical progress, producers have an opportunity to effectively hedge these kinds of uncertainties. This implies that producers generally opt for a mix of technologies including such that are still in a relatively immature state of development.

\footnotetext{
${ }^{4}$ See Mitchell et al (2006) for more information on the RO, and - more importantly - a comparison between its risk reduction potential and that of the German feed-in tariffs. Edge (2006) provides a detailed overview of the renewables industry and the involved policies in the UK.

${ }^{5}$ The levels of envisaged $\mathrm{CO}_{2}$ savings from the $\mathrm{RO}$ might seem low relative to the total level of required reductions. One might argue that e.g. large-scale hydropower techniques are already very advanced and could easily provide a larger share of the electricity mix. However, there is actually very little scope for any additional large-scale hydropower systems as suitable sites are scarce. Therefore, any additional capacity relying on hydro techniques must be small-scale. Likewise, the resources for some biomass technologies are limited, e.g. for landfill gas. Furthermore, importing crops for biomass-fired electricity generation is often not economically viable, while at the same time such imports would also cause emissions related to transportation that will reduce net potential savings. Without further improvements in UK crop yields, it is therefore fair to assume that not much more than $20 \%$ of electricity demand can be met by biomass technologies, which already take up the lion's share of renewable energy production nowadays. Similarly, wind will not constitute a higher share than $10 \%$ of demand, since there is not much scope for expansion (at least not onshore; with the advancement of offshore wind turbines, this picture will definitely change) and it cannot be relied upon during times of calm because storage possibilities are limited.
} 
More specifically, they will try to avoid downswings in the aggregate return to investment (or - in the setting of the two previous chapters - upswings in the cost of installing and operating generation equipment) and therefore a portfolio approach is ideal to determine the optimal investment strategy. In order to account for the underlying dynamics, where technical change is typically embodied, we use an extended version of the vintage-portfolio model developed in Chapter 5 and expanded in Chapter 6 to allow for uncertainties in different cost items and different types of technical change. For the sake of realism and applicability to the UK electricity sector we add a number of other features here: emissions, demand uncertainty, the difference between peak and base load technologies, physical constraints for maximum installable capacity, and policy measures such as emission caps and the Renewables Obligation. This enables us to implement several important aspects of UK climate change policy.

Even though we are using a rather limited data set, ${ }^{6}$ our preliminary findings are roughly in line with current investment outlooks. Our finding that nuclear energy might serve as a bridge to a more sustainable electricity mix, for example, is not in contrast with the projections by the DTI (2007a). This is also consistent with the views of a rationally behaving, risk averse investor.

The chapter is further organized as follows. Since the relevant literature has already been reviewed in Chapter 2 and summarized and further analyzed in Chapters 5 and 6, we immediately proceed to the setup of our model in Section 7.2. Afterwards presenting the results, potential implications for policy makers are addressed before concluding.

\subsection{The Vintage-Portfolio Model}

\subsubsection{The Basic Framework}

The basic framework of the vintage-portfolio model is the same as the one described in the previous chapter. In other words, Equations 6.1 to 6.3 remain unchanged. The present value $(\mathrm{PV})$ of total cost is refined by a new term, however: ${ }^{7}$

$$
P V=\sum_{f} \sum_{t=0}^{\theta} e^{-\rho \cdot t} \cdot\left(\psi_{t, \theta}^{f} \cdot P_{t}^{f} \cdot \kappa_{t}^{f} \cdot Y_{t}^{t}+\sum_{v=0}^{t} Q_{t}^{f} \cdot \varphi_{v}^{f} \cdot X_{v, t}^{f}\right) .
$$

Equation (7.1) resembles Equation 6.4, but for the new term $\psi_{t, \theta}^{f}=1-\left(\frac{1-\delta^{f}}{1+\rho}\right)^{\theta-t+1}$, which reflects the share of initial investment outlays that can be regarded as the

\footnotetext{
${ }^{6}$ Data were assembled from different sources, such as Anderson and Winne (2004), the DTI (2007b), the EIA (2006), and some sources had be aggregated. Furthermore, data on technical change and fuel price growth projections are often only suggestive and even though they serve the purpose of illustrating our new method perfectly, we want to warn against mistaking the investment patterns we compute with our framework as an exact prediction.

${ }^{7}$ Typically, fuel and capital costs are the most important cost-items in electricity production. As we just want to illustrate our points, we continue to leave out other cost-items like maintenance for reasons of simplicity.
} 
discounted $^{8}$ flows of factor payments (i.e. interest and depreciation charges) for the years from $t$ until the end of the planning period. The rest of the notation and assumptions are unchanged from Chapter 6. Note that $Y_{v, t}^{f}$ will decrease due to depreciation, and it therefore limits actual output on a vintage $v$ at time $t$, i.e. $X_{v, t}^{f}$, in accordance with $X_{v, t}^{f} \leq e^{-\delta^{f} \cdot(t-v)} \cdot Y_{v}^{f} \cdot{ }^{9}$

In order to calculate the variance of the PV of total cost as given by (7.1), we have made several simplifying assumptions. The first one is that the (constant) discount rate also reflects the required internal net rate of return on investment. The second one is that forecasting errors are serially uncorrelated, and that (co)variances of the growth rates of fuel and investment prices, but also of the rates of fuel-saving and capital-saving technical change, are constant. In that case, it should be noted that for constant expected values of the growth rates of prices and capital and fuel coefficients, the first order approximation of Equation (7.1) is given by:

$$
\begin{aligned}
P V & \approx \sum_{f} \sum_{t=0}^{\theta} e^{-\rho \cdot t} \cdot \psi_{t, \theta}^{f} \cdot \tilde{P_{t}^{f}} \cdot \tilde{\kappa_{t}^{f}} \cdot Y_{t}^{f} \cdot\left(1+S_{t}^{f, \hat{P^{f}}}+S_{t}^{f, \hat{\kappa^{f}}}\right)+ \\
& +\sum_{f} \sum_{t=0}^{\theta} \sum_{v=0}^{t} e^{-\rho \cdot t} \cdot \tilde{Q_{t}^{f}} \cdot \tilde{\varphi_{v}^{f}} \cdot X_{v, t}^{f} \cdot\left(1+S_{t}^{f, \hat{Q^{f}}}+S_{t}^{f, \hat{\varphi^{f}}}\right)
\end{aligned}
$$

where $S_{t}^{f, \hat{P^{f}}}=\sum_{j=0}^{t} \varepsilon_{j}^{\hat{P}^{f}}, S_{t}^{f, \hat{\kappa}^{f}}=\sum_{j=0}^{t} \varepsilon_{j}^{\hat{\kappa}^{f}}, S_{t}^{f, \hat{Q}^{f}}=\sum_{j=0}^{t} \varepsilon_{j}^{\hat{Q}^{f}}$ and $S_{v}^{f, \hat{\varphi^{f}}}=$ $\sum_{j=0}^{v} \varepsilon_{j}^{\hat{\varphi}^{f}}$, and where $\varepsilon_{j}^{x}$ is the forecasting error associated with variable $x$ for time $j$. This is again similar to Equation 6.5 apart from the term including $\psi$.

Equation (7.2) can now be used to calculate the (approximated) expected forecasting error in the PV of total capital and fuel costs. Given that $N$ is the set of stochastic variables, i.e. $N=\{\hat{P}, \hat{\kappa}, \hat{Q}, \hat{\varphi}\}$, while $n_{1}$ and $n_{2}$ are "running" elements of this set, the expectation of its squared value will be equal to the total variance of $\mathrm{PV}$ :

$$
\operatorname{var}(P V)=\sum_{t_{1}=0}^{\theta} \sum_{t_{2}=0}^{\theta} \sum_{f_{1}} \sum_{f_{2}} \sum_{n_{1} \in N} \sum_{n_{2} \in N} \min \left(t_{1}, t_{2}\right) \cdot m_{t_{1}}^{f_{1}, n_{1}} \cdot \sigma_{f_{1}, n_{1}}^{f_{2}, n_{2}} \cdot m_{t_{2}}^{f_{2}, n_{2}},
$$

where $\min \left(t_{1}, t_{2}\right)$ represents the minimum of $t_{1}$ and $t_{2} . \sigma_{f_{1}, n_{1}}^{f_{2}, n_{2}}$ is the covariance between the growth rates of the different stochastic variables $n_{1}$ and $n_{2}$ for technology families $f_{1}$ and $f_{2} \cdot{ }^{10}$ The "terms" $m_{t_{1}}^{f_{1}, n_{1}}$ and $m_{t_{2}}^{f_{2}, n_{2}}$ are defined in terms of the actual control variables of the problem, i.e. investment in individual vintages of dif-

${ }^{8}$ These flows during the period $t \ldots \theta$ are discounted back until time $t$. The term $e^{-\rho \cdot t}$ then takes into account further discounting costs until the beginning of the planning period, i.e. time zero. Note that for an infinitely long horizon, the share would approach a value of 1 , whereas for a very short horizon - the shortest one possible being 0 for investment taking place in the first year after the planning period - the share is equal to zero. So, for $t$ approaching $\theta$, the share is falling towards zero. For further details see Appendix A.

${ }^{9}$ These inequality constraints are explicitly taken into account in the determination of the optimum technology portfolio.

${ }^{10}$ In the actual calculations we will assume that all covariances are equal to zero, as we have only relatively little data at our disposal to measure these covariances properly, and our immediate purpose is to illustrate the working of the model. This has the added bonus of considerably speeding up the calculations. We implement this by requiring that $n_{2}=n_{1}$ and $f_{2}=f_{1}$ for all values of $n_{1}$ and $f_{1}$. See Appendix B for further details. 
ferent technology families and the corresponding production plans for those vintages. Appendix B provides the calculations leading to Equation 7.3.

\subsubsection{Additional Features}

In order to increase the degree of realism of the model, we have included a number of new features into the basic framework of Chapter 6. First of all, it is not just prices and technical change that are uncertain in this model, but also demand is no longer assumed to be known with certainty. The risk of facing higher demand than expected, is captured by the introduction of two demand scenarios, a low demand scenario (1.5\% growth, which is the standard extrapolation of known trends) and a high demand scenario (2.5\% growth). Weighing both scenarios by their probabilities, we can determine the optimum value of investment that needs to be undertaken in order to be able to meet demand in all circumstances. The revised demand constraints thus look as follows:

$$
\sum_{f} \sum_{v=0}^{t} X_{v, t}^{f, s} \geq D_{t}^{s}
$$

where $D_{t}^{s}$ is the expected time path of demand under scenario $s$ and $X_{v, t}^{f, s}$ are the corresponding production plans.

Second, additional capacity may not be installed without bounds, as mentioned above. In the case of hydroelectric utilities, for example, the UK has almost reached maximum installable capacity, i.e. there are not enough suitable sites left to realize additional investments. Therefore, investment is constrained here by the estimates for maximum installable capacity. We have implemented this here by including the following physical constraints on aggregate renewable capacity per technology family:

$$
\sum_{v=0}^{t} Y_{v}^{f} \cdot e^{-\delta^{f}(t-v)} \leq M_{t}^{f} \quad \forall f \epsilon R^{\prime}
$$

where $M_{t}^{f}$ is the maximum value of aggregate capacity by technology family and $R^{\prime}$ is the set of renewables.

Third, there are differences across technology families with respect to their technical characteristics. While coal-fired turbines, for example, have capacity factors of $80 \%$ and more, wind energy and solar techniques depend on external circumstances, that do not allow them to produce electricity continuously, and can thus not be used to guarantee the coverage of peak loads. This leads to the following "effective capacity" constraint:

$$
X_{v, t}^{s, f} \leq e^{-\delta^{f}(t-v)} \cdot Y_{v}^{f} \cdot C F^{f}
$$

where $C F^{f}$ is the maximum capacity factor associated with technology family $f$.

Fourth, we make a distinction between base load and peak load technologies, where typically coal, nuclear and renewables are used for base load production, whereas gas 
can be used to meet peaks in demand. Therefore we impose:

$$
\sum_{f \in P L^{\prime}} \sum_{v=0}^{t} X_{t, v}^{f, s} \geq p l \cdot D_{t}^{s}
$$

where $P L^{\prime}$ is the set of technologies suitable for peak lead production (in our case only gas) and where $p l$ is the fraction of demand to be regarded as peak load demand. More precisely, Equation (7.7) is a production constraint, where the highest peak determines the required capacity peak load supply, and the average peak load size (amplitude and duration) determines cumulative production under peak load circumstances (and the corresponding partial underutilization of peak load capacity).

Fifth, by means of the Renewables Obligation, the UK government "promotes" the actual production of at least some electricity using renewable fuels. We want to include this as an explicit constraint in our model.

$$
\sum_{f \in R^{\prime}}^{t} \sum_{v=0}^{t} X_{v, t}^{f, s} \geq \gamma D_{t}^{s}
$$

where $\gamma$ is the minimum share of renewable energy in total demand, which was initially set at $10 \%$ by the government at the beginning of this decade, but which will probably become stricter judging from the new Energy White Paper (DTI, 2007a). ${ }^{11}$

Finally, as environmental concerns pertain for an important part to (cumulative) $\mathrm{CO}_{2}$ emissions, we have included these in the model, too. In this way we can see what the introduction of emission caps would mean for the technology composition of the electricity production portfolio and the timing of investment without further specifying the design of taxes or permit trading systems needed to realize such a cap. ${ }^{12}$ If total emissions are $e_{i, t}^{s}=\sum_{f} \sum_{v=0}^{t} \omega_{i}^{f} \cdot \varphi_{v}^{f} \cdot X_{v, t}^{f, s}$ with $\omega_{i}^{f}$ equal to emissions of type $i$ per unit of fuel consumption in technology family $f$, caps on emissions constrain emissions in the following way:

$$
e_{i, t}^{s} \leq \operatorname{cap}_{i, t}
$$

where cap $_{i, t}$ is some exogenously imposed time path for emissions of type $i$.

\subsubsection{Finalizing the Model}

For a given demand scenario, indexed by $s$, we assume that producers want to minimize a weighted sum of the expected PV of their total production cost and its corresponding variance:

$$
\phi^{s}=P V^{s}+\lambda \cdot \operatorname{var}\left(P V^{s}\right)
$$

\footnotetext{
${ }^{11}$ Of course, both Equation (7.4) and Equation (7.8) could have been formulated in terms of expected demand instead of maximum demand. However, this would not change the results. If anything, the current formulation makes the constraints more binding, which is not unrealistic in the face of UK efforts to intensify their renewables target, also for the sake of enhancing energy security.

${ }^{12}$ The interested reader is referred to Appendix B for the technical details regarding the formal implementation of these additional constraints on the technology portfolio.
} 
where $\lambda$ is the relative weight of the variance of the $P V$ of total costs in the objective function, as before. In fact Equation (7.10) is similar to Equation (6.7) except for the adjustment for the respective scenarios.

Given the scenario-specific values of the objective function, the ultimate criterion for the electricity investment program is the minimization of the expected value of the variance-adjusted costs of buying new and operating total (i.e. both new and old) capacity over the entire planning period, over all demand scenarios and over all technology families, i.e. minimization of:

$$
\phi=\sum_{s} \pi_{s} \cdot \phi^{s}
$$

subject to all the constraints mentioned above. In Equation (7.11), $\pi_{s}$ is the subjective probability of scenarios arising. ${ }^{13}$ Furthermore, $\mathrm{PV}^{s}$ in (7.11) is evaluated using (7.2) with all error sums set equal to zero in order to obtain the expected value of the PV of total cost. Equation (7.3) is used to evaluate $\operatorname{var}\left(P V^{s}\right)$. In short, producers are supposed to minimize (7.11) by choosing the optimum values of both initial vintage capacity, $Y_{v}^{f}$, per family $f$ for all vintages to be installed during the planning period, and a corresponding production plan in terms of $X_{v, t}^{f, s}$ as before. $Y_{v}^{f}$ and $X_{v, t}^{f, s}$ are chosen conditionally on the expected values and (co)variances of the stochastic variables in this setting. It should be noted that capacity decisions are not scenario-specific, whereas production decisions are. The reason for this is that capacity should be sufficient to meet demand in all of the scenarios, in part through ex post variations in the rate of capacity utilization.

\subsection{Simulation Results}

\subsubsection{Technology Characterization}

Before we describe the outcomes of the various experiments, we want to broadly categorize the various production technologies in terms of the growth rates and variances of their capital and fuel costs, but also in terms of the growth rates of their capital and fuel productivity and the corresponding variances. The technology characteristics are summarized in Table $7.1 .^{14}$

Such a characterization will be of help to interpret the results obtained in the various simulation runs described further below. It follows from Table 7.1 that the

\footnotetext{
${ }^{13}$ It should be noted that we could also introduce risk aversion at this level of decision making, by amending (7.11) to include the variance in $\phi^{s}$. For reasons of preserving tractability, we have not done this here.

${ }^{14} \mathrm{~A}$ more precise representation of the data set can be found in Van Zon and Fuss (2006). Most data have been taken from Anderson and Winne (2004), while the time series used to compute the growth rates and variances mainly stem from the DTI (DTI, 2006, 2007b). The growth and variance in $\kappa^{f}$ have been calculated by looking at newly installed capacity and the associated output, while the data for $\varphi^{f}$ is computed as the amount of fuel used to produce one unit of output.

${ }^{15}$ Due to lack of data the growth and variance of capital cost are assumed to be equal and low (1\%) for all technologies. $\mathrm{n} / \mathrm{r}$ is short for "not relevant". CF is the capacity factor.
} 


\begin{tabular}{lllllllll}
\hline & Coal & Gas & Nuclear & Hydro & Biomass & Biowaste & Wind & $P V$ \\
\hline$P^{f 15}$ & medium & low & high & medium & high & high & medium & high \\
$Q^{f}$ & medium & high & medium & $\mathrm{n} / \mathrm{r}$ & medium & low & $\mathrm{n} / \mathrm{r}$ & $\mathrm{n} / \mathrm{r}$ \\
$\hat{Q}^{f}$ & medium & high & low & $\mathrm{n} / \mathrm{r}$ & $\mathrm{n} / \mathrm{r}$ & $\mathrm{n} / \mathrm{r}$ & $\mathrm{n} / \mathrm{r}$ & $\mathrm{n} / \mathrm{r}$ \\
$\sigma_{\hat{Q}^{f}}^{2}$ & medium & high & low & $\mathrm{n} / \mathrm{r}$ & $\mathrm{n} / \mathrm{r}$ & $\mathrm{n} / \mathrm{r}$ & $\mathrm{n} / \mathrm{r}$ & $\mathrm{n} / \mathrm{r}$ \\
$\hat{\varphi}^{f}$ & low & medium & medium & $\mathrm{n} / \mathrm{r}$ & high & $\mathrm{n} / \mathrm{r}$ & $\mathrm{n} / \mathrm{r}$ & $\mathrm{n} / \mathrm{r}$ \\
$\sigma_{\hat{\varphi}}^{2}$ & medium & medium & low & $\mathrm{n} / \mathrm{r}$ & high & $\mathrm{n} / \mathrm{r}$ & $\mathrm{n} / \mathrm{r}$ & $\mathrm{n} / \mathrm{r}$ \\
$\hat{\kappa}^{f}$ & low & medium & low & low & high & high & high & low \\
$\sigma_{\hat{\kappa}}^{2}$ & low & medium & low & low & low & high & high & high \\
$\mathrm{CF}$ & high & high & high & medium & high & high & low & low \\
\hline
\end{tabular}

Sources: Anderson and Winne (2004), DTI (2006, 2007b) and EIA (2006).

Table 7.1: Characterization of Technology Families

combination of low capacity factors and medium to high capital costs are likely to make wind and photovoltaic generation unattractive substitutes for carbon-based technologies, but for the fact that they do not generate any $\mathrm{CO}_{2}$ emissions. In addition to this, wind has a high variance in capital-saving technical change because the data also take into account the less mature offshore wind technologies. Biomass/biowaste has similar cost properties as wind and photovoltaics, but the prospects of cost-savings through technological change are more positive than for wind and photovoltaic generation. This also applies for the capacity factor that is an important determinant of the effective contribution of capital costs to total costs. Hydropower is an established technology in the sense that there is little or no (capital-saving) technical change, but also little variance in the same. Nuclear energy is a relatively secure technology with respect to technical change, which is relatively slow but certain. This counteracts to some extent the high capital costs, next to relatively low fuel costs and low variance in the price-growth of nuclear fuels. ${ }^{16}$ The latter does not hold for gas, which also suffers from high capital costs. Therefore, gas can be expected to have a relatively low share a priori. Also, even though technical change is relatively fast, it remains relatively uncertain. However, with a $\mathrm{CO}_{2}$ emission cap, and given the fact that gas is a peak load fuel, the share of gas in total electricity production must remain significant. Finally, coal is an "intermediate" type of fuel with medium capital and fuel costs and medium or low rates of technical change and variances of those rates.

\footnotetext{
${ }^{16}$ Please note again that this analysis refers exclusively to technical and fuel price risks, while the share of nuclear power plants in the national energy mix will always be influenced by considerations of safety risks, decommissioning factors, nuclear waste disposal difficulties and political commitment. Since our primary focus are technological and fuel price features, we abstract from these risks, but keep in mind that they will probably have an adverse effect on the adoption of nuclear technologies.
} 


\subsubsection{Simulation Runs}

In the following subsection we first describe the base run, i.e. the outcomes associated with the investment program for a planning period of 30 years that fits all the constraints that were described in more detail before, except that it does not contain a $\mathrm{CO}_{2}$ emissions cap yet. The base run has been performed with a value of $\lambda=0$ implying that the variance of the cost of the entire investment program is not an issue. The base run results are labeled $\mathrm{R} 0$ and they are discussed in more detail below. There are four other runs, called R1-R4 that have the same parameter setting as the base run with $\lambda$ equal to $0.000015,0.00003,0.000045$ and $0.00006{ }^{17}$

The results associated with these runs are presented further below. They show how increasing risk aversion influences the optimum composition of the capital stock in terms of technology families. Furthermore, we present a run that is based on a value of $\lambda=0.000015$, i.e. $\mathrm{R} 1$, and on a $\mathrm{CO}_{2}$ emission cap defined by the emission path that grows at a constant proportional rate from a level of $150 \mathrm{MtCO}_{2}$ to a level that is about $25 \%$ lower than in R0 at the end of the planning period, i.e. to a level of $(1-0.25) \cdot 350=245 \mathrm{MtCO}_{2}$. Section 7.3 .3 contains run R6 with $\lambda=0.000015$ and twice the expected variance in the growth rate of gas prices, from the beginning of the planning period. Finally, Section 7.3.4 contains the results of run R7 that pertains to a large shock in the variance of the rate of fuel-saving technical change for nuclear energy. We do this to see whether renewables could take over, more or less on their own, from nuclear energy under these circumstances.

\section{The Base Run}

These are the results for the base run, disregarding the variance in fuel prices and rates of technical change by setting $\lambda=0$. For the low growth (1.5\%) demand scenario $(S 1)$ and the high demand growth $(2.5 \%)$ scenario $(S 2)$, we have plotted the actual production shares for both scenarios, as obtained in the base run.

In both scenarios, we start out with the same distribution over technologies in the beginning. However, it is clear that gas-based generation takes over to meet the additional demand in the case of the second scenario. This increased production from gas-based electricity generation goes at the expense of coal-fired capacity, but also of hydropower and nuclear energy by a smaller margin. This can be explained by the fact that gas has the lowest investment prices and can be installed at less additional cost than any of the other technologies. This more than outweighs the disadvantage of being more expensive in terms of fuel, since the high demand scenario has a much lower probability of occurring than the standard scenario $S 1$. Indeed, gas is also a peak load fuel, and as such its higher share in $S 2$ is not very surprising.

In Figures 7.5 and 7.6 we present the underlying capacity composition. Without any risk aversion, the weight of the variance in the objective function is equal to zero. In other words, all technologies become perfect substitutes, with gradually evolving

\footnotetext{
${ }^{17}$ It should be noted that at a value of $\lambda=0.000015$, which might seem low at first glance, the standard deviation of total costs relative to total costs is of the order of $10 \%$, which looks like a reasonable order of magnitude a priori.
} 


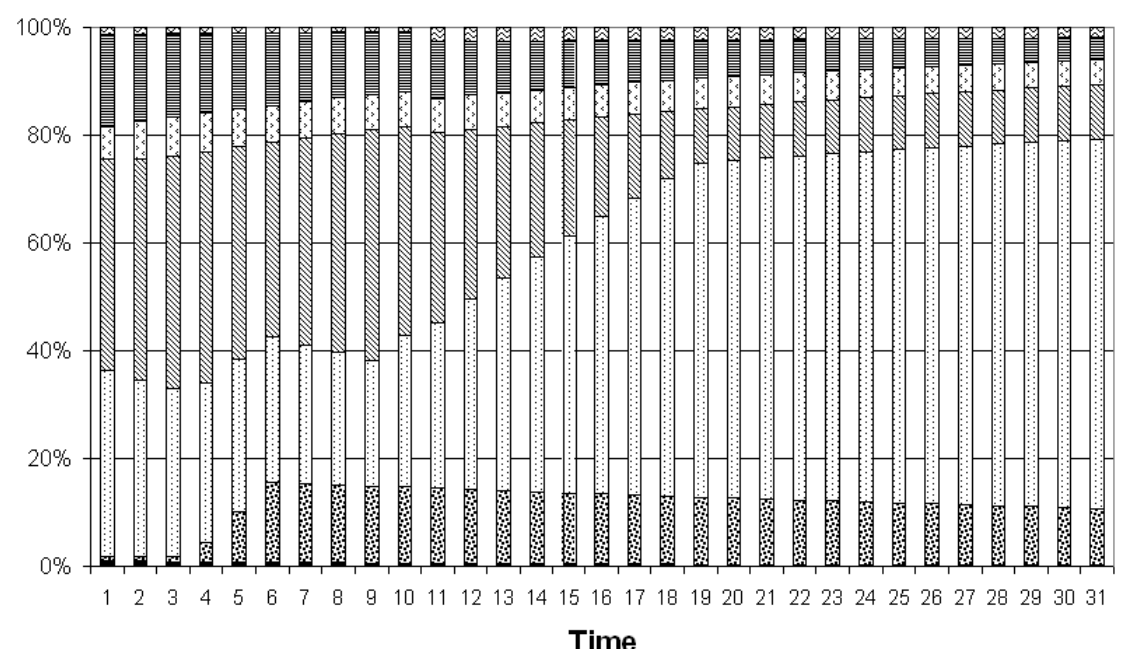

Time

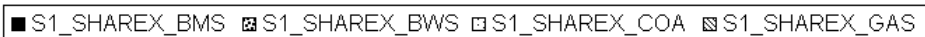

QS1_SHAREX_HYD 目S1_SHAREX_NUC 口S1_SHAREX_PHV 四1_SHAREX_WND

Figure 7.3: Production Shares for the First (Low) Demand Scenario

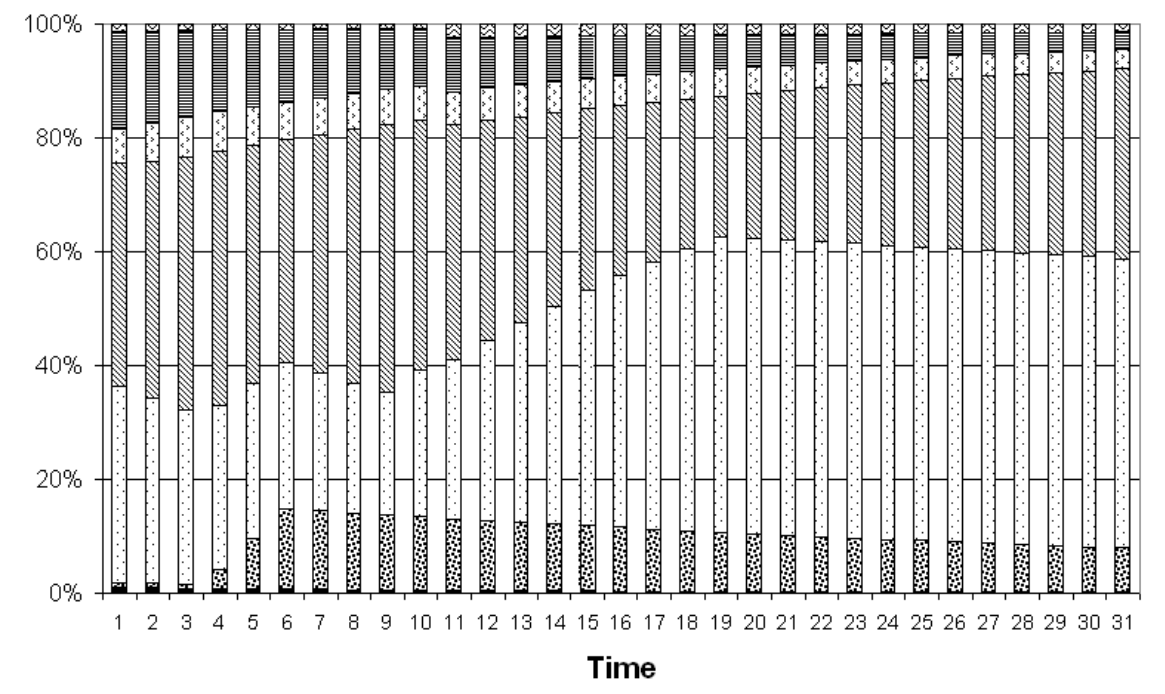

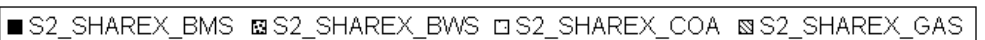
GS2_SHAREX_HYD 目S2_SHAREX_NUC םS2_SHAREX_PHV 四2_SHAREX_WND

Figure 7.4: Production Shares for the Second (High) Demand Scenario

costs characteristics per fuel technology driving the intertemporal variations in the composition of the technology portfolio. Total unit costs evolve according to increases 
in investment and fuel prices, but may also shrink as a result of either capital- or fuel-saving technical change. Other features that matter in this respect are related to constraints on maximum installable capacity, peak and base load characteristics and initial conditions (i.e. production using old vintages may continue as long as variable (fuel) costs are lower than total unit costs on new vintages (this is essentially Malcolmson's scrapping condition, cf. Malcolmson, 1975).

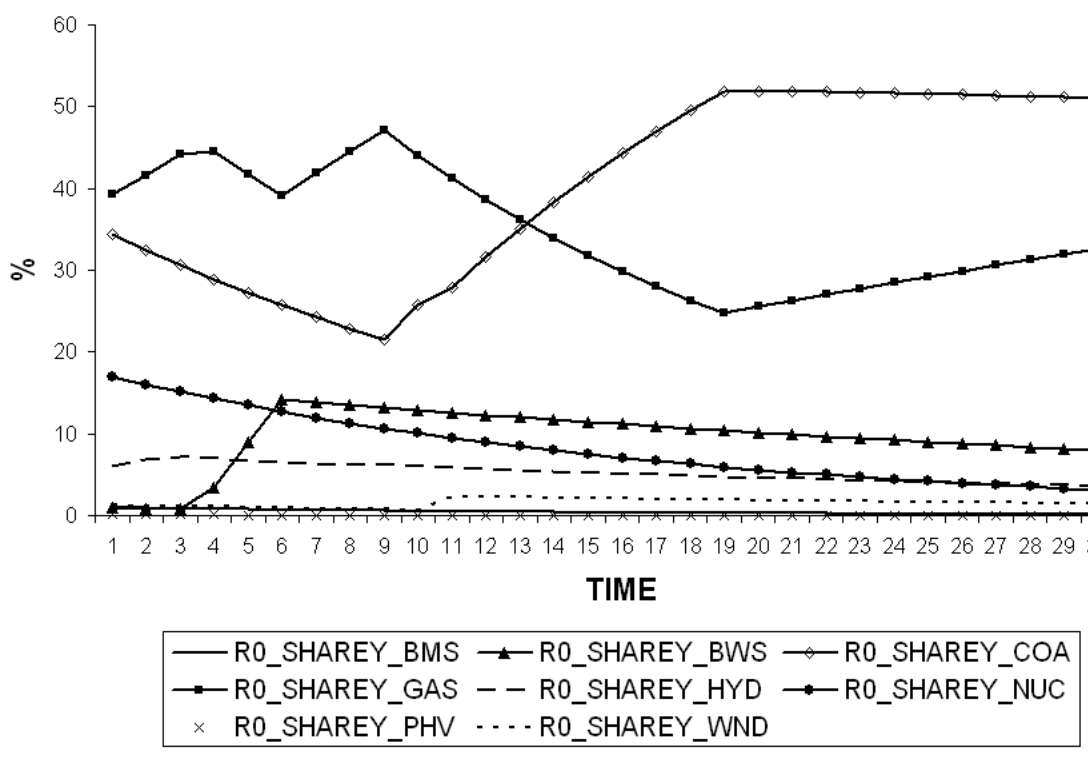

Figure 7.5: Development of Capacity Shares

Figure 7.5 illustrates the points made above more clearly. Without risk aversion, the technologies are perfect substitutes to the extent that one consistently invests in the cheapest alternative, when the PV of total unit costs for one technology falls below those of another one. In the beginning gas and hydro are the only technologies that undergo some investment, which is observable from their increasing capacity shares. The other technologies actually see a decrease in their capacity shares, which is due to depreciation, so there is no net investment in those technologies.

One may wonder why wind and biomass do not constitute a higher share of capacity here. This is in part due to the constraints that we have imposed on these technologies (and also hydro). Since it has not proven economically viable to import biomass, while domestic supplies will be limited in the future, we have applied an upper bound on the use of this technology. Investment in wind occurs after technical change has sufficiently reduced capital costs. However, the share stays rather constant afterwards, for the reason that we have excluded the much more expensive alternative of offshore wind turbines in this analysis, even though it becomes more and more infeasible to build 


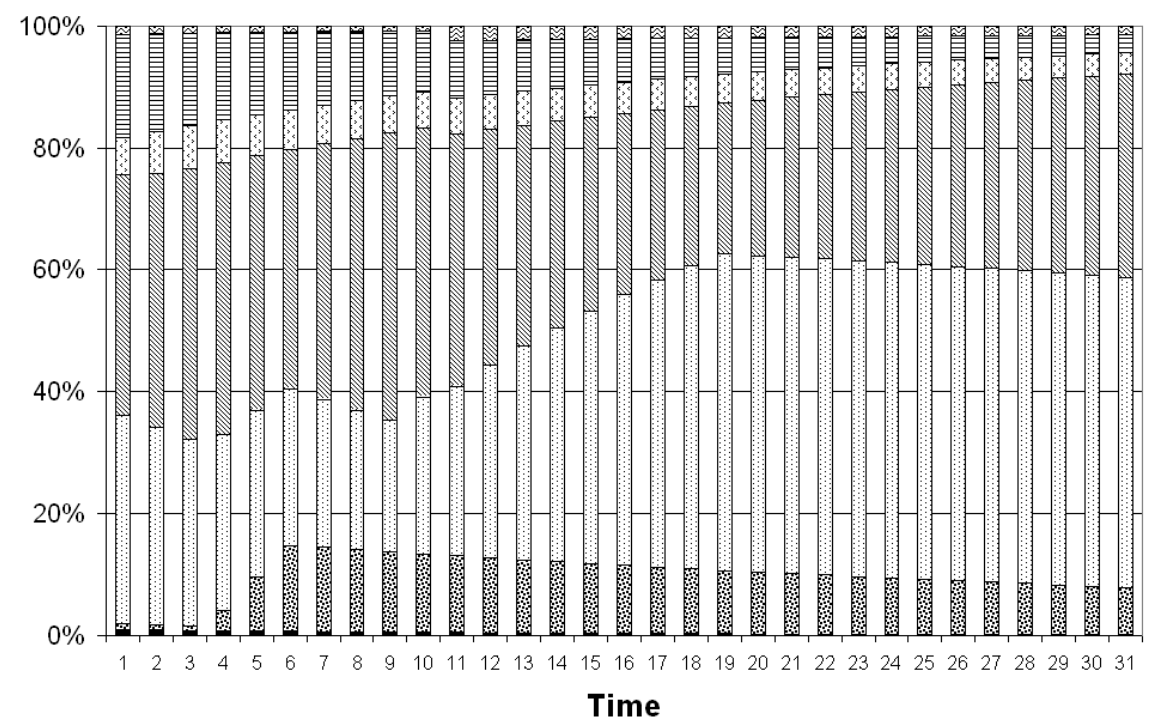

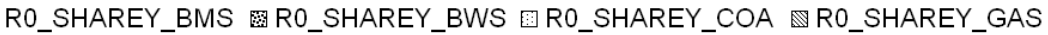

QRO_SHAREY_HYD 目RO_SHAREY_NUC $\square$ RO_SHAREY_PHV 图RO_SHAREY_WND

Figure 7.6: Composition of Capacity

additional large-scale wind farms onshore, especially in the more densely populated areas of the UK.

This leaves us with the composition of electricity generation equipment shown in Figure 7.6. Overall, we can say that gas still constitutes the major share of the electricity mix, followed by coal, whereas wind and biowaste have gained at the expense of nuclear power, hydropower, biomass and solar photovoltaic generation.

\section{Introducing Risk Aversion}

In this section we present the results of introducing increasing risk aversion. Figure 7.7 displays the relation between variance and cost. We can draw five conclusions from its shape: (1) The variance falls with increasing cost. (2) The variance is convex in costs. (3) The variance-cost profile defines the set of all (cost-)efficient portfolios. (4) The point of tangency between the variance-cost profile and the objective function determines the optimum portfolio. (5) Greater risk aversion makes the objective function flatter, i.e. there is a tradeoff between lower variance and higher total cost. These results are quite intuitive from a standard portfolio point of view and show that a portfolio approach combining irreversible investment and embodied technical change still generates the type of results known from "standard" financial portfolio theory as introduced in Chapter 2.

In Figures 7.8-7.10 we show what happens to the shares of coal, gas and nuclear in total capacity output, as the reduction in variance can essentially only be brought 


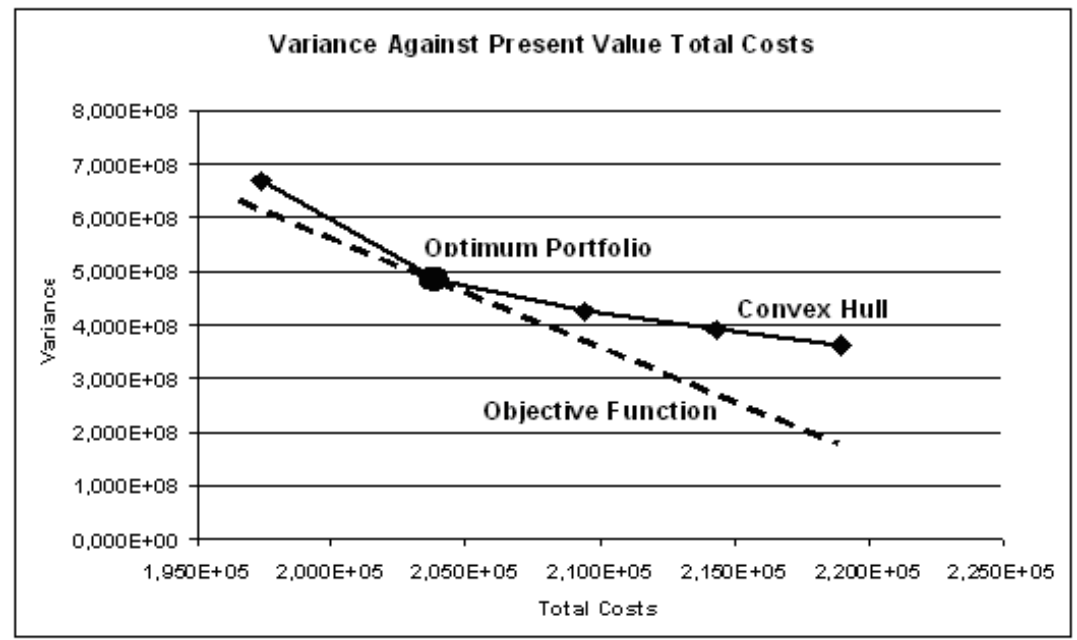

Figure 7.7: Variance against Cost

about by a reshuffling of the technology portfolio and the associated production plans. In Figure 7.8 one can see that the swings in the share of coal during the base run are stretched out more evenly over time. Shares are lower at the end of the planning period and higher at the beginning. For gas, shares fall structurally below the base run in the beginning, picking up at the end again, thus also leveling out fluctuations in shares to some extent. However, one should recall that gas is a technology with a relatively high variance both with respect to fuel price growth and with respect to technical change. Hence, while smoothing out fluctuations is always a good strategy to decrease the variance, reducing the portfolio shares of high variance technologies is especially good tactics in this particular case. In Figure 7.9 we see both principles at work.

Figure 7.10 shows that risk averse investors would gladly accept nuclear power as a "bridge" to a relatively carbon-free future. Of course, concerns about the negative externalities associated with $\mathrm{CO}_{2}$ emissions should be weighed against the legitimate concerns about the processing and quasi-permanent storage of nuclear waste material, and the threats of micro-proliferation amongst terrorist groups. Nonetheless, nuclear energy is widely regarded as a means to buy time to find the ultimate solution to our energy problems through carbon capture and storage from fossil-fuel-based generation in combination with a more intensive use of renewables. Note from Figure 7.10 that the lower the degree of risk aversion, the later the moment in time within the planning period, at which people are starting to "build the bridge". However, one should note that they may want to postpone building such a bridge or abandoning it altogether if the risks involved in decommissioning nuclear power plants would also be taken into account, for example by introducing uncertain dismantling costs. 


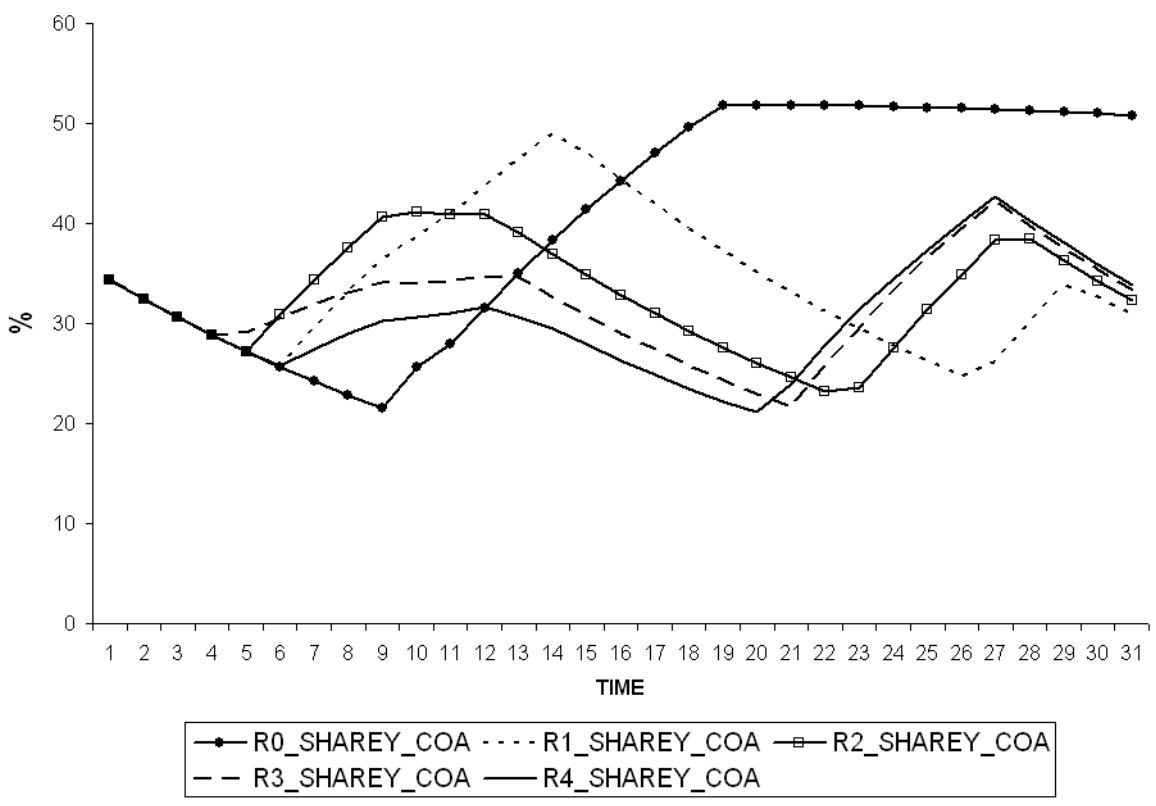

Figure 7.8: Capacity Shares Coal

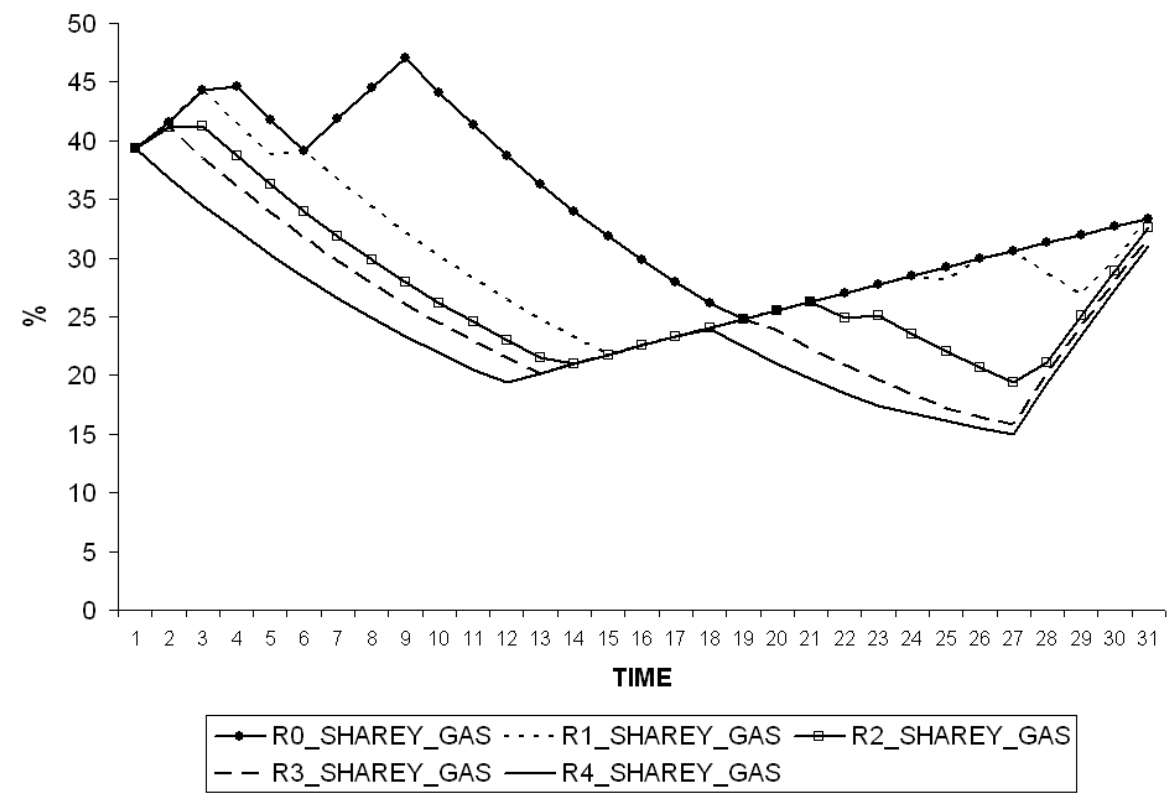

Figure 7.9: Capacity Shares Gas 


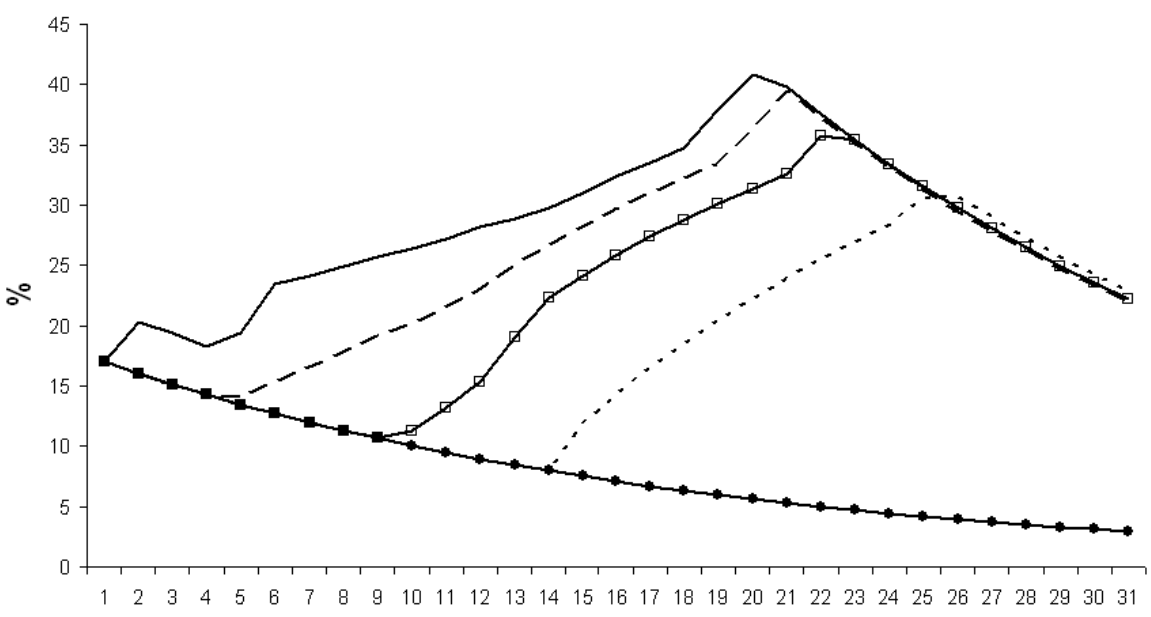

TIME

$\rightarrow$ - R0_SHAREY_NUC $\cdots \cdot-\mathrm{R} 1$ _SHAREY_NUC $\rightarrow-\mathrm{R} 2$ _SHAREY_NUC
$--\mathrm{R} 3$ _SHAREY_NUC $-\mathrm{R} 4$ _SHAREY_NUC

Figure 7.10: Capacity Shares Nuclear

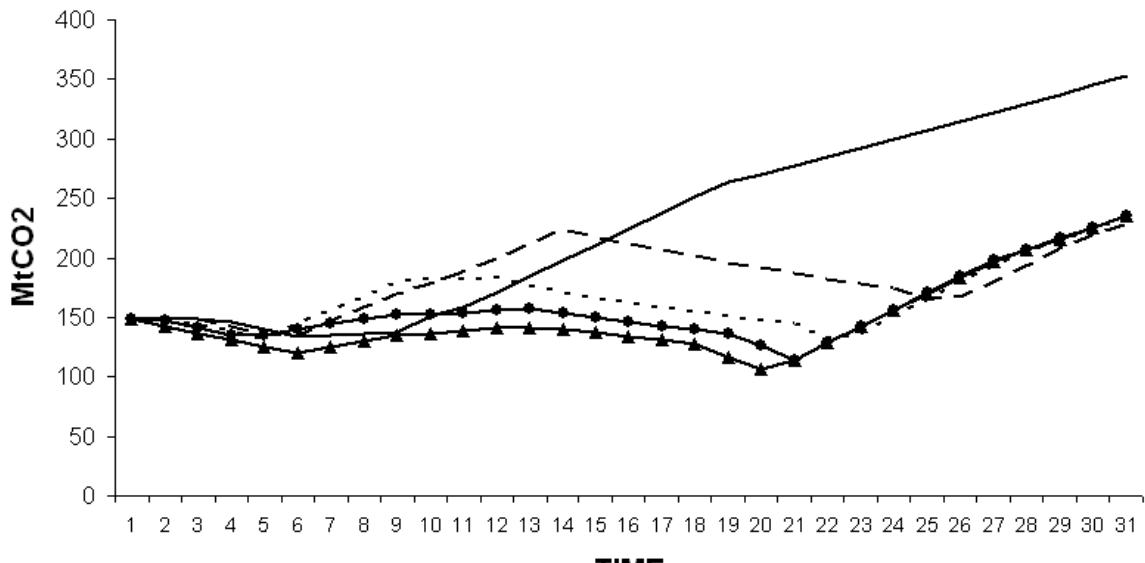

TIME

-RO_AVEM_CO2 - - R1_AVEM_CO2 - - - R2_AVEM_CO2

$\rightarrow$ R3_AVEM_CO2 —R4_AVEM_CO2

Figure 7.11: Emissions

In Figure 7.11 we show the emissions corresponding to all runs. The Figure contains the probability-weighted averages of total emissions in both demand scenarios $S 1$ and $S 2$. The one in the base run (R0) generates the highest emissions at the end of the planning period, mainly because coal is still an important portfolio ingredient 
by then. This is shown quite clearly in Figure 7.11, where fluctuations in emissions follow those in the share of coal in total capacity quite closely (cf. Figure 7.8).

\section{$\mathrm{CO}_{2}$ Emission Caps}

We now combine R1 (for $\lambda=1.5 \cdot 10^{-5}$ ) with a cap on $\mathrm{CO}_{2}$ emissions. It should be noted on beforehand that even a relatively slight degree of risk aversion generates a reshuffling of the technology portfolio such that in R0, emissions at the end of the planning period are significantly lower than emission levels in the base run (by more than 25\%). This means that our time path for emissions - beginning at $150 \mathrm{MtCO}_{2}$ and ending at $(1-0.25) \cdot 350=245 \mathrm{MtCO}_{2}$ - will not be binding at the end of the planning period (see also Figure 7.11). However, it will be binding in the middle of the planning period, as we can see quite clearly from Figure 7.12 , in which the flat stretch of emissions for run R5 coincides with the emissions constraint being binding. How the corresponding emission reductions are brought about can be seen from the capacity composition in Figure 7.13.

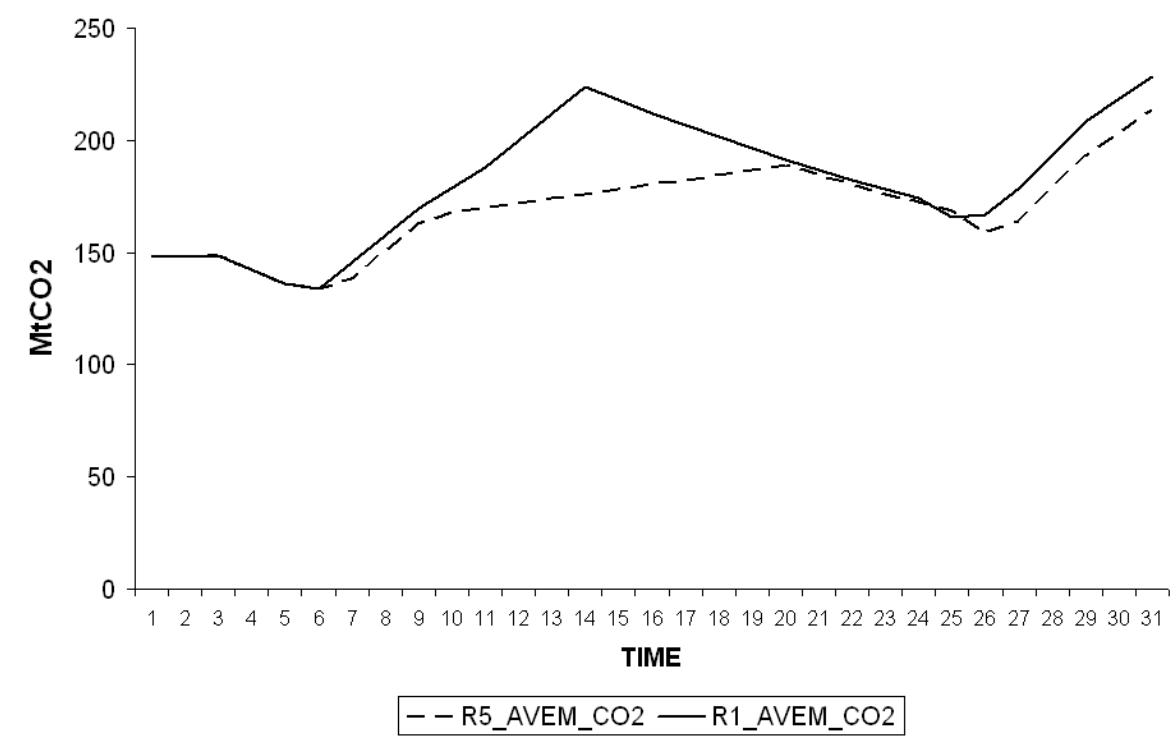

Figure 7.12: Emissions With a Cap on $\mathrm{CO}_{2}$

Figure 7.13 shows the absolute differences between the percentage capacity shares in runs R5 and R1. The carbon content of electricity production is decreased in period 6 through a simultaneous reduction in coal and an increase in gas. The more binding the $\mathrm{CO}_{2}$ emission cap becomes, the more additional carbon-free capacity is installed in this case nuclear power. Then, as emissions are reduced anyhow from period 15 on (see Figure 7.12), the technology distribution of power production almost reverts to normal - except for the fact that the share of nuclear energy is slightly above the base run, and those of gas and coal are correspondingly lower. This also leads to slightly 
lower emissions at the end of the planning period, simply because once nuclear has been installed it will remain for a relatively long time, since capital costs are sunk in the beginning and old technologies are replaced by new ones only if the total unit costs of the new technologies drop below the unit variable cost of the old technologies.

We see therefore that a temporarily binding emission constraint can induce semistructural emission reductions because the composition of the capital stock changes. In addition, due to the ex post clay character of technologies themselves, the capital stock only slowly adjusts to a situation where the caps are no longer binding. ${ }^{18}$

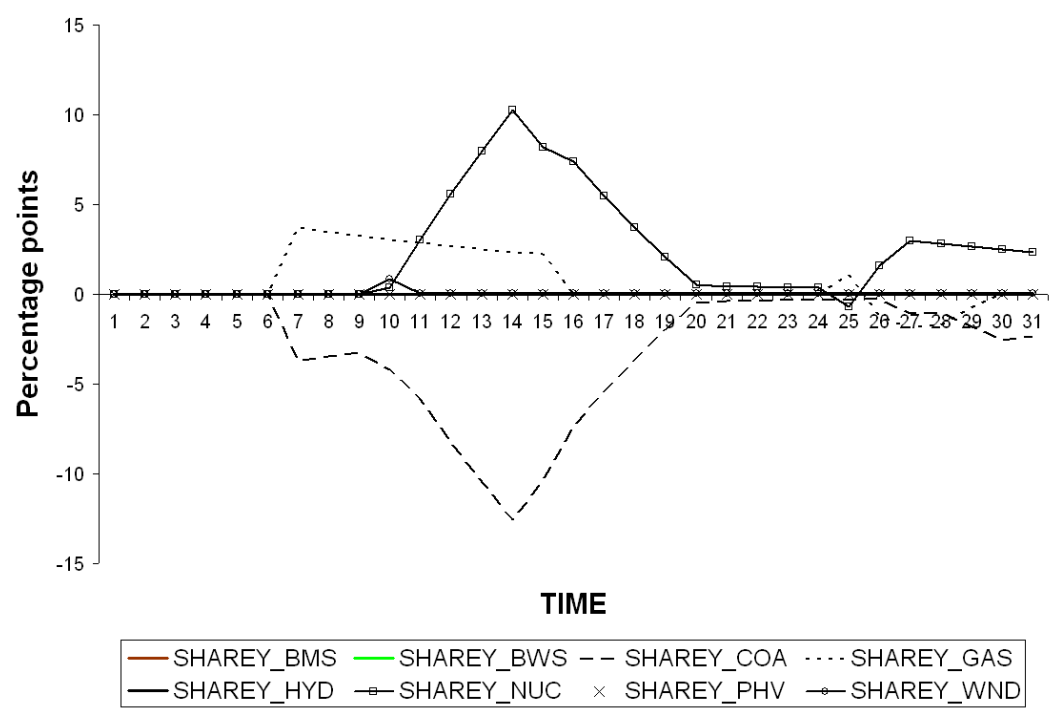

Figure 7.13: Differences Between Capacity Shares in R5 and R1

\subsubsection{Fuel Price Variance}

In experiment R6 we increase the variance of fuel price growth by $100 \%$ for gas $(\lambda=$ 0.000015). In order to see what such an increase implies, we have to compare runs R6 and $\mathrm{R} 1$, since in the latter case we do not have any $\mathrm{CO}_{2}$ emission caps either. The absolute differences between capacity shares are presented in Figure 7.14.

It can be observed that the increase in gas price growth variance significantly reduces the portfolio share of gas. Biowaste and later on also coal take over, and after a slight dip in the middle of the planning period - nuclear energy is phased in as well. At the end of the planning period, gas has become a very unattractive portfolio component indeed, and coal and nuclear energy have taken over completely.

\footnotetext{
${ }^{18}$ This adjustment of the capital stock is occurring as quickly as technically feasible, since the optimization program "knows" when the $\mathrm{CO}_{2}$ emission constraints will become nonbinding and can adapt ex ante to this situation.
} 


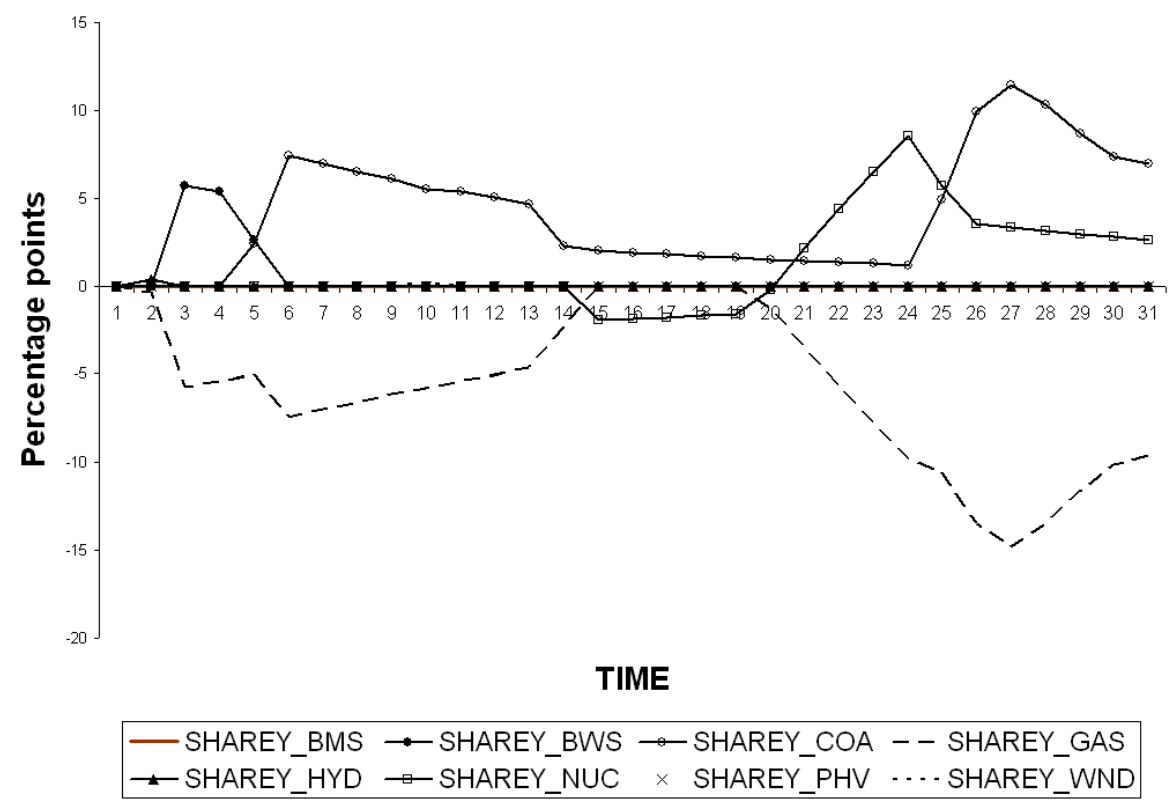

Differences Between Capacity Shares in R6 and R1

Figure 7.14: Effect of Larger Fuel Price Variance

\subsubsection{Increases in Technological Variance}

For technological uncertainty to have the largest possible impact, it is necessary to implement it as increased variance in the rate of fuel-saving technical change, as fuel consumption associated with a specific vintage is a continuous process, whereas investment takes place only at the moment of installation of that vintage. We have chosen nuclear energy for increased uncertainty with respect to technological change, first of all because controlled fusion has been a technological promise for over 50 years - and it still is. The second reason is that in our simulations, nuclear energy consistently appears to be the "savior of last resort". This leads us to wonder whether renewables would stand a chance to take over this role if nuclear energy would become less attractive for some reason. ${ }^{19}$ In order to shed more light on this issue we have performed an experiment, in which we have increased the variance of fuel-saving technical change in nuclear energy production by a factor of $100 .{ }^{20}$

Run R7 is the same as R1, except for the shock in the variance of fuel-saving technical change. The results are presented in Figure 7.15. We see that the change in the variance of technological progress in nuclear energy production, although implemented from the beginning of the planning period, takes a while before it has an impact. This

\footnotetext{
${ }^{19}$ That could also happen through security risks or other channels that we have not included here, of course.

${ }^{20}$ Since fuel costs are relatively unimportant in nuclear energy production as compared to coal- and gas-fired power plants, we need a relatively large shock for its effect to become noticeable.
} 
is due to the fact that nuclear had not been invested in during the first half of the planning period in R1 in the first place. Only from the period onward, where there was investment in nuclear in R1 (i.e. in year 14), do we see a negative deviation from the results with respect to $\mathrm{R} 1$ therefore. Also note the negative deviation in coal before period 14, which is compensated by an increase in gas capacity. Since investors are fully aware of the drop in nuclear at the beginning of the planning period already, and they know that they will have to compensate this drop by investing more heavily in coal, they actually have an incentive to decrease their installed capacity of coal earlier on because this will enable them to install a larger amount of more modern and productive vintages when the time has come to replace nuclear capacity. In other words, by reducing the share of coal earlier on, investors create room for more advanced capacity later on. The gap is closed by gas, since gas has relatively low capital cost and can therefore easily make up for the lack of coal in the short run. It should be noted that this is perfectly inline with what we have found in the previous two chapters for the impact of uncertainty on investment; only the extended model and inclusion of more diverse technologies opens up more opportunities for the investor and triggers interaction effects of the kind just observed: now it is more beneficial to immediately decrease the share of nuclear in response to larger uncertainty rather than waiting to do so and to decrease investment into its substitute earlier, so that more of the modern vintages can be installed later on.

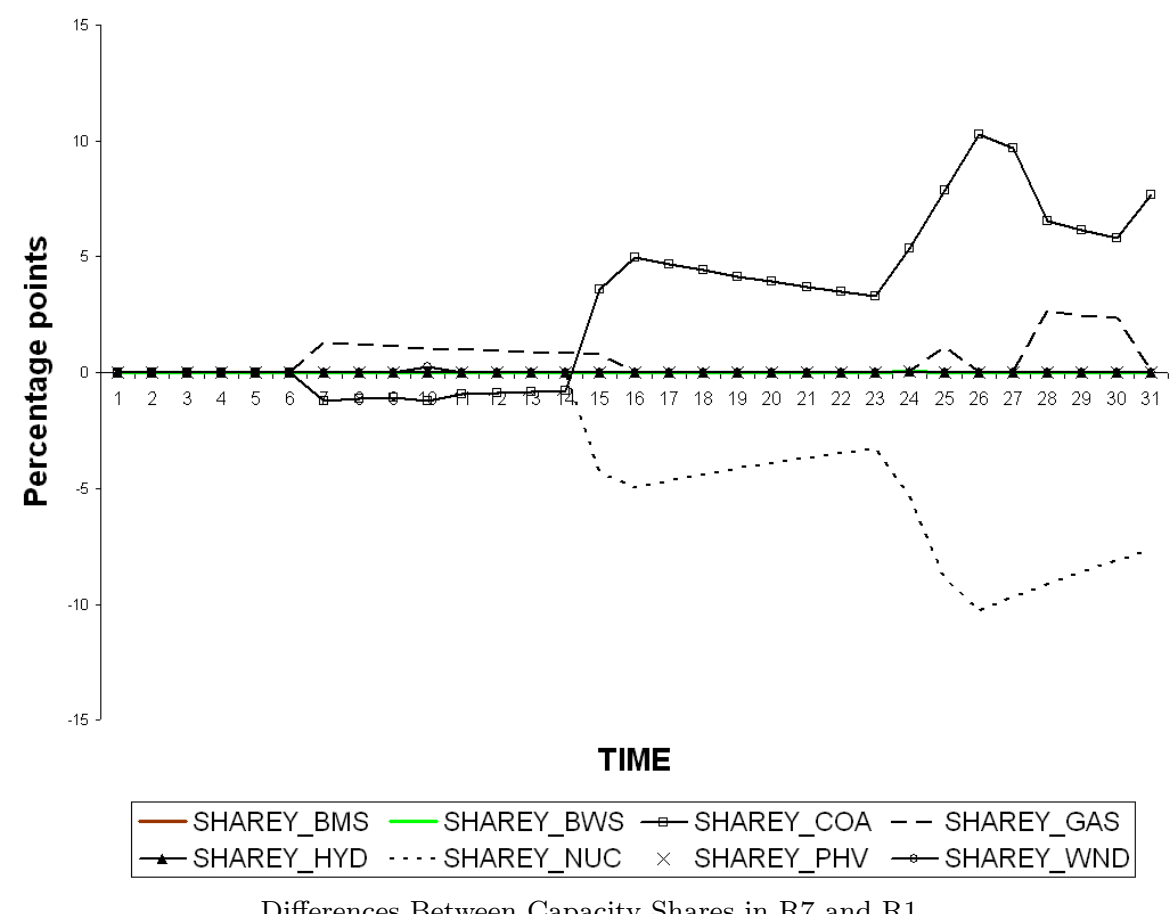

Differences Between Capacity Shares in R7 and R1

Figure 7.15: Effect of Larger Technological Variance 
This experiment is a good illustration of the mechanisms of the model, not only in the technology dimension (i.e. diversification over technology families leads to substitution of coal for nuclear, which becomes less attractive through less certain prospects of technical change), but also in the quality or vintage dimension: it pays off to wait for ongoing technical change to take place and reap the full benefits of being able to install and operate higher quality vintages when investment becomes necessary and thus to substitute investment in coal today for investment in coal at a later point in time.

\subsection{The Cost of the Renewables Obligation}

What has not been analyzed so far is the cost, at which a measure like the Renewables Obligation comes. It is very likely that producers will pass on the extra costs that they need to incur in order to meet the target to end consumers, so both industry and households will eventually face higher electricity prices as a result.

The new Energy White Paper (DTI, 2007a) itself states that the "[...] proposals for changes to the Renewables Obligation [...] could add extra costs to final consumer bills. [...] the impact of the proposed changes to the Obligation could increase electricity prices by around $2 \%$ in 2020, compared to the existing regime." (page 289). We therefore also want to investigate the magnitude of effects from increasing the quota beyond $10 \%$ in our framework.

To do so, we increase the Renewables Obligation by $1 \%$ and compare the results back to the base run in order to compute the extra costs that this would impose on producers and thus eventually on end consumers. What we observe is that total costs do indeed exceed base run costs by more than 35 million dollars in both demand scenarios. However, when we look at the variance of the portfolio, we see that the $11 \%$-portfolio has a lower variance than the $10 \%$-portfolio. This is due to fact that more renewables in the energy mix always also imply less variance from volatile fuel prices in the generating cost part. Therefore, the value of the objective function is overall higher for the 11\%-portfolio, but less so than would have been the case if the variance had been disregarded. Moreover, from the point of view of the country as a whole, a larger share of renewables also entails enhanced energy security because it makes the country's portfolio less dependent on fossil fuels. This is another point the Energy White Paper (DTI, 2007a) emphasizes in various contexts.

Even though there are apparently advantages to increasing the Renewables Obligation, however, the UK realizes that the costs to end consumers cannot be ignored. In addition to the Renewables Obligation, other measures like joining the European Trading Scheme for $\mathrm{CO}_{2}$ permits will exert further upward pressure on electricity prices and consumers and industry need to be compensated for this in other areas, although not many proposals have been advanced to that matter so far. 
Extended Vintage-Portfolio Approach to Electricity Investment \& Climate

Change Policy in the UK

\subsection{Summary and Conclusion}

In this chapter we have presented the outcomes of some simulations with an extended version of the model developed in the previous two chapters. As before, it integrates elements from optimum financial portfolio theory with a clay-clay vintage model of production for the electricity sector. The main novelties in this chapter's model version are the introduction of demand uncertainty through high and low demand scenarios that are realized with different probabilities, the addition of load profiles (peak load versus base load technologies), the inclusion of capacity factors and physical constraints on production capacity, the integration of cumulative emissions from electricity generation, accompanied by an emissions cap, and finally the allowance for a minimum share of renewables as suggested by UK policy.

These extensions add significantly to the realism and applicability of the vintageportfolio framework. In particular, it enables us to analyze existing trends in UK climate change policy, which is nowadays exerting much more influence on investors in the electricity sector than before. To achieve the goal of increasing the percentage of renewables in the energy mix and curtail emissions in order to bring the rise of cumulative emissions to a halt, so that potentially dangerous effects can be dampened and/or avoided, an ambitious policy framework has been set up, including the socalled Renewables Obligation analyzed in this chapter. While we have focussed here on a cap on overall emissions, it is important to note that such a cap will be realized through a permit trading system. This implies that the price of a permit and thus effectively the price of $\mathrm{CO}_{2}$ will become asource of uncertainty as well. Such $\mathrm{CO}_{2}$ price uncertainty has been analyzed in detail in Chapter 3 with the help of a real options model, but could easily be implemented in a further extension of the vintage-portfolio model, which could then also be reformulated to include electricity prices to allow for the possibility that $\mathrm{CO}_{2}$ price spikes can (partially) be passed on to consumers (see e.g. Reinard, 2007).

Using the present version of the vintage-portfolio model, we distinguish between eight broad technology families, i.e. coal, gas, nuclear, hydro, biomass, biowaste, wind and photovoltaic generation. We have performed a number of simulation experiments. In particular, we find that in the base run without any risk aversion, carbon emissions in the UK electricity sector range from about $150 \mathrm{MtCO}_{2}$ at the beginning of the planning period to $350 \mathrm{MtCO}_{2}$ at the end of the planning period. For an increasing degree of risk aversion we find that expected costs will rise as well, whereas the expected cost variance of the entire vintage investment program will decrease. The corresponding standard deviation as a fraction of the expected costs also decreases. However, this effect diminishes for an increasing degree of risk aversion. As in financial optimum portfolio theory, we find that the relation between the costs of the entire investment program and the corresponding variance exhibits decreasing returns to variance: a larger variance generates a less than proportionally higher rate of return in "ordinary" portfolio theory, and in our case a less than proportionally smaller expected cost of the investment program.

With respect to changes in fuel price growth variances or technological variances 
the effects are much more complicated to interpret than in our simple and illustrative examples in Chapters 5 and 6 . The effect of technological variance now opens up more opportunities than merely postponing the decrease in the concerned technology's portfolio share. Furthermore, increased risk aversion reduces fluctuations in investment over time, as expected. We find that with increased risk aversion, electricity production becomes more diversified over technologies to such an extent even that carbon emissions would be significantly reduced, mainly by switching towards nuclear energy production, rather than towards renewables. ${ }^{21}$

When introducing a cap on $\mathrm{CO}_{2}$ emissions, nuclear energy turns out to be the "savior of last resort", but also gas increases in importance. "Punishing" nuclear energy production by increasing its technological variance leads to gas and coal taking over, rather than renewables gaining a higher share. We also find that the anticipation of a switch towards another technology in the future makes producers want to invest less in that technology now and more in a substituting technology. In this way, they can benefit more from the cumulative nature of (ongoing) embodied technical change at the moment they will actually execute the switch, which is plausible given the theoretical insights gained in Chapters 5 and 6 . Nonetheless, the fact that gas and coal will take over from nuclear energy in this case, suggests that - given the admittedly crude data set we have been able to use - none of the renewables is strong or promising enough ${ }^{22}$ to take over from nuclear or coal in the medium term on its own. This implies that the conclusions drawn in the first part of the thesis - namely that large $\mathrm{CO}_{2}$ reductions can only be attained through the help of active policy support such as $\mathrm{CO}_{2}$ taxes, permit trading, subsidies for low-carbon technologies, etc - are also confirmed from the point of view of the new model.

For further research - that also extends beyond the UK case - it would be important to obtain a data set that also includes the prospects for technologies with carbon capture and storage possibilities, since it remains questionable whether countries possessing large fossil fuel resources will decline to use these and switch to renewables instead.

\footnotetext{
${ }^{21}$ However, the level of risk aversion would need to be rather high for such a result to become possible, so we cannot regard this as a very likely scenario.

${ }^{22}$ Some renewables such as hydropower are advanced enough to take up a larger share of electricity production; however, hydropower is severely constrained through geographical feasibility in the UK.
} 


\section{Appendix A: Irreversible Investment \& Capital Cost Adjustment with a Finite Planning Horizon}

The assumption of a finite planning period implies that capital goods installed at the end of the horizon are used for shorter periods of time than those installed at the beginning, ceteris paribus. In terms of total costs, fuel costs will have a relatively large impact on vintages installed at the beginning of the planning period, while capital costs will mainly affect vintages installed later. This depends on the notion that all capital costs have to be expended at the time of the installation of the concerned vintage. This is legitimate in case of an infinite lifetime of equipment (and hence an infinite planning horizon) and if the interest and the discount rate match. In that case the PV of all interest and depreciation charges adds up to total initial investment expenses. We can thus simply assume that the total PV of interest and depreciation charge over the remaining part of the planning period for a vintage installed at some point in time during the planning period will represent the relevant (as opposed to total) capital costs associated with the vintage under consideration. This assumption removes the bias against installing relatively capital-intensive equipment at the end of the planning period.

Let us first assume that the interest rate is equal to the discount rate and thus denoted by $\rho$. The rate of technical decay is $\delta$. If depreciation at historic cost prices has its impact at the end of a period, while interest payments also have to be made at the end of a period, we can write the PV of the total flow $\psi(T, \theta)$ of interest and depreciation charger for a one dollar investment outlay at time $T$ up to and including $\theta \geq T$ as:

$$
\begin{aligned}
\psi(T, \theta) & =\sum_{t=T}^{\theta}(\rho+\delta) \cdot(1-\delta)^{t-T} \cdot(1+\rho)^{-(t-T+1)} \\
& =\left(\frac{\rho+\delta}{1+\rho}\right) \cdot \sum_{t=T}^{\theta}\left(\frac{1-\delta}{1+\rho}\right)^{t-T}=\frac{\rho+\delta}{1+\rho} \cdot \sum_{t=T}^{\theta} a^{t-T}
\end{aligned}
$$

where $a=\frac{1-\delta}{1+\rho}$. Using Equation (A.1) delivers:

$$
\begin{aligned}
& \psi(T, \theta)=\frac{\rho+\delta}{1+\rho} \cdot\left\{1+a+a^{2}+\ldots+a^{\theta-T}\right\} \\
& \Rightarrow \psi(T, \theta)-a \cdot \psi(T, \theta)=\frac{\rho+\delta}{1+\rho} \cdot\left(1-a^{\theta-T+1}\right) \\
& \Rightarrow \psi(T, \theta)=\frac{\rho+\delta}{1+\rho} \cdot\left(1-a^{\theta-T+1}\right) /(1-a) \\
& \Rightarrow \psi(T, \theta)=\left(1-a^{\theta-T+1}\right)=1-\left(\frac{1-\delta}{1+\rho}\right)^{\theta-T+1}
\end{aligned}
$$

For $\theta \rightarrow \infty$, we find that $\psi(T, \theta) \rightarrow 1$. For investment just after the planning period has ended, i.e. for $T=\theta+1$, we find that $\psi(\theta+1, \theta)=0$. 


\section{Appendix B: Variance Calculations}

We can obtain Equation 7.3 by noting that the expected forecasting error of the present value of an investment program associated with technology $f$ is given by:

$$
\begin{aligned}
\varepsilon^{P V^{f}}=P V^{f}-\mathbb{E}\left(P V^{f}\right) \approx & \sum_{t=0}^{\theta} e^{-\rho \cdot t} \cdot \psi_{t, \theta}^{f} \cdot \tilde{P}_{t}^{f} \cdot \tilde{\kappa}_{t}^{f} \cdot Y_{t}^{f} \cdot\left(S_{t}^{f, \hat{P}}+S_{t}^{f, \hat{\kappa}}\right)+ \\
& \sum_{t=0}^{\theta} \sum_{v=0}^{t} e^{-\rho \cdot t} \cdot \tilde{Q}_{t}^{f} \cdot \tilde{\varphi}_{v}^{f} \cdot X_{v, t} \cdot\left(S_{t}^{f, \hat{Q}}+S_{v}^{f, \hat{\varphi}}\right)= \\
& \sum_{t=0}^{\theta} a_{t}^{f} \cdot\left(S_{t}^{f, \hat{P}}+S_{t}^{f, \hat{\kappa}}\right)+\sum_{t=0}^{\theta} \sum_{v=0}^{t} b_{v, t}^{f} \cdot\left(S_{t}^{f, \hat{Q}}+S_{v}^{f, \hat{\varphi}}\right)
\end{aligned}
$$

where $a_{t}^{f}=e^{-\rho \cdot t} \cdot \psi_{t, \theta}^{f} \cdot \tilde{P}_{t}^{f} \cdot \tilde{\kappa}_{t}^{f} \cdot Y_{t}^{f}$ and $b_{v, t}^{f}=e^{-\rho \cdot t} \cdot \tilde{Q}_{t}^{f} \cdot \tilde{\varphi}_{v}^{f} \cdot X_{v, t}^{f}$. The variables with a tilde represent the expected values of those variables.

It should be noted that Equation (B.1) can be written as:

$$
\varepsilon^{P V^{f}}=\sum_{t=0}^{\theta} S_{t}^{f, \hat{P}} \cdot a_{t}^{f}+\sum_{t=0}^{\theta} S_{t}^{f, \hat{\kappa}} \cdot a_{t}^{f}+\sum_{t=0}^{\theta} S_{t}^{f, \hat{Q}} \cdot \sum_{v=0}^{t} b_{v, t}^{f}+\sum_{t=0}^{\theta} \sum_{v=0}^{t} b_{v, t}^{f} \cdot S_{v}^{f, \hat{\varphi}} .
$$

Except for the final term on the right hand side of Equation (B.2), the forecasting error in the present value of investment and operating costs for technology family $f$ depends on a number of terms that themselves depend just on $t$. However, the last term of the right hand side of (B.2) can be written as a sum of terms that also depends on $t$ only. In that case it is relatively straightforward to compute the variance of $\varepsilon^{P V^{f}}$.

To show this, we first have to rewrite the last term as stated above. Dropping the unchanging superscripts $f$ and $\hat{\varphi}$ note that this sum can be reorganized in tabular form as shown in Table B.1. From this Table one can immediately see that the sum of all the elements in a given row can be expressed as a function of $t$ only. Consequently, the sum over all elements can be written as $\sum_{t=0}^{\theta} S_{t} \cdot \sum_{v=t}^{\theta} b_{t, v}$.

\begin{tabular}{|l|l|l|l|l|l|l|}
\hline $\mathrm{v} \backslash \mathrm{t}$ & 0 & 1 & 2 & 3 & $\ldots$ & $\theta$ \\
\hline 0 & $b_{0,0} \cdot S_{0}$ & $b_{0,1} \cdot S_{0}$ & $b_{0,2} \cdot S_{0}$ & $b_{0,3} \cdot S_{0}$ & $\ldots$ & $b_{0, \theta} \cdot S_{0}$ \\
\hline 1 & 0 & $b_{1,1} \cdot S_{1}$ & $b_{1,2} \cdot S_{1}$ & $b_{1,3} \cdot S_{1}$ & $\ldots$ & $b_{1, \theta} \cdot S_{1}$ \\
\hline 2 & 0 & 0 & $b_{2,2} \cdot S_{2}$ & $b_{2,3} \cdot S_{2}$ & $\ldots$ & $b_{2, \theta} \cdot S_{2}$ \\
\hline 3 & 0 & 0 & 0 & $b_{3,3} \cdot S_{3}$ & $\ldots$ & $b_{3, \theta} \cdot S_{3}$ \\
\hline$\ldots$ & $\ldots$ & $\ldots$ & $\ldots$ & $\ldots$ & $\ldots$ & $\ldots$ \\
\hline$\theta$ & 0 & 0 & 0 & 0 & 0 & $b_{\theta, \theta} \cdot S_{\theta}$ \\
\hline
\end{tabular}

Table B.1: Reorganizing Terms

Defining $b 1_{t}^{f}=\sum_{v=0}^{t} b_{v, t}^{f}$ and $b 2_{t}^{f}=\sum_{v=t}^{\theta} b_{t, v}^{f}$, we find that the forecasting error of the expected present value of the variance adjusted costs of the investment (and production) program per technology family $f$ is given by:

$$
\varepsilon^{P V^{f}}=\sum_{t=0}^{\theta}\left\{a_{t}^{f} \cdot\left(S_{t}^{f, \hat{P}}+S_{t}^{f, \hat{\kappa}}\right)+b 1_{t}^{f} \cdot S_{t}^{f, \hat{Q}}+b 2_{t}^{f} \cdot S_{t}^{f, \hat{\varphi}}\right\}
$$


Using the same notation as in Equation (7.3) in the main text, we define $m_{t}^{f, \hat{P}}=m_{t}^{f, \hat{\kappa}}$, $m_{t}^{f, \hat{Q}}=b 1_{t}^{f}$ and $m_{t}^{f, \hat{\varphi}}=b 2_{t}^{f}$. Equation (B.3) can then be rewritten as

$$
\varepsilon^{P V^{f}}=\sum_{t=0}^{\theta} \sum_{n \in N} m_{t}^{f, n} \cdot S_{t}^{f, n}
$$

where, as before, $N$ is the set of stochastic variables for all technology families, i.e. $N=$ $\{\hat{P}, \hat{Q}, \hat{\kappa}, \hat{\varphi}\}$, and $n$ represents the individual elements of this set. The corresponding forecasting error for the investment and operating costs over the entire technology family portfolio would consist of the sum of (B.4) over all $f$, in which case we get (B.5):

$$
\varepsilon^{P V}=\sum_{t=0}^{\theta} \sum_{f} \sum_{n \in N} m_{t}^{f, n} \cdot S_{t}^{f, n}
$$

Taking the expectation of $\left(\varepsilon^{P V}\right)^{2}$, we find that:

$$
\mathbb{E}\left(\varepsilon^{P V}\right)^{2}=\sum_{t 1=0}^{\theta} \sum_{f 1} \sum_{n 1 \in N} \sum_{t 2=0}^{\theta} \sum_{f 2} \sum_{n 2 \epsilon N} m_{t 1}^{f 1, n 1} \mathbb{E}\left(S_{t 1}^{f 1, n 1} \cdot S_{t 2}^{f 2, n 2}\right) \cdot m_{t 2}^{f 2, n 2}
$$

Under the assumption that the individual forecasting errors of all the stochastic variables are serially uncorrelated, whereas the contemporaneous co-variance of two different stochastic variables (indexed by $\{f 1, k 1\}$ and $\{f 2, k 2\})$ is constant and given by $\sigma_{f 1, n 1}^{f 2, n 2}$, it follows that the expectation part of (B.6) can be written as $\mathbb{E}\left(S_{t 1}^{f 1, n 1}\right.$. $\left.S_{t 2}^{f 2, n 2}\right)=\min (t 1, t 2) \cdot \sigma_{f 1, n 1}^{f 2, n 2}$, which implies that (B.6) can be rewritten as:

$$
\operatorname{var}(P V)=\sum_{t 1=0}^{\theta} \sum_{f 1} \sum_{n 1 \in N} \sum_{t 2=0}^{\theta} \sum_{f 2} \sum_{n 2 \epsilon N} \min (t 1, t 2) \cdot m_{t 1}^{f 1, n 1} \cdot \sigma_{f 1, n 1}^{f 2, n 2} \cdot m_{t 2}^{f 2, n 2}
$$

Since our main purpose is just to illustrate the principles involved, we have assumed that all co-variances between different variables are equal to zero in order to simplify matters as much as possible. Hence, only the variances of the stochastic variables are assumed to be non-zero. This can easily be implemented by means of a slight modification of (B.8):

$$
\operatorname{var}(P V)=\sum_{t 1=0}^{\theta} \sum_{t 2=0}^{\theta} \sum_{f 1} \sum_{f 2=f 1} \sum_{n 1 \in N} \sum_{n 2=n 1} \min (t 1, t 2) \cdot m_{t 1}^{f 1, n 1} \cdot \sigma_{f 1, n 1}^{f 2, n 2} \cdot m_{t 2}^{f 2, n 2}
$$




\section{Chapter 8}

\section{Conclusion}

\subsection{Introduction}

This thesis has contributed to investment decision-making under uncertainty and irreversibility with particular focus on the transition towards a more sustainable mix of electricity-generating technologies. The models introduced here do thus not only provide important insights for investors, but also for policy makers interested in curtailing greenhouse gas (GHG) emissions for the sake of a deceleration of global warming, who therefore need to understand how investors respond to uncertainties, climate change policy and other factors. ${ }^{1}$ The purpose of this chapter is to summarize the main conclusions that have been drawn throughout the thesis and evaluate their significanceboth from a theoretical and from a policy point of view.

We have started out in Chapter 1 by defining the problems and characterizing the stakeholders involved in investment decision-making in the electricity sector. The first player is obviously the electricity sector, which demands special frameworks for its analysis because of its peculiarities - the uncertainties pervading the decisions of investors and producers, the irreversibility of investment in the first place and the associated externality of GHG emissions. This brings us to the climate itself, which is linked to the electricity sector through the GHG emissions the latter generates, and which accumulate in the atmosphere and lead to a general warming with adverse effects that can already be felt today in terms of changed weather conditions, melting ice sheets and glaciers and rising sea levels. However, since the electricity sector does not internalize this effect, a third player comes in to make up for this deficiency. The government's role is to protect society's interests and therefore it strives to limit the sources of climate change. By enacting policies that are designed to reduce the GHG emissions from electricity production, the government thus affects the electricity sector again and creates additional factors and uncertainties that have to be taken into

\footnotetext{
${ }^{1}$ While uncertainty and irreversibility have been the main focus of the thesis, there are also important conclusions with respect to the effects of technological change itself (see Chapters 4 and 5-7).
} 
account in investment decisions. It is clear that this interrelatedness complicates the decision-making processes in the electricity sector and at the same time also the task of policy makers, who need to design an appropriate incentive structure for investors to achieve their goals of preserving the climate.

There are multiple questions that arise in this context, most importantly the issue of a transition to a more sustainable energy mix, the role of technical change and rising fuel prices (which links to concerns about energy security, see e.g. Awerbuch and Sauter, 2006), the effect of (different types of) uncertainty on investment decisions, the integration of irreversibility into decision-making frameworks, and the appropriateness of policies and what light the analysis can shed on ongoing policy debates.

In order to answer these questions we have first discerned different approaches to investment decision-making under uncertainty and irreversibility in Chapter 2. We have come to the conclusion that there are still some unresolved problems in the existing literature and that real options theory and portfolio selection offer the most suitable starting points for our purposes. The first part of thesis has then used real options to analyze the effects of different types of uncertainties, climate change policy, and fuel price and technological uncertainty from the perspective of the individual investor, who wants to optimize the timing of setting up a power plant or switching from one type of power plant to another. The second half of the thesis tries to overcome the shortcomings of mean-variance portfolio theory as traditionally applied to investment in the electricity sector to make it more suitable for such analysis (see Chapters 5 and 6 ), so that the resulting framework will be useful also for large-scale investors or the analysis of aggregate investment and energy mix composition at the country-level. By integrating elements from portfolio selection into a vintage model of investment and production, we are able to not only add the dynamics underlying technical change, but also to account for the irreversibility, which is not present in a financial portfolio where assets can be added and removed at virtually zero transaction costs (see Chapter 5 for all advantages of the new approach over standard mean-variance (M-V) portfolio selection). Extending the basic framework in Chapter 7 makes it a suitable tool for the analysis of climate change policy and the transition to more carbon-free technologies over the long term.

\subsection{Different Types of Uncertainty}

In Chapter 3 we have been focussing on the effects that climate change policy will have on an investor, who has to decide whether to install a coal-fired power plant, a coal-fired power plant with a carbon capture and storage (CCS) module or whether to retrofit the coal-fired plant without $\mathrm{CCS}$ later in the planning period when $\mathrm{CO}_{2}$ prices have risen sufficiently.

However, we do not only look at the fluctuations in the $\mathrm{CO}_{2}$ price (that could arise in the process of permit trading, for example), but we also examine what happens when policy makers give no clear signals about their intentions during climate change policy negotiations, for instance, and effectively change the direction of the $\mathrm{CO}_{2}$ price 
path. That implies that $\mathrm{CO}_{2}$ prices might drop sharply or continue to rise after the negotiations have finished. Not knowing which probabilities to assign to both events, investors will thus face a large option value of waiting and postponing investment into the CCS module, which could have saved a large amount of $\mathrm{CO}_{2}$ emissions in the meantime.

The message to policy makers clearly is that they should convey the right signs to the public and industry, as otherwise they will (a) fail to achieve their ultimate policy goals by providing too weak an incentive structure, and (b) cause financial losses to investors, while the latter are waiting for the uncertainty, which we call "policy uncertainty", to be resolved.

The fluctuations in $\mathrm{CO}_{2}$ prices, on the other hand, which can be referred to as "market uncertainty" are of much less harm to investors than is sometimes claimed (see Chapter 3). We have shown that optimizing under incomplete information, will lead to earlier investment into the CCS module than in the case where optimization can take advantage of perfect information. While this leads to slight ${ }^{2}$ losses for the investor, who exercises the investment option earlier than optimal under perfect information, this is by no means as painful as the postponement in the face of policy uncertainty and even beneficial from the point of view of achieving GHG emissions reductions. It is thus evident that a distinction between market uncertainty and the more radical policy uncertainty is warranted and useful and it conveys important insights for policy makers as well.

Another important conclusion to be drawn from Chapter 3 relates to the policy debate about cap and trade approaches (i.e. $\mathrm{CO}_{2}$ permit trading, which leads to fluctuating prices) versus deterministic and possibly escalating taxes. In particular, we do not find that stochastic $\mathrm{CO}_{2}$ prices are necessarily worse for electricity producers than a deterministic tax, so the message is that both approaches serve their goal of providing incentives to reduce $\mathrm{CO}_{2}$ emissions rather well. Only the addition of a price cap would be detrimental to this end. Introducing a ceiling on the price of $\mathrm{CO}_{2}$ emissions, however, protects the profits of carbon-intensive power plants without offering the same advantages to renewable energy technologies and do thus weaken the promotion of less carbon-intensive energy generation.

In the following section we will see how our new approach of combining portfolio selection with vintage modeling enters the picture and adds to the existing literature on irreversible investment under uncertainty.

\subsection{A New Theoretical Approach}

The vintage-portfolio model introduced in Chapter 5, further expanded in Chapter 6 and extended and applied in Chapter 7 overcomes a number of disadvantages that make standard mean-variance portfolio selection (as previously applied to electricity

\footnotetext{
${ }^{2}$ There is only a minor loss because the bringing forward of investment only concerns a short period of time, while in the case of policy uncertainty the period of waiting and paying rising $\mathrm{CO}_{2}$ penalties extends over a longer time horizon and is thus also more painful in terms of the amount of expenses.
} 
investment problems) not very suitable for investment analysis in the electricity sector when one wants to take into account dynamic features such as technical change and the irreversible nature of investment. By setting the portfolio problem into a vintage framework, both the effects of technological progress and the uncertainties surrounding it can be examined. Moreover, it enables us to develop more elaborate investment strategies that do not only take advantage of the gains from diversification over technologies that rely on different fuels and have different technological prospects, but that can also diversify over time.

The role of technological advance features importantly in this setup because we primarily face embodied technical change in the electricity sector. Since investment is irreversible, producers are "stuck" with what they have invested into, until they can update their portfolio through scrapping and to make up for technical decay. An important finding is that a decrease in technological uncertainty will therefore lead to less investment, even though the real options model in Chapter 4 concludes the opposite and "standard" M-V frameworks would also see an increase in the share of more secure assets in the generating portfolio (see Chapter 5). However, the fact that technical change will now occur with more certainty in our setting implies that more gains can be reaped later on, when that technical change has materialized (and it will do so now with larger certainty). Similarly, in the more elaborate framework of Chapter 7 we can observe that a technology, which experiences a shock in technological uncertainty is not immediately replaced by the most likely substitute. Again, it pays off to wait for ongoing technical change to take place and reap the full benefits of being able to install higher quality vintages when investment becomes necessary and thus to substitute investment in the concerned technology today for investment at a later point in time. A technology with low capital costs and possibly lower equipment lifetime will take over as a "placeholder" in the meantime.

The policy implications that we have drawn from this framework are that renewables by themselves are not capable of taking over the larger part of the energy mix, for reasonable rates of technical change and fuel price growth. The reason is that capital costs are still high, the technologies themselves immature and technical change often uncertain. While an increase in risk aversion would work in favor of renewables, a relatively large increase in the risk aversion level would be needed to make the otherwise still expensive renewables competitive. Other renewables might be developed enough, but are constrained by e.g. geographical requirements, such as large-scale hydro dams. Therefore, the phasing in of renewables will need some "assistance" from government in terms of subsidies, legislation or taxing of their fossil-fuel competitors. ${ }^{3}$ Moreover, nuclear energy has characteristics that make it attractive as a "transition technology" between electricity generation based on fossil fuels and a renewables-dominated generating mix. While this strategy has been voiced as a solution by many countries, including France and the UK, to buy some time and secure energy supply while developing renewables to make them cheaper and more efficient, the concerns of the public about safety issues, proliferation of nuclear material to terrorists and issues of long

\footnotetext{
${ }^{3}$ This is a finding also emanating from the analysis in Chapters 3 and in particular 4 .
} 
term nuclear waste disposal need to be considered as well.

We will next see how technological change and fuel prices and the uncertainty surrounding these feature in the investment decisions using both real options (Chapter 4) and the vintage-portfolio model (Chapters 5 and 6).

\subsection{The Role of Technical Change, Fuel Prices \& Uncertainty}

As already alluded to in the previous section, the newly developed vintage-portfolio approach delivers results about technological uncertainty that are quite different from what we find in real options and standard $\mathrm{M}-\mathrm{V}$ portfolio models. In fact, investment is temporarily postponed in the face of larger certainty about technological progress, while fuel price uncertainty leads to less investment in all three types of models. To put it differently, all three models find a negative relationship between uncertainty and investment for fuel prices, and the standard portfolio and real options models also do so for technological uncertainty. Only the vintage-portfolio model finds a positive relationship between technological uncertainty and investment at the beginning of the planning period, which is due to the fact that technical change is embodied in the new vintages of capital equipment, so if you can be more sure that improvements will take place, it will pay off to wait for those improvements. Intertemporal optimization in combination with the cumulative nature of technical change therefore generates results that act as if an option value of waiting has been created in the vintage-portfolio model. $^{4}$

The real options model presented in Chapter 4 also features embodied technical change, so once the equipment is installed, no further cost reductions are possible. We find that larger rates of technical change lead to later investment, which is in line with the conclusions from the vintage-portfolio model: if larger cost reductions can be expected, it pays off to wait for them - unless risk aversion is high and increases the importance of the variance in the objective function. In that case, most investment takes place in the beginning of the planning period, so as to avoid surprises later on (see Figure 6.7).

The real options approach shows that technological uncertainty leads to further postponement of investment. This is due to the fact that larger uncertainty increases the option value of waiting for another improvement to materialize because in this model innovations arrive according to a Poisson process and larger technological uncertainty is modeled through a lower arrival rate compensated for by a larger step size of improvement. This makes it worthwhile to wait longer, an option which is not actively valued in the vintage-portfolio model. In fact, for the case of the wind farm

\footnotetext{
${ }^{4}$ In Chapter 7 this effect works through the substitute technology. Please note that this is not a contradiction to earlier findings, since the investment-uncertainty relationship for technological progress has on average always been negative: the only purpose of decreasing investment into the less risky technology in the beginning of the planning period is to increase it later by a larger amount, so that the investor ultimately ends up with a larger portfolio share of the more secure technology.
} 
that we are examining in this chapter, this is not desirable from the point of view of climate preservation: a high expected rate of technical change leads investors - with both modeling approaches - to postpone investment into environmentally friendly, expensive, but rapidly developing technologies, while the effects of uncertainty do not need to be negative.

Looking at the possibility to switch from a coal-fired power plant to a wind farm adds the fuel price dimension to the real options setting in Chapter 4. Interestingly, while the option value had been exponentially upward-sloping in the case of the wind farm, the inclusion of the coal-fired plant fundamentally reshapes the option value by adding the value of keeping old capacity, which is subject to stochastic prices. What we observe is a U-shape for the option value, which is crossed by the upwardsloping plant value of the wind farm, which becomes more valuable as technical change progresses, while the coal-fired power plant looses attractiveness as coal prices rise. We find that higher growth in coal prices leads to earlier investment because it decreases the option value of keeping old, coal-fired capacity. Uncertainty about fuel prices has no significant effect for the data we use, since fuel costs contribute much less to total costs than capital costs and coal prices are projected to be relatively stable. If anything however, the option value would be increased and investment postponed, so the negative uncertainty-investment relationship is confirmed for the real options model of Chapter 4.

From a policy or climate change point of view, Chapter 4 shows that without a penalty on the emission of $\mathrm{CO}_{2}$ the option value of keeping the coal-fired plant will always exceed the plant value of the wind farm for our planning period. That confirms our findings from the vintage-portfolio model (see above) that renewables are not ready to take over from traditional technologies and need to be promoted by government. To be more precise, a $\mathrm{CO}_{2}$ price triple the size of its current value in the European permit trading system would be needed to trigger investment into wind technology within the next thirty years. While this might seem enormous, the estimations of the last IPCC report (2007) also project a $\mathrm{CO}_{2}$ price of around $100 \$$ per ton of $\mathrm{CO}_{2}$ to be necessary to stabilize emissions at a presumably "safe" level. This estimate even somewhat exceeds ours and points to the validity and policy relevance of our findings, even though we have been using a very simple framework. In the same vein, we have used the vintage-portfolio in Chapter 7 to assess whether the UK goals of reducing $\mathrm{CO}_{2}$ emissions by increasing the Renewables Obligation (amongst other measures) is realistic. We have indeed found that extra costs are high, even though they do not represent a substantial fraction of total cost. Moreover, these costs will most probably be passed on to consumers. On the positive side, the variance of the portfolio will be lower, which is a favorable side effect in terms of energy security.

\subsection{Further Research}

From a theoretical perspective there is definitely a need to extend and apply portfolio selection on a larger scale to investment in the electricity sector. We have shown 
that the combination with vintage modeling makes portfolio theory very suitable for such analysis, but other approaches are possible and issues that have to be addressed also pertain to the weakness of the $\mathrm{M}-\mathrm{V}$ model as previously applied to electricity investment when return (or cost) distributions are not normally distributed. Fortin et al (2007) have made a first step into this direction by using other risk-measures than the variance that take fat tails into account as well. However, their framework is also static with regard to the portfolio optimization part, but it could be extended in the way that we have suggested in this thesis.

It has also been shown that real options theory is a very useful decision-making tool in the electricity sector because it considers both irreversibility and values the investment option in the face of uncertainty. By slightly adapting real options models, Chapter 3 has taken different types of uncertainty into account. Chapter 4 has shown that complex processes such as technical change can be added without sacrificing much transparency. So, even though real options models tend to get complex and too intensive to solve quite quickly, much can nonetheless be analyzed using relatively simple models and this should also be taken advantage of in future research. Much has still to be done in the area of climate change policy still and also uncertainties and irreversibilities on the environmental side could be taken into account more explicitly, for example.

Another area that warrants further research is the issue of technical change. While we have treated technological progress as an exogenous process, it is obvious that policy measures - as the ones reviewed here - can also lead to endogenous technical change, as investment into research and development (R\&D) is hoped to bring about cost advantages in technologies that are or will be invulnerable to carbon penalties. ${ }^{5}$ On the other hand, resources might not only be expended for R\&D purposes in this context, but also to lobby against carbon penalties in the first place. This might be the preferred strategy of owners of old capacity or fossil fuel resources. Depending on the effectiveness of the lobbying mechanism, this can then lead to further policy uncertainty affecting the whole sector again.

While this thesis has mainly been occupied with the diffusion of technical change, further research should therefore go deeper in the sense that technological progress should be endogenized and underlying incentive schemes could be elaborated to capture the political processes underlying climate change policy.

\footnotetext{
${ }^{5}$ Many (mostly European) firms that have specialized in renewable energy technology already claim today that they have had a head start in $R \& D$, which has made them very competitive in international markets.
} 



\section{Bibliography}

Abel, A. (1983): "Optimal Investment under Uncertainty," The American Economic Review, 72, 228-233.

Abel, A., ANd J. Eberly (1999): "The Effects of Irreversibility and Uncertainty on Capital Accumulation," Journal of Monetary Economics, 44(3), 339-377.

Aghion, P., And P. Howitt (1992): "A Model of Growth through Creative Destruction," Econometrica, 60(2), 323-351.

Anderson, D., AND S. Winne (2004): "Modelling Innovation and Threshold Effects in Climate Change Mitigation," Working Paper 59, Tyndall Centre for Climate Change Research.

Armstrong, M., A. Galli, W. Bailey, And B. Couët (2004): "Incorporating Technical Uncertainty in Real Options Valuation of Oil Projects," Journal of Petroleum Science and Engineering, 44, 67-82.

Arrow, K., AND A. Fisher (1974): "Environmental Preservation Uncertainty, and Irreversibility," Quarterly Journal of Economics, 88, 312-319.

Awerbuch, S. (2006): "Portfolio-based Electricity Generation Planning: Policy Implications for Renewables and Energy Security," Mitigation and Adaptation Strategies for Global Change, 11(3), 693-710.

Awerbuch, S., And M. Berger (2003): “Applying Portfolio Theory to EU Electricity Planning and Policy-Making," Working Paper EET/2003/03, International Energy Agency.

Awerbuch, S., And R. Sauter (2006): "Exploiting the Oil-GDP Effect to Support Renewables Deployment," Energy Policy, 34, 2805-2819.

Azar, C., AND H. Rodhe (1997): "Targets for stabilization of atmospheric $\mathrm{CO}_{2}$," Science, 276, 1818.

Balcer, Y., And S. Lippman (1984): "Technological Expectations and Adoption of Improved Technology," Journal of Economic Theory, 84(2), 292-318.

Bar-Lev, D., And S. Katz (1976): "A Portfolio Approach to Fossil Fuel Procurement in the Electric Utility Industry," Journal of Finance, 31(3), 933-942.

Barbose, G., R. Wyser, A. Phadke, and C. Goldman (2008): "Reading the Tea Leaves: How Utilities in the West Are Managing Carbon Regulatory Risk in their 
Resource Plans," Report LBNL-44E, Ernest Orlando Lawrence Berkeley National Laboratory, Available at http://eetd.lbl.gov/ea/EMS/EMS_pubs.html.

Black, F., And M. Scholes (1973): "The Pricing of Options and Corporate Liabilities," Journal of Political Economy, 81, 637-659.

Blyth, W. (2007): "Climate Change Policy Risks," Presentation at conference "climate change: politics versus economics", Chatham House, London.

Blyth, W., And K. Hamilton (2006): "Aligning Climate and Energy Policy," Briefing paper, Chatham House.

Blyth, W., AND M. YAng (2007): "Modeling Investment Risks and Uncertainties with Real Options Approach," Working Paper LTO/2007/WP 01, IEA.

Bodily, S., And M. D. Buono (2002): "Risk and Reward at the Speed of Light: A New Electricity Price Model," Darden Business School Working Papers, 03-01, $66-71$.

Botterud, A. (2003): "Long-term Planning in Restructured Power Systems - Dynamic Modelling of Investments in New Power Generation under Uncertainty," Phd thesis, NTNU.

Boyarchenko, S., AND S. Levendorsky (1998): "Models of Investment under Uncertainty when Shocks are Non-Gaussian. On the Impact of the Policy Uncertainty on Investment," EERC Working Paper Series 98-02e, EERC Research Network, Russia and CIS, available at http://ideas.repec.org/p/eer/wpalle/98-02e.html.

Brealey, R., S. Myers, And F. Allen (2005): Principles of Corporate Finance. McGraw Hill Higher Education, 7th edition edn.

Brennan, M., AND E. Schwartz (1985): "Evaluating Natural Resource Investments," Journal of Business, 58, 135-157.

Caballero, R. (1991): "On the Sign of the Investment-Uncertainty Relationship," The American Economic Review, 81, 279-288.

Campbell, J. (2000): "Strategic Asset Allocation: Portfolio Choice for Long-Term Investors," Nber research summary in program report on asset pricing, National Bureau of Economic Research.

Carruth, A., A. Dickerson, and A. Henley (2000): "What do We Know about Investment under Uncertainty?," Journal of Economic Surveys, 14(2), 119-155.

Chao, H., And R. Wilson (1993): "Option Value of Emission Allowances," Journal of Regulatory Economics, 5(3), 233-249.

Chaton, C., And J. Doucet (2003): "Uncertainty and Investment in Electricity Generation with an Application to the Case of Hydro-Québec," Annual Operations Research, 120(1), 59-80.

Chen, Y.-F., And M. Funke (2003): "Option Value, Policy Uncertainty, and the Foreign Direct Investment Decision," Discussion Paper 234, Hamburg Institute of International Economics. 
Cheng, L., E. Subrahmanian, And A. Westerberg (2004): "A Comparison of Optimal Control and Stochastic Programming from a Formulation and Computation Perspective," Computers and Chemical Engineering, 29, 149-164.

Chladná, Z.; Chaldný, M., K. Möllersten, And M. Obersteiner (2004): "Investment under Multiple Uncertainties," Interim Report IR-04-077, International Institute of Applied Systems Analysis.

Copeland, B., And M. Taylor (2003): Trade and the Environment - Theory and Evidence. Pronceton University Press, Princeton.

Crutzen, P. (2006): "Albedo Enhancement by Stratospheric Sulfur Injections: A Contribution to Resolve a Policy Dilemma?," Climatic Change, 77, 211-219.

DAntzig, G. (1955): "Linear Programming Under Uncertainty," Management Science, 1, 197-206.

Davis, G., And B. Owens (2003): "Optimizing the Level of Renewable Electric R\&D Expenditures Using Real Options Analysis," Energy Policy, 31, 1589-1608.

De Groot, H. (2000): "Structural Change, Economic Growth and the Environmental Kuznets Curve," Discussion paper, Netherlands Organisation for Scientific Research.

De Jong, C.; Oosterom, A., And K. Walet (2004): "Dealing with Emissions," in Managing Energy Price Risk - The New Challenges and Solutions, ed. by V. Kaminski, Risk Books. Barclay, Division of Incisive Financial Planning Ltd., 3 edn.

Deng, S., AND S. OREN (2003): "Incorporating Operational Charactersitics and Start-up Costs in Option-based Valuation of Power Generation Capacity," Probability in the Engineering and Informational Sciences, 17(2), 155 - 181.

Department of Trade and Industry (2006): "Energy Statistics," available at http://www.dti.gov.uk/energy/statistics/index.html.

(2007a): "Energy White Paper: Meeting the Energy Challenge," available at http://www.dti.gov.uk/energy/whitepaper/page39534.html.

(2007b): "UK Energy Sector Indicators 2007," available at http://www.dti.gov.uk/energy/statistics/publications/indicators/page39558.html.

Diaz, M. (2004): "Valuation of Exploration and Production Assets: An Overview of Real Options Models," Journal of Petroleum Science and Engineering, 44(1-2), 93-114.

Dixit, A. (1990): Optimization in Economic Theory. Oxford University Press, 2nd edition edn.

Dixit, A., AND R. Pindyck (1994): Investment under Uncertainty. Princeton University Press, Princeton.

Doniger, D., A. Herzog, And D. Lashof (2006): "An Ambitious, Centrist Approach to Global Warming Legislation," Science, 314, 764-765. 
Doraszelski, U. (2001): "The Net Present Value Method Versus the Option Value of Waiting: A Note on Farzin, Huisman and Kort (1998)," Journal of Economic Dynamics and Control, 25(8), 1109-1115.

Drexhage, J. (2007): "Transforming Our Energy Infrastructure Within A Generation - Pragmatic Vision Or Pie In The Sky Dream?," Presentation at conference "climate change: Politics versus economics", Chatham House, London.

Dyner, I., AND E. LARSEn (2001): "From Planning to Strategy in the Electricity Industry," Energy Policy, 29(13), 1145-1153.

Edge, G. (2006): "A Harsh Environment: The Non-Fossil Fuel Obligation and the UK Renewables Industry," in Renewable Energy Policy and Politics: A Handbook for Decision-Making, ed. by K. Mallon. Earthscan Publications Ltd.

Elton, E., M. Gruber, And S. Brown (2003): Modern Portfolio Theory and Investment Analysis. Wiley, New York, 6 edn.

Emanuel, K. (2005): "Increasing Destructiveness od Tropical Cyclones Over the Past 30 Years," Nature, 436, 686-688.

EnERgy Information Administration (2006): "Other International Electricity Data," available at http://www.eia.doe.gov/emeu/international/electricityother.html.

European Commission (2006): "World Energy Technology Outlook: WETO H2," available at http://ec.europa.eu/research/energy/pdf/weto-h2_en.pdf.

European Wind Energy Association (2004): "Wind Energy: The Facts - An Analysis of Wind Energy in the EU-25," Report, EWEA.

FAma, E. (1970): "Multiperiod Consumption-Investment Decisions," American Economic Review, 60(1), 163-174.

FARrell, A. E. (2004): "Electricity, Environmental Impacts of," in Encyclopedia of Energy, vol. 2. Elsevier.

Farzin, Y., K. Huisman, and P. Kort (1998): "Optimal Timing of Technology Adoption," Journal of Economic Dynamics and Control, 22, 779-799.

Fialka, J. (2007): "Call for Cap on $\mathrm{CO}_{2}$ Credit Price," The Wall Street Journal, available at http://online.wsj.com/.

Fleten, S., K. Maribu, and I. Wangensteen (2007): "Optimal Investment Strategies in Decentralized Renewable Power Generation under Uncertainty," Energy, 32, $803-815$.

Fortin, I., S. Fuss, J. Hlouskova, N. Khabarov, M. Obersteiner, and J. SzolGAYOva (2007): "An Integrated CVaR and Real Options Approach to Investments in the Energy Sector," Economics series no. 209, Institute for Advanced Studies, Vienna, available at http://www.ihs.ac.at/publications/eco/es-209.pdf.

Fuss, S., D. Johansson, J. Szolgayová, and M. Obersteiner (2008): "Impact of Climate Policy Uncertainty on the Adoption of Electricity Generating Technologies," working paper, International Institute of Applied Systems Analysis. 
Fuss, S., J. Szolgayová, M. Obersteiner, And M. Gusti (2008): "Investment under Market and Climate Policy Uncertainty," Applied Energy, 85(8), 708-721.

Gao, W., R. Madlener, And P. Zweifel (2005): "Promoting Renewable Electricity Generation in Imperfect Markets: Price vs. Quantity Control," Discussion Paper 45, Centre for Energy Policy and Economics.

Garvin, M., And C. Cheah (2004): "Valuation Techniques for Infrastructure Investment Decisions," Construction Management and Economics, 22, 373-383.

Ghosal, V., And P. Loungani (2000): "The Differential Impact of Uncertainty on Investment in Small and Large Businesses," The Review of Economics and Statistics, $82(2), 338-343$.

Greenwood, J., And B. Jovanovic (2000): "Accounting for Growth," Working Paper 475, Rochester Center for Economic Research, University of Rochester.

Gregory, R., And D. James (1973): "Do New Factories Embody Best Practice Technology," The Economic Journal, 83(332), 1133-1155.

Grenadier, S., AND A. Weiss (1997): "Investment in Technological Innovations: An Option Pricing Approach," Journal of Financial Economics, 44(397-416).

Hamilton, J. (2003): "What is an Oil Shock?," Journal of Econometrics, 113, 363398.

Hanemann, W. (1989): "Information and Concept of Option Value," Journal of Environmental Economics and Management, 16, 23-37.

Hartman, R. (1972): "The Effects of Price and Cost Uncertainty on Investment," Journal of Economic Theory, 5, 258-266.

Hassett, K., And G. Metcalf (1999): "Investment with Uncertain Tax Policy: Does Random Tax Policy Discourage Investment?," The Economic Journal, 109, $372-393$

Helfat, C. (1988): Investment Choices in Industry. MIT, Cambridge.

Henry, C. (1974): "Investment Decisions under Uncertainty: The Irreversibility Effect," American Economic Review, 64, 1006-1012.

Hlouskova, J., S. Kossmeier, M. Obersteiner, And A. Schnabl (2005): "Real Options and the Value of Generation Capacity in the German Electricity Market," Review of Financial Economics, 14(3-4), 297-310.

Hotelling, H. (1931): "The Economics of Exhausible Resources," Journal of Poilitical Economics, 39, 137-175.

Humphreys, H., And K. MCClain (1998): "Reducing the Impacts of Energy Price Volatility through Dynamic Portfolio Selection," Energy Journal, 19(3).

Intergovernmental Panel on Climate Change (2007): "Climate Change 2007," Fourth assessment report, United Nations.

International Energy Agency (2000): "World Energy Outlook 2000," Discussion paper, International Energy Agency/OECD. 
(2004): "World Energy Outlook 2004," Discussion paper, International Energy Agency.

(2005a): Inquire 3 (IEA Energy Database). International Energy Agency, Paris.

- (2005b): Projected Costs of Generating Electricity (2005 Update). OECD/IEA, Paris.

(2006): Energy Technology Perspectives 2006: Scenarios and Strategies to 2050. OECD/IEA, Paris.

International Institute of Applied Systems Analysis (2007): "GGI Scenario Database," available at http://www.iiasa.ac.at/Research/GGI/DB/.

Jacoby, H., And A. Ellerman (2004): "The Safety Valve and Climate Policy," Energy Policy, 32(4), 481-491.

Jaffe, A., And R. Stavins (1994): "The Energy Paradox and the Diffusion of Conservation Technology," Resource and Energy Economics, 16, 91-122.

Johansen, L. (1959): "Substitution versus Fixed Production Coefficients in the Theory of Economic Growth: A Synthesis," Econometrica, 27, 157-176.

Jones, D. W., P. N. Leiby, And I. K. PAik (2004): "Oil Proce Shocks and the Macroeconomy: What Has Been Learned Since 1996," The Energy Journal, 25(2), $1-32$.

Jorgenson, D. (1963): "Capital Theory and Investment Behavior," The American Economic Review, 53(2), 247-259.

Jovanovic, B., And Y. Nyarko (1996): "Learning By Doing and the Choice of Technology," Econometrica, 64(6), 1299-1310.

Junginger, M., A. FaAiJ, And W. C. Turkenurg (2004): "Cost Reduction Prospects for Offshore Wind Farms," Wind Engineering, 28(1).

Kaldor, N., And Mirrlees (1962): "A New Model of Economic Growth," Review of Economic Studies, 29, 174-192.

Kaminski, V., S. Gibner, and K. Pinnamaneni (2004): "Energy Exotic Options," in Managing Energy Price Risk - The New Challenges and Solutions, ed. by V. Kaminski, Risk Books. Barclay, Division of Incisive Financial Planning Ltd., 3 edn.

Keppo, J., And H. Lu (2003): "Real Options and a Large Producer: the Case of Electricity Markets," Energy Economics, 25(5), 459-472.

Keynes, J. (1921): A Treatise on Probability, vol. 8. Macmillan, London.

Kiriyama, E., AND A. Suzuki (2004): "Use of Real Options in Nuclear Power Plant Valuation in the Presence of Uncertainty with CO2 Emission Credit," Journal of Nuclear Science and Technology, 41(7), 756-764.

Knight, F. (1921): Risk, Uncertainty and Profit. Houghton and Mifflin, Boston, MA.

Knutson, T., And R. Tuleya (2004): "Impact of $\mathrm{CO}_{2}$-Induced Warming on Simulated Hurricane Intensity and Precipiation," Journal of Climate, 17(18), 3477-3495. 
Kolstad, C. (1996a): "Fundamental Irreversibilities in Stock Externalities," Journal of Public Economics, 60, 221-233.

(1996b): "Learning and Stock Effects in Environmental Regulation: The Case of Greenhouse Gas Emissions," Journal of Environmental Economics and Management, 31, 1-18.

Krey, B., And P. Zweifel (2006): "Efficient Electricity Portfolios for Switzerland and the United States," Working paper, Socioeconomic Institute of the University of Zurich.

Ku, A. (1995): "Modelling Uncertainty in Electricity Capacity Planning," Phd thesis, London Business School.

Kumbaro $\breve{L}$ Lu, G., R. Madlener, and M. Demirel (2004): “A Real Options Evaluation Model for the Diffusion Prospects of New Renewable Power Generation Technologies," Working paper no. 35, Centre for Energy Policy and Economics Working Papers.

LAGERKVist, J. (2005): "Agricultural policy uncertainty and farm level adjustmentsthe case of direct payments and incentives for farmland investment," European Review of Agricultural Economics, Vol. 32, Issue 1, pp. 1-23, 2005.

Laurikka, H. (2006): "The Impact of Climate Policy on Heat and Power Capacity Investment Decisions," in Emissions Trading and Business, ed. by R. Antes, B. Hansjürgens, and P. Letmathe. Physica-Verlag HD, Heidelberg/NY.

Laurikka, H., And T. Koljonen (2006): "Emissions Trading and Investment Decisions in the Power Sector - a Case Study of Finland," Energy Policy, 34, 1063-1074.

Leland, H. (1972): "Theory of the Firm Facing Uncertain Demand," The American Economic Review, 62, 278-291.

Lensink, R., H. Bo, And E. Sterken (2001): Investment, Capital Market Imperfections, and Uncertainty. Edward Elgar.

Madlener, R., And G. K. V. Ediger (2005): "Modelling Technology Adoption as an Irreversible Investment under Uncertainty: The Case of the Turkish Electricity Supply Industry," Energy Economics, 27(1), 139-163.

Madlener, R., And W. Gao (2005): "Renewable Energy Policy in the Presence of Innovation: Does Pre-commitment by the Government Matter?," Working paper no. 46, Centre for Energy Policy and Economics Working Papers.

Madlener, R., G. Kumbaro ğLu, And V. Ediger (2005): "Modeling Technology Adoption as an Irreversible Investment under Uncertainty: the Case of the Turkish Electricity Supply Industry," Energy Economics, 27(1), 139-163.

Majd, S., ANd R. Pindyck (1987): "Time to Build, Option Value, and Investment Decisions," Journal of Financial Economics, 18.

Malcomson, J. (1975): "Replacement and the Rental Value of Capital Equipment Subject to Obsolescence," Journal of Economic Theory, 10, 24-41.

Malthus, T. R. (1798): An Essay on the Principle of Population. J. Johnson, London. 
Markowitz, H. (1952): "Portfolio Selection," Journal of Finance, 7(1), 77-91.

(1959): Portfolio Selection: Efficient Diversification of Investments. Wiley.

Massé, P., And R. Gibrat (1957): "Application of Linear Programming to Investments in the Electric Power Industry," Management Science, 3, 149-166.

McDonald, R., And D. Siegel (1986): “The Value of Waiting to Invest," Quarterly Journal of Economics, 101, 707-723.

Meadows, D. H., D. L. Meadows, J. Randers, and W. W. Behrens (1972): The Limits to Growth. Universe Books, New York.

Merton, R. (1969): "Lifetime Portfolio Selection Under Uncertainty: The Continuous-Time Case," Review of Economics and Statistics, 51(3), 247-257.

(1971): "Optimum Consumption and Portfolio Rules in a Continuous-Time Model," Journal of Economic Theory, 3, 373-413.

(1973a): “An Intertemporal Capital Asset Pricing Model," Econometrica, 41, $86-87$.

(1973b): "The Theory of Rational Option Pricing," Journal of Economic Management Science, 4, 141-183.

Messner, S., and M. Strubegger (1995): "User's Guide for MESSAGE III," Wp 95-69, International Institute for Applied Systems Analysis.

Mikosch, T. (1999): Elementary Stochastic Calculus With Finance in View. World Scientific Pub Co Inc.

Mitchell, C., D. Bauknecht, And P. Connor (2006): "Effectiveness through Risk Reduction: a Comparison of the Renewable Obligation in England and Wales and the Feed-in System in Germany," Energy Policy, 34, 297-305.

Möllersten, K., Z. Chladná, M. Chadný, and M. Obersteiner (2006): "Negative Emission Biomass Technologies in an Uncertain Climate Future," in Progress in Biomass and Bioenergy Research, ed. by S. Warnmer. Nova Science Publishers, NY.

Morgan, M. (2006): "Don't Grandfather Coal Plants,” Science, 314(1049).

Mulder, P., H. D. Groot, And M. Hofkes (2003): "Explaining Slow Diffusion of Energy-Saving Technologies; A Vintage Model with Returns to Diversity and Learning-By-Using," Resource and Energy Economics, 25, 105-126.

Munasinghe, M. (2004): "Sustainable Development: Basic Concepts and Application to Energy," in Encyclopedia of Energy, vol. 5. Elsevier.

Murto, P. (2007): "Timing of Investment under Technological and Revenue-Related Uncertainties," Journal of Economic Dynamics and Control, 31, 1473-1497.

Nelsen, R. (2006): An Introduction to Copulas. Springer, Berlin, 2nd edn.

NiCKell, S. (1978): The Investment Decisions of Firms. Cambridge University Press, Cambridge. 
Øкsendahl, B. (2003): Stochastic Differential Equations: An Introduction with Applications. Springer, New York.

Oxera Consulting Ltd (2005): "What Is the Potential for Commercially Viable Renewable Generation Technologies?," Report, prepared for the Department of Trade and Industry, UK.

Paddock, J., D. Siegel, And J. Smith (1988): "Option Valuation of Claims on Real Assets: The Case of Offshore Petroleum Leases," Quarterly Journal of Economics, pp. $479-508$.

PindyCK, R. (1980): "Uncertainty and Exhaustible Resource Markets," Journal of Political Economy, 88, 1203-1225.

(1988): "Irreversible Investment, Capacity Choice, and the Value of the Firm," American Economic Review, 79, 969-985.

(1991): "Irreversibility, Uncertainty and Investment," Journal of Economic Literature, 29(3), 1110-1148.

(1993): "Investments of Uncertain Cost," Journal of Financial Economics, $34,53-76$.

Pindyck, R. (2000): "Irreversibilities and the Timing of Environmental Policy," Resource and Energy Economics, 22(3), 233-259.

Pizer, W. (1997): "Prices versus Quantities Revisited: the Case of Climate Change," discussion paper, Resources for the Future.

(2002): "Combining Price and Quantity Controls to Mitigate Global Climate Change," Journal of Public Economics, 85(2), 409-434.

(2005): "Climate Policy Design Under Uncertainty," discussion paper, Resources for the Future.

Polyanin, A., And V. Zaitsev (2003): Handbook for Exact Solutions for Ordinary Differential Equations. Chapman \& Hall/CRC Press, Boca Raton, 2 edn.

Rahmstorf, S. (2006a): "Dem Sturm Begegnen: Klimawandel ist Kein Schicksal. Wir Können Ihn Erklären - und Begrenzen," Presentation.

(2006b): "Risks and Consequences of Climate Change," Presentation, Deutsches Institut für Wirtschaftsforschung, Berlin.

Reedman, L., P. Graham, and P. Coombes (2006): "Using a Real Options Approach to Model Technology Adoption Under Carbon Price Uncertainty: An Application to the Australian Electricity Generation Sector," The Economic Record, $82,64-73$.

Reinard, J. (2007): "CO 2 Allowance and Electricity Price Interaction," Information paper, OECD/International Energy Agency.

Reinelt, P., And D. Keith (2007): "Carbon Capture Retrofits and the Cost of Regulatory Uncertainty," Energy Journal, 28(4), 101-127. 
Riahi, K., A. G., And N. Nakicenovic (2007): "Scenarios of Long-term Socioeconomic and Environmental Development under Climate Stabilization," Technological Forecasting and Social Change, 47(7), 887-935.

Robinson, J. (1952): Essays in the Theory of Economic Growth. Macmillan, London.

Rockafellar, R., ANd S. Uryasev (2000): "Optimization of Conditional Value at Risk," Journal of Risk, 2, 21-42.

(2002): "Conditional Value at Risk for General Loss Distributions," Journal of Banking and Finance, 26, 1443-1471.

Rockafellar, R., And R. Wets (1991): "Scenarios and Policy Aggregation in Optimization under Uncertainty," Mathematics of Operations Research, 16, 119-147.

Roques, F., D. Newbery, And W. Nuttall (2006): "Fuel Mix Diversification Incentives in Liberalized Electricity Markets: A Mean-Variance Portfolio Approach," Working Paper 2006/33, RCAS of the European University Institute: Florence School of Regulation.

Salter, W. (1960): Productivity and Technical Change. Cambridge University Press, New York.

SAmuelson, P. (1969): "Lifetime Portfolio Selection by Dynamic Stochastic Programming," Review of Economics and Statistics, 51(3), 239-246.

Sandmo, A. (1971): "On the Theory of the Competitive Firm under Price Uncertainty," The American Economic Review, 61, 65-73.

SARKAR, S. (2000): "On the Investment-Uncertainty Relationship in a Real Options Model," Journal of Economic Dynamics and Control, 24, 219-225.

Schneider von Deimling, T., H. Held, A. Ganopolski, and S. Rahmstorf (2006): "Climate Sensitivity Estimated From Ensemble Simulations of Glacial Climate," Climate Dynamics, DOI 10.1007/s00382-006-0126-8.

Schumpeter, J. (1942): Socialism, Capitalism and Democracy. Harper and Row, New York.

Schwartz, E., And L. Trigeorgis (2001): Real Options and Investment under Uncertainty: Classical Readings and Recent Contributions. The MIT Press, Cambridge/Mass.

Seitz, N., And M. Ellison (1995): Capital Budgeting and Long-Term Financing Decisions. Dryden Press.

Selden, T., And D. Song (1994): "Environmental Quality and Development: Is There a Kuznets Curve for Air Pollution Emissions?," Journal of Environmental Economics and Management, 27, 147-162.

Slade, M. (2001): "Valuing Managerial Flexibility: An Application of Real-Option Theory to Mining Investments," Journal of Environmental Economics and Management, 41, 193-233.

Smulders, S., And L. Bretschger (2000): "Explaining Environmental Kuznets Curves: How Pollution Induces Policy and New Technologies," . 
Soete, L., And R. Turner (1984): "Technology Diffusion and the Rate of Technical Change," The Economic Journal, 94, 612-623.

Solow, R. (1956): "A Contribution to the Theory of Economic Growth," Quarterly Journal of Economics, 70, 5-94.

(1957): "Technical Change and the Aggregate Production Function," Review of Economics and Statistics, 39, 312-320.

(1960): "Investment and Technical Progress," in Mathematical Methods in the Social Sciences, ed. by K. Arrow, S. Karlin, and P. Suppes. Stanford.

(2000): Growth Theory - An Exposition. Oxford University Press, Oxford/New York, 2 edn.

Stern, N. (2006): "The Stern Review: The Economics of Climate Change," Discussion paper, Cabinet Office - HM Treasury.

ToBin, J. (1969): "A General Equilibrium Approach to Monetary Theory," Journal of Credit and Banking, 1, 15-29.

Tourinho, O. (1979): "The Valuation of Reserves of Natural Resources: An Option Pricing Approach," Phd dissertation, University of California.

Trigeorgis, L. (1996): Real Options: Managerial Flexibility and Strategy in Resource Allocation. MIT Press, Cambridge, MA.

Tseng, C., AND G. BARz (2002): "Short-term Generation Asset Valuation: A Real Options Approach," Operations Research, 50(2), 297-310.

Uddin, S., AND L. BARreto (2007): "Biomass-fired Cogeneration Systems with $\mathrm{CO}_{2}$ Capture and Storage," Renewable Energy, 32(6), 1006-1019.

Ulph, A., AND D. Ulph (1997): "Global Warming, Irreversibility and Learning," Economic Journal, 107, 636-649.

van Asselt, M. (2000): Perspectives on Uncertainty and Risk. Kluwer Academic Publishers, Dordrecht.

VAN Zon, A., AND S. Fuss (2005): "Irreversible Investment and Uncertainty in Energy Conversion: a Clay-Clay Vintage Portfolio Selection Approach," Research Memorandum RM2005-013, UNU-MERIT.

(2006): "Irreversible Investment under Uncertainty in Electricity Generation: a Clay-Clay-Vintage Portfolio Approach with an Application to Climate Change Policy in the UK," Working Paper 2006-035, UNU-MERIT.

VARIAn, H. (1993): "A Portfolio of Nobel Laureates, Markowitz, Miller and Sharpe," Journal of Economic Perspectives, 7(1).

Viebahn, P., J. Nitsch, M. Fischedick, A. Esken, D. Schüwer, N. SupersBerger, U. Zuberbühler, And O. Edenhofer (2007): "Comparison of Carbon Capture and Storage with Renewable Energies Technologies Regarding Structural, Economic, and Ecological Aspects in Germany," International Journal Of Greenhouse Gas Control, (doi:10.1016/S1750-5836(07)00024-2). 
Wagner, J., And O. Berman (1995): "Models for Planning Capacity Expansion of Convenience Stores under Uncertain Demand and the Value of Information," Annals of Operations Research, 59, 19-44.

World Commission on Environment and Development (1987): "Our Common Future (the Brundtland Report)," Report, Oxford University Press.

Wüstenhagen, R. (2004): "Umweltverträgliche Stromprodukte in Europa: Status und Schlüsselfaktoren der Marktentwicklung," Zeitschrift für Energiewirtschaft, 28(1), 17-26. 


\title{
Samenvatting
}

\author{
DUURZAME ENERGIEONTWIKKELING ONDER ONZEKERHEID
}

De opwekking van elektriciteit vormt met $40 \%$ de belangrijkste bron van $\mathrm{CO}_{2}$ emissies. Onderzoek heeft aangetoond dat de mens inderdaad in belangrijke mate bijdraagt aan de versnelling van de opwarming van de aarde door het gebruik van fossiele brandstoffen en daarmee samenhangende $\mathrm{CO}_{2}$ emissies. Vanwege de stijging van de temperatuur verandert het klimaat, hetgeen een groot aantal negatieve gevolgen heeft, zoals de stijging van de zeespiegel, de uitbreiding van woestijnen en meer extreme weersomstandigheden.

Aangezien de meeste landen van de OESO (Organisatie voor Economische Samenwerking en Ontwikkeling) reeds bestaande productie capaciteit binnen de elektriciteitssector in de komende 10 tot 20 jaren zullen moeten vervangen, zullen de investeringen voor de komende jaren de toekomstige energiesamenstelling en de daarbij behorende ontwikkeling van $\mathrm{CO}_{2}$ emissies gaan bepalen.

Het is daarom van uitermate groot belang te begrijpen hoe investeerders in deze sector hun beslissingen nemen. Investeringen in de elektriciteitssector worden gekenmerkt door hun onomkeerbaarheid, die is toe te schrijven aan de omvangrijke vaste kosten waarmee de bouw van elektriciteitscentrales gepaard gaat. Daarnaast zijn er verschillende bronnen van onzekerheid die investeringsbeslissingen beïnvloeden, zoals onzekerheid veroorzaakt door fluctuerende brandstofprijzen, onzekerheid over het tempo en de richting van technologische verandering, en onzekerheid ten aanzien van het te voeren beleid. De flexibiliteit om besluiten in het licht van deze onzekerheid uit te stellen, maakt de zogenaamde "real option theory" tot een waardevol hulpmiddel om het effect van verschillende soorten onzekerheid op het investeringsgedrag te onderzoeken.

In tegenstelling tot het standpunt van de industrie dat de schommelingen in de prijzen van $\mathrm{CO}_{2}$ emissie vergunningen tot een uitstel van investeringen in moderne, minder koolstofintensieve technologieën zullen leiden, tonen de in dit proefschrift verkregen resultaten aan dat bij onzekerheid voortvloeiend uit onvolledige informatie, optimaal investeringsgedrag leidt tot investeringen die eerder plaatsvinden dan onder perfecte informatie het geval zou zijn geweest. De onzekerheid die het gevolg is van onduide- 
lijke signalen over het te verwachten beleid ten aanzien van de sanctionering van $\mathrm{CO}_{2}$-emissies, leidt tot het ontstaan van een hoge optiewaarde van wachten en dus tot een veel latere overgang naar schone technologie.

Ook de onzekerheid waarmee de technische vooruitgang in hernieuwbare technologieën gepaard gaat, leidt tot uitstel van investeringen zoals uit analyse met behulp van het "real option"-model blijkt. De reden is dat de optiewaarde van wachten hoog is, in het geval er grote sprongen in de productiviteit of sterke dalingen in de investeringsprijzen van de betreffende technologie verwacht kunnen worden. Zelfs het gelijktijdig opnemen van de onzekerheid van de fossiele brandstofprijs in het model leidt er niet toe dat hernieuwbare energie concurrerend wordt met bestaande capaciteit die gebaseerd is op fossiele brandstoffen, althans op basis van de relevante gegevens die hier gebruikt zijn voor de korte en de middellange termijn. Dit impliceert dat de beleidsmakers investeringen extra aantrekkelijk zullen moeten maken, bijvoorbeeld door middel van een sanctie gekoppeld aan het uitstoten van $\mathrm{CO}_{2}$. Anders zal de vervanging van verouderde capaciteit plaatsvinden in de vorm van investeringen in capaciteit die op fossiele brandstoffen is gebaseerd, hetgeen tot een versterkte "lock-in" in niet-duurzame elektriciteitsopwekking zal leiden.

Het jaargangen-portefeuille-model dat in deze thesis wordt ontwikkeld, biedt een enigszins optimistischer beeld van de toekomst van duurzame brandstoffen door met de voordelen van diversificatie rekening te houden. Weliswaar brengen in het geval van bijvoorbeeld het Verenigd Koninkrijk de Britse doelstellingen om de emissies van $\mathrm{CO}_{2}$ te verminderen extra kosten met zich mee (die overigens nagenoeg verwaarloosbaar zijn als fractie van totale kosten), door naast andere maatregelen, de "Renewables Obligation" te verhogen. Daar staat echter tegenover dat de variantie van de elektriciteitsproducerende technologieportefeuille lager zal zijn, hetgeen op zichzelf (per assumptie, maar ook in de praktijk) positief wordt gewaardeerd. Aangezien de analyse zich toespitst op de kostenkant van de elektriciteitsproductie en aldus veiligheidsrisico's en kwesties rond de afvalverwijdering buiten beschouwing laat, komt kernenergie naar voren als een alternatief om de kloof tussen de bestaande, op fossiele brandstoffen gebaseerde, capaciteit en een koolstofvrij systeem te overbruggen.

Methodologisch levert de nieuwe jaargangen-portefeuille-benadering resultaten over technologische onzekerheid op die verschillen van de resultaten van 'real option' modellen en standaard optimale portfolio modellen. Onder grotere technologische zekerheid worden investeringen slechts tijdelijk uitgesteld, terwijl grotere onzekerheid in brandstofprijzen tot minder investeringen leidt in alle drie types van modellen. Alle drie modellen vinden dus een negatieve relatie tussen onzekerheid en investeringen voor grotere onzekerheid rond brandstofprijzen, en het standaard portefeuillemodel en de 'real option' modellen doen dit ook voor technologische onzekerheid. Alleen het jaargangen-portefeuille-model vindt een positieve relatie tussen technologische onzekerheid en investeringen aan het begin van de planningsperiode die is toe te schrijven aan het feit dat de technische verandering belichaamd is in de nieuwste jaargangen ("vintages") van investeringsgoederen. Het is daarom verstandig (en dus optimaal) om te wachten op de mogelijkheid te investeren in verbeterde jaargangen 
van investeringsgoederen, naarmate men er zekerder van is dat deze verbeteringen ook daadwerkelijk zullen plaatsvinden. Intertemporele optimalisering in combinatie met het cumulatieve karakter van technische verandering genereert daarom resultaten die consistent zijn met de creatie van een impliciete optiewaarde van wachten in het jaargangen-portefeuille-model. 



\section{Curriculum Vitae}

Sabine Fuss was born on December, 28th 1979 in Aachen, Germany. After finishing secondary education at Ritzefeld-Gymnasium in Stolberg, Germany, she started to study international economics at the University of Maastricht in the Netherlands in 1999. Upon graduation in 2003 she became an "Assistent in Onderzoek" at the economics department at the University of Maastricht and the Maastricht Economic Research Institute on Innovation and Technology (MERIT), which was later merged with the United Nations University (UNU-MERIT). Sabine finished the PhD program in 2007 and is currently employed as research scholar at the International Institute of Systems Analysis (IIASA) in Laxenburg, Austria. 